\title{
SEQÜENCIAMENTo E ANÁlise de Fragmentos Cloroplastidiais de Tomate para ConstruÇão de Vetores de Transformação de Cloroplastos via Recombinação Homóloga
}

\author{
IRVING JOSEPH BERGER \\ Engenheiro Agrônomo
}

Orientadora: Prof ${ }^{a}$. Dra. HELAINE CARRER

Dissertação apresentada à Escola Superior de Agricultura "Luiz de Queiroz", Universidade de São Paulo, para obtenção do título de Mestre em Ciências, Área de Concentração: Fisiologia e Bioquímica de Plantas.

PIRACICABA

Estado de São Paulo - Brasil

Setembro -2000 
BERGER, I.J. Seqüenciamento e Análise de Fragmentos Cloroplastidiais de Tomate para Construção de Vetores de Transformação de Cloroplastos via Recombinação Homóloga / Irving Joseph Berger. - - Piracicaba, 2000. 118p.

\section{ERRATA}

pág. linha

iv 12

$32 \quad 20$

3509

4420

$44 \quad 20$

7202

$75 \quad 07$

$\begin{array}{ll}78 & 02\end{array}$

$79 \quad 08$

$79 \quad 11$

$82 \quad 04$ onde se lê...

herdabilidade

...Figuras 17, 18, 19, 20 e 21 ...

... seqüência comum...

... homologia de $99,2 \%$...

... mutações ...

... Figuras 22 e 23.

... Figuras 22 e 23 ...

... tomate (Tom) e tabaco (Tab)...

... Figuras 28 e 29 ...

... Figuras 28 e 29 ...

... sendo o padrão genético... leia-se...

herança

... Figuras 11, 12, 13, 14 e 15 ...

... seqüência sobreposta ...

... identidade de $99,2 \%$...

... divergências ...

... Figuras 16 e 17.

... Figuras 16 e 17 ....

... tomate (LE) e tabaco (NT)...

... Figuras 22 e 23 ...

... Figuras 22 e 23 ...

... sugerindo que a estrutura genética ... 
Dados Internacionais de Catalogação na Publicação (CIP) DIVISĀO DE BIBLIOTECA E DOCUMENTAÇĀO - Campus "Luiz de Queiroz"/USP

\author{
Berger, Irving Joseph \\ Seqüenciamento e análise de fragmentos cloroplastidiais de tomate para construção \\ de vetores de transformação de cloroplastos via recombinação homóloga / Irving Joseph \\ Berger. - - Piracicaba, 2000. \\ 118 p. : il. \\ Dissertação (mestrado) - - Escola Superior de Agricultura Luiz de Queiroz, 2000. \\ Bibliografia.
}

1. Cloroplasto 2. Recombinação genética 3. Tomate 4. Transformação genética I. Título

CDD 635.642 
À toda minha familia

e em especial minha

esposa Roberta e nossa

pequena Pietra,

DEDICO 


\section{AGRADECIMENTOS}

À Profa. Dra. Helaine Carrer pela orientação, por todas as oportunidades e constante incentivo na continuidade de minha formação acadêmica;

Ao Prof. Dr. Ralph Bock (Universidade de Freiburg) pela co-orientação e valiosa contribuição em minha formação;

À Dra. Dirce Maria Carraro pela orientação no seqüenciamento, montagem das seqüências e freqüentes sugestões;

À Escola Superior de Agricultura "Luiz de Queiroz" e Universidade de São Paulo que me acolheram desde a graduação;

Ao Centro de Biotecnologia Agrícola (CEBTEC) e ao Departamento de Ciências Biológicas pela oportunidade e conhecimentos concebidos;

Ao curso de Pós-Graduação em Fisiologia e Bioquímica de Plantas pela oportunidade à erudição;

Ao CNPq, CAPES e DAAD pelo apoio financeiro;

A todos os amigos do CEBTEC que de alguma forma contribuíram para alcançar este objetivo: Prof. Dr. Murilo, Prof. Dr. Gallo, Prof. Dr. Otto, Fátima, Enio, Romeu, Amaral, Solizete, Clara, Matheus, Adriano, Reimar, Adriano Malosso, Rosana, Daniela, Telma, Fábio e Felipe. Em especial ao amigo Tercilio que muito contribuiu nas discussões e construção da seqüência alvo utilizada na construção dos vetores de transformação. 


\section{SUMÁRIO}

LISTA DE ABREVIATURAS E SÍMBOLOS................................................................. iii

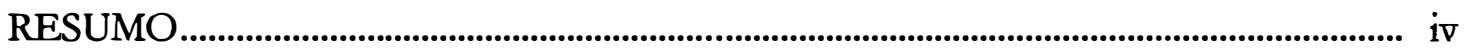

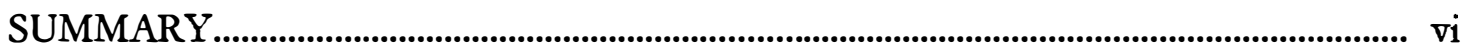

1 INTRODUÇÃO........................................................................................................... 01

2 REVISÃO DE LITERATURA................................................................................ 04

2.1 Cloroplasto: Estrutura e Aspectos Relevantes.................................................................. 04

2.2 Transformação de Cloroplastos........................................................................................ 08

2.3 Aspectos Biotecnológicos da Transformação de Cloroplastos...................................... 14

3 MATERIAL E MÉTODOS............................................................................ 19

3.1 Material vegetal................................................................................................................. 19

3.2 Isolamento de cloroplastos e ptDNA.......................................................................... 19

3.3 Clonagem e seqüênciamento de fragmentos de ptDNA............................................. 19

3.3.1 Sequenciamento do fragmento cloroplastidial clonado no plasmídio pIJB1 $(8,6 \mathrm{~kb})$ através de subclonagens por enzimas de restrição....................................................................... 20

3.3.2 Sequenciamento do fragmento cloroplastidial clonado no plasmídio pIJB2 $(6,4 \mathrm{~kb})$ através de minibibliotecas shotgun......................................................................................... 22

3.4 Análise de homologia..................................................................................................... 23

3.5 Obtenção da sequência flanqueadora de ptDNA para construção de vetores de transformação.................................................................................................................... 24

3.6 Construção do gene marcador seletivo.......................................................................... 26

3.7 Construção final de vetores de transformação de cloroplasto de tomate via recombinação homóloga.................................................................................................. 30

3.7.1 Vetor de transformação pIJB18 com 12 sítios de restrição..................................................... 30

3.7.2. Vetor de vansformação $\mathrm{PIJ} 20$ com 14 sítios de restrição...................................................... 31

4 RESULTADOS E DISCUSSÃO.................................................................................. 32

4.1 Clonagem e seqüenciamento de fragmentos de ptDNA.............................................. 32 
4.1.1 Seqüenciamento do fragmento cloroplastidial clonado no plasmídio pIJB1 (8,6 kb) através de subclonagens por enzimas de restrição.

4.1.2 Seqüenciamento do fagmento cloroplastidial clonado no plasmídio pIJB2 (6,4 kb) através de minibibliotecas shotgun.

4.2 Análise de homologia nas regiões codificadoras e nos espaços

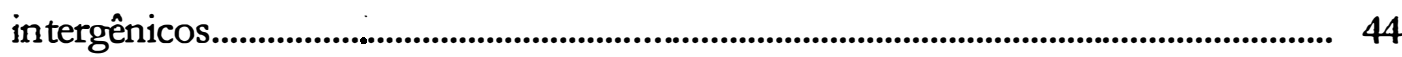

4.3 Identificação de sítios únicos de restrição para construção de vetores de transformação via recombinação homóloga.................................................................. 75

4.4 Construção do gene marcador seletivo........................................................................ 76

4.5 Construção de vetores de transformação de cloroplasto de tomate via recombinação homóloga........................................................................................ 79

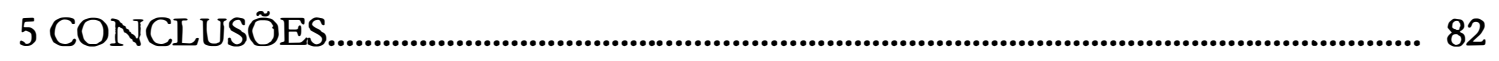

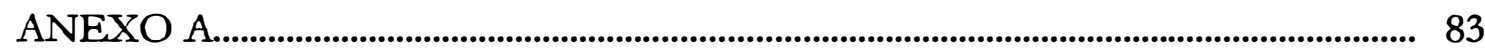

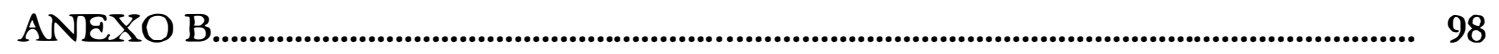

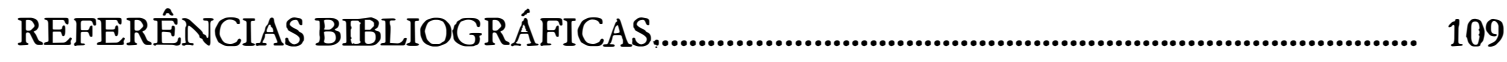




\section{LISTA DE ABREVIATURAS E SÍMBOLOS}

Nucleotídeos:
A Adenina
$\mathrm{T}$ Timina
C Citosina
G Guanina

\section{Aminoácidos:}
A Alanina
$\mathrm{R} \quad$ Arginina
$\mathrm{N} \quad$ Asparagina
D Ácido Aspartico
B Asparagina ou Ácido Aspartico
C Cisteína
Q Glutamina
E Ácido Glutâmico
Z Glutamina ou Ácido Glutâmico
G Glicina
$\mathrm{H} \quad$ Histidina
I Isoleucina
L Leucina
$\mathrm{K} \quad$ Lisina
M Metionina
F Fenilalanina
P Prolina
S Serina
$\mathrm{T}$ Treonina
W Triptofano
$\mathrm{Y}$ Tirosina
V Valina

\section{Outros:}
$\mathrm{pb} \quad$ pares de bases
$\mathrm{Kb} \quad$ quilobases (1000 pares de bases)
Primer oligonucleotídeo sintetizado 


\title{
Seqūr nciamento e ANÁlise de Fragmentos Cloroplastidiais de TOMate Para CONSTRUÇÃo de Vetores de Transformação de Cloroplastos VIA RECOMBINAÇÃo HOMÓLOGa
}

\author{
Autor: IRVING JOSEPH BERGER \\ Orientadora: Profa. HELAINE CARRER
}

\section{RESUMO}

A coordenação de células vegetais requer a participação de três sistemas genéticos distintos, porém interdependentes durante seu desenvolvimento. Além da informação genética alojada no núcleo, células vegetais contém DNA em seus cloroplastos e mitocôndrias, as quais são organelas semi-autônomas possuidoras de sua própria maquinaria necessária à transcrição gênica, síntese proteica e parte da replicação. $O$ estudo de novas alternativas tecnológicas levou ao desenvolvimento da tecnologia de transformação do genoma cloroplastidial (plastoma) de plantas superiores, gerando otimistas expectativas no melhoramento de plantas. Plantas possuindo genoma cloroplastidial transformado (transplastômicas) possuem algumas vantagens quando comparadas aos transformantes nucleares, pois possibilitam transformação dirigida, garantem segurança ambiental na dispersão de genes via pólen, uma vez que a característica de herdabilidade maternal dos cloroplastos ocorre na maioria das espécies cultivadas, e apresentam extraordinários níveis de expressão do gene introduzido. O sistema de tranformação de cloroplastos de plantas superiores foi desenvolvido inicialmente em tabaco e mais recentemente em Arabidopsis thaliana e batata (Solanum tuberosum). As semelhanças genéticas entre tabaco e tomate (ambos pertencentes à família Solanaceae) apontam essa 
importante espécie como forte candidata ao sucesso na expressão de transgenes, disponibilizando ao melhorista de plantas uma ferramenta altamente eficiente e vantajosa. Visando o desenvolvimento da tecnologia de transformação de cloroplastos de tomate (Lycopersicon esculentum L.) fragmentos cloroplastidiais de tomate IAC-Santa Clara foram clonados e analisados para a construção de vetores de transformação via recombinação homóloga. Isolamento e clonagem de fragmentos PstI/SalI de cloroplastos de tomate deram origem aos plasmídios pIJB1 e pIJB2, contendo fragmentos de 8.660 pb e $6.366 \mathrm{pb}$ respectivamente. Seqüenciamento e análise dos fragmentos revelaram que as seqüências são altamente homólogas aos respectivos fragmentos em tabaco, especialmente nas regiões codificadoras, e o mapeamento gênico mostrou que o posicionamento relativo das regiões codificadoras é também conservado entre as duas espécies. Espaços intergênicos mostraram-se menos conservados, sugerindo que divergências evolutivas ocorram principalmente em áreas não diretamente envolvidas na expressão gênica. Uma diferença bastante marcante encontrada está em um fragmento de 437 pb presente em tabaco entre as regiões codificadoras dos genes $\operatorname{tr} \mathrm{E}$ e $\operatorname{tr} \mathrm{T}$ e ausente no DNA cloroplastidial de tomate. Análise do padrão de restrição das seqüências cloroplastidiais apontou a seqüência SmaI/XboI (2404 pb) contendo o sítio único de restrição StuI entre os genes pet N e psbM como opção ideal para a contrução de vetores de transformação de cloroplastos de tomate. Foi construído um cassete plastídio-específico atpI-aadA-rps14, que confere resistência aos antibióticos espectinomicina e estreptomicina, o qual foi inserido no sítio StuI na seqüência alvo SmaI/XhoI. Assim, permitiu a construção de dois vetores para transformação de cloroplastos de tomate, pIJB18 e pIJB20 disponíveis para a inserção de novos genes de interesse agronômico nesta espécie. Transformação de cloroplastos poderá facilitar o estudo da regulação gênica cloroplastidial e auxiliar o melhoramento genético de espécies cultivadas. $O$ recente sucesso na expressão de toxinas conferindo resistência a insetos, resistência ao herbicida glifosato e especialmente de hormônio do crescimento humano em cloroplastos de tabaco, levam a acreditar que a tecnologia promete revolucionar o conceito e a aplicabilidade das plantas transgênicas no melhoramento genético. 


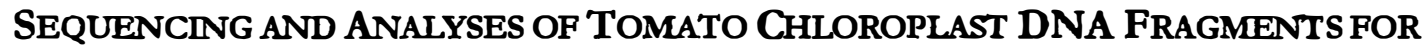 Construction of Chloroplast Transformation Vectors via Homologous RECOMBINATION}

Author: IRVING JOSEPH BERGER Adviser: Prof. HELAINE CARRER

\section{SUMMARY}

Plant cell coordination involves three different genetic systems, which are interdependents during its development. Besides the genetic information localized in the nucleus, plant cells contain DNA in chloroplasts and mitochondria, which are semiautonomous organelles with its own necessary machinery for transcription, protein synthesis and part of replication. Studies for new altemative technologies made possible the development of the chloroplast genome (plastome) transformation technology, generating optimistic expectations in plant biotechnology. Chloroplast genome transformed plants (transplastomic plants) have some advantages when compared to nuclear transformants, they facilitate driven transformation, they guarantee environmental safety conceming gene dispersion and they present extraordinary expression levels of the introduced gene. Chloroplast transformation technology for higher plants was first developed in tobacco and more recently in Arabidopsis thaliana and potato (Solanum tuberosum). The genetic similarity between tobacco and tomato chloroplast genomes (both belonging to the Solanaceae family) point these important species as strong candidate to the success in transgene expression, making available a highly efficient and advantageous tool to plant breeders. Seeking the 
development of the tomato (Lycopersicon esculentum L.) chloroplast transformation technology, chloroplast DNA fragments of IAC-Santa Clara tomato were cloned and analyzed for transformation vectors construction. Isolation and cloning of PstI/SaII tomato chloroplast fragments generated the pIJB1 and the pIJB2 plasmids, with fragments of 8,660 bp and 6,366 bp respectively. Sequencing and analysis of both fragments revealed that the sequences are highly homologous to the respective fragments in tobacco, specially concerning coding regions. Gene mapping showed that the relative positioning of the coding regions is also conserved between the two species. Intergenic spaces was shown less conserved, indicating that evolutionary divergences occurs mainly in regions that are probably not directly involved in gene expression. The biggest difference found is a $437 \mathrm{pb}$ fragment present in tobacco between the coding regions of the $t m \mathrm{E}$ and $t m \mathrm{~T}$ genes but absent in the tomato chloroplast DNA. Restriction pattern analysis of the chloroplast sequences pointed the $S m a I / X b o I(2404 \mathrm{pb})$ sequence with a single $S t u I$ restriction site between the pet $\mathrm{N}$ and $p s b \mathrm{M}$ genes as ideal option for vector contruction and consequent tomato chloroplast transformation. Plastid-specific cassette atpl-aadA-rps14, confering resistance against spectinomycin and streptomycin, was constructed and inserted into the SmaI/XboI targetting sequence at the $S t u I$ site, allowing the construction of two vectors for tomato chloroplast transformation, pIJB18 and pIJB20. Both are available for insertion of new genes and their expression in this species. It is clear that the ability to transform chloroplasts will facilitate the study of plastid gene regulation and the application of the genetic engineering in the improvement of crop species. Recent successes on expression of exogenous genes: toxins confering resistance to insects, resistance to glyphosate and especially human growth hormone synthesis in tobacco chloroplasts, suggest that the technology promises to revolutionize the concept and the application of the transgenic plants in the genetic breeding. 


\section{INTRODUÇÃO}

Programas de melhoramento normalmente requerem longo tempo para a transferência de genes de interesse entre espécies vegetais e estão muitas vezes limitados pela freqüente incompatibilidade sexual entre espécies cultivadas ou ainda por diversos outros fatores. Em busca de altemativas, melhoristas e estudiosos de plantas têm utilizado intensivamente técnicas de biologia molecular e de cultivo de células e tecidos no desenvolvimento de tecnologia agrícola.

A cultura de tecidos vegetais tem possibilitado, por exemplo, a limpeza de vírus, a propagação de matrizes de alto potencial produtivo e a produção de metabólitos secundários através do cultivo de células vegetais in vitro. Recentemente, com o desenvolvimento da engenharia genética tem-se tomado possível a manipulação das características genéticas através da introdução e expressão de genes de interesse agronômico em espécies cultivadas, tais como resistência a herbicidas e insetos, aumento de valor nutritivo e conservação pós-colheita.

Hoje já é indiscutível o potencial e a aplicabilidade da biologia molecular no setor agrícola, no entanto também crescentes são as tentativas de se mostrar a existência de riscos e a necessidade de regulação rigorosa no desenvolvimento de plantas transgênicas. Tal fato ocorre principalmente em função da introdução de genes no material genético nuclear ser uma prática comum em experimentos de engenharia genética, gerando discussões bastante polêmicas, como o potencial risco de fluxo gênico via pólen em cruzamentos entre espécies relacionadas, significando por exemplo o risco de transferência de resistência à herbicidas a determinadas plantas invasoras.

Em células vegetais o DNA pode ser encontrado em três compartimentos distintos, porém in terdependentes na coordenação celular: no núcleo, nos cloroplastos e nas mitocôndrias. Em vista disso, estudos em tecnologias de transformação de organelas têm 
sido uma área de grande interesse nos últimos anos, principalmente porque estas apresentam herança matemal na maioria das espécies vegetais cultivadas, tomando-se um valioso método de melhoramento de plantas com controle ambiental. Uma vez que o pólen não carrega organelas na maioria das espécies cultivadas comercialmente, a possibilidade de fluxo gênico indesejado toma-se impossibilitado através de cruzamento.

Por outro lado, estando os cloroplastos diretamente associados a diversos processos fisiológicos, bioquímicos e genéticos do crescimento e desenvolvimento das plantas, o estabelecimento de uma tecnologia de transformação desta organela mostra-se de grande importância também como ferramenta de estudo dos diversos aspectos da expressão gênica cloroplastidial in vivo. Diversos estudos fisiológicos e bioquímicos passaram a ser possíveis com a manipulação do genoma cloroplastidial, especial atenção dada ao estudo do funcionamento dos diferentes genes relacionados à fotossíntese.

Os cloroplastos também estão envolvidos no processo de maturação de frutos. Em frutos de tomate (Lycopersicon esculentum L.), o desenvolvimento de cromoplastos a partir de cloroplastos envolve processos degradativos e sintetizadores, incluindo a quebra do sistema de membranas dos tilacóides com a concomitante degradação de clorofila, a conversão de reservas de amido em açúcares e a síntese em larga escala do pigmento vermelho licopeno envolvido na síntese de vitamina $A$. $O$ entendimento do controle da expressão gênica em cloroplastos durante esse processo de desenvolvimento seria importante tanto como um sistema modelo para o desenvolvimento de plastídios, como também para a proposição e estudo dos mecanismos envolvidos no amadurecimento de frutos, por exemplo do próprio tomate (Phillips, 1985a).

Nesse contexto, este trabalho teve como objetivo principal o desenvolvimento da tecnologia de transformação de cloroplastos de tomate (Lycopersicon esculentum L.) pela construção de vetores de transformação via recombinação homóloga, possibilitando futura introdução de novas características desejadas na espécie, seja a nível agronômico ou nutricional. Para tanto, são objetivos parciais a construção de um gene marcador seletivo, o isolamento, o seqüenciamento e análise de fragmentos do DNA de cloroplasto ( $\mathrm{ptDNA}$ ) de tomate para obtenção de uma região apropriada para inserção do gene marcador e/ou possíveis genes de interesse. 
Desta forma, este trabalho tem por meta produzir resultados para o estabelecimento de protocolo eficiente de transformação e expressão de genes com aplicação biotecnológica em plantas de tomate, cultura que apresenta grande importância agrícola em nosso país e no mundo como um todo. 


\section{REVISÃO DE LITERATURA}

\subsection{Cloroplasto: Estrutura e Aspectos Relevantes}

Os cloroplastos são as organelas mais abundantes de uma família de organelas de dupla membrana denominadas genericamente plastídios e de comurn ocorrência em células vegetais. Os plastídios são originados de proplastídios, pequenos corpos vesiculares produzidos na divisão celular. Plastídios sem pigmentação são denominados leucoplastos, entretanto freqüentemente são sítios de acúmulo de amido, passando a ser chamados de amiloplastos. Os cloroplastos contém os pigmentos fotossintéticos, sendo responsáveis pela fotossintese e pela predominante coloração verde das folhas. Leucoplastos de folhas (etioplastos) e cloroplastos são frequentemente interconversíveis, dependendo do estádio fisiológico da célula e das condições de luminosidade. Elaioplastos armazenam óleos e lipídios. Cromoplastos contém outros pigmentos que não a clorofila e por exemplo a cor característica de frutos de tomate e cenoura é devido à presença de cromoplastos contendo carotenóides. Os pigmentos em cromoplastos são usualmente tão concentrados que apresentam-se na forma de depósitos cristalinos (Hopkins, 1995).

Além de responsáveis pelo processo de fotossíntese, plastídios também participam na biossíntese de aminoácidos, nucleotídios, lipídios e amido (Sugiura, 1992), e estão diretamente envolvidos em uma gama de processos degradativos e sintetizadores no climatério de frutos, incluindo a degradação de clorofila na membrana dos tilacóides, a conversão de amido em reservas de açúcares e a síntese de pigmentos carotenóides (Phillips, 1985b). Isso se deve ao fato de a coordenação de células vegetais ser dependente de três distintos, porém interdependentes sistemas genéticos durante seu desenvolvimento. Além do núcleo, cloroplastos e mitocôndrias possuem seu próprio genoma (DNA) e tais DNAs 
organelares possuem sua própria maquinaria de trancrição e tradução, possibilitando inclusive parte do controle de sua auto-replicação (Schuler, 1989).

O genoma típico de cloroplastos (plastoma) é circular, possui de 120 a $180 \mathrm{~kb} \mathrm{em}$ plantas superiores, é idêntico em todos os tipos de plastídios e possui uma região duplicada com orientação invertida de aproximadamente 25 kb (Palmer, 1985; Maliga, 1993). Sequências completas de genomas cloroplastidiais permitem concluir que esse DNA (ptDNA) contém cerca de 120-130 genes, incluindo codificadores de rRNAs, tRNAs, peptídios não identificados e regiões de provável codificação de polipeptídios (ORFs ou "quadros de leitura aberta") (Lindholm, 1992; Sugiura, 1992).

O número de cloroplastos e cópias do genoma por célula é dependente do tipo de célula. Uma célula meristemática de tabaco possui de 10 a 15 proplastídios, cada um contendo aproximadamente 50 cópias do genoma, enquanto uma célula foliar possui em tomo de 100 cloroplastos contendo até 100 cópias do genoma (Maliga, 1993). Uma grande diferença nesses números já foi demonstrada para diferentes espécies. Bendich (1987) relata variação entre 1.900 a 50.000 cópias do genoma em células foliares de diferentes plantas (Tabela 1). No entanto, segundo Maliga et al. (1993), as plantas devem possuir um sistema de reparo bastante eficiente, eliminando a maioria das mutações e alterações do genoma, visto que a uniformidade das cópias é mantida dentro da espécie.

TABELA 1. Número de cópias do genoma plastidial em plantas superiores.

\begin{tabular}{|c|c|c|c|}
\hline Planta & \% do Total de DNA & Genomas/Célula & Genomas/Plastídio \\
\hline Ervilha & 12 & 10.000 & 270 \\
\hline Soja & 17 & 13.000 & $*$ \\
\hline Espinafre & 23 & 13.000 & 200 \\
\hline Beterraba & 11 & 1.900 & 100 \\
\hline Batata & 8 & 3.000 & 22 \\
\hline Trigo & 17 & 50.000 & 100 \\
\hline Tabaco* & - & 10.000 & 900 \\
\hline
\end{tabular}

Fonte: Bendich (1987); Carrer \& Maliga (1995).

* Dado desconhecido. 
Esse enorme número de cópias do genoma é provavelmente reflexo de um aumento da atividade metabólica, diretamente ligada à taxa fotossintética do tecido. Propõe-se que esse elevado número de cópias reflete um aumento na necessidade de ribossomos organelares que pode somente ser satisfeita também pelo aumento do número de genes codificadores de RNA ribossomal (rRNA), resultando em multiplicação do genoma (Bendich, 1987). Obviamente todos os genes são multiplicados e seus trancritos também serão mais abundantes, uma vez que a regulação da expressão gênica cloroplastidial ocorre preferencialmente em nível póstranscripcional e a taxa de transcrição não varia significativamente para os diversos genes (Mayfield \& Bruick, 1999).

As diversas cópias do genoma presentes em cada cloroplasto não se apresentam uniformemente distribuídas na organela e são tampouco encontradas isoladas, mas em associações com proteínas formando discretas estruturas referidas como nucleóides (Kuroíwa et al., 1981 e Dyer, 1984 citados por Lidholm, 1992). Por sua vez, dado o número total já mencionado de cópias do genoma, o número de nucleóides por plastídio, assim como sua distribuição e composição, podem variar consideravelmente entre espécies, tecidos, tipos de plastídios e durante a diferenciação plastidial. $\mathrm{O}$ número de genomas por nucleóide é variável (de 1 a mais de 12 cópias), resultando em diferentes graus de ploidia (Hermann et al., 1992). Diante dessa característica os cloroplastos são tidos como um sistema genético altamente poliplóide (Maliga et al., 1994)

É certo que tal organização do genoma em nucleóides trata-se de característica remanescente daquela encontrada em bactérias (Watson et al., 1987 citado por Lidholm, 1992). Diversos relatos científicos, tais como a origem procariótica do mecanismo de divisão de cloroplastos (Osteryoung et al., 1998), a constituição molecular dos genes plastidiais, especialmente os promotores (Sugiura, 1992), a organização dos genes, a ocorrência de recombinação homóloga e os processos relacionados tal como a conversão gênica (Maliga et al., 1994), vêm comprovando a teoria de que os cloroplastos teriam sido originados de uma ou mais interações endossimbióticas entre algas unicelulares não fotossintetizantes e uma eubactéria fotossintetizante, uma cianobactéria (Gray, 1991). Como consequência, a mais marcante característica organizacional de cromossomos plastidiais, com reflexo direto sobre a expressão gênica, é que a grande maioria de seus genes é tipicamente organizada em unidades de transcrição policistrônicas, como em procariotos, lembrando fielmente a organização em "operons" de seus ancestrais bacterianos (Herrmann et al., 1992). A similaridade mostra-se suficientemente grande 
para que os cloroplastos sejam tidos como estruturas caracteristicamente procarióticas (Sugiura, 1992; Lidholm, 1992; Schuler, 1989), embora apresentem alguns mecanismos de regulação da expressão além daqueles comuns aos procariotos (Mayfield \& Bruick, 1999) e alguns de seus genes também apresentem pequenos íntrons, regiões não traduzidas típicas de genomas eucarióticos.

Importante mecanismo de regulação da expressão gênica cloroplastidial a se considerar, similar ao que ocorre também em mitocôndrias, é o editamento de RNA, um dos vários mecanismos envolvidos na modificação e maturação pós-transcricional de mRNAs plastidiais, sem no entanto estar evolutivamente relacionado a outros diversos processos de editamento de transcritos caracterizados em outros sistemas genéticos (Bock, 1998b). A ocorrência do fenômeno de editamento, descoberta em cloroplastos por Benne e colaboradores em 1986 e relatada pela primeira vez em cloroplastos de milho (Hoch et al., 1991), alterou a idéia clássica do fluxo da informação genética do DNA para proteínas via RNA (Bock, 1998b). Entendido como um mecanismo adicional do controle da síntese de produtos gênicos funcionais em plastídios, o editamento pode ser definido como qualquer evento pós-transcricional que altera a seqüência de nucleotídeos da molécula de RNA com relação à molécula de DNA molde da qual esse RNA se originou (Lidholm, 1992). Conseqüentemente, o editamento de RNA pode cancelar ou corrigir aparentes desvios do código genético universal, uma vez que a seqüência de aminoácidos de um polipeptídeo traduzido via transcrito editado não é necessariamente idêntica àquela predita na respectiva seqüência do gene (Lindholm, 1992). Em cloroplastos de plantas superiores o editamento de RNA é caracterizado por simples conversões de resíduos de citosina a uracila (pirimidina-pirimidina; C $\rightarrow$ U) (Hoch et al., 1991; Kudla et al., 1992 citados por Bock, 1998b), embora conversões do tipo $U \rightarrow C$ tenham sido recentemente relatadas em transcritos do musgo Antboceros formosae (Yoshinaga et al., 1996), caracterizando um processo de "editamento reverso" aparentemente ausente em plantas superiores.

O editamento de RNA em cloroplastos parece ser um dos primeiros processos pós-transcricionais e pré-traducionais, representando assim um passo adicional ao mecanismo de processamento "tradicional" operante em transcritos plastidiais: maturação das extremidades 3' e 5', processamento de mRNAs policistrônicos em monocistrônicos e "splicing" quando na existência de íntrons. A freqüência de eventos de editamento em cloroplastos é relativamente baixa e foi estimada em aproximadamente 25 sítios para genomas plastidiais completos (Maier et al., 1995), embora atualmente já existam 31 sítios particularmente caracterizados no plastoma de 
tabaco (Hirose et al., 1999). Como exemplo, o gene $\not 220$ de tabaco apresenta apenas um sítio de editamento $(\mathrm{uCa} \rightarrow \mathrm{uUa}$ ), enquanto os genes $r p o \mathrm{~B}$ e $n d b \mathrm{~B}$ apresentam respectivamente 6 e 9 sítios (Hirose et al., 1999). Curiosamente, esses dados contranstam com os mais de 1000 sítios de editamento encontrados em mitocôndrias de plantas superiores, onde o sistema de editamento mostra-se bastante similar ao que ocorre em cloroplastos (Maier et al., 1996, Hanson et al., 1996 e Mulligan \& Maliga, 1998 citados por Bock, 1998b).

Uma questão central no que se refere ao editamento de RNA em cloroplastos é como explicar a extraordinaria alta especificidade na seleção de resíduos individuais de citosina para modificação (Bock, 1998b). Diversos estudos in vivo demonstraram que seqüências do mRNA flanqueando o sítio de editamento estão diretamente envolvidas no reconhecimento molecular de sítios de editamento em plastídios (Chaudhuri et al., 1995; Bock et al., 1996; Chaudhuri \& Maliga, 1996), no entanto não podem ser identificadas quaisquer seqüências ou estruturas consenso (elementos cis-acting consenso), seja a nível primário ou secundário, que possam estar envolvidas nesse reconhecimento (Bock, 1998b; Hirose et al., 1999). Diversos indicativos também levam a acreditar que fatores trans-acting sítio-específicos (proteínas) de origem nuclear (extraplastídica) participem na seleção e reconhecimento de sítios de editamento (Ralph \& Koop, 1997), entretanto a natureza molecular da especificidade de tais fatores-acting para o editamento de RNA permanece desconhecida (Bock, 1998b). Uma atrativa enzima candidata a compor a subunidade catalítica de um hipotético editossoma ("editosome") é uma citosina desaminase, enzima capaz de atuar diretamente sobre polinucleotídeos (Bock, 1998b).

\subsection{Transformação de Cloroplastos}

A transformação de organelas in vivo, como altemativa à transformação nuclear, passou a ser realidade após o desenvolvimento do sistema de biolística, Klein et al. (1987). A primeira transformação de cloroplastos foi em Chlamydomonas reinharditii, uma alga unicelular que apresenta somente um cloroplasto, em 1988, pelo grupo do Dr. John Boyton (Boyton et al., 1988). Em plantas superiores, a transformação de cloroplastos foi estabelecida dois anos depois, em tabaco (Nicotiana tabaccum), pelo grupo do Dr. Pal Maliga (Svab et al., 1990), sendo extensivamente explorada desde então (Svab \& Maliga, 1993; Staub \& Maliga, 1993; Bock et al. 1994; Carrer \& 
Maliga, 1995; Serino \& Maliga, 1998; Kota et al., 1999). O genoma mitocondrial, por sua vez, também tem sido objetivo de estudo em vários laboratórios de pesquisa do mundo, mas nenhum resultado positivo em plantas foi obtido até o momento, desde que a mitocôndria da levedura Saccharomyces cerevisae (Johnston et al., 1988) e da alga Cblamydomonas reinhardtii (RandolphAnderson et al., 1993) foram transformadas com sucesso, levando-nos portanto a acreditar que a transformação do genoma mitocondrial de plantas deverá ser conseguida num futuro próximo.

Com base nos diversos estudos desenvolvidos em tabaco, transformação estável do genoma plastidial tem sido realizada por meio das etapas que seguem: (i) introdução do DNA transformante codificando resistência à antibiótico por meio de biobalística ou via tratamento com PEG (polietilenoglicol), (ii) integração estável do DNA transformante por dois eventos de recombinação homóloga, de tal forma que o funcionamento normal do genoma plastidial não seja alterado e (iii) eliminação seletiva de cópias originais do genoma plastidial e acúmulo do transplastoma durante sucessivas divisões celulares em meio seletivo (Svab \& Maliga, 1993; Staub \& Maliga, 1993; Bock et al. 1994; Carrer \& Maliga, 1995; Serina \& Maliga, 1998; Kota et al., 1999; Bock \& Hagemann, 1999 e muitos outros).

Dessa maneira, o sistema de transformação de organelas está primariamente ancorado na introdução de material genético no interior de células e mais especificamente no ambiente cloroplastidial. O desenvolvimento do sistema de biobalística, ou bombardeamento de partículas (Klein et al, 1987), tomou possível bombardear ácidos nucléicos em qualquer tecido ou célula alvo, assim como praticamente todos os compartimentos subcelulares de uma célula eucariótica (Sanford et al, 1987; Sanford et al., 1991) . Particulas de tungstênio ou ouro cobertas com o plasmídio vetor (DNA transformante), lançadas sob pressão de gás hélio, são capazes de transpor a membrana dupla que envolve as organelas, a principal barreira na introdução de genes nesses compartimentos celulares (Bock \& Hagemann, 1999) (Figura 1.A, B).

Como metodologia altemativa para trasformação de cloroplastos de tabaco, protocolos de transformação química baseada em polietilenoglicol foram desenvolvidos e têm sido também utilizados com sucesso (Spörlein et al, 1991; Koop et al., 1992; Golds et al., 1993; O'Neill et al., 1993; Koop et al., 1996). Segundo Koop et al. (1996) a obtenção de transformantes plastômicos mediada por polietileno glicol (PEG), em protoplastos, trata-se de uma alternativa simples, de alta reprodutibilidade e baixo custo ao processo de biolística. Por si só a transformação baseada em PEG não representaria uma limitação à maiores taxas de obtenção de transformantes regenerados, como demonstrado para tabaco, no entanto sua aplicação fica bastante limitada pelo 
menor desenvolvimento da cultura de protoplastos e regeneração de plantas nas diversas espécies vegetais (Koop et al., 1996). Neste aspecto, o processo de biobalística não representa uma restrição, uma vez que, tratando-se de um método de introdução de DNA puramente físico, não se trata de um sistema espécie específico.

Uma vez inserido o DNA transformante, a obtenção de transformantes estáveis (referidos como plantas transplastômicas) depende da integração estável desse DNA exógeno no genoma cloroplastidial. Tratando-se de um compartimento celular tipicamente procariótico, a integração do DNA transformante, como quaisquer eventos de recombinação em cloroplastos parecem ocorrer unicamente por recombinação homóloga (seqüências homólogas ao DNA endógeno são integradas a este por transposição da seqüência original). Conseqüentemente, a seqüência de DNA a ser introduzida no genoma cloroplastidial deve ser flanqueada por regiões de homologia com seqüência de DNA do próprio cloroplasto (Figura 2). Vetores de transformação para expressão de genes de resistência à antibióticos como espectinomicina (aad $A$ ) e kanamicina (nptII) no genoma plastídico de tabaco foram construídos utilizando-se da sequência codificadora do gene de resistência flanqueado com sequências homólogas do DNA de genoma plastídico (Svab \& Maliga, 1993; Carrer et al., 1993). Esta sequência homóloga do DNA plastídico é chamada sequência "alvo", uma vez que dirige a introdução do DNA transformante no genoma plastídico. A recombinação homóloga parece ser um sistema altamente eficiente em plastídios de plantas superiores. Evidências diretas têm sido mostradas por experimentos de cotransformação que revelam uma alta freqüência de integração simultânea de dois marcadores fisicamente não ligados (Carrer \& Maliga, 1995). Em adição, demonstrando a alta eficiência do processo de recombinação, Kavanagh et al. (1999) realizaram a transformação de cloroplastos de tabaco utilizando seqüência alvo de cloroplastos de Solanum nigrum, mostrando que taxas equivalentes de transformação de cloroplastos de tabaco podem ser obtidas pelo flanqueamento do gene de interesse por seqüências cloroplastidiais parcialmente homólogas (homeólogas). Da mesma forma, Sidorov et al. (1999) realizaram a transformação estável de cloroplastos de batata através de vetores plastídio-específicos para tabaco, promovendo a expressão de GFP ("green fluorescent protein") nas plantas transformadas.

No entanto, conforme discutido anteriormente, o sistema genético cloroplastidial é altamente poliplóide e o sistema de transformação, buscando transformantes estáveis, requer que cada uma das cópias do genoma seja alterada uniformemente. Para isso tornam-se necessárias de 15 a 20 divisões celulares (Bock \& Hagemann, 1999). A transformação é iniciada pela integração 
de um segmento de DNA em uma ou algumas cópias do genoma, de tal forma que o transformante primário é normalmente heteroplásmico, contendo cópias de genomas transformados e não transformados. Após vários repetidos ciclos de regeneração do transformante primário em meio sintético (Fig. 1D, E e F), sob forte pressão de seleção (meio de cultura contendo altas concentrações de antibiótico), eventualmente obtém-se plantas homoplásticas (quando todas as cópias do genoma plastídico estão alteradas uniformemente). A manutenção de alta pressão de seleção favorece a também alta expressão das moléculas de DNA transformadas, de tal modo que há um acúmulo do transplastoma (genoma transformado) e eliminação dos genomas originais (Maliga, 1993; Bock \& Hagemann, 1999).

Dessa forma, o sucesso no sistema de transformação toma-se dependente da eficiência da marca genética seletiva utilizada para identificar e seletivamente ampliar o transgenoma. $\mathrm{O}$ gene introduzido deve ter um fenótipo possível de ser utilizado para seleção dos transgenes ou estar ligado a um gene marcador seletivo como $a a d A, n p t \Pi$, aac $C 1$ e outros, dependendo da cultura em estudo(Bock \& Hagemann, 1999). O gene gus, por exemplo, codificando a enzima $\beta$ glucuronidase, foi ligado ao gene mutante $16 S r R N A$ que confere resistência ao antibiótico espectinomicina como um gene passageiro, demonstrando expressão da enzima em genoma plastídico (Staub \& Maliga, 1992). No entanto, os mais eficientes marcadores seletivos disponíveis para a trasnformação de cloroplastos de plantas superiores são os construídos com o gene quimérico dominante aad $A$, utilizado primariamente na transformação nuclear de tabảco via Agrobacterium por Svab et al. (1990). O aadA é um gene originalmente bacteriano que codifica a enzima aminoglicoside $3^{\prime \prime}$-adenililtransferase, conferindo resistência aos antibióticos espectinomicina e estreptomicina. Quando expresso no cloroplasto o gene aad $A$ permite o crescimento e regeneração de células vegetais em meio sintético contendo os antibióticos (Bock \& Hagemann, 1999). Mais recentemente, o desenvolvimento do sistema FLARE-S ("fluorescent antibiotic resistence enzyme, spectinomycin and streptomycin"), pela fusão das seqüências codificadoras de GFP e AAD, oferece concomitante resistência aos antibióticos espectinomicina e estreptomicina e a expressão de fluorescência sob luz ultra-violeta (Khan \&,Maliga, 1999), prometendo facilitar a obtenção de transformantes cloroplastidiais homoplásmicos pela facilidade do acompanhamento visual. Em adição, uma provável importante conseqüência do sistema marcador FLARE-S será a potencial viabilização da extensão da tecnologia de transformação de cloroplastos para plastídios não-verdes em células embriogênicas de espécies cereais (Khan \& Maliga, 1999). Por fim, para facilitar a expressão do gene marcador em cloroplastos, a região 
codificadora deve ser fundida a sinais de expressão plastídio-específicos: (i) uma região $5^{\prime}$ não traduzida contendo um promotor plastidial, assim como uma seqüência de iniciação de tradução e (ii) uma região 3' não traduzida típica do sistema genético plastidial, conferindo estabilidade ao transcrito, sem no entanto finalizar a transcrição (Stem and Gruissem, 1987).

Diante dessa linha de pensamento, não só a eficiência do marcador é fundamental para o sucesso da transformação, mas também um sistema eficiente de regeneração de plantas in vitro por meio de explantes foliares. Todo processo de seleção está baseado em sucessivos e repetidos ciclos de regeneração sob pressão de seleção (meio sintético contendo antibiótico) para o favorecimento do acúmulo do transplastoma, de forma que um protocolo eficiente de regeneração toma-se um pré-requisito incontestável, podendo realmente representar um fator limitante para o sucesso do melhoramento genético de plantas baseado em manipulações ao nível molecular. $\mathrm{O}$ estabelecimento da cultura de tecidos e células in vitro com alta taxa de regeneração de plantas férteis é altamente dependente de fatores endógenos à própria espécie ou mesmo grandes diferenças entre variedades de uma mesma espécie são encontradas. No entanto, a técnica já se mostra muito bem estabelecida para tabaco e algumas outras culturas, de modo que não existem perpectivas pessimistas quanto às possibilidades de viabilização do cultivo in vitro de um grande número de espécies de interesse agronômico. Por exemplo, a cultura de células e tecidos de tomate (Lycopersicon esculentum), utilizando como explantes segmentos de hipocótilo ou folhas de plântulas, possibilita altas taxas de formação de calos e regeneração de plantas (Faria \& Illg, 1996; Gill et al., 1995), de tal forma que o sistema de transformação de plantas de tomate via Agrobacterium tumefaciens (McCormick et al., 1986) tem apresentado resultados significantes no melhoramento desta cultura, permitindo a introdução de novas características de interesse, tais como a resistência ao herbicida glifosato (Fillati et al., 1987) e estudos de RNA antisense retardando senescência de frutos, através da redução de expressão da enzima ACC sintase (1aminociclopropano-1-carboxilato sintase) da biossíntese de etileno (Nakatsuka et al., 1997; Nakatsuka et al., 1998; Liu et al., 1998) ou mesmo inibição da expressão gênica da pectina esterase (Hall et al., 1993). 

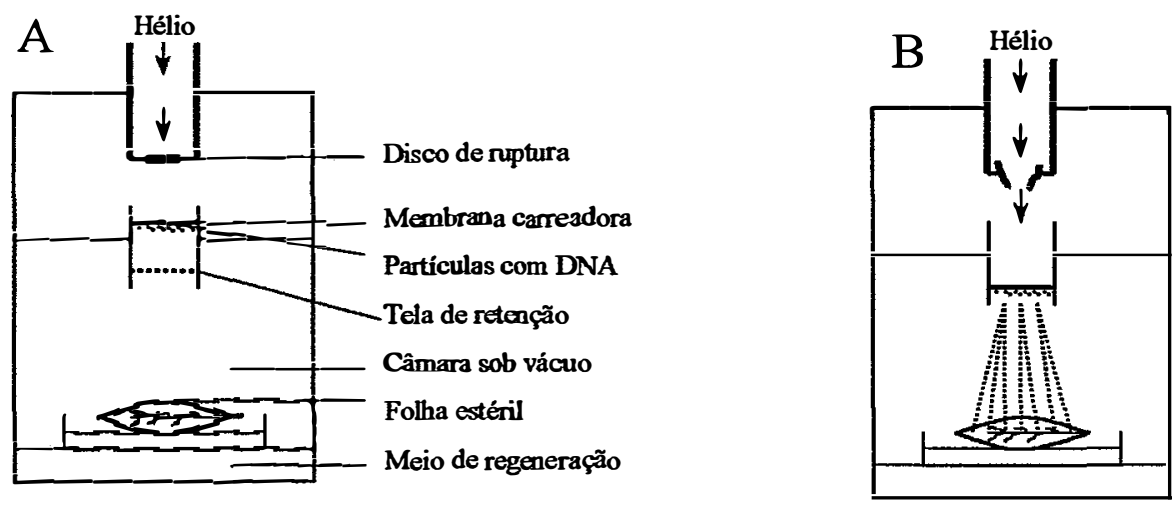

C

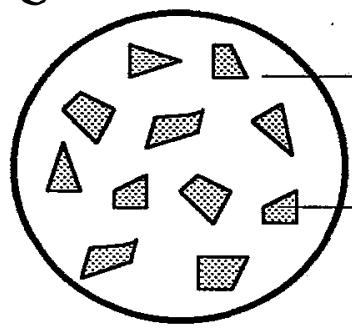

$\mathrm{E}$

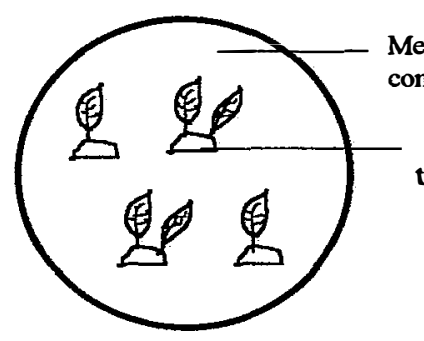

Meio de regeneração com espectinomicina

Tecido regenerado do transformante primánio

Calo resistente com brotosregenerantes (transformante primário)

$\mathrm{D}$

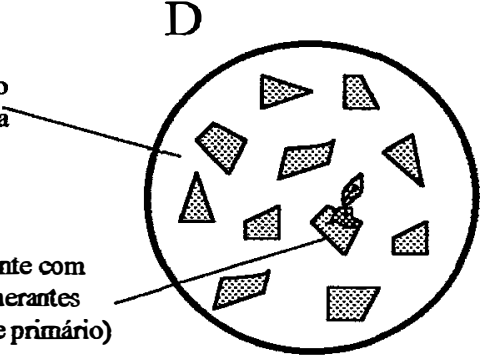

F

Meio de enraizamento sem antibiótico

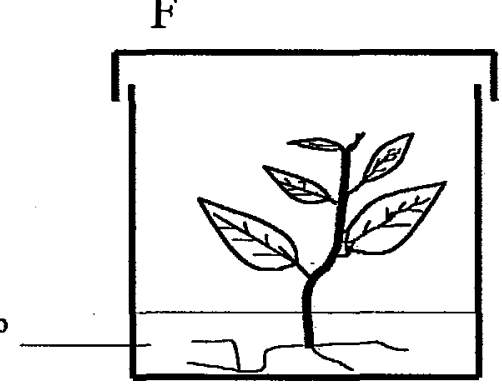

Figura 1. Tecnologia de Transformação de Cloroplastos de Plantas Superiores. Adaptado de Bock \& Hagemann (1999) 

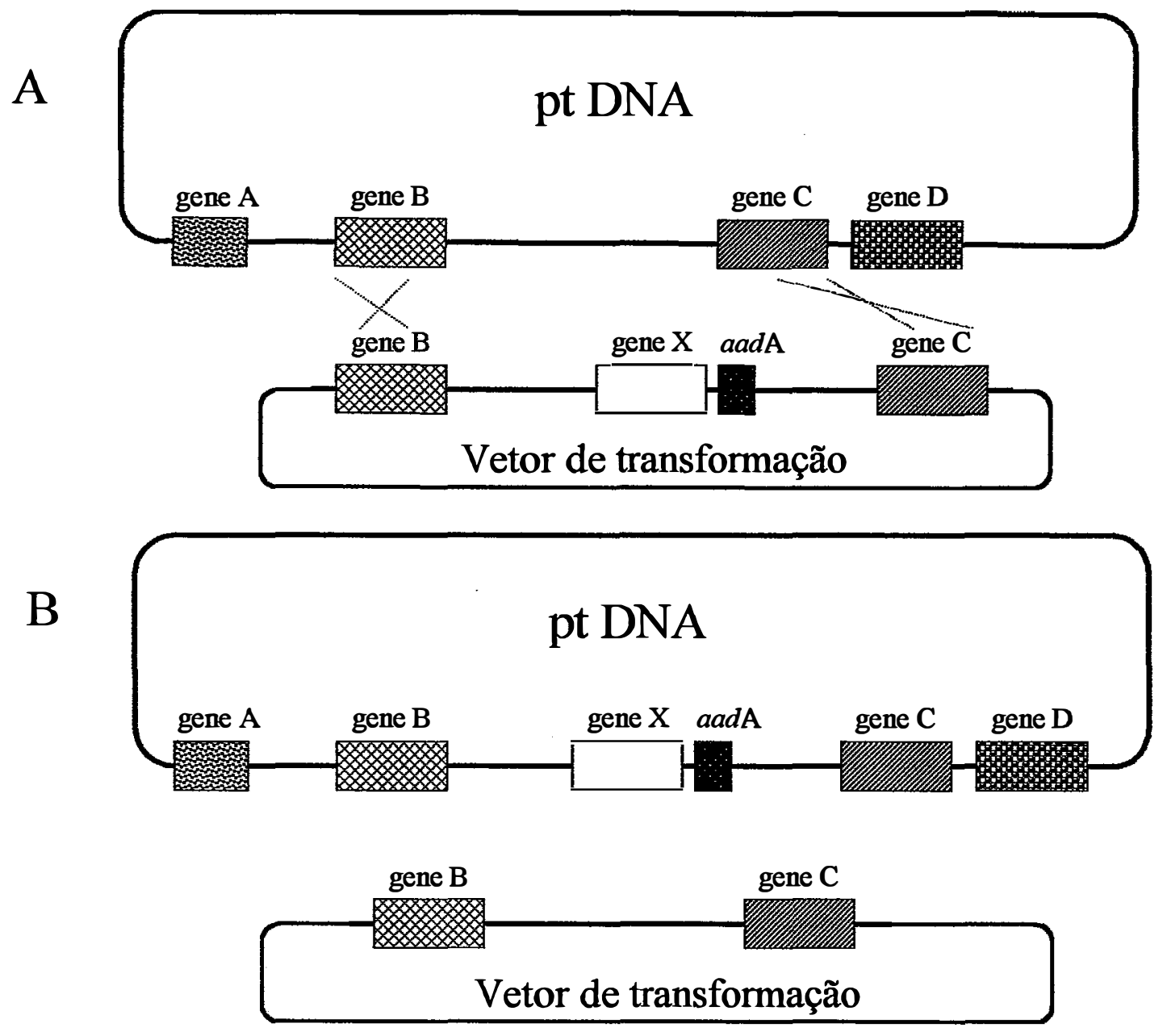

Figura 2. Integração do DNA transformante por dois eventos de Recombinação Homóloga. Adaptado de Bock \& Hagemann (1999).

\subsection{Aspectos Biotecnológicos da Transformação de Cloroplastos}

A tecnologia de transformação de cloroplastos, embora ainda pouco reconhecida por biotecnologistas, uma vez que até o momento somente tabaco, Arabidobsis e batata iveram o genoma cloroplastidial transformado entre as plantas superiores, promete revolucionar a engenharia genética e o melhoramento de plantas (Bock \& Hagemann, 
1999). Muito já foi estudado em termos de expressão gênica e funcionamento da maquinaria cloroplastidial, levando a acrediwar que plantas transplastômicas representam uma provável solução para os diversos aspectos de risco associados às plantas transgênicas nucleares.

Características inerentes ao sitema genético predominantemente procariótico e poliplóide dos cloroplastos já comprovaram a potencialidade de geração de plantas transgênicas mais eficientes e ecologicamente seguras. Nesse contexto, a primeira aplicação biotecnológica da transformação de cloroplastos veio com a geração de plantas de tabaco transplastômicas expressando em seus plastídios extraordinários altos níveis da toxina cristal de Bacillus thurigiensis (gene Cry1A), conferindo praticamente total resistência a diversos insetos (McBride et al., 1995). Da mesma forma, plantas transplastômicas de tabaco expressando protoxinas Cry2Aa2 também de Bacillus thurigiensis resultaram em níveis 20 a 30 vezes maiores do que aqueles expressos por plantas transgênicas nucleares comerciais, garantindo resistência total a diversos lepidópteros (Kota et al., 1999). Essas primeiras aplicações biotecnológicas já resultam no interesse público e industrial pelas numerosas vantagens atrativas oferecidas por plantas engenheiradas em seu genoma cloroplastidial (Bock \& Hagemann, 1999). As principais vantagens de plantas transplastômicas sobre plantas transgênicas nucleares são:

(a) Segurança ambiental: $\mathrm{Na}$ grande maioria das plantas cultivadas cloroplastos e mitocôndrias são matemalmente herdados (Gilham et al., 1991). Conseqüentemente, o pólen dessas plantas não carrega organelas, de tal forma que a possibilidade de fluxo gênico indesejado com a dispersão de transgenes, resultando por exemplo em biótipos resistentes de plantas daninhas, é impossibilitada, minimizando uma série de riscos ecológicos muitas vezes associados às plantas transgênicas nucleares ( Maliga, 1993; Bock \& Hagemann, 1999).

(b) Alto nível de acúmulo de transcritos: Uma aplicação bastante vantajosa em se transformar genoma de cloroplastos refere-se ao alto nível de acúmulo da proteína de interesse em plantas transplastômicas, provavelmente em função do grande número de cópias do genoma em cloroplastos e de sua eficiente maquinaria policistrônica de tradução 
de mRNAs. Plantas de tabaco transplastômicas apresentaram acúmulo de 2,5 a $3 \%$ de $\boldsymbol{\beta}$ glucuronidase (GUS), determinado por Staub \& Maliga (1993); 1\% de neomicina fosfotransferase (nptII), Carrer et al. (1993), 3 a 5\% da toxina Bt (Cry1A), McBride et al. (1995) e 8 a 18\% da proteína sintética FLARE-S (GFP fundido a AAD), Khan \& Maliga (1999), da proteína solúvel total, vindo a demosntrar as expectativas já geradas em 1993 quando acreditava-se que estudos de otimização da expressão gênica poderiam levar a um significante aumento na concentração da proteína de interesse em plantas transplastômicas (Maliga, 1993).

(c) Inserção dirigida: A integração do DNA transformante via recombinação homóloga através do flanqueamento do gene de interesse por seqüências endógenas do ptDNA (seqüências "alvo") possibilita a introdução dirigida e programada desse DNA no genoma plastídico (Maliga, 1993). Essa precisão no ponto de inserção, resultante da recombinação homóloga, evita incontrolados "efeitos de posição" de ocorrência comum em transformantes nucleares (com conseqüente silenciamento gênico, por exemplo) e toma possível a inativação ou modificação de genes plastidiais de forma previsível (Koop et al., 1996) de tal forma a garantir que o funcionamento normal do genoma cloroplastidial não seja alterado (Maliga, 1993).

(d) Ausência de efeitos epigenéticos: Efeitos epigenéticos, decorrentes de interações entre dois ou mais genes (Strickberger, 1985), produzindo fenótipos diferenciados e indesejados são de freqüente ocorrência em experimentos de transformação nuclear (Bock \& Hagemann, 1999). No entanto, efeitos epigenéticos não são conhecidos em plastídios, sendo provavelmente ausentes em organelas celulares, fazendo com que experimentos de transformação de cloroplastos sejam mais previsíveis e confiáveis quando comparados a transformantes nucleares (Bock \& Hagemann, 1999).

(e) Eliminação do gene marcador de resistência a antibiótico: Outra principal preocupação pública a respeito de plantas transgênicas é a massiva liberação de genes de resistência à antibióticos que são usualmente utilizados como genes marcadores 
seletivos em transformação de plantas. Remoção desse gene marcador após a geração da planta transgênica, portanto, é altamente desejável. A posse de tais técnicas de eliminação do marcador é também importante por uma segunda razão: o número de genes marcadores seletivos disponíveis para transformação é limitado. Cada introdução adicional de gene endógeno à planta transgênica iria requerer um novo marcador seletivo conferindo uma resistência diferente daquela(s) previamente utilizada(s), a menos que fosse permitida uma reciclagem e o mesmo gene marcador pudesse ser reutilizado (Bock \& Hagemann, 1999). Duas diferentes estratégias estão disponíveis para reciclagem de marcadores em transformação de cloroplastos (Fischer et al., 1996): (i) recombinação homóloga entre duas repetições diretas flanqueando o gene marcador seletivo e (ii) cotransformação de um vetor contendo o gene desejado e um segundo vetor "auxiliar" contendo um gene marcador seletivo, rompendo um ORF ("open reading frame" ou quadro de leitura aberto) essencial ao cloroplasto e consequentemente prevenindo que plantas transformadas tornem-se homoplásmicas para o gene de resistência. Quando homoplasmia é verificada para o gene de interesse, o gene heteroplásmico de resistência poderá ser prontamente eliminado sob pressão de seleção.

(f) Expressão de rotas biossintéticas como "operons": A possibilidade de introduzir diversos transgenes em uma planta por meio de um mesmo vetor construído trata-se de uma característica particularmente atrativa da tecnologia de transformação de cloroplastos (Bock \& Hagemann, 1999). Em oposição ao que ocorre no compartimento núcleo-citoplasma, mRNAs policistrônicos podem ser eficientemente traduzidos em plastídios (Staub \& Maliga, 1995), dessa forma permitindo a expressão simultânea de diversos transgenes sob controle de um único promotor e estabilizados por uma também única região 3' não traduzida (Staub \& Maliga, 1995). Isto, associado à natureza procariótica do sistema genético de expressão cloroplastidial, trazem à tona a atrativa possibilidade de expressar "operons" bacterianos completos (por exemplo, codificando rotas biossintéticas) em plastídios sem a necessidade excessiva de engenheiramento de sinais de expressão ou de regiões codificadoras (Bock \& Hagemann, 1999). 
As óbvias vantagens de plantas transplastômicas enumeradas fazem da tecnologia de transformação de cloroplastos uma ferramenta extremamente valiosa que realmente promete eliminar muitos dos problemas e possíveis riscos associados às tecnologias clássicas de obtenção de transgênicos. As duas citadas aplicações biotecnológicas da transformação de cloroplastos na tecnologia $B t$, assim como a geração de plantas de tabaco transplastômicas altamente resistentes ao glifosato (Daniell et al., 1998) e mais recentemente expressando altos níveis ( $>7 \%$ das proteínas solúveis totais) do hormônio humano somatrotopina (Staub et al., 2000), provavelmente representem apenas o início de uma nova era em biotecnologia de plantas. Outros trabalhos já demonstraram a possibilidade de extensão da transformação de cloroplastos para Arabidopsis thaliana (Sikdar et al., 1998) e batata (Sidorov et al., 1999), abrindo as portas para o uso da tecnologia em espécies cultivadas. O manejo de resistências, a exploração do potencial aumento do conteúdo nutritivo de plantas cultivadas, assim como da resistência a doenças ou mesmo da produção de enzimas e fármacos em plantas, parecem ser oportunidades altamente viabilizadas pelo uso da tecnologia de transformação de cloroplastos (Bock \& Hagemann, 1999). 


\section{MATERIAL E MÉTODOS}

\subsection{Material vegetal}

Plantas de tomate (Lycopersicon esculemtum L.) variedade IAC-Santa Clara foram cultivadas em casa-de-vegetação a partir de sementes doadas pelo Departamento de Produção Vegetal, Setor de Horticultura, ESALQ/USP. Para o isolamento de cloroplastos e DNA cloroplastidial ( $\mathrm{ptDNA}$ ) foram utilizadas folhas jovens.

\subsection{Isolamento de cloroplastos e ptDNA}

Cloroplastos intactos de tomate foram isolados através de gradiente de Percoll para posterior isolamento de DNA ( $\mathrm{ptDNA}$ ) conforme metodologia descrita por Bock (1998). O ptDNA isolado foi purificado em gradiente de Cloreto de Césio em ultracentrífuga segundo Romano(1998).

\subsection{Clonagem e seqüênciamento de fragmentos de ptDNA}

Uma vez que a seqüência de nucleotideos do genoma cloroplastidial de tomate ainda não foi determinada, tomou-se como referência o mapa de restrição (Figura 3) do genoma cloroplastidial de tomate publicado por Phillips (1985b). Foram utilizadas as enzimas de restrição SalI e PstI para digestão do ptDNA de tomate e potencial clonagem de fragmentos de aproximadamente 6,4, 6,5, 8,3, 8,6 e 8,7 kb (Phillips, 1985b). Dois fragmentos SaI/Pst, de aproximadamente $8,6 \mathrm{~kb}$ e $6,4 \mathrm{~kb}$, foram clonados via shotgun em vetores plasmidiais pBlueScript [pBS $\mathrm{KS}(-)$ ] resultando os plasmídios pI]B1 e pIJB2 respectivamente. Os fragmentos de DNA cloroplastidial foram sequenciados com Big Dye Terminators em sequenciador automático de DNA ABI Prism 377 (PerkinéElmer) conforme protocolos do fabricante (Applied Biosystems) otimizados para as condições do 
Laboratório de Biologia Molecular do Centro de Biotecnologia Agrícola (CEBTEC/ESALQ/USP), seguindo as estratégias:

a) Subclonagem através de digestões enzimáticas;

b) Preparação de minibiblioteca shotgun com fragmentos entre 0,8 a 2,0 kb.

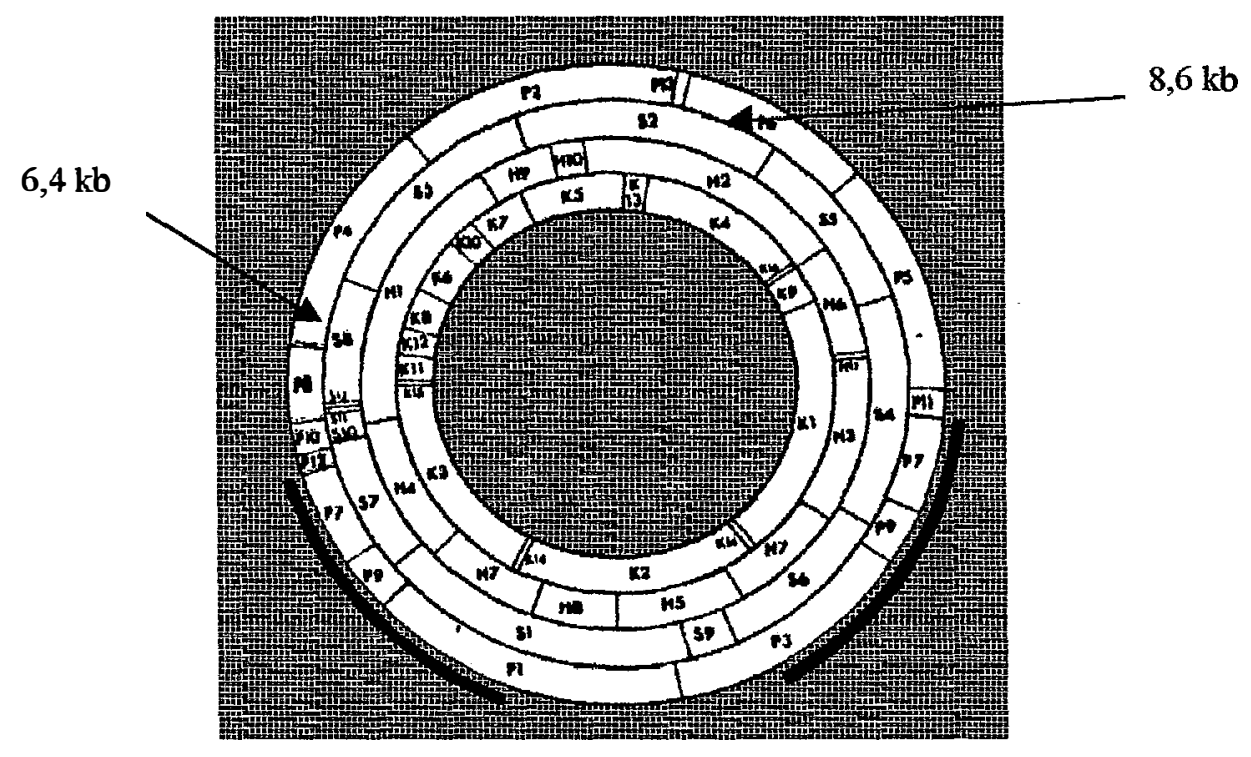

Figura 3. Mapa de restrição de DNA cloroplastidial de tomate indicando os fragmentos oriundos de restrições com as enzimas $\mathrm{H}=H \not p a \mathrm{I}, \mathrm{S}=\mathrm{Sall}, \mathrm{K}=K \not n \mathrm{I}$ e $\mathrm{P}=$ PstI. Fragmentos clonados estão indicados por setas. Adaptado de Phillips (1985b)

\subsubsection{Sequenciamento do fragmento cloroplastidial clonado no plasmídio pIJB1 (8,6}

\section{kb) através de subclonagens por enzimas de restrição:}

Com base em digestões enzimáticas promovidas pelas enzimas de restrição PstI, SacI, ClaI, XbaI, SmaI, BamHI, XboI, KpnI, HindIII e Sall foi estabelecido um mapa de restrição inicial para o fragmento de DNA cloroplastidial de 8,6 kb (pIJB1). De acordo com o mapa de restrição obtido, o fragmento foi subclonado em cinco sub-fragmentos conforme apresentado na Figura 4. As extremidades dos clones pIJB3, pIJB4, pIJB5, pIJB6 e pIJB8 foram sequenciadas via primers universais 'Foward' (5'-CCCAG TCACG ACGTT GTAAA ACG-3') e 'Reverse' (5'-AGCGG AtAAC AATTT CACAC AGG-3'). Para o seqüenciamento completo destes fragmentos foram sintetizados primers nas direções 5' e 3' 
baseados nos resultados de seqüenciamento de suas respectivas extremidades. As seqüências dos primers utilizados estão apresentadas na Tabela 2. A análise e montagem da seqüência completa do fragmento cloroplastidial foram realizadas através do software Sequencher 3.1 (Genes Codes Corporation) utilizando-se da seqüência completa de cada um dos sub-fragmentos. Os sub-fragmentos de pIJB6 e pIJB8 foram montados em sequência única, devido a seqüência de pIJB8 estar inclusa em pIJB6, ver Figura 4.

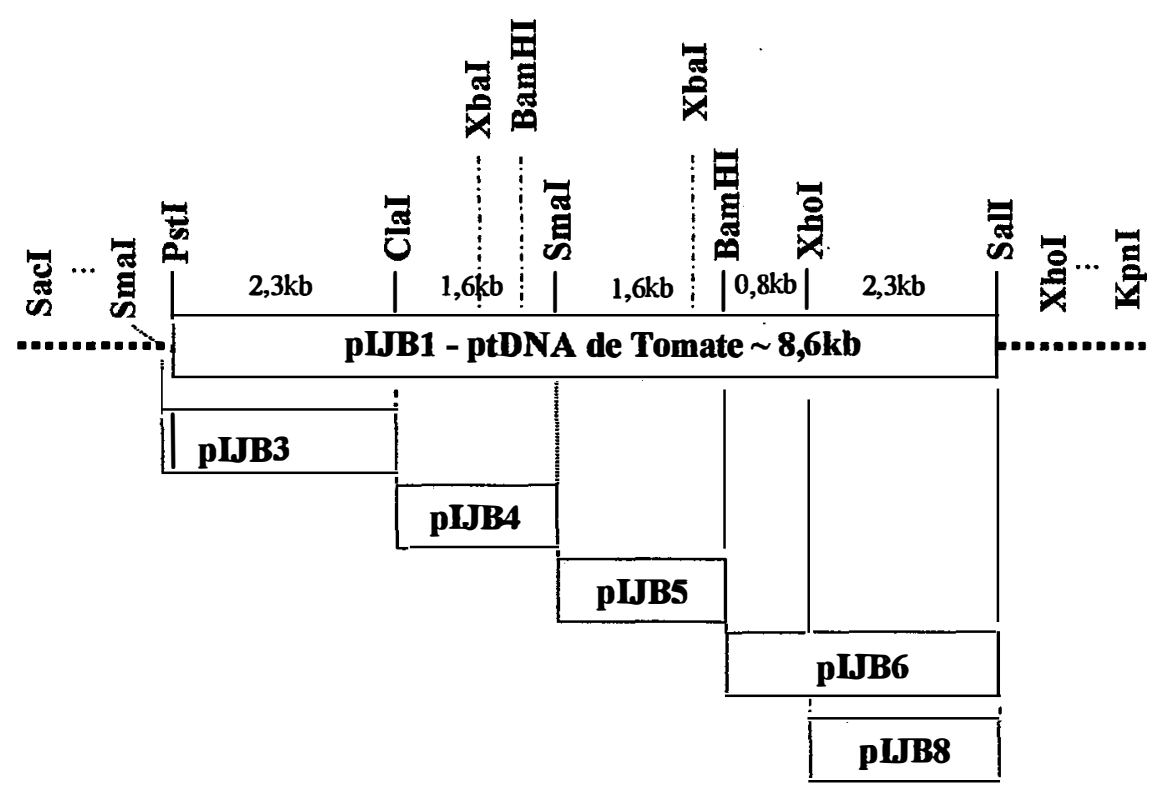

Figura 4. Fragmento cloroplastidial de tomate referente ao plasmídio pIJB1 com representação dos subfragmentos flanqueados pelas enzimas de restrição utizadas para a subclonagem. 
Tabela 2. Primers utilizados para o sequenciamento completo dos subfragmentos cloroplastidiais de tomate referentes aos plasmídios pIJB3, pIJB4, pIJB5, pIJB6 e pIJB8.

\begin{tabular}{|c|c|}
\hline Plasmídio & Primer: seqüência \\
\hline \multirow[t]{4}{*}{ pIJB3 } & IB3-5': 5' GAA ATG TAA CAA ACG 3' \\
\hline & IB3-3': 5' АTC АAT АTT CGA TCG A 3' \\
\hline & IB3-1: 5' CAT GAG GCT GAT C 3' \\
\hline & IB3-2: 5' CCA GAG AAT GCG A C $3^{\prime}$ \\
\hline \multirow[t]{4}{*}{ pIJB4 } & IB4-5': 5' TAG GAA GTA TAG GAG 3' \\
\hline & IB4-3': 5' CCG CAG СТT CCG CCT 3' \\
\hline & IB4-1: 5' GCC АTC АTA CTA TG 3' \\
\hline & IB4-2: 5' CAT TAC ATG CAT C $3^{\prime}$ \\
\hline pIJB5 & IB5-3': 5' ATG CTA TGT CAA TC 3' \\
\hline \multirow[t]{2}{*}{ pIJB6 } & IB6-5': 5' CCG CAG TAA CAT C 3' \\
\hline & IB6-2: 5' GAT АAT TCT АТA TCG 3' \\
\hline \multirow[t]{2}{*}{ pIJB8 } & IB8-5': 5' GAA TGC ATG AAT G 3' \\
\hline & IB8-3': 5' GTG АTT CAT ACA CAG 3' \\
\hline
\end{tabular}

\subsubsection{Seqüenciamento do fragmento cloroplastidial clonado no plasmídio pIJB2 (6,4}

\section{kb) através de minibibliotecas shotgun:}

A estratégia utilizada para o seqüenciamento completo do fragmento cloroplastidial de 6,4 kb (pIJB2) foi através da preparação de minibibliotecas shotgun. Foram utilizados 20 $\mu \mathrm{g}$ do plasmídio pIJB2 (vetor mais fragmento) preparado através de MaxiPrep/QLAGEN (Cat. \# 12162), o qual foi submetido à nebulização $\left(5 \mathrm{X} / 8\right.$ segundos a $1,5 \mathrm{kgf} / \mathrm{cm}^{2}$, gás hélio). As extremidades dos fragmentos foram reparadas por reação catalizada pelas enzimas T4 DNA polimerase e Klenow polimerase para obtenção de extremidades abruptas (blunt ends) conforme protocolo descrito por PROMEGA (1996). Fragmentos de 0,8 a 2,0 $\mathrm{kb}$ foram isolados por eletroforese em gel de agarose ('Low Melting Point') por excisão da 
banda correspondente. A purificação foi realizada via extração fenol/éter. Para a obtenção da biblioteca, os sub-fragmentos purificados foram ligados ao vetor plasmidial $\mathrm{pUC18} / \mathrm{SmaI}$ (Sume Clone/Amersham-Pharmacia) e inseridos via transformação em E. coli linhagem DH5 $\alpha$. Das colônias obtidas foram realizadas minipreparações de plasmídios, os quais tiveram as extremidades dos respectivos fragmentos seqüenciadas utilizando primers universais reverse (R) e foward (F) (já descritos).

Como altemativa, para reduzir o número de reações de seqüenciamento das regiões referentes ao vetor, uma nova minibiblioteca foi obtida utilizando-se somente a seqüência Sall/Pst de 6,4 kb amplificada in vitro via PCR em reação catalisada pela enzima elongase (DNA polimerase, GIBCO cat.\#10481-018). O fragmento amplificado de 6,4 kb foi fragmentado via nebulização ( $7 \mathrm{X} / 8$ segundos a $1,5 \mathrm{kgf} / \mathrm{cm}^{2}$, gás hélio) e os sub-fragmentos obtidos foram reparados segundo protocolo descrito anteriormente. Para a montagem da seqüência completa do fragmento cloroplastidial $(6,4 \mathrm{~kb})$ foram utilizados os resultados obtidos do seqüenciamento das extremidades dos subclones resultantes das duas estratégias citadas acima, utilizando o software Sequencher 3.1 (Genes Codes Corporation).

\subsection{Análise de homologia}

Análises de homologia com genomas de cloroplastos de plantas já sequenciados, tais como tabaco, arroz e milho foram realizadas via BLAST Search (NCBI - National Center for Biotechnology Information - http://www.ncbi.nlm.nih.gov/BLAST/ ). A identificação e localização de regiões codificadoras e espaços intergênicos nos fragmentos foi realizada com base na seqüência do genoma cloroplastidial de tabaco (Sugiura et al., 1998) através de alinhamentos via BLAST Search e DIALIGN 2.1 (Morgenstem, 1999 Universität Bielefeld - http://bibiserv.techfak.uni-bielefeld.de/dialign/). Em função da maior homologia entre regiões codificadoras de genomas cloroplastidiais (Shimada \& Sugiura, 1991) procedeu-se ao alinhamento e análise de homologia (nucleotídeos e aminoácidos) entre as regiões codificadoras $r p o \mathrm{~B}$ (incompleta), $\operatorname{trn} \mathrm{C}, p e t \mathrm{~N}(y c f 6), p s b \mathrm{M}, \operatorname{trn\mathrm {D}}$, $\operatorname{tr} \mathrm{Y}, \operatorname{trn\mathrm {E}}, \operatorname{trn\mathrm {T}}, p s b \mathrm{D}, p s b \mathrm{C}$ (derivadas do plasmídio $\mathrm{pIJB1}), r p 20,5^{\prime} r p s 12, c l p \mathrm{P}, p s b \mathrm{~B}, p s b \mathrm{~T}$ e $p s b \mathrm{~N}$ (derivadas do plasmídio pIJB2) de tomate (Lycopersicon esculentum L.) com os genomas de Zea mays, Oryza sativa, Nicotiana tabacum, Pinus thunbergii e Marchantia polymorpha (Bock, 
2000, doação de arquivo de alinhamentos, trabalho não publicado). Em adição foram analisados conteúdo de GC ( $\mathrm{G}+\mathrm{C}$ em \%), ocorrência de duplicações, deleções, substituições e inserções com relação ao genoma de tabaco, assim como o padrão de restrição para os fragmentos cloroplastidiais de tomate clonados em pIJB1 e pIJB2. Com base em Hirose et al. (1999) foi analisada a ocorrência de sítios de editamento de mRNA já relatados para os plastomas de tabaco e milho.

\subsection{Obtenção da sequência flanqueadora de ptDNA para construção de vetores de transformação}

O seqüenciamento completo dos fragmentos de cloroplasto de tomate dos plasmídios pIJB1 e pIJB2 permitiu a construção de mapas de restrição detalhados das respectivas sequências. Análise da sequência e mapa de restrição do plasmídio pIJB1 (8.660 pb) permitiu a identificação de um sítio único de restrição para a enzima StuI contido no espaço intergênico entre os genes $p s b \mathrm{M}$ e pet $\mathrm{N}(y c f)$. Com base no mapa de restrição do

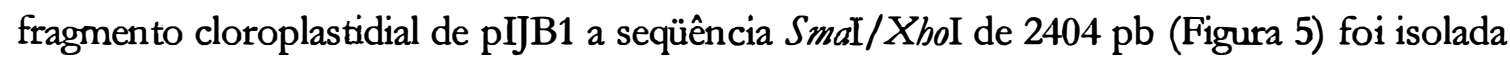
por digestão enzimática e clonada em pBS KS(-) nos sítios Ecl136II/XboI. Restrição com SmaI (presente no fragmento) e Ecl136II (presente no vetor $\mathrm{pBS}$ ) resultam em extremidades abruptas as quais puderam ser ligadas resultando na perda do sítio SmaI e Ecl136I, o que era desejável (Figura 6a). Outros sítios de restrição originalmente presentes no vetor (XboI, EcaO109I, DraII, $A p a \mathrm{I}$ e $K p n \mathrm{I}$ ) foram eliminados por digestão $X b o \mathrm{I} / K \not n \mathrm{I}$ seguida por tratamento pela exonuclease Mung Bean. O plasmídio resultante pTCTJ2 contendo a seqüência alvo está representado na Figura $6 \mathrm{~b}$. 


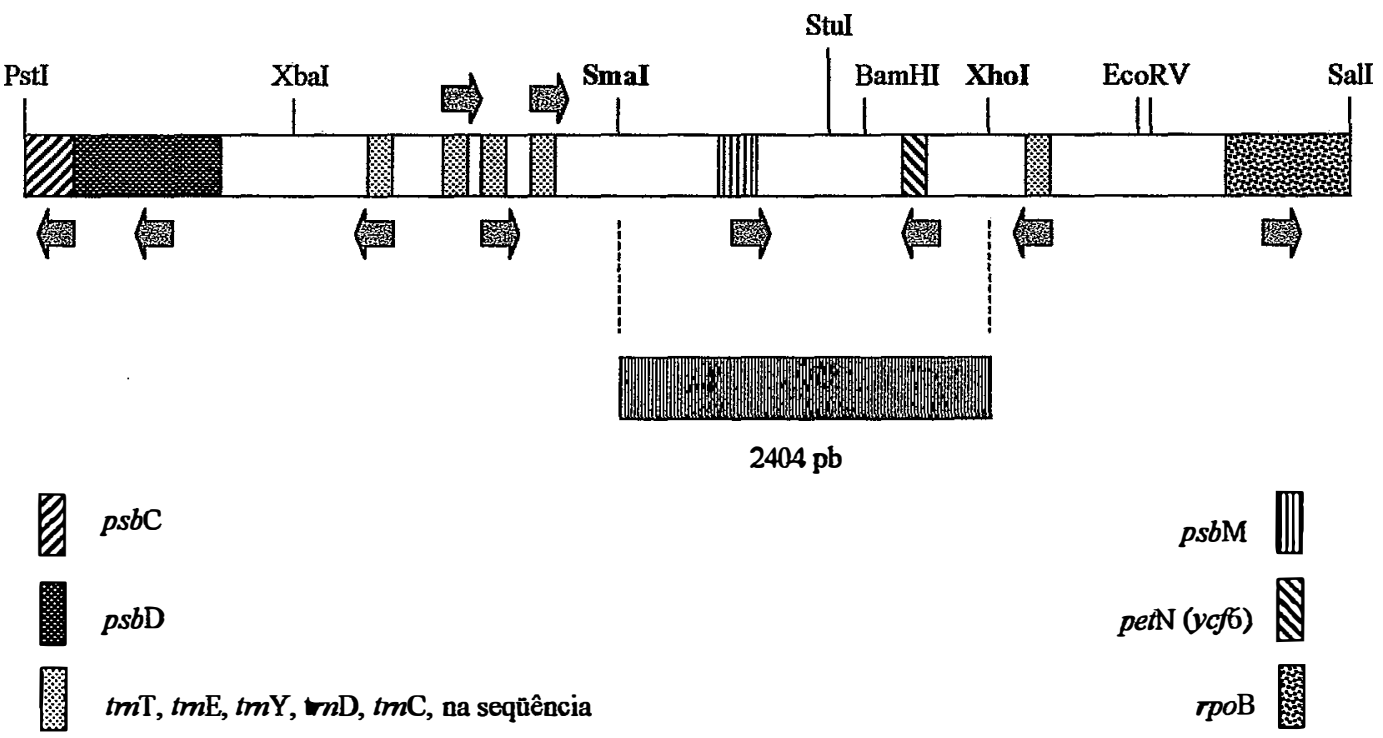

Figura 5. Mapa de restrição referente ao fragmento cloroplastidial de tomate $(8.660 \mathrm{pb})$ plasmídio pIJB1. Sítios SmaI/XhoI flanqueiam a região de $2.404 \mathrm{pb}$ contendo o sítio único de restrição para StuI. Setas em cor cinza representam o sentido da transcrição da respectiva região codificadora. 


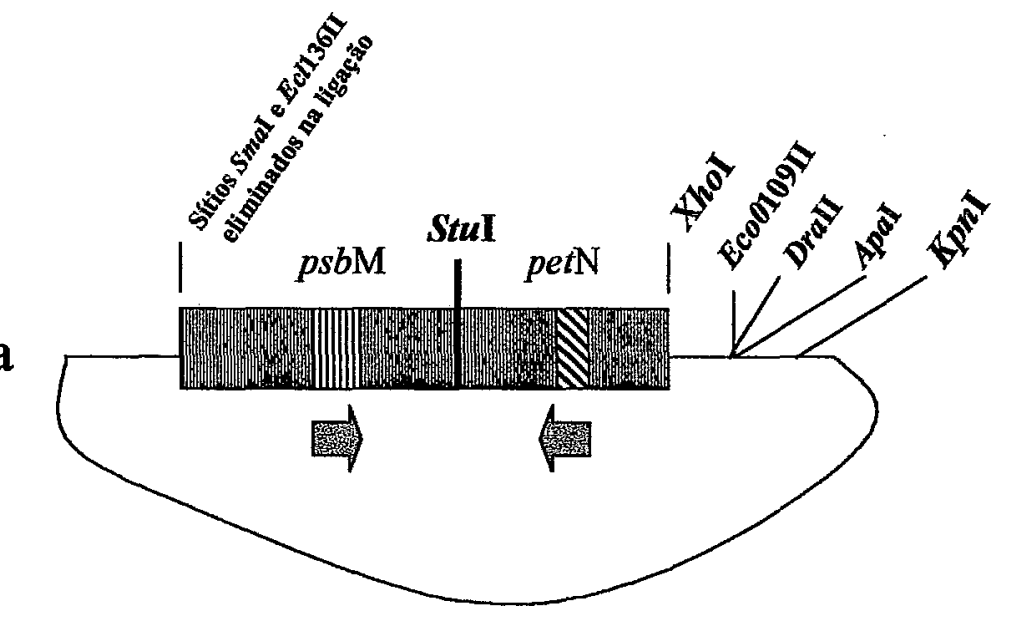

Digestão XhoI/KpnI seguida por tratamento pela nuclease Mung Bean

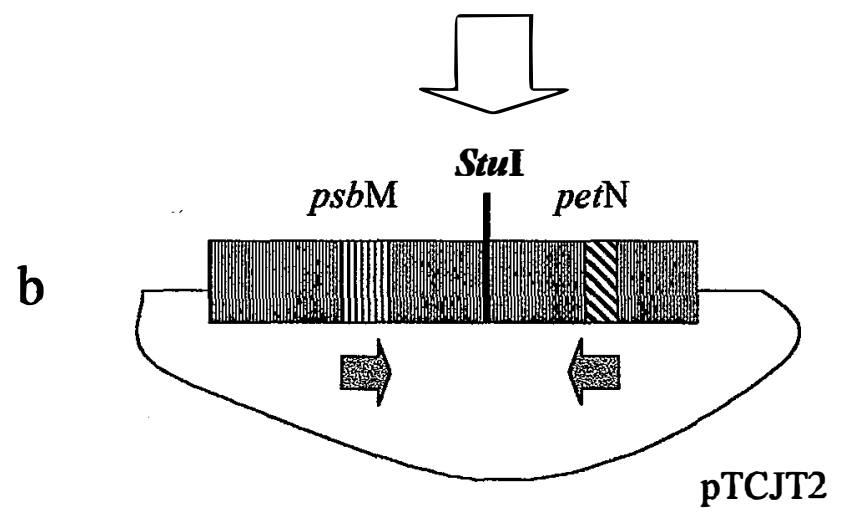

Figura 6. Estratégia de eliminação dos sítios de restrição adjacentes à seqüência de ptDNA para construção do plasmídio p'TCJT2 contendo a seqüência alvo de cloroplasto de tomate para construção de vetores de transformação via recombinação homóloga.

\subsection{Construção do gene marcador seletivo}

A região do promotor do gene atpI e a região terminalizadora do gene $r p s 14$ de cloroplasto de tomate (IAC-Santa Clara) foram amplificados via PCR para construção do gene marcador quimérico aadA. Os primers utilizados para a amplificação encontram-se listados na Tabela 3. 
Tabela 3. Primers sintetizados para a amplificação via PCR das seqüências promotora do gene atpI e terminalizadora do gene $r p s 14$ de cloroplasto de tomate IAC-Santa Clara. A introdução de novos sítios de restrição nas sequências encontra-se indicada.

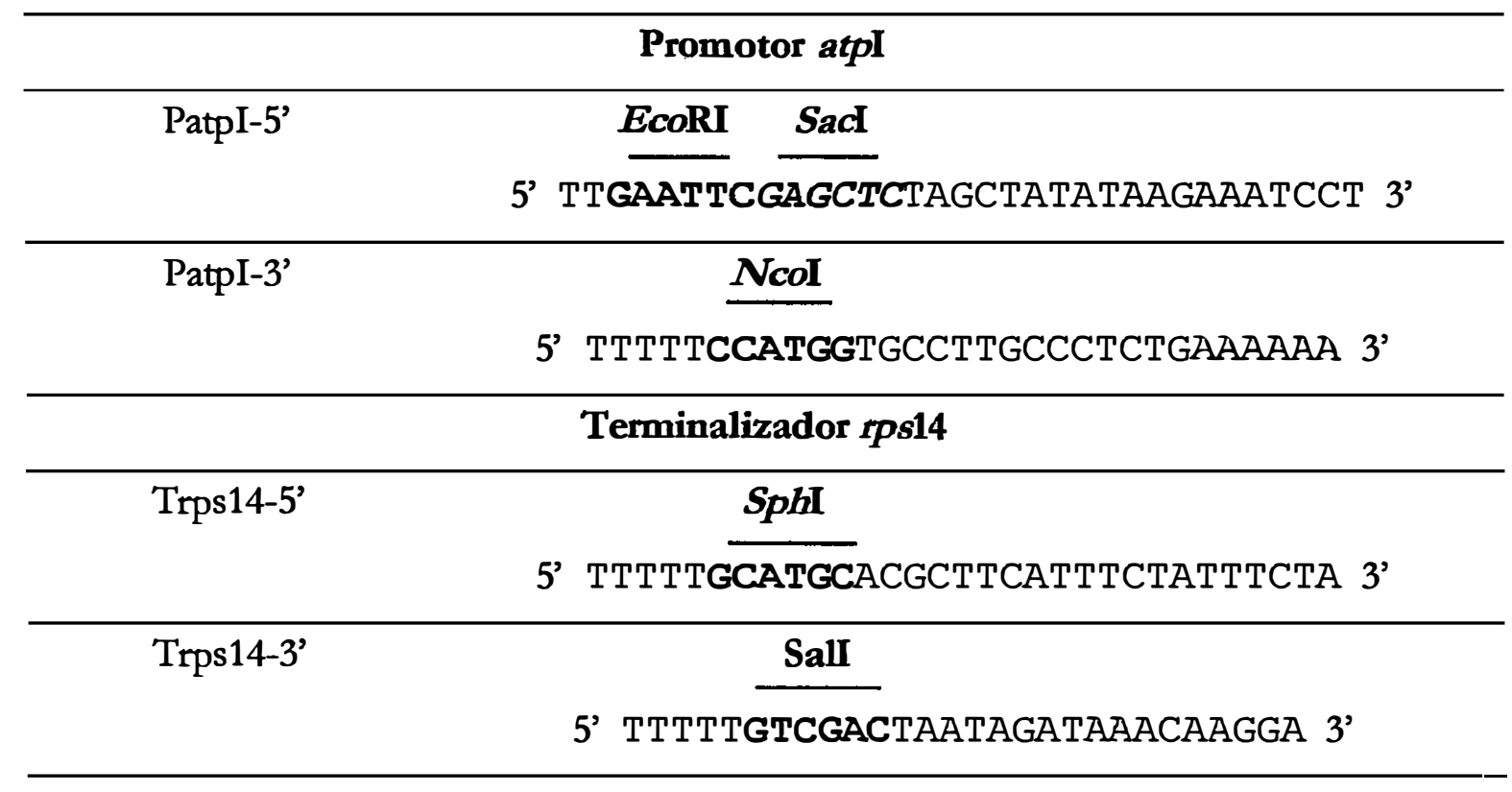

Sucessivas subclonagens foram realizadas para a troca do promotor $16 \mathrm{~S}$ de Nicotiana tabacum e terminalizador $r b c \mathrm{~L}$ de Chlamydomonas reinhardtii pelas seqüências de tomate (promotor PatpI/terminalizador Trps14) na construção pUC-16S-aadA gentilmente cedida por Ulrich-Hans Koop/Universidade de Munique, Alemanha. A partir do plasmídio pUC-16S-aadA que contém a região codificadora do gene aadA (conferindo resistência aos antibióticos espectinomicina e estreptomicina) foi realizada a troca do região promotora do gene 16S (Figura 7a) pela região promotora do gene atpI (PatpI) de tomate via restrição com as enzimas $\mathrm{E} c \mathrm{RI} / \mathrm{NcoI}$, originando o plasmídio pIJB10 (Figura $7 \mathrm{~b}$ ). $\mathrm{O}$ cassete flanqueado pelas enzimas de restrição EcoRI/SaI (Figura 7b) foi isolado e inserido em vetor pBS KS (-) para eliminar os sítios PstI, SphI e HindIII, oriundos do vetor original no plasmídio pIJB10, 
uma vez que outros sítios para as mesmas enzimas estão presentes entre a região codificadora do gene aadA e o terminalizador do gene rbcL. Assim obteve-se o plasmídio pIJB11, que contém sítios únicos para PstI, SphI e HindIII (Figura 7c) desejáveis para as futuras clonagens. A partir do plasmídio pIJB11 foi realizada troca da região terminalizadora do gene $r b c \mathrm{~L}$ pela região terminalizadora do gene $\not p s 14$ (Trps14) de tomate, originando o plasmídio pIJB12 (Figura 7d) utilizando-se dos sítios SphI/SalI. O isolamento do cassete atpI-aadA-rps14 via sítios SacI/HincII e clonagem em vetor pBC nos sítios SacI/NotI-Klenow resultaram no plasmídio pIJB13 (Figura 7e). Obteve-se assim um cassete de expressão do gene aadA (aminoglicosídeo 3"-adenililtransferase), conferindo resistência aos antibióticos espectinomicina e estreptomicina, sob controle da expressão pelas seqüências 5' PatpI e 3' Trps14 de cloroplasto de tomate contendo diversos sítios de restrição únicos necessários para novas construções.

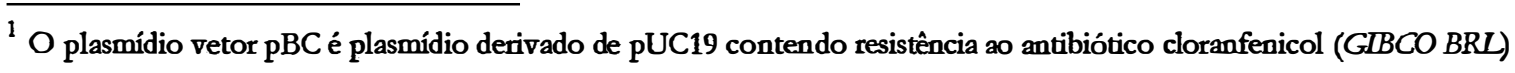


$\mathbf{a}$

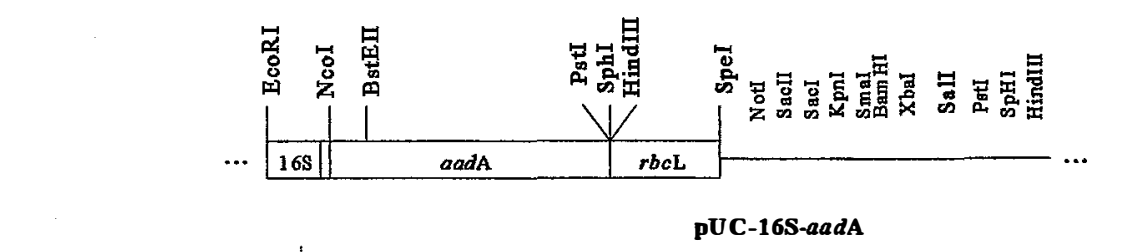

b
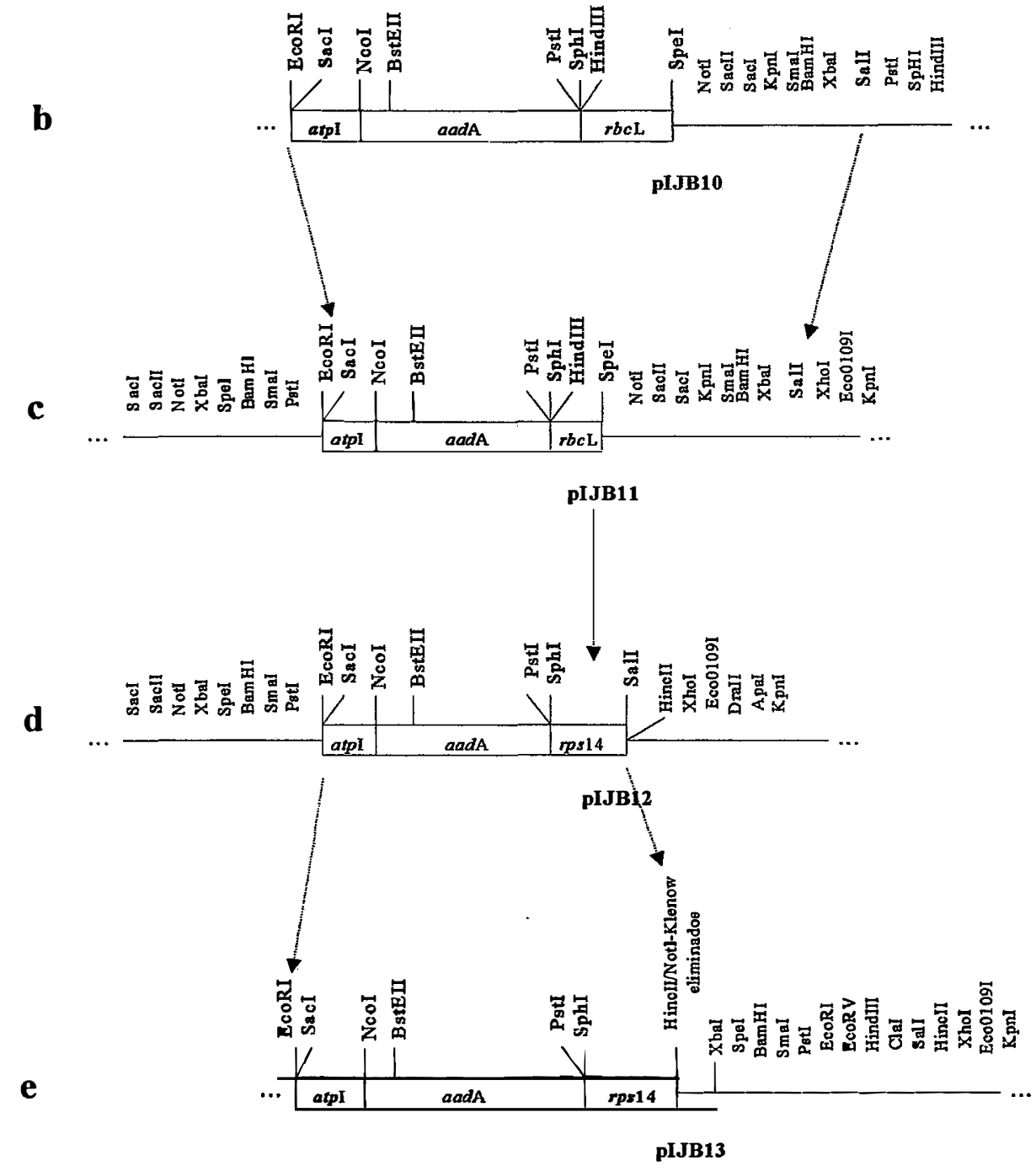

Figura 7. Estratégia utilizada para construção do gene marcador (cassete atpl-aadA-pps14). a) construção inicial pUC-16S-aadA; b) substituição da região promotora P16S pela região promotora PatpI de cloroplasto de tomate; c) Clonagem do cassete de expressão em vetor $\mathrm{pBS}$ para eliminação dos sítios de restrição PstI, SphI e HindIII; d) Substituição da região terminalizadora TrbcL pela região terminalizadora Trps14 de cloroplasto de tomate; e) construção final contendo o cassete de expressão plastídioespecifico. 


\subsection{Construção final de vetores de transformação de cloroplasto de tomate via recombinação homóloga}

\subsubsection{Vetor de transformação pIJB18 com 12 sítios de restrição}

Para a construção do vetor de transformação pIJB18, ou seja, o gene marcador seletivo flanqueado por seqüências homólogas de DNA cloroplastidial, o cassete atpI-aadArps14, contendo uma seqüência 3' (polylinker) com 12 sítios de restrição (XbaI, SpeI, BamHI, SmaI, PstI, EcoRI, EcoRV, HindIII, ClaI, SalI, HincII, XboI) foi isolado do plamídio pIJB13 por digestão SacI/Eco0109I (Figura 8), onde a seqüência teve as extremidades reparadas com a enzima polimerase Klenow (Large fragment of DNA Polymerase I, E. coli) para obtenção de extremidades abruptas e construção do vetor. O plasmídio pTCJT2 (Figura 6b) foi clivado no sítio StuI para a inserção do cassete de aadA. A seleção dos plasmídios recombinantes se deu por plaqueamento em meio de cultura LB (Ausubel et al., 2000) semisólido contendo espectinomicina na concentração de $100 \mu \mathrm{g} / \mathrm{mL}$. Confirmação complementar da inserção do cassete de aadA foi obtida por análise de restrição com as enzimas EcoRV, Sall (presentes no polylinker junto ao cassete de aadA e ausentes no ptDNA), Xbal (com sítios tanto no polylinker, junto ao cassete de aadA, como no ptDNA), e $S t u I$ (presente no ptDNA original, eliminado com a inserção do cassete).

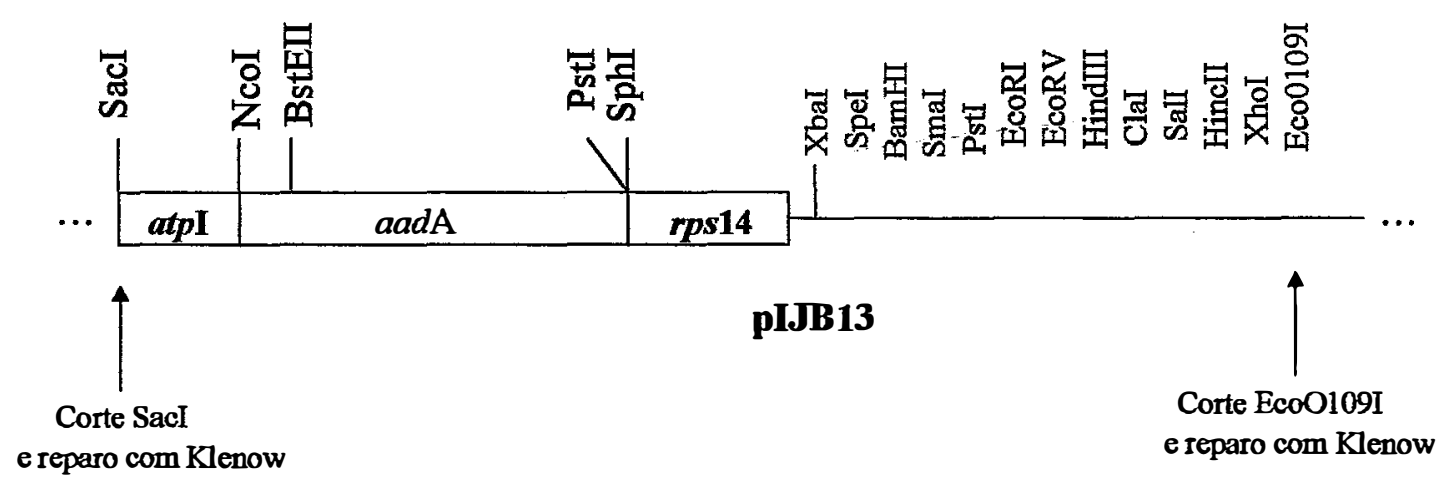

Figura 8. Cassete aadA e polylinker. Excisão de pIJB13 pelas enzimas SacI/Eco0109I. 


\subsubsection{Vetor de transformação pIJB20 com 14 sítios de restrição}

Com o objetivo de gerar um vetor com os sítios EcoO109I, e $K \not n I$ foi obtido o vetor pIJB20. O cassete atpI-aadA-rps14, contendo uma seqüência 3' com 14 sítios de restrição (XbaI, SpeI, BamHI, SmaI, PstI, EcoRI, EcoRV, HindIII, ClaI, Sal, HincII, XhoI, EcoO109I e $K \not n I)$ foi isolado do plamídio pIJB13 por digestão com Ec1136II (Isosquizômero para SacI)/Ac655I (Isosquizômero para KpnI) (Figura 9), onde a extremidade gerada pela enzima Acc65I foi reparada com a enzima polimerase Klenow (Large fragment of DNA Polymerase I, E. col) para obtenção de extremidade abrupta, recomposição do sítio de $K p n I$ (quando ligado com StuI) e construção do vetor. O plasmídio pTCJT2 (Figura 6b) foi também clivado no sítio StuI para a inserção do cassete de aadA. Da mesma forma a seleção dos plasmídios recombinantes se deu por plaqueamento em meio de cultura LB (Ausubel et al., 2000) semi-sólido contendo espectinomicina na concentração de $100 \mu \mathrm{g} / \mathrm{mL}$. Confirmação da inserção do cassete de aadA foi obtida por análise de restrição com as enzimas EcoRV, Sal (presentes no polylinker junto ao cassete de aadA e ausentes no ptDNA), XbaI (com sítios tanto no polylinker, junto ao cassete de aadA, como no ptDNA), StuI (presente no ptDNA original, eliminado com a inserção do cassete) e também KpnI (ausente na construção final de pIJB18, no entanto reconstituído na construção do vetor pIJB20)

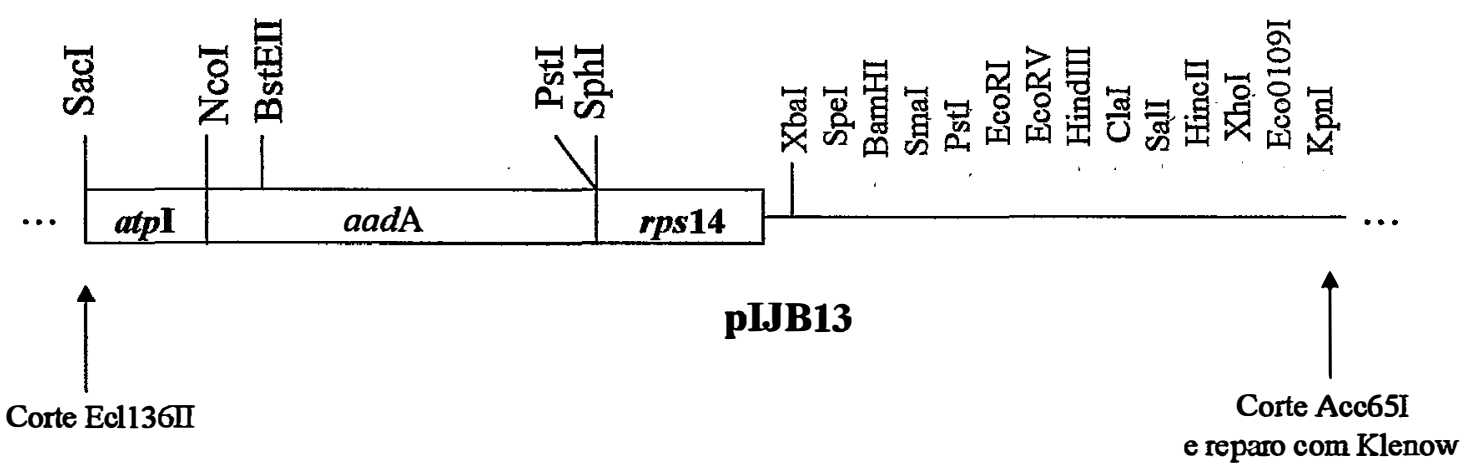

Figura 9. Cassete aadA e polylinker. Excisão de pIJB13 pelas enzimas Ech136II/Acc55I, respectivamente isoesquizômeros das enzimas SacI/KpnI; Ecl136II gera extremidades abruptas ("blunt ends"), a qual recupera o sítio KpnI quando ligada à extremidade gerada pela enzima StuI. 


\section{RESULTADOS E DISCUSSÃO}

\subsection{Clonagem e seqüenciamento de fragmentos de ptDNA.}

Com base no mapa de restrição publicado em Phillips (1985b), dois fragmentos de DNA cloroplastidial de tomate IAC-Santa Clara de 8.660 pb e 6.366 pb foram clonados em vetor pBS KS(-), através de digestão pelas enzimas PstI e SalI, resultando nos plasmídios pIJB1 e pIJB2 respectivamente. Seqüenciamento das extremidades do inserto em pIJB1 revelou que a seqüência corresponde à região compreendida entre os genes $p s b \mathrm{C}$ e $\not p o \mathrm{~B}$ em tabaco (Shinozaki et al., 1986). Da mesma forma, seqüenciamento das extremidades do inserto em pIJB2 revelou que a sequência é correspondente àquela compreendida entre os genes $\not p l 20$ e $p s b \mathrm{~N}$ em tabaco (Shinozaki et al., 1986). Os fragmentos correspondentes em tabaco apresentam respectivamente 9127 pb e 6375 pb.

\subsubsection{Seqüenciamento do fragmento cloroplastidial clonado no plasmídio pIJB1 (8,6} kb) através de subclonagens por enzimas de restrição.

Como primeira etapa da estratégia de seqüenciamento do fragmento cloroplastidial de tomate em pIJB1, foi estabelecido o mapa de restrição inicial para a sequência por digestões mediadas pelas enzimas PstI, SacI, ClaI, XbaI, SmaI, BamHI, XhoI, KpnI, HindIII e Sall como mostrado na Figura 10.

Com base no mapa de restrição estabelecido, o fragmento foi subclonado resultando em cinco sub-fragmentos (Figura 10) em vetores pBS (-). Os sub-fragmentos deram origem aos plasmídios pIJB3, pIJB4, pIJB5, pIJB6 e pIJB8 conforme as Figuras 17, $18,19,20$ e 21 respectivamente. 


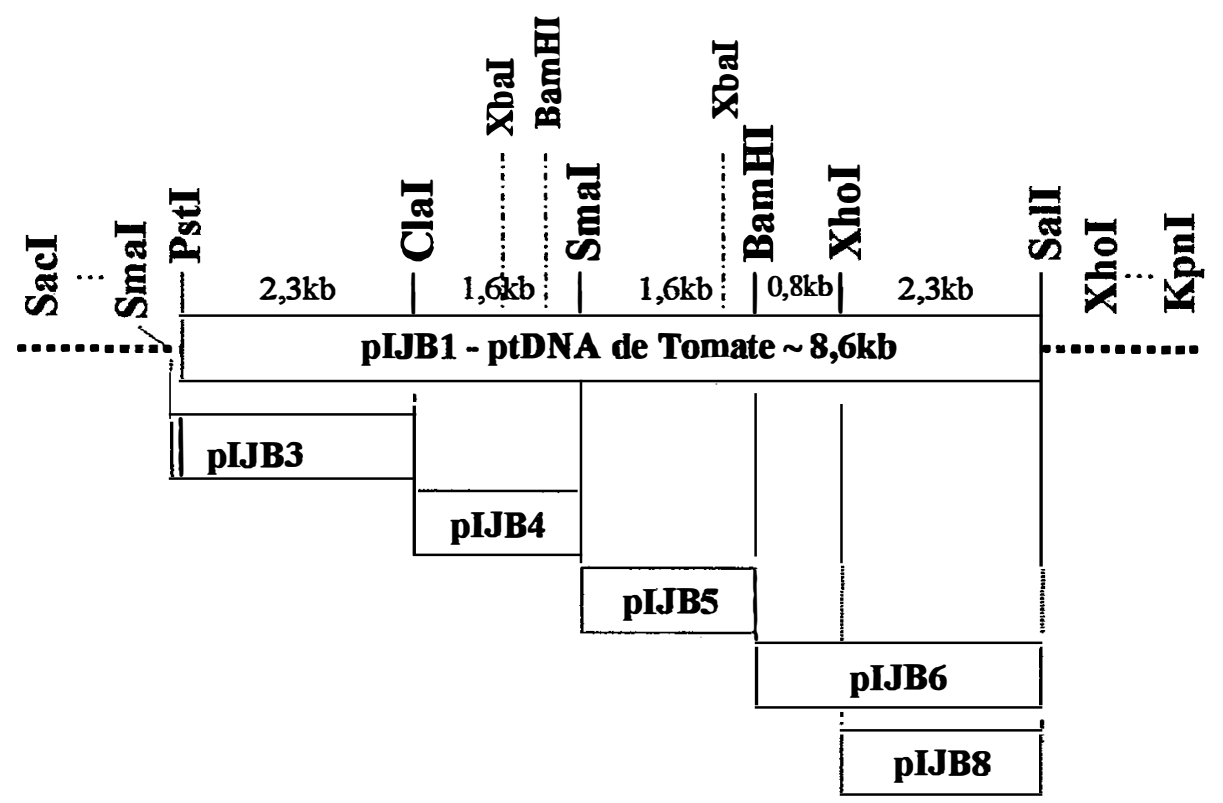

Figura 10. Subclonagem do fragmento cloroplastidial de tomate (pIJB1). Geração de 5 subfragmentos clonados em pBS (-) resultando nos subclones $\mathrm{pIJB3}$, pIJB4, pIJB5, pIJB6 e pIJB8.

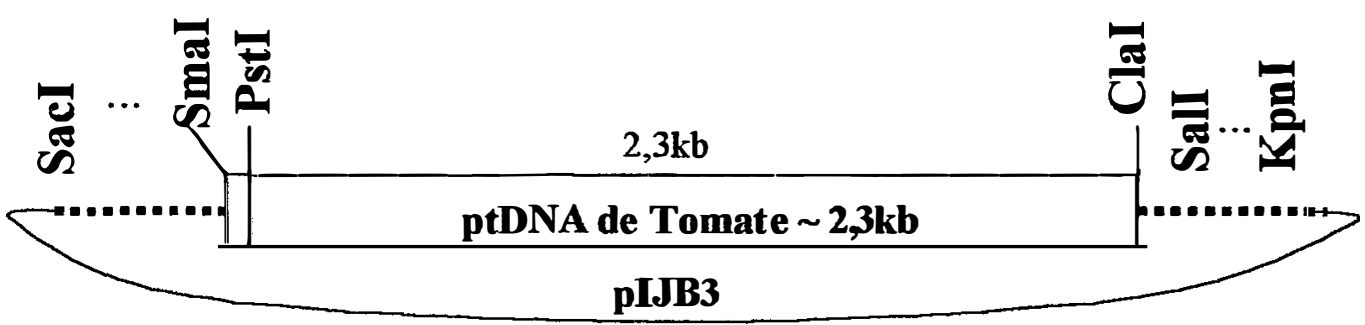

Figura 11. Subclone pIJB3 de pIJB1. Subfragmento SmaI/ClaI clonado em pBS SK (-). 


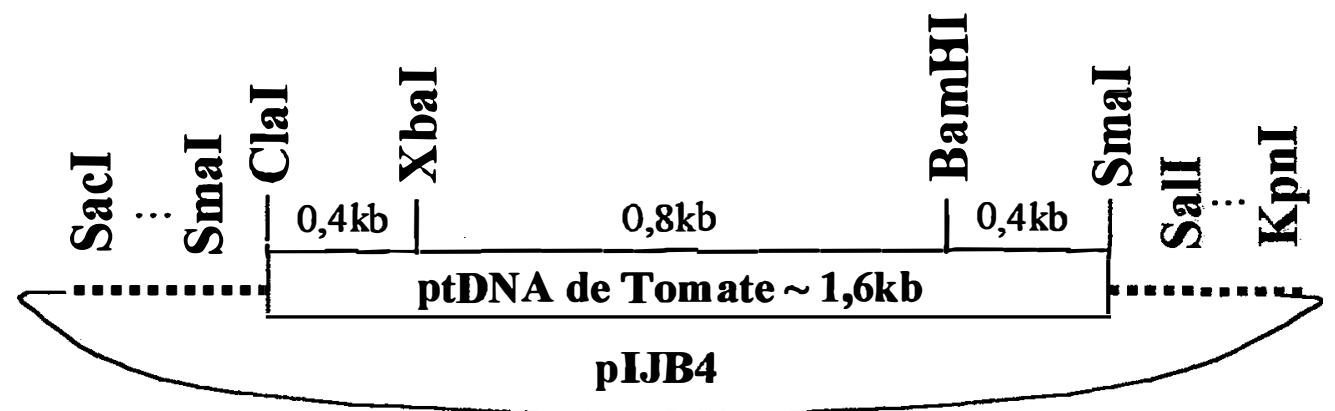

Figura 12. Subclone pIJB4 de pIJB1. Subfragmento ClaI/SmaI clonado em pBS SK (-).

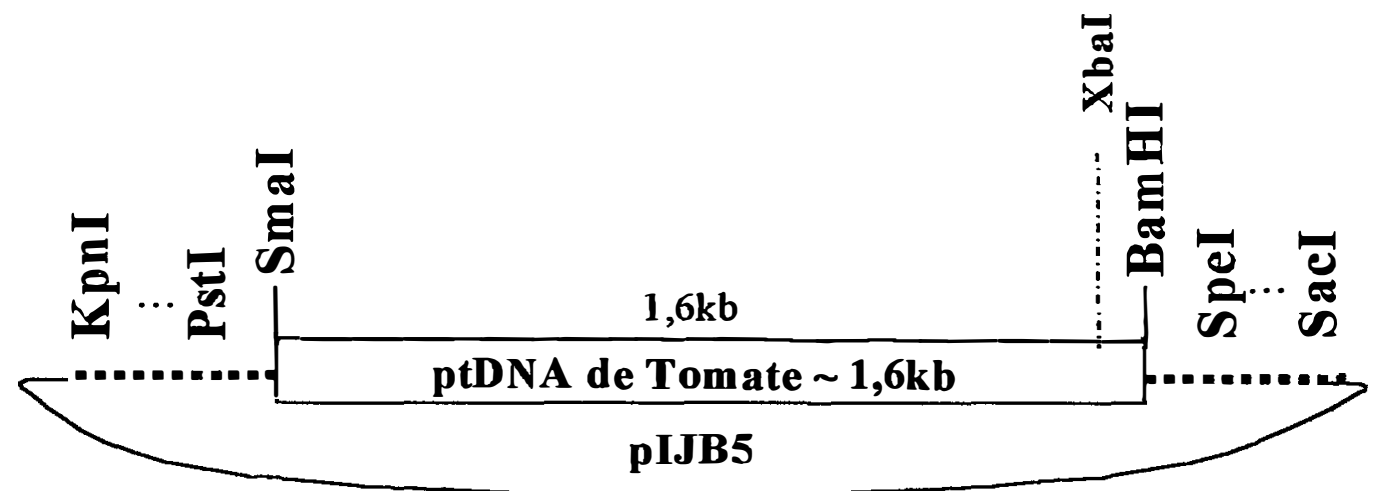

Figura 13. Subclone pIJB5 de pIJB1. Subfragmento SmaI/BamHI clonado em pBS KS (-).

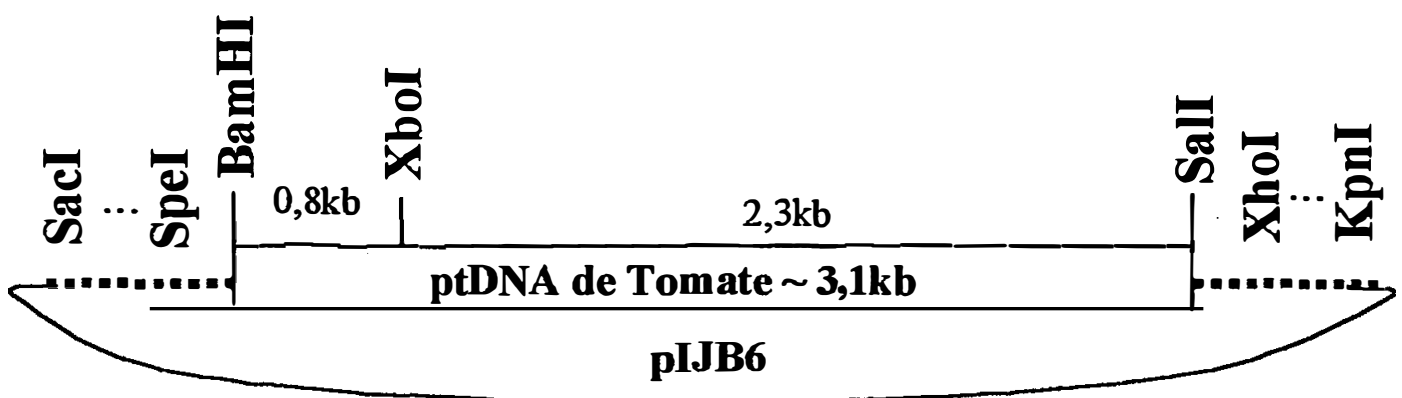

Figura 14. Subclone pIJB6 de pIJB1. Subfragmento BamHI/Sall clonado em pBS SK (-). 


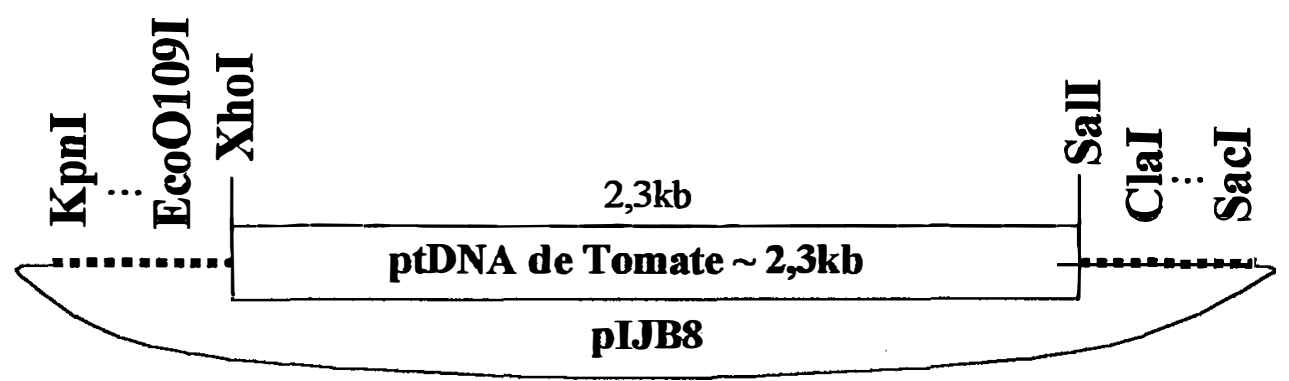

Figura 15. Subclone pIJB8 de pIJB1. Subfragmento XhoI/Sal clonado em pBS KS (-).

Seqüenciamento completo dos subfragmentos e montagem do fragmento íntegro de 8.660 pb gerou a seqüência apresentada no Quadro 1, orientada no sentido Pst $\rightarrow$ Sall. Para seqüenciamento completo dos sub-fragmentos, garantindo alta qualidade, foram necessárias 31 reações de seqüenciamento com cerca de 400 a 600 bases cada.

Quadro 1. Seqüência completa do fragmento de DNA cloroplastidial de tomate de $8.660 \mathrm{pb}$ clonado no plasmídio pIJB1. Seqüências codificadoras respectivamente dos genes $p s b \mathrm{C}$ (incompleta), $p s b \mathrm{D}, \operatorname{tr} i \mathrm{~T}, \operatorname{tr} \mathrm{E}, \operatorname{tr} \mathrm{Y}, \operatorname{trn\mathrm {D}}, p s b \mathrm{M}, p e t \mathrm{~N}(y c f), t r n \mathrm{C}$ e $r p o \mathrm{~B}$ (incompleta) estão representadas em negrito. Os genes $p s b \mathrm{C}$ e $p s b \mathrm{D}$ possuem uma seqüência comum que está destacada por letras sublinhadas $(17 \mathrm{pb})$.

\begin{tabular}{|c|c|c|}
\hline \multicolumn{3}{|c|}{ Seqüência Completa: Fragmento de 8.660 pb } \\
\hline & PstI & \\
\hline 0001 & CTGCAGAAGAAATTAAATGAAGTACTCCAGATACAAAGTATGGAAAGGTA & 0050 \\
\hline 0051 & TCTATAACTTCTCCCCCAGGGCCTACCCCCCAACCTAGAGTAGCTAGGTG & 0100 \\
\hline 0101 & GGGAAGTAAAATCAATCCTTGTTCATACATAGGCTTCTCGGGTACGAAAT & 0150 \\
\hline 0151 & GGGCCACTTCAAATAGGTTCATTGCTCCGGCCCAGAATACGATTAATCCA & 0200 \\
\hline 0201 & GCATGGGCTACATGAGCCCCTAGTAGTTTACCGGATAGATTGATAAGTCG & 0250 \\
\hline 0251 & GGCATTCCCGGCCCACCAAGCGAAACCTGTGGTTTCTTGGTCACGACCAG & 0300 \\
\hline 0301 & СTAAGGCTAAAGTTCCATTAAAGAGCGTTTCCACGTGGTAGAACCTCCTC & 0350 \\
\hline 0351 & AGGGAATATAAGGTTTTCATGAGGCTGATCTTGAGCCGCCATCCAAGCGC & 0400 \\
\hline 0401 & GAATACCTTCGTTTAAGAGAATATTTTTGGTGTAGAAAGTCTCAAATTCA & 0450 \\
\hline 0451 & GGATCTTCCGCTGCGCGAATTTCCTGAGAAACGAAGTCATAGGCACGTAG & 0500 \\
\hline 0501 & GTTCAGAGCTAGACCGACTACTCCAAGAGCACTCATCCATAAACCGGTCA & 0550 \\
\hline 0551 & СTGGTACAAATAACATAAAGAAATGTAACCAACGTTTATTGGAAAAAGCA & 0600 \\
\hline 0601 & ACCCCAAAGATTTGGGACCAAAAGCGGTTAGCGGTGACCATTGAATAAGT & 0650 \\
\hline 0651 & TTCTTCGGCTTGAGTTGGGTTAAAAGCACGGAATGTATTTGCACCATCAC & 0700 \\
\hline 0701 & СGTCTTCAAATAAAGTATTTTCTACGGTAGCACCATGAATGGCGCATAGC & 0750 \\
\hline 0751 & AAAGCAGCCCCCAATACACCGGCAACTCCCATCATATGAAAGGGGTTCAA & 0800 \\
\hline 0801 & GGTCCAATTATGAAACCCTTGAAAAAATAGGATGAATCGAAATATAGCTG & 0850 \\
\hline 0851 & СТACACCAAAACTAGGTGCAAAGA & 0900 \\
\hline
\end{tabular}


0901 ATCAGAAATACAGAAACAAAAACAGCAATTGGACCAGAGAATGCGATTGC 0951 ATTATAAGGTCTCAATTGAACAGATCGAGCAAGCTCGAATTGACGTAACA 1001 TGAAACCTATTAGGCCAAAAGCTCCATGGAGAGCAACAAAAGTCCACAGA 1051 CCCCCCAATTGACACCAACGAGTAAAATCTCCTTGTGCTTCAGGACCCCA 1101 TAGTAACAACAACGAATGTGCTAAACTATTAGCAGGAGTAGAAACCGCGG 1151 CAGTTAAGAAATTGCAGCCTTCCAAATAAGAACTGGCCAATCCATGGGTA 1201 TACCATGAAGTTACAAAGGTTGTACCTGTGAACCAACCCCCTACAGCGAA 1251 ATAGGCACAAGGAAAGAGCAATAGACCGGACCAGCCTACAAAAACGAAAC 1301 GGTCCCTCCGTAACCAGTCATCCATAATATCAAATAAATCATTTTCGTCT 1351 TTGGTAAACTTACCAATGGCTATAGTCATAGTGATCCTCCTATTCAACTA 1401 CTTCGACCATTTCCGAGCACCTCATATCTTTTTCGGGGCGTCCCAAGATC 1451 CGATCATTTTTGTCTGATTTCTCTTGCACTGCCCTTCCCAATGGGTTTCG 1501 AAGATAAAAATCCTTTATTGATTAGCCCATAAACTGACCTAGGTAAATCC 1551 ATGAACTCCATTGGATTATTCCTTCTGACTAAGCATATGAACCATGAATT 1601 GTCTTAATAAGATAATTCAATCAATCCCTTGTTTTGAAAGAACTCTTCAA 1651 GGACCAAACGGTCCCTTTCCTTCATACTTCATATAAATAAATCGAAAACC 1701 CCAGAGTATATCTTTCCCCGGATCGAAGGAAAAAAGACAGTTCGATCGAA 1751 TATTGATTTTTAGATTCTTTTATCTGTTAGAAAAAGAGATAATCTACTAT 1801 TTTTCCTTTTAGAAAATCTAAAATTCAATAAATAAATAGGAGACTGGAAA 1851 TGAAAGTCTCTTTCTCGGGATCTATTCTTCATCACACTGGTGGAACAAAA 1901 CAAAAATACCGGATGCAACGATATTGAAATATTTGGTACATGAAGCCATG 1951 ATCTGATAGATATACATCGAAATCAATCTACAATCTACTTAАTATAATTA 2001 ATATATAATATAGATGAAATTAATCTTTGATCTAGAATCAAAGAAAAATA 2051 ATAAATGGCTCTTATGGTGTGCCTTGGAAGAAAGGTTTCTCTGTAGAGGA 2101 AAGGAATAACAAATTATTCCGATAATTTTTCCTATAGAAAATCTAGTAAC 2151 AAGAAGATTTAATCGGAAATATCGACAAATTCTTGTGGAGTCCAAAACAA 2201 AAAAATGAAATAAAAAAAATCAACTGCTCCAATTTCATCTCTATCGAATT 2251 TTAATATCAGAATAGCGGATATAGTCATGATTCAATAGGTCAGGTCCACT 2301 TACTTTTTACTTTTTCTTTTGTTGATTTCTAACCTTTCGAATCGATTTGG 2351 TTGGTATAATGGAAAATAGGAATATTCGGTGATTCAAGAAGTGACTTTTC 2401 ATTATTCCTAAATTCATACTAATGAAAATTGACTAAACAAATGTTCAACT 2451 TTATAACTAAGTATAATGATAATGTATTATCCAGTTAGTTACTTTTTTTA 2501 TTACAAATAAAAAGAAAATTCTCCCATCAAATATGAATACTAGATTGGGG 2551 TTTTACAAAGCCCCTTATCGGATTTGAACCGATGACTTACGCCTTACCAT 2601 GGCGTTACTCTACCACTGAGTTAAAAGGGCCTTTTTTATTTAATTCCGGA 2651 ATTATTCACTATGTGGATTAAATATCTATATGTACTTATATTATAAACAT 2701 AAGTATATATGCATTAAGTACGTGCAGTAGATACATAGTGTCTAGTGGCT 2751 CATTGTTGAATAATAAAATGGATTTACCTAGGAAGTATAGGAGAAAATGC 2801 AATGAATTGTTTCAAGACCGACTCGAATAGAAATAAATTCAATTGAAATA 2851 ATTAAAAAAAATACTACTACTAGATTTCTAATGTCGATTCTAATGAATAA 2901 TTCGTCAATGACGAATAAAAAACAATTCTATGCAATTCTGAAGGGGGGAA 2951 AGATCCCTCGGCTAGAATCATTTGATTATATTGACAATTTTAAAAAACGG 3001 ATCATACTATCATCATAGTATGATGGCCGTTGGTCAAGCGGGCCCCCATC GTCTAGTGGTTTAGGACATCTCTCTTTCAAGGAGGCAGCGGGGATTCGAA TTCCCCTGGGGGTAGGGTACTACGAAAGGAAATTGATCATGGATTACCAA 3201 ACGGACTGTAAATTCGTTGGCAATATGTCTACGCTGGTTCAAATCCAGCT 3251 CGGCCCAATAATTCGCCAATCCGCCATGAGATGATATAACTCCCTTTGTA 3301 CTTCAGAAATACCCGATCCGGAGATAAAAAAGAATCAAATTTTCTGCTAG

0950 1000 1050 1100 1150 1200 1250 1300 1350 1400 1450 1500 1550 1600 1650 1700 1750 1800 1850 1900 1950 2000 2050 2100 2150 2200 2250 2300 2350 2400 2450 2500 2550 2600 2650 2700 2750 2800 2850 2900 2950 3000 3050 3100 3150 3200 3250 3300 3350 
3351 ATCCCGTATTTCCCTGGGATTGTAGTTCAATTGTCAGAGCACCGCCCTG 3401 TCAAGGCGGAAGCTGCGGGTTCGAGCCCCGTCAGTCCCGACGGATCCAAT

3451 АААTATATCAАAAAATCTCTCCСTTTTTCTGAAGGGGACCGGGGGAAGAA 3501 TTCCATTGTCAAAGCAAAGGGGAAATCCTTATTTCTTTTTTCTTTCCTTT 3551 TGGTAGGAGAAAGACATATGCGGTTGGATTAGTACAATTATTGGTAGCAT 3601 TATAGTCAGTATTCCAAGAAATGCTGGCTTTTTCGATTGCCCCCGATGCA 3651 TGTAATGGAATCGAGTACTATACTTTTTTGAGGCGCGCATACACAAAAGG 3701 ААTTCCTTTGTTGTCCAATACAAAATTGAATATAAGAAAATACTTTCCAG 3751 AAAAAACAAAAAAAAAAAДAAAACAATTTCTTTTTCTGGCTACGGATTTA 3801 TGGAACCTGACTTACTAGTTTGAAGTTGCAAAATAGATTTCATGCAAATT 3851 GCACACTGAGCTTTTGGTATAGGTGTCCCGGGGGCTAATAATCGACGAAG 3901 AAAGGAGGGGGAAGGACAGATCAACCAAAGATCCTACTCCTCTTAGAAAG 3951 GCGAATGAATCATTTTTCCTATTTTTCATTTTGTTTTAAGGCCCCATCGA 4001 CGACCGAACAAATCGGAAAATAGTCAATTTGATGAATATTCATTTTATAC 4051 GGTCTCATCTTTATCACACTTCTTTGTCTTCCAAGTCAAAAATAGTTTCG 4101 TTCTAAACTCCTTTCTTTTTCCATTTAGCTTTTATTGTTTGTTTGGGTTT 4151 GTAACTATGTGACCACTGGAAGTGGAAGAGCTATTTGATGAGACTTCATC 4201 AGATGATTGTACAAGAAGGAACTAGATAGATTAGAGAGAAAAAAAGAACA 4251 GATAATAAAAAATGATAAATAAATAAAGGAATTTTGGGTTAGGTCAGCAA 4301 TCCGAGTTTGGGGCGGTATGGATAAAAGAACTTCCTATGTTATACTATTC 4351 AATTCTCGACGACGAATTTATTTGATAGTTCAGATATTGTTATTCATGAT 4401 ATTGATCTGATTCAAGATCATCGAGAGGTAATATTCATTCATTGAATTTA 4451 CAGGCCAAAGATTTATCATCTCTATGGGATTAAATCCCGAGTTATTGCGA 4501 AGTAAAAAACCGATGAGATTATGGAAGTAAATATTCTTGCATTTATTGCT 4551 ACTGCACTATTTATTCTAGTTCCTACCGCTTTTCTACTTATCATTTATGT 4601 AAAAACAGTCAGTCAAAACGATTAATTATTAACTAATTTGAATGAAACTT 4651 GACTTCTGAGTTCTTAGCCAAAATTGACGAAATAAAATGAAAAAGATTCC 4701 АATTTCATGTCTTAAATGAAATGAGTGGACTAGAATCGGCAGTATTCTAA 4751 TAGATAGATAGTATGGTAGAAAGATTCATCTATTTCTTTCTACCATACTA 4801 TTTATTAGTTAGATTCTTGTTATAAAGCTGCCCCCTGGAATAAAATAAAG 4851 ATAGAGGCTGCATTTGATATGGATCTATATATCAATCTACAATATTATCT 4901 TGATATATGTGAATATCAATTCCATATATGGGATTGACATAGCATCCAAT 4951 TCCATTTATTTGCTATATCTATTTGTTCTGATCAATCTGAATTACTCCTA 5001 TGTCTTATAGTTTGAATTACTATATTTTTGATTTCCAATATGAATCTCAG 5051 TATCTATTGAGAGAATCAAATCAATGAAGCAAAAGCGATAGATATAGGCA 5101 TATTCAAAAAATCACGTAGTAATCTTTTTTTTTTTAACATTCCTAAGAAG 5151 TAAACCATTGACAGTAGTTCCACGGGCATCGAAAAGGAAGAGTAAACCTC 5201 ACTGATTTTTAAGGCCTGAACCATGATATGAAATAAGTCGATAAAGTCTA 5251 AATCCAATTTCCAAAATTCGAAAGGTAAATGCGCAATATGTGACTCACCT 5301 GACGATCTTATTCTAAATAGTATCTCGTTAGACAACCACTATGTTTATAT 5351 ССTTTCTTTCTCATACAAAGTGCTTATACACTTAACAAAACCACTTTTTC 5401 TTTGAACAGTAAAGAGAGAACCAAATAAAAAACGGGTCCGGCCCTCCTCA 5451 GTATCACCTAGGAAGAGGCCATTGATTGGAATAGAAAATTTAGTAAGAAT 5501 TAGGTTCGAATAAATTTCCTGGGATCCTTTTCCTTTCGAACTACAAACAT 5551 GGGAATCGTTGAAATAGTTCTTTGATTGAAAGAGGCTGATTCCTATAATA 5601 CATTACTCCAGTCGAGTCCAATGGAATTTCAAAATGAAGATATTTTTATT 5651 TTGTTCCAAACGTGTTGCAGAACCATCTAGAAAGCAATTGATAATGATAC 5701 AGTTTGCTTCCTTAACTCAATTAGCAGAACCCCTAGAGTCCACTCCTTCC 5751 CCACACTACGAGTGAAAGGGAAAAAGTAAAGACTACCATTAAAGCAGCCC

3400 3450 3500 3550 3600 3650 3700 3750 3800 3850 3900 3950 4000 4050 4100 4150 4200 4250 4300 4350 4400 4450 4500 4550 4600 4650 4700 4750 4800 4850 4900 4950 5000 5050 5100 5150 5200 5250 5300 5350 5400 5450 5500 5550 5600 5650 5700 5750 5800 
5801 AAGCAAGACTTACTATATCCATATGAATTATGTCCCCTATCTCTATAAAT 5851 ATAAAGGAATTGTTCCATTATTCCTCACTAATAATAGTAGAATCAATGGC 5901 GCAGAGTCAAAAAGAACGAAGACTATTAATAAACCAATCCAATAAATTCG 5951 CTCATTTTATAAGAAATTTCTATATGATTTATAATCGGGAAAGATTAAAC 6001 CCAAGCAAAATCCGCAGTAACATCTCAAGGGAATGTTACTAATGGAACAT 6051 GTAGGAATAATAGGTCCTATTCTTTTTTTGTTGACCCTCATTTGAATTGA 6101 TTGGATGCTTGAGCACTGAGATATTTTCGTGAGTTCCTCGTATATAATAA 6151 AGTATCTTCCGCCCCCTTCCACAACTATTTCGATTTCCTATCGGGCTCTC 6201 CAAGGTCCAGTCATTATACAATGGATTAATAATAGAAAATTTTGATTTGT 6251 AGTAGAAGGTAATTGCGAAGTCTTGATAGCCCCTCGAGCATTCGAATATT 6301 TACTTGAAAGCTAAGCCTAAATATGCAATGCAAGGATATTTACAATTTTT 6351 TCTAAAAACACCCAGACCAAAACAAGTATCAACAGTCTGCTTTCTCTGCT 6401 TCTGCTGGCGAATCATTCGGCGGGTTATATCAACAGAAGAAAAAAAGAGA 6451 TTTCCAGTTTTTTGTTGATCAGGCGACACCCGGATTTGAACTGGGGAAAA 6501 AAGGATTTGCAGTCCTCTGCCTTACCACTCGGCCATGTCGCCAAAATGCT 6551 ACAAATACAAAATAGATGAAAACTTTCCCGGATTACTGAACTGCTTTTTT 6601 ATTGTACTTGCACCTTGAGTTCTGTTTTCCTTAATTTTTCCTAAAAGTCA 6651 AАGAAATCCTAATCCTTCTTCССTTTTGATTGGGTTTGATTCATCСTTTC 6701 AАTTTCGATTGAGTCTATCTCCAAATTCATAATGTTCAAAACTTTCTCTT 6751 ACCTTTCTATTGAAAAATCAAATGTGGATTTTCATTCGCAAAATACAAAA 6801 TTCAACTTTCAGAAAATAGGACCCAGTAACTATTGCCTTAGAATGCATGA 6851 ATGATTCTTGGATTTGAATCTCCCAATTTTGGTTTCCTAATGACATAAGA 6901 AAATACAACTTGATATATGATATATAACCAATCAGTTCAGTATGGATTTT

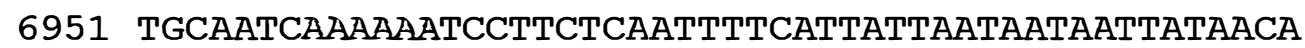
7001 ACAATTATCAGTATATGTAAACCCCCCAAAAGATAAATTGTTAGACGGAT 7051 ATATATTATTTATATATGTTCCCGATATAGAATTATCAGATATCAGAAAA 7101 GTATCATACTTCAATTTGAATTTTGAATTGAATAGAAAATTGAAATTATG 7151 TTTTCGGAGAGCACAACCTGTGTTGCCCCGAATAGAACATAAAACGACAA 7201 TAAAACAATAAAAGAGAAGAAAGACAGATATTATAGATATCTCCACACGT 7251 GTTTAAGCCATACAAACCTTCTTTTCTTATCCACTTCACAATCGTATTCT 7301 ACTCAAAАATCCGTAAACAAАATATCTCTCTTCTCTGCGAАTCATTTTTT 7351 GAACAATTGAAATCCATAACATAAGGGGGGTTAAATGCTAAAAAACCGAT 7401 TCTAATTCTATATATTCTTTCTGATTTTTTATGCCTTTATCTCAGCCGAA 7451 AAGATCAAATGTCCCAATCCAATTTATTTTTTCTGGGTATTCAAGCAGGT 7501 TGGAATATGTATTATCATAATAATGGTAGAAATGGAATCATTTTTCTTTT 7551 TATATTCTATACAAAATCCTATAACTTCATTAATAAGTCTAAGTAGCAGA 7601 AGTAGGTTTCTAGGGATGTTTTATCAATTTCTTTCCATTTGTATCTGTTG

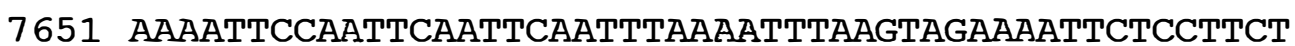
7701 TCCTCCGTTCATACGTATTTCATACATTCCAGATATGGAGTTGGGTAAAA 7751 TTTCATGTGATTCGGTAAACAAAATAGAAATGCCATCATTGCTAGATCAT 7801 TTATCTAATCTATCTAATTAGATACAGAATGAACCAATAGTGGGATTTTT 7851 TGCTAAATGGGAAATTTAAAATGCTCGGGGATGGAAATGAGGGAATATCT 7901 ACAATACCTGGATTTAATCAGATACAATTTGAAGGATTTTGTAGGTTCAT 7951 TGATCAAGGTTTGACGGAAGAACTTTATAAGTTTCCAAAAATTGAAGATA 8001 CAGATCAAGAAATTGAATTTCAATTATTTGTGGAAACATATCAATTGGTC 8051 GAACCCTTGATAAAGGAAAGAGATGCTGTGTATGAATCACTCACATATTC 8101 TTCTGAATTATATGTATCCGCGGGATTAATTTGGAAAAACAGTAGGGATA 8151 TGCAAGAACAAACAATTTTTATCGGAAACATTCCTCTAATGAATTCCCTG 8201 GGAACTTCTATAGTCAATGGAATATATAGAATTGTGATCAATCAAATATT

5850 5900 5950 6000 6050 6100 6150 6200 6250 6300 6350 6400 6450 6500 6550 6600 6650 6700 6750 6800 6850 6900 6950 7000 7050 7100 7150 7200 7250 7300 7350 7400 7450 7500 7550 7600 7650 7700 7750 7800 7850 7900 7950 8000 8050 8100 8150 8200 8250 
8251 GCAAAGTCCCGGTATTTATTACCGATCAGAATTGGACCATAACGGAATTT

8301 CGGTCTATACCGGCACCATAATATCAGATTGGGGAGGAAGATCAGAATTA

8300

8351 GAAATTGATAGAAAAGCAAGGATATGGGCTCGTGTAAGTAGGAAACAAAA

8350

8401 AATATCTATTCTAGTTCTATCATCAGCTATGGGTTTGAATCTAAGAGAAA

8400

8451 TTCTAGAGAATGTTTGCTATCCTGAAATTTTTTTGTCTTTTCTGAATGAT

8450

8501 AAGGAGAGAAAAAAAATTGGGTCAAAAGAAAATTCCATTTTGGAGTTTTA

8551 TCAACAATTTGCTTGTGTAGGTGGCGATCCGGTATTTTCTGAATCCTTAT

8601 GTAAGGAATTACAAAAGAAATTCTTTCAACAAAGATGTGAATTAGGAAGG

8651 ATTGGTCGAC

\subsubsection{Seqüenciamento do fragmento cloroplastidial clonado no plasmídio pIJB2 (6,4}

\section{kb) através de minibibliotecas shotgur.}

O plasmídio pIJB2 foi totalmente seqüenciado através da construção de minibibliotecas onde fragmentos aleatórios foram gerados por quebra física das fitas do DNA por nebulização. Cerca de 100 clones derivados da biblioteca de plasmídio foram seqüenciados via primers universais $\mathrm{R}$ e $\mathrm{F}$ (reverse' e 'foward'), no entanto apenas cerca de $15 \%$ continham fragmentos derivados de DNA cloroplastidial de tomate ( $p t D N A)$. Como metodologia altemativa, 96 clones gerados da biblioteca de fragmento isolado (amplificado via PCR/Elongase) foram seqüenciados utilizando o primer universal F. A montagem através do programa Sequencher 3.1 da seqüência completa do fragmento cloroplastidial de $6.366 \mathrm{pb}$ clonado em pIJB2 (mostrado na íntegra no Quadro 2). Para a obtenção da seqüência completa do fragmento foram utilizadas as seqüências geradas por ambas as bibliotecas (total de 124 seqüências). Tal metodologia gerou naturalmente (devido a aleatoriedade dos subfragmentos clonados) um maior número de repetições por base seqüenciada, garantindo alta qualidade e confrabilidade do seqüenciamento; cada base foi seqüenciada de 5 a 10 vezes através desta metodologia. No seqüenciamento do fragmento cloroplastidial do plasmídio pIJB1 cada seqüência foi repetida em média duas vezes, gerando da mesma forma uma seqüência de alta confiabilidade, no entanto com um número menor de reações de seqüenciamento (31). Por outro lado, houve dificuldade em se obter subclones com tamanhos adequados para o sequenciamento completo do subfragmento, uma vez que para a subclonagem existe dependência por sítios únicos de restrição para as respectivas subclonagens mediadas por enzimas de restrição. Para o seqüenciamento 
completo dos sub-fragmentos houve a necessidade do uso de primers sintéticos, com conseqüente aumento do custo e tempo para obtenção das seqüências.

Quadro 2. Seqüência completa do fragmento de DNA cloroplastidial de tomate de $6.366 \mathrm{pb}$ clonado no plasmídio pIJB2. Seqüências codificadoras respectivamente dos genes $p s b \mathrm{~N}, p s b \mathrm{~T}, p s b \mathrm{~B}, c \not p \mathrm{P}\left(\right.$ exons 1,2 e 3), 5' $p s 1^{12}$ e $r p l 20$ estão apresentadas em negrito.

\begin{tabular}{c} 
Seqüência Completa: Fragmento de $6.366 \mathrm{pb}$ \\
\hline PstI
\end{tabular}

0001 CTGCAGTTCGTCTTGGACCAGATCTAGAACTGTTCTCAACAGTTTGTGTA

0050

0051 GCCATAAATCCTATTGTATTCATTGAGATCTGTTGACTTTGTATACCATT

0100

0101 CCGTTGTAAATAAACGATCCTATCATAGATCCATTAGAGGATCCCСАATT

0150

0151 ATATAАATATGATAAGAATGGAAACAGCAACCCTAGTCGCCATCTTTATA

0200

0201 TCTGGTTTACTTGTAAGTTTTACTGGGTACGCCTTATATACCGCTTTTGG

0250

0251 GCAACCTTCTCAACAACTAAGAGATCCATTCGAGGAACATGGAGACTAGT

0300

0301 TGAAGTACTGAGCCTCCCGATATCGGGAGGCTCAGTACTTCAACTGAGAT

0350

0351 AATGAAAAAAAAATTATTTCACCСTTTTAGTTCTTTTTAGTTCGAATTGT

0400

0401 AGGCGGTTCTCGAAAAAAGATAGCGAAAAAAATTATCCCTAGAGTCGAGA

0450

0451 CTAAGAGGATGTATAAACCAATGCTTCCATAAATTCGATCGTGGTTTAC

0500

0501 AATTATAGCTTTCATACCTGTTTGTTTCTTTTTATTTCCTTTTTTTTATC

0550

0551 ATCTTCCAGATAAAGAACGAACAAGAGTAAAAACGAAGTTGATTCAAATA

0600

0601 AAGATTTCTCGGGTACCCTATGTCAATAAAAGTAAAAGAAAGAAAATAAG

0650

0651 GGCGAAAGAAAGATACCAAAGCAATGTTGTATTCAGGCTGCCTGTCTTTT 0700

0701 TGTAGTTGGATCTCCAAGTTTTTGGAATGCTCCAAATTCGACTTGAGCAT 0750

0751 CTAAATCTGGGTCAATACCAGCAAAAACATCTCTGAACAAGGTTCTAGCA 0800

0801 CCATGCCAAATGGTCCGAAGAAGAGAGCAAAGCAAACGAAGCATGCCC 0850

0851 AAAAGTAAACCAACCCCTTGGACTGCTACGAAAAACACCATCGGATTTCA 0900

0901 AAGTAGCACGATCTAATTCGAAAATTCACCCAATTGAGCTCGTCGAGCA 0950

0951 TATTTTTTCACAGTAGCAGGATCACTATAACTGACGCCGTTGAGTTCACC 1000

1001 GCCGTAGAACTCAACAGTTACACCTACTTGTTCAACACTATACTTCGATT 1050

1051 CTGCCCTTCTAAAAGGAACATCGGCTCTAACAATCCCATCGCCGTCTACC 1100

1101 AAAACGACCGGAAATGTTTCAAAAAAAGTAGGCATACGAGGTACAAAAAG 1150

1151 TTCACGCCCTTCCTTATCTCTAAAGATAGGGTGCCTAACCATCCAACCG 1200

1201 CTATTCCATCCCCGTTATCCATTGAACCTGCTCTGAATAATCCTCCTTTT 1250 
1251 GCCGGATTATTGCCGATGTAATCATAAAAAGCTAATTTTCAGGAATTTT 1300

1301 AGACCAGGCTTCTGATAAACTTTGATTTTCTGCTAGCCCAGCACTAACTC 1350

1351 TTCGATATATTTCTTGCTGGAAGTACCCCTGATCCCATTGATAACGAGTG 1400

1401 GGCCCAAATAATTCAATCGGGTAGTTGCCGAACCATACCACATAGTTCC 1450

1451 GGCAACAACAAAAGCTGCAAAAAAGACAGCAGCGATACTACTGGAAAGGA 1500

1501 CGGTTTCAATATTTCCCATACGCAATCCTTTGTATAGACGTTGTGGCGGA 1550

1551 CGGACGCTAAGATGGAATAGGCCCGCTATATGCCCAATGTTCCTGCTGC 1600

1601 AATATGATGAGAGGCTATTCCTCCTGGAACAAAAGGATCAAAACCTTCCA 1650

1651 CGCCCCACGCTGGATTTACAGGTTGTACTTTTCCCGTTAGTCCATAAGGA 1700

1701 TCGGACACCCATATTCCGGGACCATACAAGCCTGTTACATGAAATGCACC 1750

1751 AAAACCAAAACAAGCCACCCCTGAGAGAAATAAATGAATTCCAAAGATCT 1800

1801 TTGGCAAATCCAAAGAGGGTTTCCTGTACGTTCATCACAAAATATTTCT 1850

1851 AGATCCCAATACACCCAATGCCAGATAGCTGCCAAAAAGCATAAGCCAGA 1900

1901 AAACACAATATGTGCTCCCGCTACACCTTCGTAACTCCAAATACCTGGAT 1950

1951 TCGTTACAGTCCCCCCTGTGATACTCCAACCGCCCCATGAATTGGTTATT 2000

2001 CCTAAACGAGTCATGAAGGGTATAACGAACATACCCTGTCTCCACATTGG 2050

2051 ATCAAGAACAGGATCAGAAGGATCAAAAACCGCTAATTCATACAGAGCCA 2100

2101 TCGAACCGGCCCAACCAGCAACCAGAGCTGTATGCATTATATGAACAGAA 2150

2151 AGCAACCGACCGGGATCATTCAATACAACGGTATGAACACGATACCAAGG 2200

2201 CAAACCCATGGAAATACCCCTTATATCAAAGATAAATGAACACTACGTAA 2250

2251 СTTTATTGCATTGGAAAAGACTATAATATGACTATCCTATGGACCACTCT 2300

2301 TGTTGAGTCAATTATTTCCGAACAAGGGTTTCTATTCTGTTGGTAATAAT 2350

2351 GGAACAATTCTGTTCGTAGGAACAAAGAGAAGCAGATTTATTCTATACTC 2400

2401 GATAAGTACCAATACGCAATGGGGGAGTTGATCCCATTTTCTATGAGCGA 2450

2451 ATGAGTCCATACTTATTTATCATTAGAAAGACCTATTCGTAATAATTTGA 2500

2501 GTTTATTCATTCTGTCTTTCTTTATGAATTTTGAGAATCTATGGATAAAA 2550

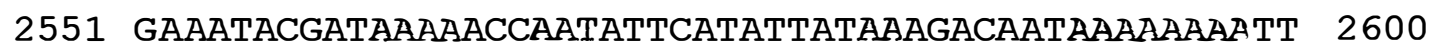

2601 GTTACGTTTCCACCTCAAAGTGAAATATAGTATTTAATTCGTTCTTTCAT 2650

2651 TTAATGCCTATTGGTGTCCAAGAGTTGTATTCCGAAATCCTGGAGATCC 2700

2701 AATTTCATCTTGGGTTGACATATAGTGCGACTTGTCAGATATATTGGGTC 2750

2751 ATATGGTATTTCCCCGTTCTCTCCCCCGATCGAGATATCCCCCGTTTCGC 2800

2801 CCAAGAAAGATAAATTGAATCATCAAAAATTTGGAGCGTGAAGTGCAATT 2850

2851 AGATCCATTTTTGAGGGGATTCATATTACTATTATCAATTAGAАTAАTTT 2900 
2901 ATGGTTGGCTTGGTTGGACTAAATAAATGAAGTATCCAGGCTCCGTTTAG 2951 AAAAAACCCAATTGGATTGGTAAGATATCTATGTAAGATATCTATGATTG 3001 CTATTCATATTTTTTCTTTGTAAAGAGATCCTAATTGTCAAGCAAAGTTA

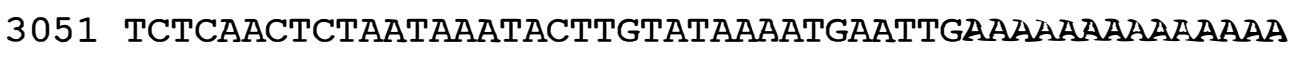
3101 АААTACAAAAAGAAATGGTAATGGGAGCATTTGTCCTATATGTACAAATC 3151 CAAATCGGGCGGATCTTTACCCGGAGTAGAGCATAAACCTAAAAAGATGA 3201 AACAGACCCATTCAGGAACAAGAAAATACCATCGCGGTTTGGATTAAATC 3251 TCGATGAAAGAATACATCAATGAGAAGTTAATTCGATAAGTTTAATGACC 3301 СTTTCTTATAACTTCGAATTTTATAATAGAAAATATCAAAAAGGAGTAAA 3351 AACTCGTCTTTATTGAAAAATCGAAGAAAAGCCCTTTCGTTAGAAGTAAG 3401 AAAGAACCCTTGTAGAAAAAAAGAAAGAGGACTGGAATCTCTACATTGAT 3451 TCACAATTTTTTTGAACCGTATGCATCAAAAGGCGCATGTACGGTTCCTA 3501 AGGGATACAATTTTACCCTAATCAACCGACTTTATCGAGAAAGATTACTT 3551 TTTTTAGGCCAAGGGATTGGTACCGAGCTTTCGAATCAACTTATTGGTCT 3601 TATGTTGTATCTCAGTATGGAGGATGAGAACAAAACCTGTATTTGTTTG 3651 TAAACTCTCCTGGGGGCTGGGTAATACCTGGGATCGCCATTTATGATACT 3701 ATGCAATTGTGCGACCAGATATCCATACAATATGCCTAGGATTAGCTGC 2950 3000 3050 3100 3150 3200 3250 3300 3350 3400 3450 3500 3550 3600 3650 3700 3751 TTCAATGGGATCTTTTATCCTGGCCGGAGGACAACTTACCAAACGTATAG 3750 3801 CATTCCCTCACGCTTGGCGCCAATGAGGTTTTTATTTGAGAAAAAAAAGA 3800 3851 AGACTATGCCTTCGCCATATGAATACTAAGTAATAATAGCATGGCACTTC 3850 3901 GAATTCGATATGAGAAATTTTTGTATTGTTTTTTTTTTTCAAАACATTAG 3900 3951 ATTCTGTATCGAGAGAGTAGTATGAGATAAGGGGTATTTCCGATTTTCTA 3950 4001 TTATATATCGgGAGTTCAGTTCAGCGTCACAAACTTTTTGTTTTCATGCC 4000 4051 GGAGAGTTCTTAACAATATTTATGTTATGAAAGAGTACGAAAAAAAAATA 4050 4101 АTTTTTCCTTATTTGATCGGATTAAAAAGAAACTTTGGGATTGCTGAATC 4100 4151 ACAGACAAAAAAAAGAAAAAATAAACATATAAAGCAACGGAGCCATCATA 4150 4201 GTATTTTTGAATTCCTCCGAAAGGAAGGATGGCAАTTTGATTATTTACCC 4200 4251 ATCTGAGTCTGATAGATTCTATTTTTCTCTTTCTTCAATGGGGGTCAАTT 4250 4300 4301 TTCTTGTAGAGCCGTATGCACAAAAGATGCCTGTACGGTTGTTCAATTCT 4350 4351 АTСTTTTTTСTATTСTTTATСTTTСTTTTTTCTTTGCTTTATCATGCGAG 4400 4401 ATAGGGGAAGCTTTTATTTTGTTATATCATCAGGGTATGATACATGAAC 4450 4451 CTTATAGTGGTTTTTATATGGCACAAGTAGGCAATTTTCCTGGAAGCG 4500 4501 ATAGAAATGGCGAACTGCGTGAAACCTCACAAGGTTTATGCAGAAAA 4550 
4551 AACGGGCCAACCGTGTGGGTTATACACGAAGATATGGAAAGAGATATTT 4600 4601 TTATGTCAGCAACAGAAGCCAAGCTTATGGAATTTTGATTTTGTAGCG 4650 4651 GTTCAAGGAAAAGAACATGGATTTCACGCAGATCTATGATTTGAGATTTT 4700 4701 АтСTTCGAATTGAATATTCTATTAAATAGAAGTAATTCACCATCATTCGG 4750 4751 TTAGGATCAATCTAAACCAACCCATCATATTATGTATACGATTCAACATG 4800 4801 CCAACTATTAAACAACTTATTAGAAATACAAGACAGCCAATCAGAAATGT 4850 4851 CACGAAATCCCCCGTCTTCGGGGTGCCCTCAGCGTCGAGGAACATGTA 4900 4901 CTAGGGTGTATGTGCGACTCGTTTAGATCATGAGCTGGCACAAAAAGCAA 4950 4951 GAAAACTACTTTTACAGTATCAATGATCAGTACCGGTGAATGGGATAGGA 5000 5001 TGGAAAAAGGAACTCCATCCATTATAAAAAAAAAACTCTACCATATCCCC 5050 5051 CTCTATTGTGTATGAAGTTTATGGTTTCCGTTGGTGTAAATCCAATCACC 5100 5101 TGAATTTAAGATGATAAGAAATTCTCCATTGGTAACAAATGGTTATCCAT 5150

5151 TAAGCGGAGGAAATCTTATTTAAAAAGCATAAAACATAAAGATTAGGTAG 5200

5201 GCTCCCAАTCTGGCAAGAACGGACTAAGAGGGTCAGCTACCCAGCAAACT 5250

5251 TTCATAATTAAATACCGTTACTGTATAGGTAGATCTGATTGTGAAAGACC 5300

5301 TATTACTGGACAATTCATGGGTAGAGCCAAAGCGTGTGAACTATACAAGT 5350

5351 TCCСААТАСАTСAАTTAGTTGATTAAATATTAAAАATTAAAGTATAAAG 5400

5401 TAAAGGCTCCGGTGTATAGAGAAGACCTCACCGTTTAAGAAGTAACCATA 5450

5451 GAAACGAAGGAACCСАСТАTTTCTTTTTTTATTTCTTTTATTTAСTATAT 5500

5501 TTTTGATACCTAGGAAAATACAATTTCTTAGTTCTGTCTTATTTCGCAGT 5550

5551 GAAATACCTAAAAAAAAATCGTGGTCGGGAAGGTTAGAGTAGCCAAAGCC 5600

5601 ATTGGAATTTTGATTTTATACATTGGAAAAATCCGTTTTGTTATTAATAG 5650

5651 ACTAGGAAGGGGGAAAAGAATAACTGAAAGAAAGGCAATCAATTAGTTAT 5700

5701 TCGTCAAAGTTTCATTTATTCAATGACCAGAATTAAACGGGGATATATAG 5750

5751 CTCGGAGACGTAGAACAAAAATTCGTTTATTTGCATCAAGCTTTCGAGGG 5800

5801 GCTCATTCAAGGCTTACTAGAACTATTACTCAACAGAAAATAAGAGCTTT 5850

5851 AGTTTCGGCTCATCGGGATAGGGATAGGAAAAAAGAGATTTTCGTCGTT 5900

5901 TGTGGATCACTAGGATAAACGCAGTAATTCGCAAAGGGAGTATCCTAT 5950

5951 AGTTATAGTAGATTAATACACGATCTGTACAAGAGACAGTTGCTTCTTAA 6000

6001 CCGTAAAATACTTGCACAAATAGCTATATCAAATAGGAATTGCTTTATA 6050

6051 TGATTTCGAACGAAATCATAAAGGAAGTAGATTGGAAAGAATCCACCAGA 6100

6101 ATAATTTAAATGGAGTTACCCGGAGAATGAACTCCGGGAAGGTAGAGTAG 6150

6151 AAATTAGTATGAGAAAATATACTAAAGTAGTCAAAATGAATGAACACGTT 6200 
6201 CAATTCAATAAAAACAGATTTCTTTTTTTCCGATTCATTTTTTTCTTAGG 6250

6251 ACACGATACTCAAATCTAGATTCACTCAAATCTAGATTCTTGTAATTATG 6300

6301 ATTCAAGTGAAGAAAAAGTAAGCCTATTTATTTCGGGCTTTAAAACCAGT 6350

6351 AGTTCTAGCGGTCGAC $\quad 6365$

SalI

\subsection{Análise de homologia nas regiões codificadoras e nos espaços intergênicos}

As análises comparativas de homologia de regiões codificadoras e espaços intergênicos (espaçadores) entre as seqüências cloroplastidiais de tomate $\mathrm{e}$ tabaco encontram-se listadas nas Tabelas 4 e 5. Para o fragmento cloroplastidial contido no plasmídio pIJB1 (8.660 pb) as seqüências apresentam de 93 a 100\% de identidade. As regiões codificadoras dos genes $\operatorname{trn} \mathrm{C}, p e t \mathrm{~N}(y c f 6), p s b \mathrm{M}, \operatorname{trn} \mathrm{D}, \operatorname{tr} \mathrm{Y}, \operatorname{trn} \mathrm{E}, \operatorname{trn} \mathrm{T}$ e $p s b \mathrm{D}$ presentes no fragmento são altamente conservadas, apresentando $100 \%$ de identidade às de tabaco, exceção ao $p s b \mathrm{M}$ e ao $p s b \mathrm{D}$ que apresentam 99,0\% e 99,2\% de identidade respectivamente. A região codificadora do gene $p s b \mathrm{M}$ possui uma substituição do nucleotídeo $\mathrm{C}$ (em tabaco) por $\mathrm{T}$ (em tomate) na posição +78 , sem no entanto alterar o códon para o aminoácido isoleucina (TAC $\rightarrow$ TA7). É interessante salientar que o códon encontrado em tomate é aquele também encontrado nos genes correspondentes em Zea mays (GenBank/EMBL/DDBJ acession number - \# X86563), Oryza sativa (\# X15901) e Marchantia polymorpha (\# X04465), como apresentado no Quadro 3, podendo sugerir que uma mutação teria ocorrido em tabaco. Por sua vez, embora apresente homologia de 99,2\% em nucleotídeos, a região codificadora do gene $p s b \mathrm{D}$ não apresenta qualquer modificação com relação à seqüência de aminoácidos codificados, mostrando-se idêntica à proteína encontrada em tabaco. Para o fragmento cloroplastidial contido no plasmídio pIJB2 (6.366 pb), as seqüências apresentam 97 a 100\% de identidade. No entanto, observou-se que o gene $c \not p \mathrm{P}$, que apresenta um grande acúmulo de mutações, especialmente em dois de seus três exons, apresentou menor homologia com relação à seqüência correspondente em 
tabaco, apresentando apenas 78,9 e $81,7 \%$ de identidade para os exons 1 e 3 respectivamente (Tabela 4).

Em função da alta homologia encontrada para as regiões codificadoras entre diferentes genomas cloroplastidiais (Shimada \& Sugiura, 1991; Maier et al., 1995), o Quadro 3 apresenta o alinhamento e a homologia das regiões codificadoras de Lycopersicon esculentum (LE) $t m \mathrm{C}, p e t \mathrm{~N}(y c \sigma), p s b \mathrm{M}, t r n \mathrm{D}, t r n \mathrm{Y}, t r n \mathrm{E}, t r i ́ \mathrm{~T}$ e $p s b \mathrm{D}$ (derivadas do plasmídio pIJB1), $\not p l 20,5$ ' $p s 12, c \not p \mathrm{P}, p s b \mathrm{~B}, p s b \mathrm{~T}$ e $p s b \mathrm{~N}$ (derivadas do plasmídio $\mathrm{pIJB} 2)$ analisadas em relação aos plastomas de Zea mays (ZM), Oryza sativa (OS), Nicotiana tabacum (NT - GenBank \# Z00044), Pinus thunbengii (PT - GenBank \# D17510), Marchantia polymorpha (MP), Bock $(2000)^{2}$. O Quadro 3 mostra claramente que o gene chp P trata-se de um gene menos conservado nas espécies vegetais consideradas; é observado que os resultados obtidos em tomate corrobora os resultados encontrados em outras espécies (alinhamentos cedidos por Bock, 2000¹). O Quadro 3 apresenta também os respectivos alinhamentos de aminoácidos codificados pelos genes sequenciados, reforçando mais uma vez a alta homologia entre regiões codificadoras cloroplastidiais e seus respectivos produtos finais (proteínas ou tRNAs) nos diversos plastomas. Nesse aspecto, vale ressaltar os resultados encontrados para a região codificadora do gene $p s b \mathrm{~B}$ de tomate, embora esta apresente 11 substituições de bases quando comparada à seqüência codificadora de tabaco (Shimada \& Sugiura, 1991; Bock, 2000), a seqüência de tomate gera uma proteína idêntica à de tabaco, uma vez que todas as substituições ocorrem na terceira base dos respectivos códons não ocorrendo alteração do mesmos (Quadro 3). A análise completa de homologia entre as diversas regiões codificadoras, aminoácidos codificados e espécies consideradas podem ser visualizados diretamente no Quadro 3, onde encontram-se destacadas as respectivas substituições de nucleotídeos e conseqüentes reflexos na seqüência de aminoácidos.

Análise da ocorrência de sítios de editamento de RNA nas seqüências cloroplastidiais clonadas em pIJB1 e pIJB2 com base em Hirose et al. (1999), levou à observação da manutenção do padrão encontrado em tabaco na seqüência de tomate. No gene $r p l 20$ mostra-se presente um sítio de editamento no códon correspondente ao aminoácido 103, gerando o códon para Leucina (uUa) por editamento a partir do códon

${ }^{2}$ BOCK, R. (Freiburg Universität, Alemanha) Comunicação Pessoal, 2000. 
para Serina $(\mathrm{uCa})$ presente na seqüência do gene. No gene $\not p o \mathrm{~B}$ foi confirmada a presença de sítios de editamento nos códons 113 (Serina $(\mathrm{uCu}) \rightarrow$ Fenilalanina $(\mathrm{uUu})$ ), 158 (Serina $(\mathrm{uCa}) \rightarrow$ Leucina (uUa)) e 184 (Serina (uCa) $\rightarrow$ Leucina (uUa)); da mesma forma, os sítios de editamento presentes nos códons 189 e 208 do gene $r p o \mathrm{~B}$ de milho estão ausentes em tabaco e também não ocorrem na seqüência de tomate. Os sítios de editamento encontramse destacados no Quadro 3 com a respectiva identificação.

Em contrapartida ao que ocorre predominantemente na análise de regiões codificadoras, os dados mostram menor homologia nas regiões intergênicas (espaçadores), incluindo substituições, inserções, duplicações, e algumas deleções em tomate, indicando que divergências ocorrem principalmente em regiões provavelmente não funcionais ou não diretamente envolvidadas na codificação de proteínas. Todas as divergências encontram-se destacadas nos anexos A e B, contendo as seqüências completas dos fragmentos de tomate alinhados com as respectivas seqüências de tabaco (Shimada \& Sugiura, 1991; GeneBank/EMBL/DDBJ acession number Z00044). A diferença mais marcante está em um fragmento de $437 \mathrm{pb}$ presente na região intergênica de tabaco entre as regiões codificadoras dos genes trnE e $t r n \mathrm{~T}$, mas ausente no DNA cloroplastidial de tomate. O alinhamento da região encontra-se no Quadro 4. Embora não hajam dados concretos, análise destas seqüências leva a acreditar que em algum momento da evolução do ptDNA de tomate, algum pareamento de seqüências parcialmente complementares tenha levado à formação de uma pequena alça ("loop") e sua conseqüente eliminação durante a replicação. Outras divergências podem ser destacadas, as seqüências CTTTTTA ( $p s b \mathrm{D}-t r n$ T), TCAGT, GATATAT (trm- $r p o \mathrm{~B})$, TCTAGAT'T'TGAGTGA ( $p p 20-r p s 18)$, ATAGATATCTTAC $(c l p \mathrm{P}(1)-c l p \mathrm{P}(2))$ e TTTT ( $p s b \mathrm{~T}-p s b \mathrm{~N})$ encontram-se duplicadas em tomate, o que não ocorre em tabaco. Em oposição, as seqüências AGAA (psbM-petN), CCTCC, TT'TT'T e T'TTT'T'T $(c \not p \mathrm{P}(2)-c \not p \mathrm{P}(3))$ e TTCTAATTGA (clpP(1)-chpP(2)) estão duplicadas em tabaco e apresentam-se em cópia única em tomate. 
Tabela 4. Regiões codificadoras: comparação do tamanho e análise de homologia entre as seqüências de nucleotideos dos fragmentos cloroplastidiais de tomate $(8.660 \mathrm{pb}$ e $6.366 \mathrm{pb}$ ) e as regiões correspondentes do plastoma de tabaco. O plasmídio pIJB1 corresponde ao fragmento de 8.660 pb e o plamídio pIJB2 corresponde ao fragmento de $6.366 \mathrm{pb}$.

\begin{tabular}{|c|c|c|c|}
\hline \multirow{2}{*}{$\begin{array}{c}\text { Região } \\
\text { Codificadora }\end{array}$} & \multicolumn{2}{|c|}{ Tamanho (pb) } & \multirow{2}{*}{$\begin{array}{c}\text { Identidade } \\
(\%)\end{array}$} \\
\hline & Tomate & Tabaco & \\
\hline \multicolumn{4}{|l|}{ RNAs de transferência } \\
\hline trnE-UUC (pIJB1) & 73 & 73 & 100 \\
\hline trnY-GUA (pIJB1) & 84 & 84 & 100 \\
\hline trnD-GUC (pIJB1) & 74 & 74 & 100 \\
\hline $\operatorname{trnC-GCA~(pIJB1)~}$ & 72 & 72 & 100 \\
\hline trnT-GGU (pIJB1) & 72 & 72 & 100 \\
\hline \multicolumn{4}{|l|}{ Fotossintema II } \\
\hline$p s b \mathrm{D}(\mathrm{pIJB} 1)$ & 1062 & 1062 & 99,2 \\
\hline$p s b \mathrm{M}(\mathrm{pIJB1})$ & 105 & 105 & 99,0 \\
\hline$p s b \mathrm{~B}(\mathrm{pIJB} 2)$ & 1527 & 1527 & 99,3 \\
\hline psbT (pIJB2) & 104 & 104 & 97,1 \\
\hline$p s b \mathrm{~N}(\mathrm{pIJB} 2)$ & 132 & 132 & 100 \\
\hline \multicolumn{4}{|l|}{ Outros genes } \\
\hline$p e t \mathrm{~N}(y c f 6)(\mathrm{pIJB} 1)$ & 90 & 90 & 100 \\
\hline$r p 20(\mathrm{pIJB} 2)$ & 387 & 387 & 99,2 \\
\hline $5^{\prime} \not p s 12$ (pIJB2) & 114 & 114 & 100 \\
\hline $\operatorname{cpp} \mathrm{P}$ (exon 1) (pIJB2) & 71 & 71 & 81,7 \\
\hline clpP (exon 2) (pIJB2) & 292 & 292 & 94,2 \\
\hline $\operatorname{chp} \mathrm{P}$ (exon 3) (pIJB2) & 228 & 228 & 78,9 \\
\hline
\end{tabular}


Tabela 5. Espaços intergênicos: comparação do tamanho e análise de homologia entre as seqüências de nucleotideos dos fragmentos cloroplastidiais de tomate $(8.660 \mathrm{pb}$ e $6.366 \mathrm{pb}$ ) e as regiões correspondentes do plastoma de tabaco. O plasmídio pIJB1 corresponde ao fragmento de $8.660 \mathrm{pb}$ e o plamídio pIJB2 corresponde ao fragmento de $6.366 \mathrm{pb}$.

\begin{tabular}{|c|c|c|c|}
\hline \multirow{2}{*}{$\begin{array}{c}\text { Espaço } \\
\text { Intergênico }\end{array}$} & \multicolumn{2}{|c|}{ Tamanho (pb) } & \multirow{2}{*}{$\begin{array}{c}\text { Identidade } \\
(\%)\end{array}$} \\
\hline & Tomate & Tabaco & \\
\hline \multicolumn{4}{|l|}{ pIJB1 (8.660 pb) } \\
\hline$p s b \mathrm{D}-t r n \mathrm{~T}$ & 1178 & 1218 & 96,5 \\
\hline $\operatorname{trn} \mathrm{T}-\operatorname{trn} \mathrm{E}$ & 411 & 848 & $93,4\left(44,5^{*^{1}}\right)$ \\
\hline $\operatorname{trn} \mathrm{E}-\operatorname{trn} \mathrm{Y}$ & 59 & 59 & 93,2 \\
\hline$t r n \mathrm{Y}-t m \mathrm{D}$ & 108 & 108 & 97,2 \\
\hline $\operatorname{trn} \mathrm{D}-p s b \mathrm{M}$ & 1081 & 1072 & 93,3 \\
\hline$p s b \mathrm{M}-p e t \mathrm{~N}$ & 1107 & 1132 & 95,3 \\
\hline $\operatorname{pet} \mathrm{N}-\operatorname{trn} \mathrm{C}$ & 648 & 670 & 94,0 \\
\hline $\operatorname{trn} \mathrm{C}-p p \mathrm{~B}$ & 1328 & 1281 & 95,6 \\
\hline \multicolumn{4}{|l|}{ pIJB2 (6.366 pb) } \\
\hline$p s b \mathrm{~N}-p s b \mathrm{~T}$ & 77 & 77 & 94,8 \\
\hline$p s b \mathrm{~T}-p s b \mathrm{~B}$ & 201 & 201 & 99,0 \\
\hline$p s b \mathrm{~B}-\operatorname{cpp} \mathrm{P}(1)$ & 444 & 449 & 98,9 \\
\hline $\operatorname{clp} \mathrm{P}(1)-\operatorname{clp} \mathrm{P}(2)^{*^{2}}$ & 798 & 807 & 94,1 \\
\hline$c \not p \mathrm{P}(2)-\operatorname{clp} \mathrm{P}(3)^{*^{3}}$ & 617 & 637 & 95,6 \\
\hline$c \not p \mathrm{P}(3)-5^{\prime} \not p s 12$ & 138 & 138 & 99,3 \\
\hline $5^{\prime} r p s 14-r p 20$ & 811 & 811 & 95,8 \\
\hline
\end{tabular}

${ }^{1}$ Homologia desde que considerada a deleção de 437 pb em tomate;

$*^{2}$ Íntron 1; $*^{2}$ Íntron 2 . 
Quadro 3. Alinhamento e homologia entre as seqüências de nucleotídeos e aminoácidos das regiões codificadoras plastidiais $\not p o \mathrm{~B}, \operatorname{trn} \mathrm{C}$, pet $\mathrm{N}(y c f), p s b \mathrm{M}, \operatorname{tm} \mathrm{D}, \operatorname{trn} \mathrm{Y}, \operatorname{tr} \mathrm{E}$, trm T, $p s b \mathrm{D}, p s b \mathrm{C}(\mathrm{pIJB} 1), \not p l 20,5^{\prime} \not p s 12, c l p \mathrm{P}, p s b \mathrm{~B}, p s b \mathrm{~T}$ e $p s b \mathrm{~N}$ (pIJB2) contidas nos plastomas de Zea mays (ZM), Oryza sativa (OS), Nicotiana tabacum (NT), Lycopersicon esculentum (LE), Pinus thunbergii (PT), e Marchantia polymorpha (MP). Asteriscos $\left(^{*}\right)$ indicam identidade total; Pontos (.) indicam que existem somente dois nucleotídeos ou aminoácidos diferentes na respectiva posição; Espaços em branco ( ) indicam que existem mais de dois nucleotídeos ou aminoácidos diferentes na respectiva posição; Em negrito encontram-se destacados os nucleotídeos alvo de substituição, os respectivos códons e aminoácidos codificados em tomate quando em comparação à seqüência de tabaco. Traços $(-)$ representam ausência do nucleotídeo ou aminoácido. Sítios de editamento encontram-se destacados em negrito-itálico-sublinhado na seqüência de tomate; número abaixo entre parênteses indica o códon a ser editado tomando-se o códon ATG como número 1.

GAACTTTCGTTTTAGCTGGTCGTGACCAAGAAACCACCGGCTTTCCTTGGTGGGC GAACTTTTGTTTTAGCTGGTCGTGACCAAGAAACCACCGGTTTTGCTTGGTGGGC GAACTTTAGCCTTAGCTGGTCGTGACCAAGAAACCACTGGTTTCGCTTGGTGGGC GAACTTTAGCCTTAGCTGGTCGTGACCAAGAAACCACaGGTTTCGCTTGGTGGGC GAACTATAGCTTTAGCTGGTCGTGATCAAGAAACCACTGGTTTCGCTTGGTGGGC GAACTTTAGCTTTAGGTGGTCGTGATCAAGAAACCACAGGTTTTGCTTGGTGGGC

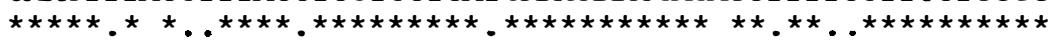

TGGGAATGCCAGACTTATCAATTTGTCCGGTAAACTACTTGGAGCTCATGTAGCC CGGGAATGCCAGACTTATCAATTTGTCGGGTAAACTACTTGGAGCTCACGTAGCC CGGGAATGCCCGACTTATCAATTTATCCGGTAAACTACTAGGGGCTCATGTAGCC CGGGAATGCCCGACTTATCAATCTATCCGGTAAACTACTAGGGGCTCATGTAGCC CGGTAATGCCCGACTTATCAATTTGTCGGGTAAATTGCTTGGGGCTCACGTGGCT AGGTAATGCTAGACTTATTAATTTATCTGGAAAGTTACTTGGAGCTCATGTAGCT

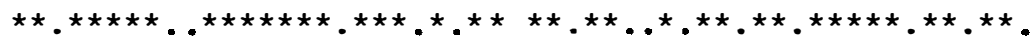




\begin{tabular}{|c|c|}
\hline PSBCPT & CATGCCGGATTAATTGTATTCTGGGCCGGAGCAATGAACCTATT \\
\hline PSBCMP & 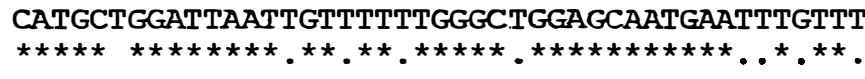 \\
\hline PSBCZM & ATTTCGTACCAGAAAAGCCCATGTATGAACAAGGGTTGATTT" \\
\hline PSBCOS & ATTTCGTACCAGAAAAACCCATGTATGAACAAGGGTTGATTTTI \\
\hline PSBCNT & ATTTCGTACCAGAGAAGCCTATGTATGAACAAGGATTAATTTT \\
\hline PSBCLE & ATTTCGTACCCGAGAAGCCTATGTATGAACAAGGATTgATTTT \\
\hline PSBCPT & АTTTCGTACCGGAAAAACCTATGTATGAACAAGGATTGATTCTG \\
\hline PSBCMP & 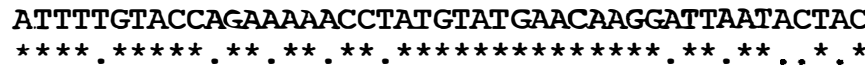 \\
\hline PSBCZM & AGCTACTCTAGGTTGGGGAGTAGGGTCGGGGGGAGAAGTTCTA \\
\hline PSBCOS & AGCTACTCTAGGTTGGGGAGTAGGGCCCGGGGGAGAAGTTCTAC \\
\hline PSBCNT & AGCTACTCTAGGTTGGGGGGTAGGCCCTGGGGGAGAAGTTATAC \\
\hline PSBCLE & AGCTACTCTAGGTTGGGGGGTAGGCCCTGGGGGAGAAGTTATAC \\
\hline PSBCPT & AGCTACTCTAGGATGGGGAGTCGGTCCTGGTGGGGAAATCGTG \\
\hline PSBCMP & 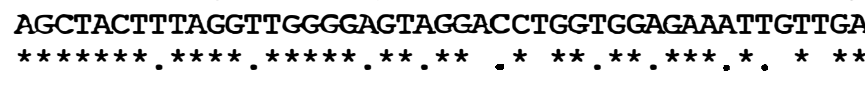 \\
\hline PSBCZM & TACTTTGTATCCGGAGTACTTCACTTAATTTCCTCCGCAG 370 \\
\hline PSBCOS & TACTTTGTATCTGGAGTACTTCATCTAATTTCCTCCGCAG 370 \\
\hline PSBCNT & TACTTTGTATCTGGAGTACTTCATTTAATTTCTTCTGCAG 370 \\
\hline PSBCLE & TACTTTGTATCTGGAGTACTTCATTTAATTTCTTCTGCAG 37 \\
\hline PSBCPT & TATTTTGTATCTGGGGTACTTCACTTAATTTCTTCTGCGG 370 \\
\hline PSBCMP & 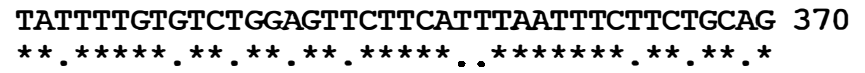 \\
\hline
\end{tabular}

psbc: aminoácidos

PSBCZM PSBCOS MKILYSLRRFYHVETLFNGTFVLAGRDQETTGFPWWAGNARLINLSGKLLGAHVA 55 MKILYSLRRFYHVETLFNGTFVLAGRDQETTGFAWWAGNARLINLSGKLLGAHVA MKTLYSLRRFYHVETLFNGTLALAGRDQETTGFAWWAGNARLINLSGKLIGAHVA MKTLYSLRRSYPVETLFNGT IALAGRDQETTGFAWLAGNARLINLSGKLLGAHVA PSBCPT PSBCMP MKILYSQRRFYPVETLFNGTLALGGRDQETTGFAWWAGNARLINLSGKLLGAHVA

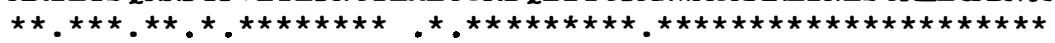

220 220 275 275 275 275 275 275

PSBCZM PSBCOS PSBCNT PSBCPT PSBCMP HAGLIVFWAGAMNLFEVAHFVPEKPMYEQGLILLPHIATLGWGVGSGGEVLDTFP HAGLIVFWAGAMNLFEVAHFVPEKPMYEQGLILLPHLATLGWGVGPGGEVLDTFP HAGLIVFWAGAMNLFEVAHFVPEKPMYEQGLILLPHLATLGWGVGPGGEVIDTFP HAGLIVFWAGAMNLFEVAHFVP EKPMYEQGLILLPHLATLGWGVGPGGEIVDTFP HAGLIVEWAGAMNLFEVAHFVPEKPMYEQGLILLPHLATLGWGVGPGGEIVDTFP

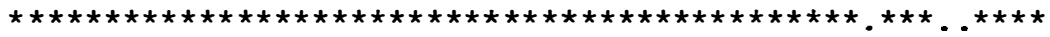

PSBCZM PSBCOS PSBCNT PSBCPT PSBCMP

\begin{tabular}{|c|c|}
\hline FVSGVLH & 123 \\
\hline I & \\
\hline YF & \\
\hline YFVSGVLHLI SSAV & \\
\hline YFVSGVLH] & \\
\hline
\end{tabular}

\section{psbD: Nucleotídeos}

PSBDZM PSBDOS PSBDNT PSBDLE PSBDPT PSBDMP
ATGACTATAGCCGTTGGTAGAGTTACTAAAGAAGAAAACGATCTATTCCСCCTTA ATGACTATAGCCCTTGGTAGAGTTACTAAAGAAGAAAATGATTTATTTGATATTA ATGACTATAGCCCTTGGTAAGTTTACCAAAGACGAAAATGATTTATTTGATATTA ATGACTATAGCCATTGGTAAGTTTACCAAAGACGAAAATGATTTATTTGATATTA ATGACTATAGCCCTTGGAAAGTCTTCTAAAGAAGAAAAAACTTTATTTGATACTG ATGACTATAGCCATTGGAAAGTCTTCCAAAGAACCAAAAGGTTTATTTGATAGCA

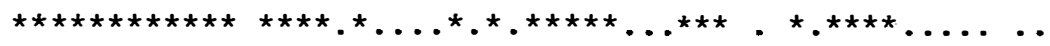




\begin{abstract}
PSBDZM
PSBDOS

PSBDNT

PSBDLE

PSBDPT

PSBDMP

TCGACGACTGGTTACGAAGGGACCGCTTCGTTTTTGTAGGATGGTCCGGCTTATT TGGACGACTGGTTACGAAGGGACCGTTTTGTTTTTGTAGGATGGTCTGGCCTATT TGGATGACTGGTTACGGAGGGACCGTTTCGTTTTTGTAGGCTGGTCCGGTCTATT TGGATGACTGGTTACGGAGGGACCGTTTCGTTTTTGTAGGCTGGTCCGGTCTATT TGGATGACTGGCTACGCAGAGACCGTTTCGTTTTTGTGGGTTGGTCCGGTCTATT TGGATGACTGGCTAAGGAGAGACCGTTTTGTATTTGTAGGTTGGTCTGGTCTATT

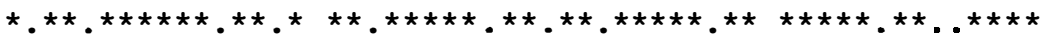

PSBDZM PSBDOS PSBDNT PSBDLE PSBDPT PSBDMP

PSBDZM PSBDOS PSBDNT PSBDLE PSBDPT PSBDMP

PSBDZM PSBDOS PSBDNT PSBDLE PSBDPT PSBDMP

GCTCTTTCCTTGTGCTTATTTCGCTTTAGGGGGTTGGTTTACAGGGACTACTTTT GCTTTTTCCTTGTGCTTATTTCGCTTTAGGAGGTTGGTTTACAGGGACAACTTTT GCTCTTTCCTTGTGCCTATTTCGCTGTAGGGGGTTGGTTCACAGGTACAACCTTT GCTCTTTCCTTGTGCCTATTTCGCTGTAGGGGGTTGGTTCACAGGTACCACCTTT GCTCTTTCCTTGTGCCTATTTTGCCTTAGGTGGATGGTTCACGGGTACAACCTTT GCTTTTTCCTTGTGCATATTTTGCTTTAGGTGGATGGTTTACAGGTACAACCTTT

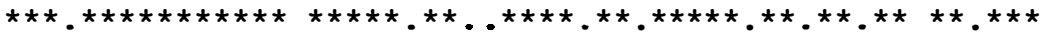

GTAACTTCTTGGTATACCCATGGATTGGCTAGTTCCTATTTGGAAGGTTGCAATT GTAACTTCTTGGTATACCCATGGATTGGCGAGTTCCTATTTGGAAGGTTGCAATT GTAACTTCATGGTATACCCATGGATTGGCCAGTTCTTATTTGGAAGGCTGCAATT GTAACTTCATGGTATACCCATGGATTGCCCAGTTCTTATTTGGAAGGCTGCATTT GTGACTTCATGGTATACTCACGGATTGGCCAGTTCCTATCTGGAAGGTTGTAATT GTAACTTCATGGTATACTCATGGATTAGCTAGTTCTTATTTAGAAGGTTGTAATT

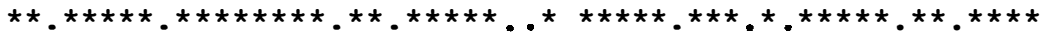

TCTTAACCGCGGCGGTTTCCACACCTGCCAATAGTTTAGCACACTCTTTGTTGCT TCTTAACCGCAGCAGTTTCCACCCCTGCCAATAGTTTAGCACACTCTTTGTTGCT TCTTAACTGCCGCGGTTTCTACTCCTGCTAATAGTTTAGCACATTCGTTGTTGTT TCTTAACTGCCGCGGTTTCTACTCCTGCTAATAGTTTAGCACATTCGTTGTTGTT TCCTAACTGCCGCAGTTTCTACTCCTGCTAATAGTTTAGCACATTCTTTGCTGCT TTTTAACTGCCGCTGTTTCTACCCCAGCAAATAGTTTAGCTCATTCTTTACTATT

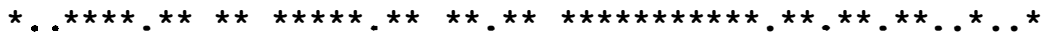

PSBDZM PSBDOS PSBDNT PSBDLE PSBDPT PSBDMP

PSBDZM PSBDOS PSBDNT PSBDLE PSBDPT PSBDMP

PSBDZM PSBDOS PSBDNT PSBDLE PSBDPT PSBDMP

PSBDZM PSBDOS PSBDNT PSBDLE

ACTATGGGGACCGGAAGCACAGGGAGATTTTACTCGTTGGTCTCAATTAGGTGGT ACTATGGGGCCCGGAAGCACAAGGGGATTTTACTCGTTGGTGTCAATTAGGTGGT ACTATGGGGTCCTGAAGCACAAGGAGATTTTACTCGTTGGTGTCAATTGGGGGGT ACTATGGGGTCCTGAAGCACAAGGAGATTTTACTCGTTGGTGTCAATTGEGGGGT ATTATGGGGTCCCGAAGCACAAGGAGATTTGACTCGTTGGTGTCAATTAGGTGGT ATTATGGGGACCTGAAGCACAAGGTGATTTTACTCGTTGGTGTCAATTAGGCGGT

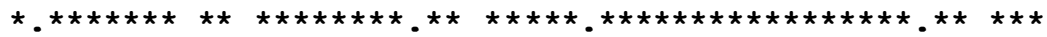

CTTTGGACTTTTCTCGCTCTCCATGGAGCTTTTGCACTAATAGGTTTCATGCTAC CTGTGGACTTTTGTTGCTCTCCATGGGGCTTTTGCACTAATAGGTTTCATGTTAC CTGTGGACTTTTGTTGCTCTCCATGGAGCTTTTGGCCTAATAGGTTTCATGTTAC CTGTGGACTTTTGTTGCTCTCCATGGAGCTTTTGGCCTAATAGGTTTCATGTTAC CTATGGACCTTCGTTGCTCTTCACGGTGCTTTCGGTCTAATAGGTTTCATGTTAC TTATGGACTTTTGTAGCTCTTCATGGTGCATTTGGCTTAATAGGCTTTATGTTAA

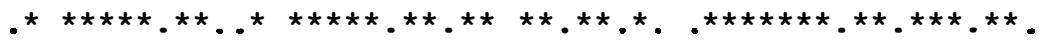

GTCAATTTGAACTTGCTCGGCCTGTTCAATTGCGGCCTTATAATGCAATTTCATT GTCAATTTGAACTTGCTCGGTCTGTTCAATTGCGGCCTTATAATGCAATTTCATT GTCAATTCGAGCTTGCTCGATCTGTTCAATTGAGACCTTATAATGCAATCGCATT GTCAATTCGAGCTTGCTCGATCTGTTCAATTGAGACCTTATAATGCAATCGCATT GTCAATTTGAACTTGCTCGATCTGTACAATTGCGACCTTATAATGCAATTGCATT GACAATTTGAACTTGCTCGATCTGTTCAATTACGTCCTTATAATGCAATTGCGTT

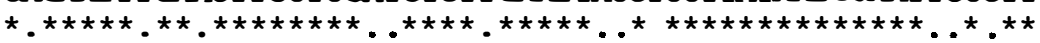
CTCTGGCCCAATCGCTGTTTTTGTTTCCGTATTCCTGATTTATCCACTGGGGCAA СTCTGGTCCAATTGCTGTTTTTGTTTCTGTATTTCTGATTTATCCACTGGGTCAG CTCTGGTCCAATTGCTGTTTTTGTTTCTGTATTTCTGATTTATCCACTAGGTCAG 


\begin{abstract}
PSBDPT
CTCTGCTCCAATTGCTGTCTTTGTTTCTGTATTTTTGATCTATCCATTGGGACAG TTCTGGACCTATTGCTGTTTTTGTATCTGTTTTTCTTATTTATCCTTTAGGACAA

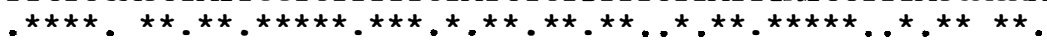
TCTGGTTGGTTCTTCTCGCCGAGTTTTGGCGTAGCAGCTATATTTCGCTTCATCC PSBDOS PSBDNT PSBDLE PSBDPT PSBDMP TCCGGTTGGTTCTTTGCGCCGAGTTTTGGCGTAGCAGCGATATTTCGATTCATCC TCTGGTTGGTTCTTTGCACCTAGTTTTGGTGTAGCAGCTATATTTCGATTCATCC TCTGGTTGGTTCTTTGCACCTAGTTTTGGTGTAGCAGCTATATTTCGATTCATCC TCCGGTTGGTTTTTCGCACCTAGTTTTGGTGTAGCAGCTATTTTCCGTTTTATCC TCAGGTTGGTTTTTTGCACCTAGTTTTGGTGTAGCTGCAATTTTTAGATTTATTC

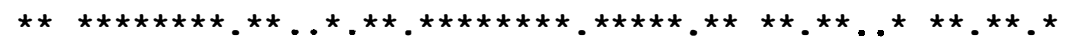

PSBDZM PSBDOS PSBDNT PSBDLE PSBDPT PSBDMP

TTTTCTTCCAAGGATTTCATAATTGGACGTTGAAACCATTTCATATGATGGGAGT TCTTCTTCCAAGGATTTCATAATTGGACGTTGAACCCATTTCATATGATGGGAGT TCTTTTTTCAAGGGTTTCATAATTGGACGTTGAACCCATTTCATATGATGGGAGT TATTTTTTCAAGGGTTTCATAATTGGACCTTGAACCCCTTTCATATGATGGGAGT TCTTCTTTCAAGGTTTTCATAATTGGACCTTGAATCCATTTCATATGATGGGAGT TTTTTTTTCAAGGCTTTCATAACTGGACTTTAAACCCATTTCATATGATGGGTGT

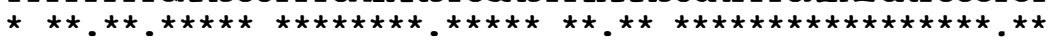

PSBDZM PSBDOS PSBDNT PSBDLE PSBDPT PSBDMP

PSBDZM PSBDOS PSBDNT PSBDLE PSBDPT PSBDMP

PSBDZM PSBDOS PSBDNT PSBDLE PSBDPT PSBDMP

PSBDZM PSBDOS PSBDNT PSBDLE PSBDPT PSBDMP

PSBDZM PSBDOS PSBDNT PSBDLE PSBDPT PSBDMP

TGCCGGAGTATTAGGCGCAGTTCTGCTATGCGCTATCCACGGGGCTACCGTAGAA TGCCGGAGTATTAGGCGCGGCTCTGCTATGCGCTATTCATGGGGCAACCGTGGAA TGCCGGTGTATTGGGCGCTGCTTTGCTATGCGCCATTCATGGTGCTACCGTAGAA TGCCGGTGTATTGGGGGCTGCTTTGCTATGCGCCATTCATGGTGCTACCGTAGAA TGCCGGAGTATTGGGTGCTGCTCTTCTATGCGCTATTCATGGTGCTACCGTGGAA CGCTGGAGTTTTAGGGGCTGCTCTTTTATGCGCAATTCACGGTGCTACTGTTGAG

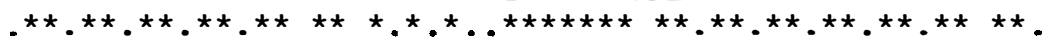

AACACTCTATTCGAAGATGGCGATGGTGCAAATACCTTCCGTGCTTTTAACCCAA AACACTCTATTTGAGGACGGTGATGGTGCAAATACCTTCCGCGCTTTTAACCCAA AATACTTTATTTGAAGACGGTGATGGTGCAAATACATTCCGTGCTTTTAACCCAA AATACTTTATTTGAAGACGGTGATGGTGCAAATACATTCCGTGCTTTTAACCCAA AATACTTTATTTGAAGATGGTGATGGTGCAAATACGTTCCGTGCTTTTAACCCGA AATACATTATTTGAAGATGGTGATGGTGCAAACACATTCCGTGCTTTTAATCCAA

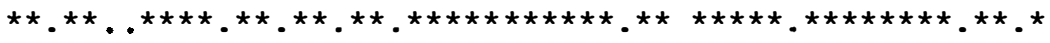
CTCAAGCCGAAGAAACTTATTCAATGGTCACCGCTAACCGCTTTTGGTCCCAAA CTCAAGCCGAAGAGACTTATTCCATGGTCACTGCTAACCGCTTCTGGTCCCAGAT CTCAATCTGAAGAAACATATTCTATGGTTACTGCGAATCGTTTTTGGTCTCAAAT

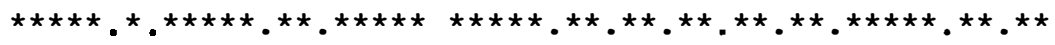

СTTTGGTGTTGCTTTTTCCAATAAACGTTGGTTACATTTCTTTATGCTATTTGTA CTTTGGTGTTGCTTTTTCCAATAAACGTTGGTTACATTTCTTTATGCTATTTGTA CTTTGGGGTTGCTTTTTCCAATAAACGTTGGTTACATTTCTTTATGTTATTTGTA CTTTGGGGTTGCTTTTTCCAATAAACGTTGGTTACATTTCTTTATGTTATTTGTA TTTTGGGGTTGCTTTTTCCAATAAACGTTGGTTACATTTCTTCATGTTATTTGTG TTTTGGTGTTGCTTTTTCTAATAAACGTTGGTTACACTTTTTTATGCTATTCGTA

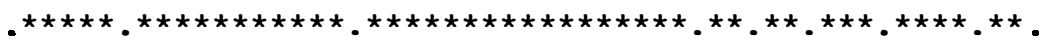

CCCGTCACCGGTTTATGGATGAGTGCTATTGGCGTAGTTGGTCTGGCTCTGAACC CCGGTCACCGGTTTATGGATGAGTGCTATTGGCGTAGTCGGCCTGGCTCTGAACC CCAGTAACCGGTTTATGGATGAGTGCTCTTGGAGTAGTCGGTCTAGCCCTGAACC CCAGTGACCGGTTTATGGATGAGTGCTCTTGGAGTAGTCGGTCTAGCTCTGAACC CCAGTGACCGGTTTATGGATGAGTGCCATTGGAGTAGTTGGTCTAGCTCTAAACT CCAGTAACTGGATTATGGATGAGTGCTATTGGGGTTGTAGGTTTAGCTTTAAATT

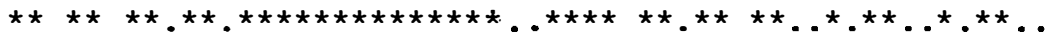

880 880 880 880 880 880 
PSBDZM PSBDOS PSBDNT PSBDLE PSBDPT PSBDMP

PSBDZM PSBDOS PSBDNT PSBDLE PSBDPT PSBDMP

PSBDZM PSBDOS PSBDNT PSBDLE PSBDPT PSBDMP

PSBDZM PSBDOS PSBDNT PSBDLE PSBDPT PSBDMP
TACGTGCCTATGACTTCGTTTCCCAGGAAATCCGTGCAGCGGAAGATCCTGAATT TACGTGCCTATGACTTCGTTTCCCAGGAAATCCGTGCAGCGGAAGATCCTGAATT TACGTGCCTATGACTTCGTTTCTCAGGAAATTCGCGCAGCGGAAGATCCTGAATT TACGTGCCTATGACTTCGTTTCTCAGGAAATTCGCGCAGCGGAAGATCCTGAATT TACGTGCCTATGATTTTGTTTCCCAGGAGATCCGTGCAGCAGAAGATCCTGAATC TACGTGCCTACGATTTTGTTTCCCAAGAAATTCGTGCAGCAGAGGATCCAGAATT

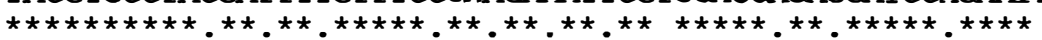

TGAGACTTTCTACACCAAAAATATTCTTTTAAACGAGGGTATTCGTGCGTGGATG TGAGACTTTCTACACCAAAAATATTCTTTTAAACGAGGGTATTCGTGCGTGGATG TGAGACTTTCTACACCAAAAATATTCTCTTAAACGAAGGTATTCGCGCTTGGATG TGAGACTTTCTACACCAAAAATATTCTCTTAAACGAAGGTATTCGCGCTTGGATG TGAGACTTTCTACACAAAAAATATTCTCCTGAACGAAGGTATTCGTGCTTGGATG TGAAACTTTTTATACAAAAAATATTTTATTAAATGAAGGTATTAGAGCTTGGATG

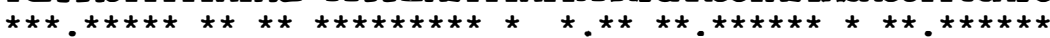

GCAGCTCAGGATCAGCCTCATGAAAATCTTATATTCCCTGAGGAGGTTCTACCAC GCAGCTCAGGATCAGCCTCATGAAAATCTTATATTCCCTGAGGAGGTTCTACCAC GCGGCTCAAGATCAGCCTCATGAAAACCTTATATTCCCTGAGGAGGTTCTACCAC GCGGCTCAAGATCAGCCTCATGAAAACCTTATATTCCCTGAGGAGGTTCTACCAC GCGGCTCAAGATCAGCCTCATGAAAACCTTATATTCCCTGAGGAGGTCCTACCCC GCAGCTCAAGATCAGCCTCATGAAAATCTTGTATTCCCAGAGGAGGTTCTACCCC

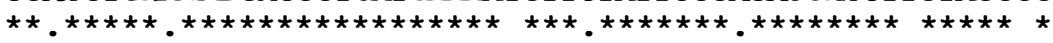

\begin{tabular}{|c|c|}
\hline GTGGAAACGCTCTT--- & 1059 \\
\hline GTGGAAACGCTCTTTAA & 1062 \\
\hline GTGGAAACGCTCTTTAA & 6 \\
\hline GTGGAAACGCTCTTTAA & 106 \\
\hline GTGGAAACGCTCTTTAA & 106 \\
\hline 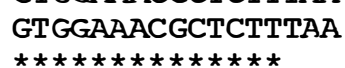 & \\
\hline
\end{tabular}

\section{psbD: Aminoácidos}

PSBDZM PSBDOS PSBDNT PSBDLE PSBDPT PSBDMP

PSBDZM PSBDOS PSBDNT PSBDLE PSBDPT PSBDMP

PSBDZM PSBDOS PSBDNT PSBDLE PSBDPT PSBDMP
MTIAVGRVTKEENDLF PLIDDWLRRDRFVFVGWSGLLLFPCAYFALGGWFTGTTF MTIALGRVTKEENDLFDIMDDWLRRDRFVFVGWSGLLLF PCAYFALGGWFTGTTF MTIALGKFTKDENDLFDIMDDWLRRDRFVFVGWSGLLLFPCAYFAVGGWFTGTTF MTIALGKFTKDENDLFDIMDDWLRRDRFVFVGWSGLLLFPCAYFAVGGWFTGTTF MT IALGKSSKEEKTLFDTVDDWLRRDRFVFVGWSGLLLF PCAYFALGGWFTGTTF MT IAIGKSSKEPKGLFDSMDDWLRRDRFVFVGWSGLLLF PCAYFALGGWFTGTTF

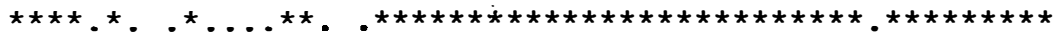

VTSWYTHGLASS YLEGCNFLTAAVSTPANSLAHSLLLLWGPEAQGDFTRWSOLGG VTSWYTHGLASSYLEGCNFLTAAVSTPANSLAHSLLLLWGPEAQGDFTRWCQLGG VTSWYTHGLASSYLEGCNFLTAAVST PANSLAHSLLLLWGPEAQGDFTRWCQLGG VTSWYTHGLASSYLEGCNFLTAAVSTPANSLAHSLLLLWGPEAQGDFTRWCQLGG VTSWYTHGLASS YLEGCNFLTAAVSTPANSLAHSLLLLWGPEAQGDLTRWCQLGG VT SWYTHGIASSYLEGCNFLTAAVSTPANSLAHSLLLLWGPEAQGDFTRWCQLGG

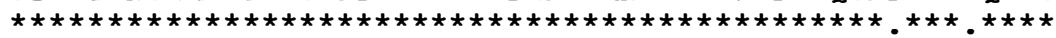

LWTFLALHGAFALIGFMLRQFELARPVQLRPYNAISFSGPIAVFLSVFLI YPLGQ LWTFVALHGAFALI GFMLRQFELARSVQLRPYNAISFSGPIAVFVSVFLIYPLGQ LWTFVALHGAFGLIGFMLRQFELARSVQLRPYNAIAFSGPIAVFVSVFLIYPLGQ LWTFVALHGAFGLIGFMLRQFELARSVQLRPYNAIAFSGPIAVFVSVFLIYPLGQ LWTFVALHGAFGLIGFMLRQFELARSVQLRPYNAIAFSAPIAVFVSVFLIYPLGQ LWTFVALHGAFGLIGFMLRQFELARSVQLRPYNAIAFSGPIAVFVSVFLIYPLGQ

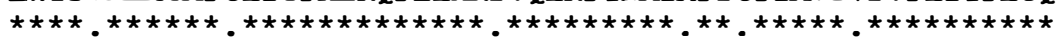




\begin{tabular}{|c|c|c|c|}
\hline PSBDOS & \multicolumn{2}{|c|}{ SGWFFAPSFGVAAI FRF ILFFQGFHNWTLNPFHMMGVAGVLGAALLCAIHGATVE } & 220 \\
\hline PSBDNT & \multicolumn{2}{|c|}{ SGWFFAPS FGVAAI FRFILFFQGFHNWTLNPFHMMGVAGVLGAALLCAIHGATVE } & 220 \\
\hline PSBDLE & \multicolumn{2}{|c|}{ SGWFFAPS FGVAAIFRFILFFQGFHNWTLNPFHMMGVAGVLGAALLCAIHGATVE } & 220 \\
\hline PSBDPT & \multicolumn{2}{|c|}{ SGWFFAPSFGVAAI FRF ILF FQGFHNWTLNP FHMMGVAGVLGAALLCAIHGATVE } & 220 \\
\hline PSBDMP & \multicolumn{2}{|c|}{ 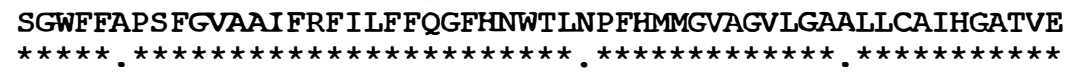 } & 220 \\
\hline PSBDZM & \multicolumn{2}{|c|}{ NTLFEDGDGANTFRAFNPTQAEETYSMVTANRFWSQIFGVAFSNKRWLHFFMUFV } & 275 \\
\hline PSBDOS & \multirow{2}{*}{\multicolumn{2}{|c|}{$\begin{array}{l}\text { NTLFEDGDGANT FRAFNPTQAEETYSMVTANRFWSQIFGVAFSNKRWLHFFMUFV } \\
\text { NTLFEDGDGANT FRAFNPTQAEETYSMVTANRFWSQIFGVAFSNKRWLHFFMUFV }\end{array}$}} & 275 \\
\hline PSBDNT & & & 275 \\
\hline PSBDLE & \multicolumn{2}{|c|}{ NTLFEDGDGANTFRAFNPTQAEETYSMVTANRFWSQIFGVAFSNKRWLHF FMUFV } & 275 \\
\hline PSBDPT & \multicolumn{2}{|c|}{ NTLFEDGDGANTFRAFNPTQAEETYSMVTANRFWSQIFGVAFSNKRWLHFFMIFV } & 275 \\
\hline PSBDMP & \multicolumn{2}{|c|}{ 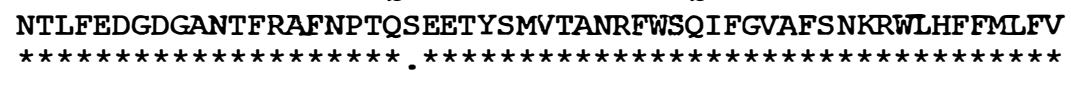 } & 275 \\
\hline PSBDZM & \multicolumn{2}{|c|}{ PVTGLWMSAIGVVGLALNLRAYDFVSQEIRAAEDPEFETFYTKNILLNEGIRAWM } & 330 \\
\hline PSBDOS & \multicolumn{2}{|c|}{ PVTGLWMSAIGVVGLALNLRAYDFVSQEI RAAEDPEFETFYTKNILLNEGIRAWM } & 330 \\
\hline PSBDNT & \multicolumn{2}{|c|}{ PVTGLWMSALGVVGLALNLRAYDFVSQEI RAAEDPEFETFYTKNILLNEGIRAWM } & 330 \\
\hline PSBDLE & \multicolumn{2}{|c|}{ PVTGLWMSALGVVGLALNLRAYDFVSQEIRAAEDPEFETFYTKNILLNEGIRAWM } & 330 \\
\hline PSBDPT & \multicolumn{2}{|c|}{ PVTGLWMSAI GVVGLALNLRAYDFVSQEIRAAEDPESETFYTKNILLNEGIRAWM } & 330 \\
\hline PSBDMP & \multicolumn{2}{|c|}{ 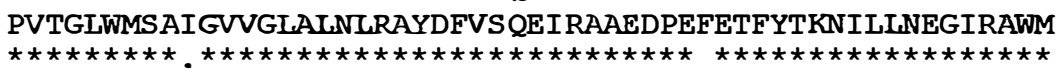 } & 330 \\
\hline PSBDZM & AAQDQPHENLI F PEEVLPRGNAL & 353 & \\
\hline PSBDOS & AAQDQDPHENLI F PEEVLPRGNAL & 353 & \\
\hline PSBDNT & AAQDQ̄PHENLI F PEEVLPRGNAL & 353 & \\
\hline PSBDLE & AAQDQPHENLIF PEEVLPRGNAL & 353 & \\
\hline PSBDPT & AAQDQPHENLIF PEEVLPRGNAL & 353 & \\
\hline PSBDMP & 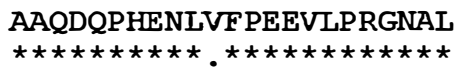 & 353 & \\
\hline
\end{tabular}

\section{tIrT (GGU) : Nualeotídeos}

TRNTZM GCCCTTTTAACTCAGTGGTAGAGTAATGCCATGGTAAGGCATAAGTCATCGGTTC TRNTOS GCCСTTTTAACTCAGTGGTAGAGTAATGCCATGGTAAGGCATAAGTCATCGGTTC TRNTNT TRNTLE TRNTPT TRNTMP GCCСTTTTAACTCAGTGGTAGAGTAACGCCATGGTAAGGCGTAAGTCATCGGTTC GCCСTTTTAACTCAGTGGTAGAGTAACGCCATGGTAAGGCGTAAGTCATCGGTTC GCCСTTTTAACTCAGCGGTAGAGTAACGCCATGGTAAGGCGTAAGTCATCGGTTC GCCCTTTTAACTCAGTGGTAGAGTAACGCCATGGTAGGGCGTAAGTCATCGGTTC

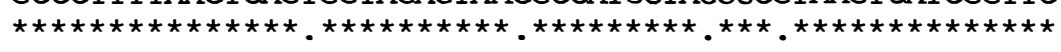

$\begin{array}{lll}\text { TRNTZM } & \text { AAATCCGATAAAGGGCT } & 72 \\ \text { TRNTOS } & \text { AAATCCGATAAAGGGCT } & 72 \\ \text { TRNTNT } & \text { AAATCCGATAAGGGGCT } & 72 \\ \text { TRNTLE } & \text { AAATCCGATAAGGGGT } & 72 \\ \text { TRNTPT } & \text { AAGTCCGATAAAGGGCT } & 72 \\ \text { TRNTMP } & \text { AAATCTGATAAAGGGCT } & 72\end{array}$

trnE (UUC): Nualeotídeos

TRNEZM GCCCCCATCGTCTAGTGGTTCAGGACATCTCTCTTTCAAGGAGGCAGCGGGTATT TRNEOS GCCCCTATCGTCTAGTGGTTCAGGACATCTCTCTTTCAAGGAGGCAGCGGGGATT TRNENT GCCCCCATCGTCTAGTGGTTTAGGACATCTCTCTTTCAAGGAGGCAGCGGGGATT TRNELE GCCCCCATCGTCTAGTGGTTTAGGACATCTCTCTTTCAAGGAGGCAGCGGGGATT TRNEPT ' GCCCCTATCGTCTAGTGGATCAGGACATCTCTCTTTCAAGGAGGCAACGGGGATT TRNEMP GCCCCCATCGTCTAGTGGCCTAGGACACCTCTCTTTCAAGGAGGCGACGGGGATT

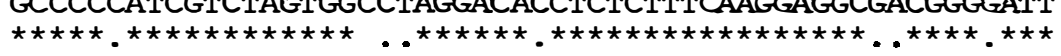




$\begin{array}{lll}\text { TRNEZM } & \text { CGACTTCCCCTGGGGGTA } & 73 \\ \text { TRNEOS } & \text { CGACTTCCCCTGGGGGTA } & 73 \\ \text { TRNENT } & \text { CGAATTCCCCTGGGGTA } & 73 \\ \text { TRNELE } & \text { CGAATTCCCCTGGGGGTA } & 73 \\ \text { TRNEPT } & \text { CAACTTCCCCTGGGGGTA } & 73 \\ \text { TRNEMP } & \text { CGAATTCCCCTGGGGGTA } & 73 \\ & \star . \star . \star \star \star \star \star \star \star \star \star \star \star \star & \end{array}$

\begin{tabular}{|c|c|c|c|}
\hline TRNYZM & \multicolumn{2}{|c|}{ GGGTCGATGCCCGAGCGGTTAATGGGGACGGACTGTAAATTCGTTGACGATATGT } & 55 \\
\hline TRNYOS & \multicolumn{2}{|c|}{ GGGTCGATGCCCGAGCGGTTAATGGGGACGGACTGTAAATTCGTTGACAATATGT } & \\
\hline TRNYNT & \multicolumn{2}{|c|}{ GGGTCGATGCCCGAGCGGTTAATGGGGACGGACTGTAAATTCGTTGGCAATATGT } & \\
\hline TRNYLE & \multicolumn{2}{|c|}{ GGGTCGATGCCCGAGCGGTTAATGGGGACGGACTGTAAATTCGTTGGCAATATGT } & \\
\hline TRNYPT & \multicolumn{2}{|c|}{ GGGTCGATGCCCGAGTGGTTAATGAGGACGGACTGTAAATCCGTTGGCAATATGC } & \\
\hline TRNYMP & \multicolumn{3}{|c|}{ 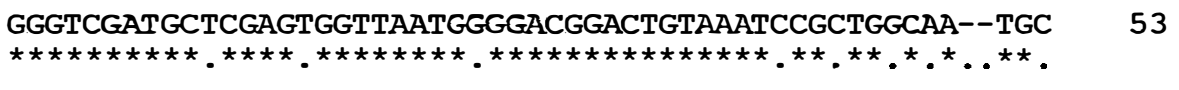 } \\
\hline TRNYZM & СTACGCTGGTTCAAATCCAGCTCGGCCCA & 84 & \\
\hline TRNYOS & CTACGCTGGTTCAAATCCAGCTCGGCCCA & 84 & \\
\hline TRNYNT & СTACGCTGGTTCAAATCCAGCTCGGCCCA & 84 & \\
\hline TRNYLE & СTACGCTGGTTCAAATCCAGCTCGGCCCA & 84 & \\
\hline TRNYPT & СTACGCTGGTTCAAATCCAGCTCGACCCA & 84 & \\
\hline TRNYMP & 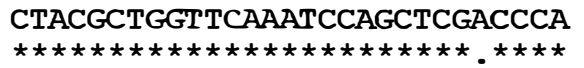 & 82 & \\
\hline
\end{tabular}

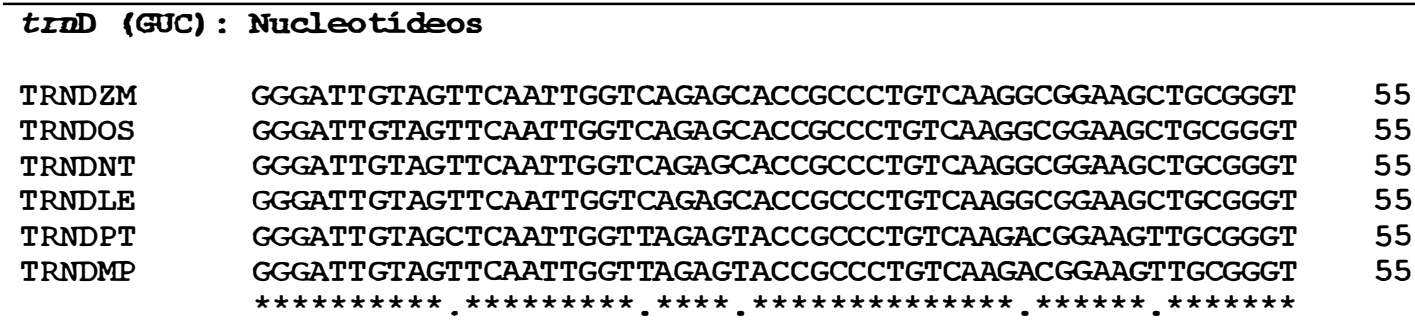

TRNDZM TCGAGCCCCGTCAGTCCCG 74

TRNDOS TCGAGCCCCGTCAGTCCCG 74

TRNDNT TCGAGCCCCGTCAGTCCCG 74

TRNDLE TCGAGCCCCGTCAGTCCCG 74

TRNDPT TCGAGTCCCGTCAGTCCCG 74

TRNDMP TCGAGCCCCGTCAATCCCG 74

\begin{tabular}{|c|c|c|}
\hline PSBMZM & ATGGAAGTAAATATTCTCGCATTTATTGCTA--CAGCATTGTTCATTCTAGTTCC & 53 \\
\hline PSBMOS & ATGGAAGTCAATATTCTCGCATTTATTGCTA--CTGCATTGTTCATTCTAGTTCC & 53 \\
\hline PSBMNT & АTGGAAGTAAATATTCTTGCATTTATTGCTA--СTGCACTATTTATTCTAGTTCC & 53 \\
\hline PSBMLE & АTGGAAGTAAATATTCTTGCATTTATTGCTA--СTGCACTATTTATTCTAGTTCC & \\
\hline PSBMPT & ATGGAAGTAAATACCCTTGCATTTATTGCTGTTCTAC--TGTTCCTTGCAGTTCC & 53 \\
\hline PSBMMP & 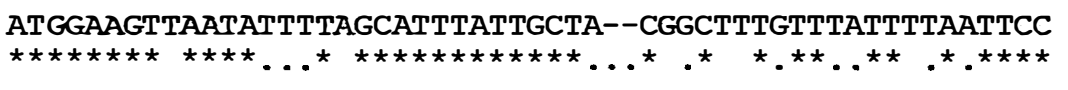 & 53 \\
\hline PSBMZM & TACTGCСTTTTTACTTATTATTTATGTAAAAACAGCCAGT-CAA--------AАT & 99 \\
\hline PSBMOS & TACTGCCTTTTTACTTATTATTTATGTAAAAACAGTCAGC-CAA--------AAT & 99 \\
\hline PSBMNT & TACСGСТTTTСТАСТTATСАTTTACGTAAАAACAGTCAGT-CAA--------AАC & 99 \\
\hline PSBMLE & TACCGCTTTTCTACTTATCATTTAtGTAAAAACAGTCAGT-CAA--------AAC & 99 \\
\hline
\end{tabular}




\begin{tabular}{|c|c|c|c|}
\hline PSBMPT & \multicolumn{2}{|c|}{ TACTGCTTTTCTACTTATCCCTTACGTCAAAACGGCCAGTGCAAGCAGTGGAAGC } & 108 \\
\hline PSBMMP & 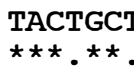 & 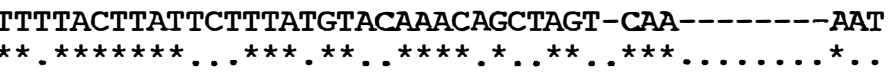 & 99 \\
\hline PSBMZM & GATT-- & 103 & \\
\hline PSBMOS & GATTAA & 105 & \\
\hline PSBMNT & GATTAA & 105 & \\
\hline PSBMLE & GATTAA & 105 & \\
\hline PSBMPT & AATTGA & 114 & \\
\hline PSBMMP & AGTTAA & 105 & \\
\hline
\end{tabular}

psbM: Aminoácidos

\begin{tabular}{|c|c|}
\hline PSBMZM & MEVNILAFIATALFILVPTAFLLI IYVKTASQN---D \\
\hline PSBMOS & MEVNILAFIATALFILVPTAFLLI IYVKTVSQN---D \\
\hline PSBMNT & MEVNILAFIATALFILVPTAFLLI IYVKTVSQN---D \\
\hline PSBMLE & MEVNILAFIATALFILVPTAFLLI IYVKTVSQN---D \\
\hline PSBMPT & MEVNTLAFIAVLLFLAVPTAFLLI PYVKTASASSGSN \\
\hline PSBMMP & $\begin{array}{l}\text { MEVNILAFIATALFILIPTAFLLILYVQTASQN---S } \\
\star \star \star \star \\
. \star \star \star \star \star\end{array}$ \\
\hline
\end{tabular}

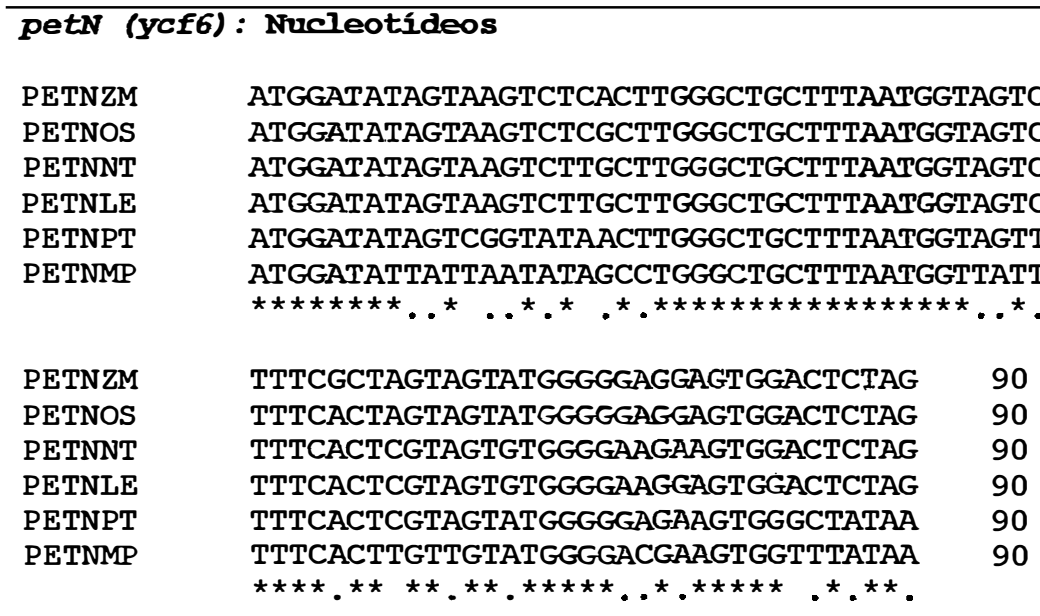

petN: Aminoácidos

\begin{tabular}{|c|c|}
\hline PETNZM & MDIVSLTWAALMVVFTFSLSLVVWGRSGL \\
\hline PETNOS & MDIVSLAWAALMVVFTFSLSLVVWGRSGL \\
\hline PETNNT & MDIVSLAWAALMVVFTFSLSLVVWGRSGL \\
\hline PETNLE & MDIVSLAWAALMVVFTFSLSLVVWGRSGL \\
\hline PETNPT & MDIVGITWAALMVVFTFSLSLVVWGRSGL \\
\hline PETNMP & 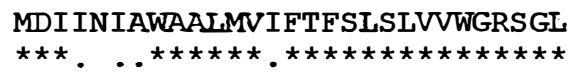 \\
\hline
\end{tabular}

tIAC (GCA) : Nucleotídeos

TRNCZM GGCGGCATGGCCAAGTGGTAAGGCAGGGGACTGCAAATCCTTTAC-CCCCAGTTC TRNCOS GGCGGCATGGCCAAGCGGTAAGGCAGGGGACTGCAAATCCTTTAT-CCCCAGTTC TRNCNT GGCGACATGGCCGAGTGGTAAGGCAGAGGACTGCAAATCCTTTTTTCCCCAGTTC TRNCLE TRNCPT GGCGACATGGCCGAGTGGTAAGGCAGAGGACTGCAAATCCTTTTTTCCCCAGTTC GGCGACATAGCCAAGCGGTAAGGCAGAGGACTGCAAATCCTCCAT-CCCCAGTTC GGCGACATGGCCAAGTGGTAAGGCAGAGGACTGCAAATCCTTTAT-CCCCAGTTC 


$\begin{array}{lll}\text { TRNCZM } & \text { AAATCTGGGTGCCGCCT } & 71 \\ \text { TRNCOS } & \text { AAATCTGGGTGCCGCCT } & 71 \\ \text { TRNCNT } & \text { AAATCCGGGTGTCGCCT } & 72 \\ \text { TRNCLE } & \text { AAATCCGGGTGTCGCCT } & 72 \\ \text { TRNCPT } & \text { GAATCCGGGTGTCGCCT } & 71 \\ \text { TRNCMP } & \text { AAATCTGGGTGTCGCTT } & 71 \\ & . \star \star \star \star . \star \star \star \star \star \star \star \star \star . ~ & \end{array}$

IpoB : Nucleotídeos

RPOBZM ATGCTCCGGAATGGAAATGAGGGAATGTCCACAATACCCGGATTTAGTCAGATCC RPOBOS ATGCTCCGGAATGGAAATGAGGGAATGTCCACAATACCCGGATTTAGTCAGATCC RPOBNT ATGCTCGGGGATGGAAATGAGGGAATATCTACAATACCTGGATTTAATCAGATAC RPOBLE RPOBMP ATGCTCGGGGATGGAAATGAGGGAATATCTACAATACCTGGATTTAATCAGATAC ------------ATGGAGATTTTTATACTCCCTGAATTTGGTAAAATAC

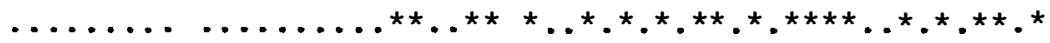

RPOBZM RPOBOS RPOBNT RPOBLE RPOBMP

RPOBZM RPOBOS RPOBNT RPOBLE RPOBMP

RPOBZM RPOBOS RPOBNT RPOBLE RPOBMP

RPOBZM RPOBOS RPOBNT RPOBLE RPOBMP

RPOBZM RPOBOS RPOBNT RPOBLE RPOBMP

RPOBZM RPOBOS RPOBNT RPOBLE RPOBMP

AATTCGAGGGATTTTGTAGATTCATTAATCAAGGCTTGGCGGAAGAACTTGAGAA AATTCGAGGGATTTTGTAGGTTCATTAATCAAGGCTTGGCAGAAGAACTTGAGAA AATTTGAAGGATTTTGTAGGTTCATTGATCAAGGTTTGACGGAAGAACTTTATAA AATTTGAAGGATTTTGTAGGTTCATTGATCAAGGTTTGACGGAAGAACTTTATAA AATTTGAAGGATTTAATCGTTTTATAAATCAAGGTTTGAGTGAAGAACTTAGTAA

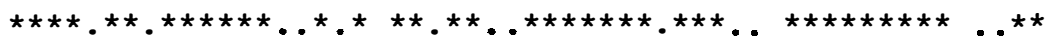

GTTTCCCACAATTAAAGATCCAGATCACGAAATTGCATTTCAATTATTTGCGAAA 165 GTTTCCAACAATTAAAGATCCAGATCACGAAATTTCATTTCAATTATTTGCGAAA 165 GTTTCCAAAAATTGAAGATACAGATCAAGAAATTGAATTTCAATTATTTGTGGAA GTTTCCAAAAATTGAAGATACAGATCAAGAAATTGAATTTCAATTATTTGTGGAA TTTTCCAATAATTGAAGATATAGATCAAGAATTCGAGTTTCAAATATTTGGTGAA

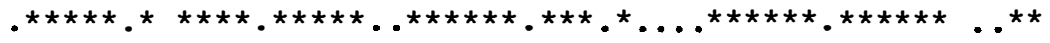

GGATATCAATTGCTAGAACCCTCGATAAAAGAAAGGAATGCTGTGTATGAATCAC GGATATCAATTGCTAGAACCTTCGATAAAAGAAAGGGATGCTGTGTATGAATCAC ACATATCAATTGGTCGAACCCTTGATAAAGGAAAGAGATGCTGTGTATGAATCAC ACATATCAATTGGTCGAACCCTTGATAAAGGAAAGAGATGCTGTGTATGAATCAC CAATATAAATTAGCAGAACCATTATTAAAAGAAAGAGATGCCGTCTATCAATCTA

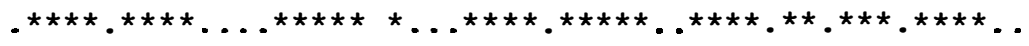

TCACCTATTCTTCCGAATTATATGTATCCGCGAGATTAATTTT------TGGTTT TCACCTATTCTTCCGAATTATACGTATCCGCGCGATTAATTTT------TGGTTT TCACATATTCTTCTGAATTATATGTATCCGCGGGATTAATTTGGAAAAACAGTAG TCACATATTCTTCTGAATTATATGTATCCGCGGGATTAATTTGGAAAAACAGTAG TTACCTATTCATCCGACGTTTACGTACCAGCTCAATTAACACAAAAAAAAAAAGG

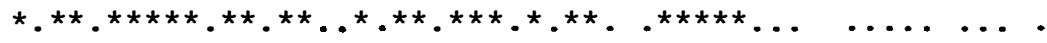

CGATGTGCAAAAGGAAACCATTTCTATTGGAAACATTCCTATAATGAATTCCTTA CGATGTGCAAAAGCAAACCATTTCTATTGGAAACATTCCTATAATGAATTCCTTA GGATATGCAAGAACAAACAATTTTTATCGGAAACATTCCTCTAATGAATTCCCTG GGATATGCAAGAACAAACAATTTTTATCGGAAACATTCCTCTAATGAATTCCCTG AAAAATACAAAAACAAATAGTTTTTCTTGGAAGTATTCCTTTAATGAATTCTCAA

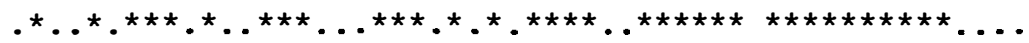

GGAACCTTTATAATAAATGGAATATACCGAATTGTGATCAATCAAATATTGCTAA GGAACCTTTATAATAAATGGAATATACCGAATTGTGATCAATCAAATATTGCTAA GGAACTTCTATAGTCAATGGAATATATAGAATTGTGATCAATCAAATATTGCAAA GGAACT TCTATAGTCAATGGAATATATAGAATTGTGATCAATCAAATATTGCAAA GGTACTTTTGTTGTTAATGGAGTAGCTCGAGTTATAATTAATCAAATTTTACGAA

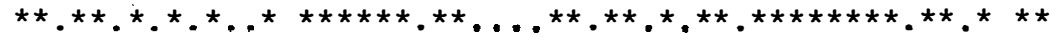
110 110 110 110 
RPOBZM RPOBOS RPOBNT RPOBLE RPOBMP

RPOBZM RPOBOS RPOBNT RPOBLE RPOBMP

RPOBZM RPOBOS RPOBNT RPOBLE RPOBMP

RPOBZM RPOBOS RPOBNT RPOBLE RPOBMP

RPOBZM RPOBOS RPOBNT RPOBLE RPOBMP

RPOBZM RPOBOS RPOBNT RPOBLE RPOBMP

RPOBZM RPOBOS RPOBNT RPOBLE RPOBMP

RPOBZM RPOBOS RPOBNT RPOBLE RPOBMP
GTCCTGGTATTTACTACCGCTCGGAATTAGACCATAAGGGAATTTCTATATATAC GTCCTGGTATTTACTACCGCTCGGAATTAGACCATAAAGGAATTTCTATCTACAC GTCCCGGTATTTATTACCGATCAGAATTGGACCATAACGGAATTTCGGTCTATAC GTCCCGGTATTTATTACCGATCAGAATTGGACCATAACGGAATTTCGGTCTATAC GTCCCGGAATTTATTATAATTCAGAATTAGATCATAACGGAATTCCTATATATAC

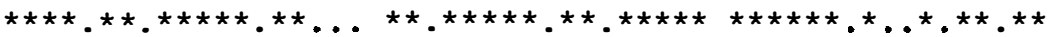

CGGGACTATAATATCAGATTGGGGAGGAAGGTCGGAATTAGCAATTGATAAAAAA CGGGACTATAATATCAGATTGGGGAGGAAGATCGGAATTAGCAATTGATAAAAAA CGGCACCATAATATCAGATTGGGGAGGAAGATCAGAATTAGAAATTGATAGAAAA CGGCACCATAATATCAGATTGGGGAGGAAGATCAGAATTAGAAATTGATAGAAAA TGGAACGTTAATTTCCAATTGGGGAGGAAGACTAAAATTAGAAATTGATGGAAAA

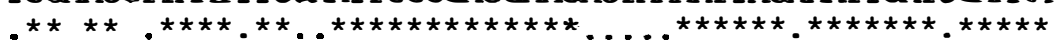
(158)

GAAAGGATATGGGCTCGCGTGAGTAGAAAACAAAAGATATCTATTTTAGTTCTAT GAAAGGATATGGGCTCGCGTGAGTAGAAAACAAAAGATATCTATTCTAGTTCTAT GCAAGGATATGGGCTCGTGTAAGTAGGAAACAAAAAATATCTATTCTAGTTCTAT GCAAGGATATGGGCTCGTGTAAGTAGGAAACAAAAAATATCTATTCTAGTTCTAT ACAAGAATATGGGCACGTATAAGTAAAAAAAGAAAAGTTTCTATTTTAGTTTTAT

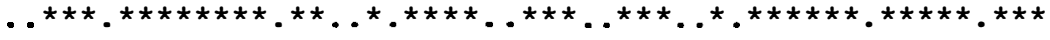

CATCAGCTATGGGTTCGAATCTAAGAGAAATTTTAGATAATGTTTCCTACCCCGA CATCAGCTATGGGTTCAAATCTAAAAGAAATTCTAGATAATGTTTCCTACCCTGA CATCAGCTATGGGTTTGAATCTAAGAGAAATTCTAGAGAATGTTTGCTATCCTGA CATCAGCTATGGGTTTGAATCTAAGAGAAATTCTAGAGAATGTTTGCTATCCTGA TATTAGCTATGGGTTTAAATTTACAAAATATTTTAGACAGTGTTTGTTATCCTAA

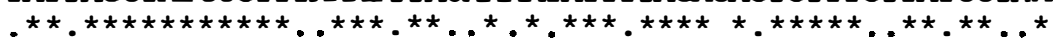

AATTTTCTTGTCTTTCCCGAATGCTAAGG-AGAAGAAGAGGATT--GAGTCAAAA AATTTTCTTGTCTTTCCCTAATGCTAAGG-AGAAGAAGAGGATT--GAGTCAAAA AATTTTTTTGTCTTTTCTGAGTGATAAGG-AGAGAAAAAAAATT--GGGTCAAAA AATTTTTTTGTCTTTTCTGAATGATAAGG-AGAGAAAAAAAATT--GGGTCAAAA AАTTTTTTTAGAGTTTATAAAAAAAAACACAAAAAAAGAATATCCGAATTCAACA

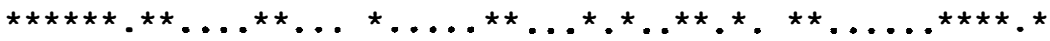

GAAAAAGCTATTTTGGAGTTTTATCAACAATTTGCTTGTGTAGGTGGGGACCTGG GAAAAAGCTATTTTGGAGTTTTATCAACAATTTGCTTGTGTAGGTGGGGACCTGG GAAAATGCCATTTTGGAGTTTTATCAACAATTTGCTTGTGTAGGTGGCGATCCGG GAAAAT tCCATTTTGGAGTTTTATCAACAATTTGCTTGTGTAGGTGGCGATCCGG GAAGACGCTATAGTGGAACTTTATAAACACCTATATTGCATAGGTGGAGATCTTT

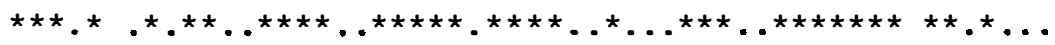

TATTTTCGGAGTCCTTATGCGAGGAATTACAAAAGAAATTTTTTCAACAAAAATG TATTTTCGGAATCCTTATGTGAGGAATTACAAAAGAAATTTTTTCAACAAAAATG TATTTTCTGAATCCTTATGTAAGGAATTACAAAAGAAATTCTTTCAACAAAGATG TATTTTCTGAATCCTTATGTAAGGAATTACAAAAGAAATTCTTTCAACAAAGATG TTTTTTCTGAATCGATACGCAAAGAATTACAAAAAAAATTTTTTCAACAGAGATG

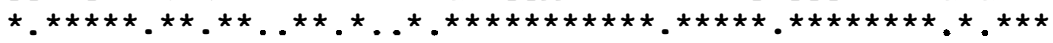

TGAATTAGGAAGAGTTGGTCGAC TGAATTAGGAAGGATTGGTCGAC TGAATTAGGAAGGATTGGTCGAC TGAATTAGGAAGGATTGGTCGAC 784 784 790 790 TGAGTTAGGCAAAATTGGACGAT 775

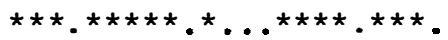

761 761 767 767 752.

\section{IPOB: Aminoácidos}




\begin{tabular}{|c|c|c|}
\hline RPOBOS & MLRNGNEGMSTI PGFSQIQFEGFCRFINQGLAEELEKFPTIKDPDHEISFQLFAK & 55 \\
\hline RPOBNT & MLGDGNEGISTI PGENQIQFEGFCRFIDQGLTEELYKF PKIEDTDQEIEFQLFVE & 55 \\
\hline RPOBLE & MLGDGNEGISTI PGFNQIQFEGFCRFIDQGLTEELYKFPKIEDTDQEIEFQLFVE & 55 \\
\hline RPOBPT & MRLDENEGAFTI PEFGKIQFEGFCRFI DQGIMEELHNF PKIEDIDKEIEFRLFGN & 55 \\
\hline RPOBMP & 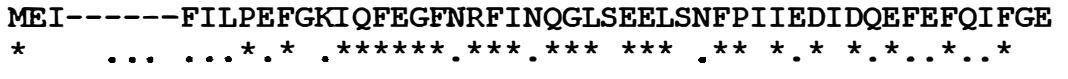 & 49 \\
\hline RPOBZM & GYQLLEPSIKERNAVYESLTYSSELYVSARLIF--GFDVQKETISIGNI PIMNSL & 108 \\
\hline RPOBOS & GYQLLEPS IKERDAVYESLTYSSELYVSARLI F--GFDVQKQTISIGNI PIMNSL & 108 \\
\hline RPOBNT & TYQLVE PLIKERDAVYESLTYSSELYVSAGLIWKNSRDMQEQTIFIGNI PLMNSL & 110 \\
\hline RPOBLE & TYQLVE PLIKERDAVYESLTYSSELYVSAGLIWKNSRDMQEQTIFIGNI PIMNSL & 110 \\
\hline RPOBPT & EYELAEPFIKERDAVYQSLTYYSELYVPARSIRRNSRKIQKQTVFLGNIPLMNSH & 110 \\
\hline RPOBMP & 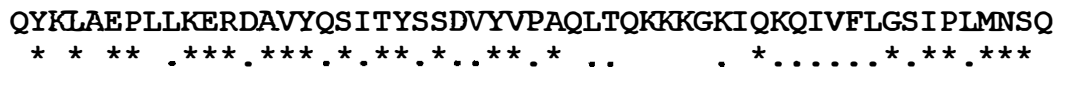 & 104 \\
\hline RPOBZM & GTFI INGIYRIVINQILLSPGIYYRSELDHKGIS-IYTGTI ISDWGGRSELAIDK & 162 \\
\hline RPOBOS & GTFI INGIYRIVINQI LLSPGIYYRSELDHKGIS-IYTGTI ISDWGGRSELAIDK & 162 \\
\hline RPOBNT & GTSIVNGIYRIVINQILQS PGIYYRSELDHNGIS-VYTGTI ISDWGGRSELEIDR & 164 \\
\hline RPOBLE & GTSIVNGIYRIVINQILQSPGIYYRSELDHNGIS-VYTGTI ISDWGGRSELEIDR & 164 \\
\hline RPOBPT & GTFVVNGIYRVVVNQILIS PGIYYRSELDHNRINYIYTGTLISDWGRRSKLEIDV & 165 \\
\hline RPOBMP & 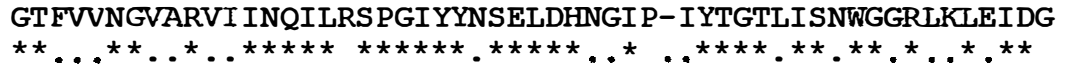 & 158 \\
\hline RPOBZM & KERIWARVSRKQKISILVLSSAMGSNLREILDNVSYPEIFLSFPNAKEKKRIE-- & 215 \\
\hline RPOBOS & KERIWARVSRKQKISILVLSSAMGSNLKEILDNVSYPEI FLSF PNAKEKKRIE-- & 215 \\
\hline RPOBNT & KARIWARVSRKQKISILVLSSAMGLNLREILENVCYPEIFLSFLSDKERKKIG-- & 217 \\
\hline RPOBLE & KARIWARVSRKQKISILVLSSAMGLNLREILENVCYPEIFLSFINDKERKKIG-- & 217 \\
\hline RPOBPT & GERIWARVSRKQKISI PVLLSAMGLNLEEILDNTRYPERFLFLLKKKGRWEREEY & 220 \\
\hline RPOBMP & 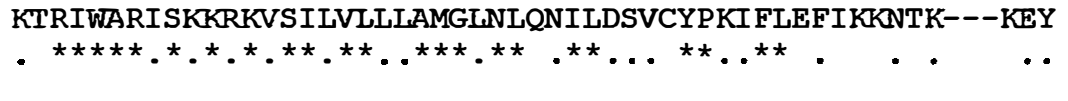 & 210 \\
\hline $\begin{array}{l}\text { RPOBZM } \\
\text { RPOBOS }\end{array}$ & $\begin{array}{l}\text {--SKEKAILEFYQQFACVGGDLVFSESLCEELQKKFFQQKCELGRVGRRNMNRRL } \\
\text {--SKEKAILEFYQQFACVGGDLVFSESLCEELQKKFFQQKCELGRIGRRNMNRRL }\end{array}$ & $\begin{array}{l}268 \\
268\end{array}$ \\
\hline RPOBNT & - -SKENAILEFYQQFACVGGDPVFSESLCKELQKKFFQQRCELGRIGRRNMNRRL & 270 \\
\hline RPOBLE & --SKENSILEFYQQFACVGGDPVFSESLCKELQKKFFQQRCELGRIGRRNMNRRL & 270 \\
\hline RPOBPT & LWSREKAILEFYKKUYCISGDLVFSESLCKELQKKFFRKRCELGKIGRRNLNQKL & 275 \\
\hline RPOBMP & 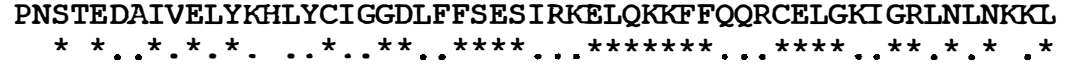 & 265 \\
\hline
\end{tabular}

\section{Ip120: Nucleotídeos}

RPL20ZM ATGACCAGAGTTCCGCGAGGATATATAGCTCGGAGACGACGAACAAAAATGCGTT RPL200S RPL20NT RPL20LE RPL20PT RPL20MP ATGACCAGAGTTCCGCGAGGATATATAGCTCGGAGACGACGGGCAAAAATGCGTT ATGACCAGAATTAAACGGGGATATATAGCTCGGAGACGTAGAACAAAAATTCGTT ATGACCAGAATTAAACGGGGATATATAGCTCGGAGACGTAGAACAAAAATTCGTT ATGACCAGAGTGAAACGTGGATATATAGCTCGAAAACGTCGGAAAAAAATTCTTG ATGACTAGAGTTAAACGTGGTTATGTAGCACGAAAACGGCGTAAAAATATTCTTA

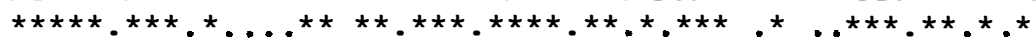

RPL20ZM RPL200S RPL20NT RPL20LE RPL20PT RPL20MP

RPL20ZM RPL200S RPL20NT
САTTTGCСTCAAACTTTAGGGGGGCTCATTTAAGACTTAATCGAGTGATTACTCA CATTTGCCTCAAACTTTAGAGGGGCTCATTTAAGACTTAATCGAATGATTACTCA TATTTGCATCAAGCTTTCGGGGGGCTCATTCAAGGCTTACTCGAACTATTACTCA TATTTGCATCAAGCTTTCGaGGGGCTCATTCAAGGCTTACTaGAACTATTACTCA CATTTGTATCAGGCTCTCGAGGGGCCCATTCGAAACTTTTTCGAACTGCTAACCA CGСTTACATCTGGATTTCAAGGAACTCATTCGAAACTTTTTAGAACTGCTAATCA

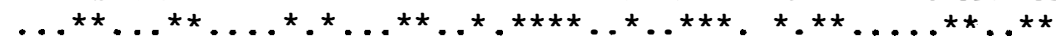
ACAAGTAAGAAGAGCTTTTGTTTCTTCTCATCGAGATAGAGGCAGGCAAAAGAGG ACAGGTAAGAAGAGCGTTTGTTTCCTCTCATCGAGATAGAGTCAGGCAAAAGAGG ACAGAAAATAAGAGCTTTAGTTTCGGCTCATCGGGATAGGGATAGGAAAAAGAGA 


\begin{tabular}{|c|c|c|}
\hline RPL20LE & ACAGAAAATAAGAGCTTTAGTTTCGGCTCATCGGGATAGGGATAGGAAAAAGAGA & 165 \\
\hline RPL20PT & ACGGAAAGCTAGAGCCTTAGTTTCCGCCCACCGAGATAGAGGTAAACGCAAGAGA & 165 \\
\hline \multirow[t]{2}{*}{ RPL20MP } & ACAAGGAATGAGAGCATTAGCATCATCTCATCGCGATAGAGGTAAACGAAAAAGA & 165 \\
\hline & 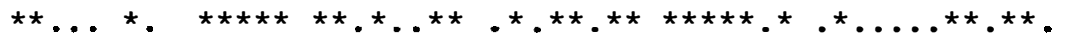 & \\
\hline RPL20ZM & GATTTTCGTCGTTTGTGGATCACTCGGATAAACGCAGCAACACGGGTATATAACG & 220 \\
\hline RPL200S & GATTTTCGGCGTTTGTGGATCAGTCGGATAAACGCAGCAACGCGGATACATAAAG & 220 \\
\hline RPL2 ONT & GATTTTCGTCGTTTGTGGATCACTCGGATAAACGCAGTAATTCGCGAAAGGGGAG & 220 \\
\hline RPL20LE & GATTTTCGTCGTTTGTGGATCACTAGGATAAACGCAGTAATTCGCGAAAGGGGAG & 220 \\
\hline RPL20PT & GATCTTCGTCGTTTGTGGATTACTCGGATCAATGCAGCAGCTCGTGCCAATGGGG & 220 \\
\hline \multirow[t]{2}{*}{ RPL20MP } & ААTCTTAGACGTTTATGGATTACTCGAGTTAATGCAGCCGCAAGAGATAATGGAA & 220 \\
\hline & 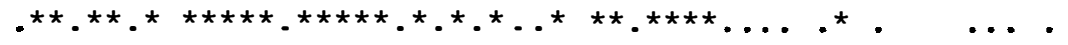 & \\
\hline RPL20ZM & TATTCAАTAGTTATAGTAАATTAATACACAATCTGTCCAAGAAGGAATTGATTCT & 275 \\
\hline RPL200S & TATTCGATAATTATAGTAAATTAATACACAATCTTTACAAGAAAGAATTGATTCT & 275 \\
\hline RPL20NT & TATCCTATAGTTATAGTAGATTAATACACGATCTGTACAAGAGACAGTTGCTTCT & 275 \\
\hline RPL20LE & TATССТATAGTTATAGTAGATTAATACACGATCTGTACAAGAGACAGTTGСTTCT & 275 \\
\hline RPL20PT & TTTСTTATAАT------AGATTCATCCAATATTTGTACAAGAGGCAGTTGCTTCC & 269 \\
\hline \multirow[t]{2}{*}{ RPL2OMP } & ТTТССТАТААТ------АААТТААТTGААТАТTТАТАТААААААААААТTСТTТT & 269 \\
\hline & 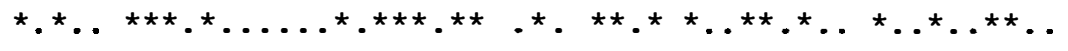 & \\
\hline RPL20ZM & TAATCGTAAAATGCTTGCACAAGTAGCTGTATCAAATCСАААTAАTСТTTA---- & 326 \\
\hline RPL200S & TAATCGTAAAATCCTTGCACAAGTAGCTGTATTAAATTCAAATAATCTTTA---- & 326 \\
\hline RPL20NT & 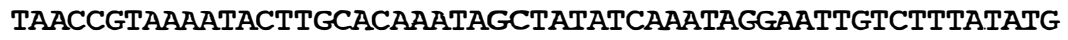 & 330 \\
\hline RPL20LE & TAACCGTAAAATACTTGCACAAATAGCTATATCAAATAGGAATTGTCTTTATATG & 330 \\
\hline RPL20PT & AAATCGTAAAACACTTGCACAAATAGCTGTATTAGATAGTAATTGCTTTTCCA-- & 322 \\
\hline \multirow[t]{2}{*}{ RPL2 OMP } & AАATAGAAAAATTCTAGCTCAAATAGCTATATTAGATAAATTTTGTTTTTCGA-- & 322 \\
\hline & 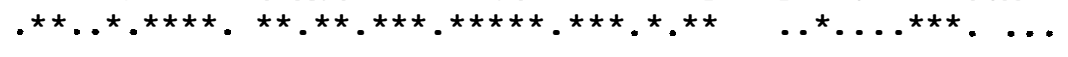 & \\
\hline RPL20ZM & ----C--ACGATTTCCAATAAAATAAGGATC-------ATC---------AAT- & 357 \\
\hline RPL200S & ----C--ACGATTTCCAATAAAATAAAGATT-------ATC---------AATT & 35 \\
\hline RPL20NT & ATTTCGAACGAAATCATAAAGGAAGTAGATTGGAAAGAATCCACCAGAATAATTT & \\
\hline RPL2OLE & ATTTCGAACGAAATCATAAAGGAAGTAGATTGGAAAGAATCCACCAGAATAATTT & 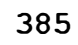 \\
\hline RPL20PT & ----CСАTCTTTAАСАACTTATCGTATGATGAAATAGGTT------------ & 358 \\
\hline \multirow[t]{2}{*}{ RPL2 OMP } & ----СААТААТТАА---------АААТАТТ АТТАСАGАAT-------------- & 349 \\
\hline & . $\ldots{ }^{\star} \quad \ldots . * \ldots \ldots \ldots \ldots$ & \\
\hline RPL20ZM & 357 & \\
\hline RPL20OS & 360 & \\
\hline RPL2ONT & 387 & \\
\hline RPL2 OLE & 387 & \\
\hline RPL20PT & AG $\quad 360$ & \\
\hline RPL2OMP & AA 351 & \\
\hline
\end{tabular}

\section{Ip120: Aminoácidos}

RPL20ZM RPL200S RPL20NT RPL2OLE RPL2 OPT RPL2 OMP

RPL20ZM RPL200S RPL2 ONT RPL2 OLE
MTRVPRGYIARRRRTKMRSFASNFRGAHIRINRVITQQVRRAFVSSHRDRGRQKR MTRVPRGYIARRRRAKMRSFASNFRGAHLRUNRMITQQVRRAFVSSHRDRVRQKR MTRIKRGYIARRRRTKIRLFASSFRGAHSRLTRTITQQKIRALVSAHRDRDRKKR MTRIKRGYIARRRRTKIRLFASSFRGAHSRLTRTITQQKIRALVSAHRDRDRKKR MTRVKRGYIARKRRKKILAFVSGSRGAHSKLFRTANQRKARALVSAHRDRGKRKR MTRVKRGYVARKRRKNILTLTSGFQGTHSKLFRTANQQGMRALASSHRDRGKRKR

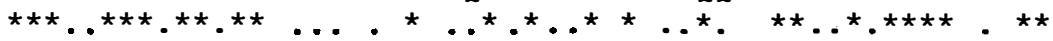
DFRRLWISRINAATRIHKVFDNYSKT IHNTYKKT DFRRLWITRINAVIRERGVSYSYSRL IHDL YKRQLLLNRKIIAQIAISNRNCLYM DFRRLWITRINAVIRERGVSYSYSRLIHDLYKRQLLLNRKILAQIAISNRNCLYM 


\begin{tabular}{|c|c|c|c|}
\hline \multirow{3}{*}{$\begin{array}{l}\text { RPL20PT } \\
\text { RPL20MP }\end{array}$} & \multicolumn{2}{|c|}{ DLRRLWITRINAAARANGV--SYNRF IQYLYKRQLLPNRKTLAQIAVLDSNCFST } & \multirow{2}{*}{$\begin{array}{l}108 \\
108\end{array}$} \\
\hline & \multicolumn{2}{|c|}{ NLRRLWITRVNAAARDNGI--SYNKL IEYLYKKKILLNRKI LAQ̃IAI LDKFCFST } & \\
\hline & 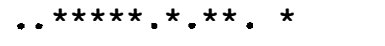 & 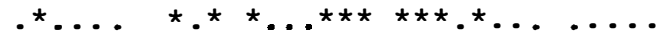 & \\
\hline RPL20ZM & ISNKI--------RIIN & 119 & \\
\hline RPL200S & ISNKI----- - KIIN & 119 & \\
\hline RPL20NT & ISNEIIKEVDWKESTRII- & 126 & \\
\hline RPL20LE & ISNEI IKEVDWKESTRII- & 126 & \\
\hline RPL20PT & I ENNLSYDE--------IG & 119 & \\
\hline RPL20MP & IIKNIITE----- - - - & 116 & \\
\hline & $\ldots \ldots \ldots$ & & \\
\hline
\end{tabular}

5'Ips12: Nucleotídeos

RPS12ZM ATGCCAACGGTTAAACAACTTATTAGAAATGCAAGACAGCCAATACGAAATGCTA RPS120S ATGCCAACGGTTAAACAACTTATTAGAAACGCAAGACAGCCAATACGAAATGCTA RPS12NT RPS12LE RPS12PT RPS12MP ATGCCAACTATTAAACAACTTATTAGAAATACAAGACAGCCAATCAGAAATGTCA ATGCCAACTATTAAACAACTTATTAGAAATACAAGACAGCCAATCAGAAATGTCA ATGCCCACTATTCAACAACTTATTAGAAATGCAAGACAGCCAATAGAGAATAGAA ATGCCTACTATTCAACAATTAATTAGAAATAAAAGACAACCCATCGAAAATAGAA

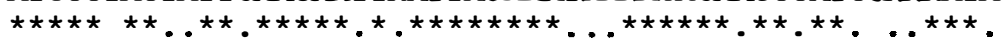

55

55

55

55

55

55

RPS12ZM

RPS120S

RPS12NT

RPS12LE

RPS12PT

RPS12MP

RPS12ZM

RPS120S

RPS12NT

RPS12LE

RPS12PT

RPS12MP
GAAAATCGGCCGCGCTTAAGGGATGTCCTCAGCGTCGAGGAACATGTGCTAGGGT GAAAATCGGCCGCGCTTAAGGGATGTCCTCAGCGTCGAGGAACATGTGCTAGGGT CGAAATCCCCCGCTCTTCGGGGCTGTCCTCAGCGTCGAGGAACATGTACTAGGGT CGAAATCCCCCGCTCTTCGGGGGTGCCCTCAGCGTCGAGGAACATGTACTAGGGT CAAAATCACCAGCCCTTAAAGGATGCCCTCAACGTAGAGGAGTATGTACTAGAGT

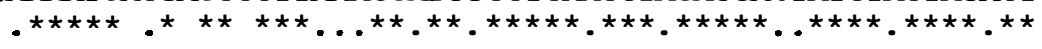

GTAT 114

GTAT 114

GTAT 114

GTAT 114

GTAT 114

GTAT 114 AAAAATCTCCTGCTCTTCGAGGATGTCCTCAGCGTAGAGGAGTATGTGCTAGGGT
110

110

110

110

110

110

\footnotetext{
5'Ips12: Aminoácidos

RPS12ZM MPTVKQLIRNARQPIRNARKSAALKGCPQRRGTCARVY 38

RPS12OS MPTVKQLIRNARQPIRNARKSAALKGCPQRRGTCARVY MPTIKQLIRNTRQP IRNVTKS PALRGCPQRRGTCTRVY MPTIQQLIRNARQPIENRKKSPALRGCPQRRGVCARVY MPTIQQLIRNKRQPIENRTKSPALKGCPQRRGVCTRVY RPS12PT RPS12MP

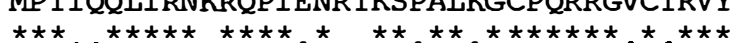
38 38 38 38
}

\section{cIpP : Nucleotídeos}

CLPP ZM

CLPPOS

CLPPNT

CLPPLE

CLPPPT

CLPPMP

CLPPZM CLPPOS
ATGCCCATTGGTGTTCCAAAAGTACCTTACCGGATTCCCGGAGATGAAGAAGCGA ATGCCCATTGGTGTTCCAAAAGTACCTTACCGGATTCCCGGAGATGAAGAAGCGA ATGCCTATTGGTGTTCCAAAAGTCCCTTTCCGAAGTCCTGGAGAGGAAGATGCAT ATGCCTATTGGTGTTCCAAgAGTtgtaTTCCGAAaTCCTGGAGAtCCAatTtCAT ATGCCCGTTGGTGTTCCAAAAGTGCCTTTCCGAGCCCCTGGAGATGAAGATGCAA ATGCCTATTGGTGTTCCGAAAGTTCCTTTTCGTCTCCCAGGAGAAGAAGATGCTG

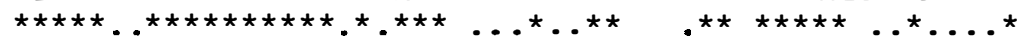

CTTGGGTTGACTTATACAATGTTATGTATCGAGAAAGGACACTTTTTTTAGGTCA CTTGGGTTGACTTATACAATGTTATGTATCGAGAAAGGACACTTTTTTTAGGTCA 


\begin{tabular}{|c|c|c|}
\hline CLPPNT & CTTGGGTTGACGTATACAACCGACTTTATCGAGAAAGATTACTTTTTTTAGGCCA & 110 \\
\hline CLPPLE & СTTGGGTTGACаTATACAACCGACTTTATCGAGAAAGATTACTTTTTTTAGGCCA & 110 \\
\hline CLPPPT & СTTGGGTCGACTTATACAACCGACTTTATCGAGAGAGATTACTTTTTTTGGCTCA & 110 \\
\hline \multirow[t]{2}{*}{ CLPPMP } & TTTGGATTGACGTATAAAGGGTTATGATTCATCAACCTGC--------TAGTTCT & 102 \\
\hline & 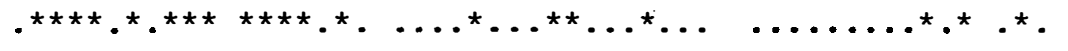 & \\
\hline CLPPZM & AGAGATTCGTTGCGAGATCACAAATCATATTACAGGTCTGATGGTATATCTCAGT & 165 \\
\hline CLPPOS & AGAGATTCGTTGCGAGGTCACGAATCATATTACAGGTCTCATGGTATATCTCAGT & 165 \\
\hline CLPPNT & AGAGGTTGATAGCGAGATTTCGAATCAACTTATTGGTCTTATGGTATATCTCAGT & 165 \\
\hline CLPPLE & AGgGATTGgTACCGAGCTTTCGAATCAACTTATTGGTCTTATGtTgTATCTCAGT & 165 \\
\hline CLPPPT & GGATATCAATCACGAGATTGCAAATCAACTCATGGGTCTCATGGTÄTATTTGAGT & 165 \\
\hline \multirow{3}{*}{ CLPPMP } & TATTATGATGGACAAGCTGGAGAATGTATTATGGAAGCAGAAGAAGTTTTGAAAC & 158 \\
\hline & 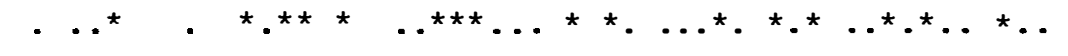 & \\
\hline & $\cdot$ & \\
\hline CLPPZM & ATAGAAGATGGAAATAGCGATATTTTTTTGTTTATAAATTC----CCTTGGCGGT & 216 \\
\hline CLPPOS & ATAGAAGATGGAAGTAGCGATATTTTTTTGTTTATAAACTC----CCCCGGCGGT & 216 \\
\hline CLPPNT & ATCGAGGATGAGACCAAAGATCTGTATTTGTTTATAAACTC----TCCTGGGGGC & 216 \\
\hline CLPPLE & ATgGAGGATGAGAaCAAAGACCTGTATTTGTTTGTAAACTC----TCCTGGGGGC & 216 \\
\hline CLPPPT & GCAGAAGATTCAAATAAAGATATTTTCTCATTTATCAACTG----TCCCGGTGGA & 216 \\
\hline \multirow[t]{2}{*}{ CLPPMP } & TTCGTGATTG--TATTACTAAAGTTTATGTACAAAGAACTGGTAAACCTTT---A & 205 \\
\hline & 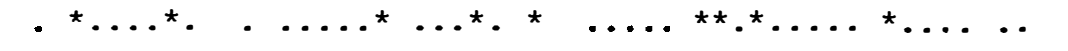 & \\
\hline CLPPZM & TGGCTAATCTCAGGAATGGCGATTTTTGATACGATGCAAACGGTGACACСTGATA & 271 \\
\hline CLPPOS & TGGTTAATCTCAGGAATGGCGATTTTTGATACGATGCAAACGGTAACACCAAATA & 271 \\
\hline CLPPNT & TGGGTAATACCTGGGGTGGCTATTTATGATACTATGCAATTTGTGCGACCAGATG & 271 \\
\hline CLPPLE & TGGGTAATACCTGGGaTCGCCATTTATGATACTATGCAATTTGTGCGACCAGATa & 271 \\
\hline CLPPPT & TCAGTAATACCAGGGGTAGGTCTTTTCGATATGATGCAAGCAATAGTACCAGATG & 271 \\
\hline \multirow[t]{2}{*}{ CLPPMP } & TGGGTAATTTCTGAAGATATGGAAAGAGATGTTTTTATGTCAGCAAAAGAAGCAA & 260 \\
\hline & 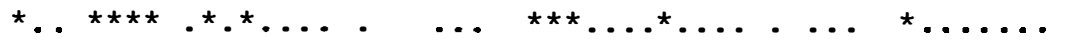 & \\
\hline CLPPZM & TATATACAATATGCCTCGGAATAGCCGCGTCCATGGCCTCCTTCATTCTGCTTGG & 326 \\
\hline CLPPOS & TATATACAACATGCCTAGGAATAGCCGCGTCCATGCCGTCCTTCATTCTGCTTGG & 326 \\
\hline CLPPNT & TCCATACAATATGCATGGGATTAGCCGCTTCAATGGGATCTTTTATCCTGGTCGG & 326 \\
\hline CLPPLE & TCCATACAATATGCcTaGGATTAGCtGCTTCAATGGGATCTTTTATCCTGGCCGG & 326 \\
\hline CLPPPT & TACATACAATATGCATGGGGGTAGCTGCTTCAATGGGATCTTTCATCCTAATCGG & 326 \\
\hline \multirow[t]{2}{*}{ CLPPMP } & ААСTTTATGGTATTGTAGACTTAGTTGCTA--TAGAAAACAATTCTACTATTAАA & 313 \\
\hline & 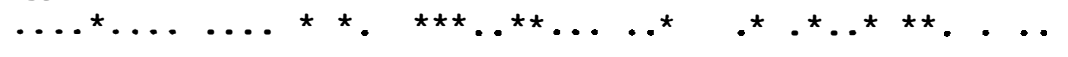 & \\
\hline CLPPZM & AGGAGAACCCACCAAGCGTATAGCATTCCCTCACGCTAGG------ATTATGCTT & 375 \\
\hline CLPPOS & AGGAGAACCCACCAAGCGTATAGCATTCCCCCACGCGAGG------ATTATGCTT & 375 \\
\hline CLPPNT & AGGAGAAATTACCAAACGTCTAGCATTCCCTCACGCTAGGGTAATGATCCATCAA & 381 \\
\hline CLPPLE & AGGACAACTTACCAAACGTATAGCATTCCCTCACGCTAGGGTAATGAT-A---- & 375 \\
\hline CLPPPT & GGGAGAAATGCCTAAACGTATAGCATTACCTCACGCTAGG------ATTATGATC & 375 \\
\hline \multirow[t]{2}{*}{ CLPPMP } & AATTAG------CAATCGA----СTTTA--TCGTGAAAGATTACTTTTTTTA--- & 347 \\
\hline & 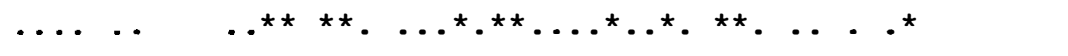 & \\
\hline CLPPZM & САССААССTGCTAGTGCTTATTATCGGGCAAGGACACCAGAATTTTTACTAGAAG & 430 \\
\hline CLPPOS & САCCAACCTGCTAGTGCTTATTATCGGGCAAGAACACCAGAATTTTTACTAGAAG & 430 \\
\hline CLPPNT & -----CСTGCTAGTTCTTTTTATGAGGCACAAACAGGCGAATTTGTCCTGGAAG & 430 \\
\hline CLPPLE & CAtGAACCTtaTAGTggTTTTTATatGGCACAAgtAGGCGAATTTGTCCTGGAAG & 436 \\
\hline CLPPPT & САCСАACCTGCTAGTTCCTATTAT--GACG-GATCGGCTGCAGATTTTCATAACG & 430 \\
\hline \multirow[t]{2}{*}{ CLPPMP } & ----GGCCAACAAGT------AGATGACGAAAT----AGCAAATCAACTTATTG & 397 \\
\hline & 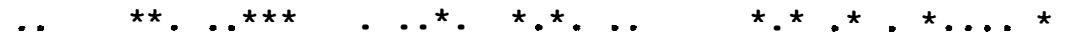 & \\
\hline CLPPZM & TGGAAGAGTTACACAAAG------TTCGCGAAATGATCACAAGGGTTTATGCACT & 479 \\
\hline CLPPOS & TGGAAGAGTTACACAAAG------TTCGCGAAATGATCACAAGGGTTTATGCACT & 479 \\
\hline CLPPNT & CGGAAGAACTGCTGAAAC------TGCGTGAAACCСTCACAAGGGTTTATGTACA & 479 \\
\hline CLPPLE & CGatAGAAaTGgCGAAAC------TGCGTGAAACCCTCACAAGGGTTTATGCAGA & 479 \\
\hline CLPPPT & ---AATCGAAACACGTAACGATGCTTCGCGATTACATAACCAGATGTTATATAGA & 476 \\
\hline
\end{tabular}




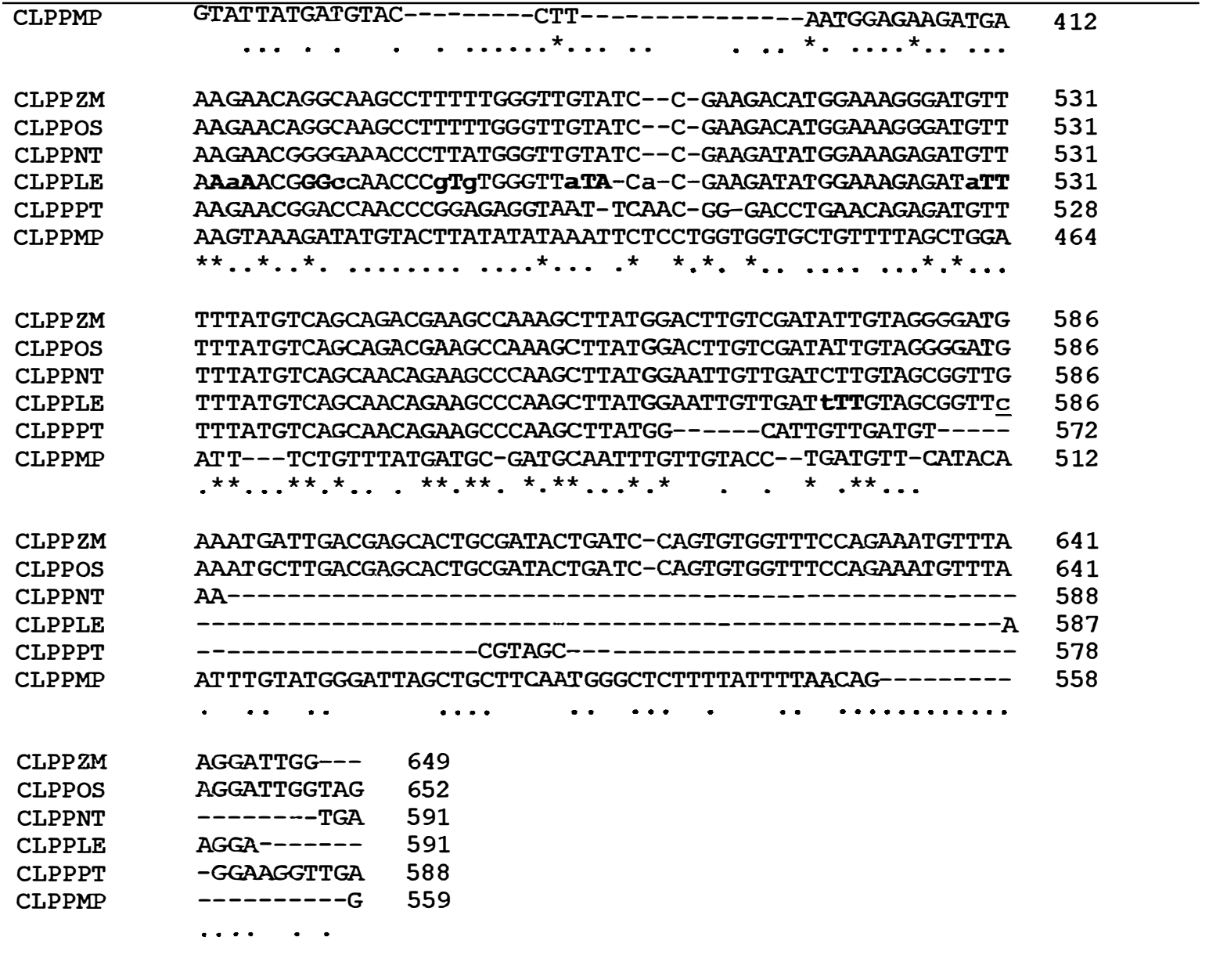

clpP: Aminoácidos

CLPP ZM MPIGVPKVPYRIPGDEEATWVDLYNVMYRERTLFLGQEIRCEITNHITGLMVYLS

CLPPOS MP I GVPKVPYRI PGDEEATWVDLYNVMYRERTLFLGQEIRCEVTNHITGLMVYLS MP IGVPKVPFRSPGEEDASWVDVYNRLYRERLLFLGQEVDSEISNQLIGLMVYLS CLPPNT CLPPLE CLPPPT CLPPMP MP IGVPRVVFRNPGDPISSWVDIYNRLYRERLLFLGQGIGTELSNQLIGLMLYLS MPVGVPKVPFRAPGDEDATWVDLYNRLYRERLLFLAQDINHEIANQTMGLMVYLS MPIGVPKVPFRLPGEEDAVWIDVYNRLYRERLLFLGQQVDDEIANQLIGIMMYLN

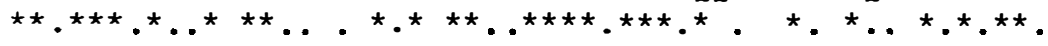

CLPP ZM IEDGNSDIFLFINSLGGWLISGMAIFDTMQTVTPDIYTICLGIAASMASFILLGG

CLPPOS CLPPNT CLPPLE CLPPPT CLPPMP IEDGSSDI FLF INSPGGWLISGMAIFDTMQTVTPNIYTTCLGIAASMP SF ILLGG IEDETKDLYLF INSPGGWVI PGVAIYDTMQFVRPDVHTICMGLAASMGSFILVGG MEDENKDLYLFVNSPGGWVIPGLAIYDTMQFVRPDIHTICLGIAASMGSFILAGG $\bar{A} E D S \bar{N} K D I F S F \bar{I}$ NCPGGSVIPGV'GLFDMMQAIVPDV̈HTICM GEDESKDMYLYINSPGGAVLAGISVYDAMQFVVPDVHT ICMGLAASMGS FILTGG

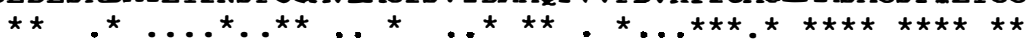




\begin{tabular}{|c|c|c|}
\hline CLPPPT & GEVIQRDLNRDVFMSATEAQAYGIVDVVA----------EG--------- & 196 \\
\hline CLPPMP & LWVI SEDMERDVFMSAKEAKUYGIVDLVA---IENNSTI KN-- - & 203 \\
\hline & 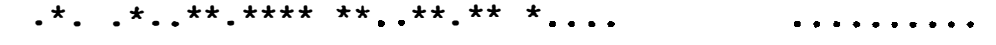 & \\
\hline
\end{tabular}

psbB : Nucleotídeos

PSBBZM

PSBBOS

PSBBNT

PSBBLE

PSBBPT

PSBBMP

PSBBZM

PSBBOS

PSBBNT

PSBBLE

PSBBPT

PSBBMP

PSBBZM

PSBBOS

PSBBNT

PSBBLE

PSBBPT

PSBBMP

PSBBZM

PSBBOS

PSBBNT

PSBBLE

PSBBPT

PSBBMP

PSBBZM

PSBBOS

PSBBNT

PSBBLE

PSBBPT

PSBBMP

PSBBZM PSBBOS PSBBNT PSBBLE PSBBPT PSBBMP

PSBBZM PSBBOS PSBBNT PSBBLE
ATGGGTTTGCCTTGGTATCGTGTTCATACTGTCGTATTGAATGATCCGGGTCGAT ATGGGTTTGCCTTGGTATCGTGTTCATACTGTCGTATTGAATGATCCGGGTCGAT ATGGGTTTGCCTTGGTATCGTGTTCATACCGTTGTATTGAATGATCCCGGTCGGT ATGGGTTTGCCTTGGTATCGTGTTCATACCGTTGTATTGAATGATCCCGGTCGGT ATGGGTTTGCCTTGGTATCGCGTTCATACCGTCGTATTGAATGATCCTGGACGGT ATGGGTTTACCTTGGTATCGTGTTCATACAGTTGTGTTAAATGATCCAGGTCGCT

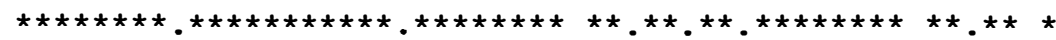

TGCTTTCGGTGCATATAATGCACACAGCTCTAGTTTCTGGTTGGGCTGGTTCGAT TGCTTTCGGTGCATATAATGCACACAGCTCTAGTTTCTGGTTGGGCTGGCTCGAT TGCTTTCTGTTCATATAATGCATACAGCTCTGGTTGCTGGTTGGGCCGGTTCGAT TGCTTTCTGTTCATATAATGCATACAGCTCTGGTTGCTGGTTGGGCCGGTTCGAT TAATTTCTGTACATATAATGCATACAGCTCTAGTTGCTGGTTGGGCTGGTTCAAT TAATCGCTGTTCATTTAATGCATACTGCTTTAGTTTCTGGTTGGGCAGGTTCTAT

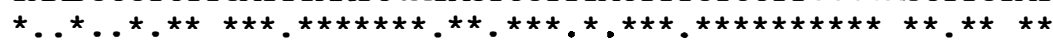

GGCTTTATACGAATTAGCGGTTTTTGATCCCTCTGATCCTGTTCTGGATCCAATG GGCTTTATACGAATTAGCGGTTTTTGATCCCTCTGATCCTGTTCTGGATCCAATG GGCTCTGTATGAATTAGCGGTTTTTGATCCTTCTGATCCTGTTCTTGATCCAATG GGCTCTGTATGAATTAGCGGTTTTTGATCCTTCTGATCCTGTTCTTGATCCAATG GACTCTGTACGAATTAGCAGTTTTTGATCCATCCGATCCTGTTCTTGATCCAATG GGCTTTATATGAATTAGCTGTTTTTGATCCTTCTGATCCAGTTCTTGATCCAATG

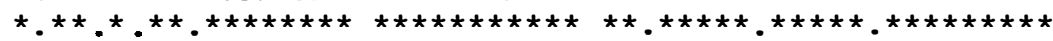

TGGAGACAAGGTATGTTCGTCATCCCCTTCATGACTCGTTTAGGAATAACGAATT TGGAGACAAGGTATGTTCGTCATTCCTTTCATGACTCGTTTAGGAATAACCAATT TGGAGACAGGGTATGTTCGTTATACCCTTCATGACTCGTTTAGGAATAACCAATT TGGAGACAGGGTATGTTCGTTATACCCTTCATGACTCGTTTAGGAATAACCAATT TGGAGACAAGGTATGTTCGTTATACCTTTTATGACTCGTTTGGGAATAAAGGATT TGGAGACAAGGCATGTTTGTTATACCTTTTATGACTCGTTTAGGAATAACGAAAT

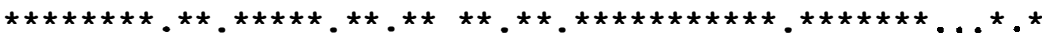

CGTGGGGTGGTTGGAGTATTTCAGGAGGAACTGTAACGAATCCGGGTATTTGGAG CGTGGGGTGGTTGGAGTATTTCAGGAGGAACTGTAACGAATCCGGGTATTTGGAG CATGGGGCGGTTGGAGTATCACAGGGGGGACTGTAACGAATCCGGGTATTTGGAG CATGGGGCGGTTGGAGTATCACAGGGGGGACTGTAACGAATCCaGGTATTTGGAG CATGGAGTGGATGGAACATCACCGGAGAAACTGTAATTAATCCCGGTATTTGGAG CCTGGGGGGGTTGGAGTATTACAGGAGAAACTGTTACTAACGCAGGTATCTGGAG

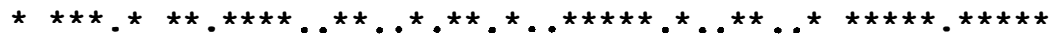

110

110

110

110

110

110

165

165

165

165

165

165

220

220

220

220

220

220

275

275

275

275

275

275

TTATGAAGGTGTGGCAGGTGCGCATATTGTGTTTTCTGGCTTGTGTTTCTTGGCA TTATGAAGGCGTGGCAGGGGCGCATATTGTGTTTTCTGGCTTGTGTTTCTTGGCA TTACGAAGGTGTAGCTGGAGCACATATTGTGTTTTCTGGCTTATGCTTTTTGGCA TTACGAAGGTGTAGCgGGAGCACATATTGTGTTTTCTGGCTTATGCTTTTTGGCA TTATGAAGGTGTGGCCGTGGCACATATCGTGTTTTCTGGCCTGTGCTTTTTGGCA TTATGAAGGAGTAGCTGCAGTACATATTGTTTTATCAGGATTACTTTTTTTGGCA

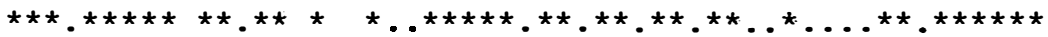

GCTATCTGGCATTGGGTATATTGGGACCTAGAAATATTCTGTGATGAGCGGACGG GCTATCTGGCATTGGGTATATTGGGACCTCGAAATATTCTGTGATGAGCGGACGG GCTATCTGGCATTGGGTGTATTGGGATCTAGAAATATTTTGTGATGAACGTACAG GCTATCTGGCATTGGGTGTATTGGGATCTAGAAATATTTTGTGATGAACGTACAG 


\begin{tabular}{|c|c|c|}
\hline PSBBPT & GCTATCTGGCATTGGGTATATTGGGATCTGGACATATTCTGTGATGAACGTACGG & 385 \\
\hline PSBBMP & 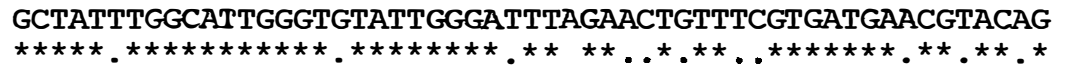 & 385 \\
\hline PSBBZM & GAAAACСTTСTTTGGATTTGCCСAAGATCTTTGGAATTCATTTATTTCTTGCAGG & 440 \\
\hline PSBBOS & GAAAACСTTCTTTGGATTTGCCCAAGATCTTTGGAATTCATTTATTTCTTGCAGG & 440 \\
\hline PSBBNT & GAAAACCTTCTTTGGATTTGCCAAAGATCTTTGGAATTCATTTATTTCTCTCAGG & 440 \\
\hline PSBBLE & GAAAACССTCTTTGGATTTGCCAAAGATCTTTGGAATTCATTTATTTCTCTCAGG & 440 \\
\hline PSBBPT & GAAAACGTTGTTTAGATTTGCCAAAAGTATTTGGAATTCATTTATTCCTCTCAGG & 440 \\
\hline PSBBMP & 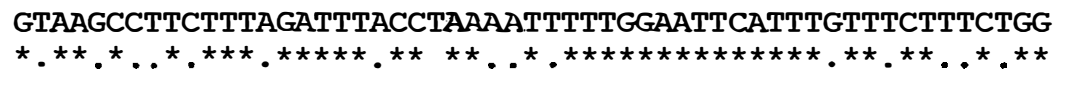 & 440 \\
\hline PSBBZM & GGTGGCTTGTTTTGGCTTTGGTGCATTTCATGTAACGGGTTTATATGGCCCTGGG & 495 \\
\hline PSBBOS & GGTGGCTTGCTTTGGCTTTGGCGCATTTCATGTAACTGGTTTGTATGGTCCTGGG & 495 \\
\hline PSBBNT & GGTGGCTTGCTTTGGTTTTGGTGCATTTCATGTAACAGGCTTGTATGGTCCCGGA & 495 \\
\hline PSBBLE & GGTGGCTTGTTTTGGTTTTGGTGCATTTCATGTAACAGGCTTGTATGGTCCCGGA & 495 \\
\hline PSBBPT & AGTAGCTTGTTTCGGATTTGGAGCATTTCATGTAACGGGTTTGTATGGTCCTGGG & 495 \\
\hline PSBBMP & 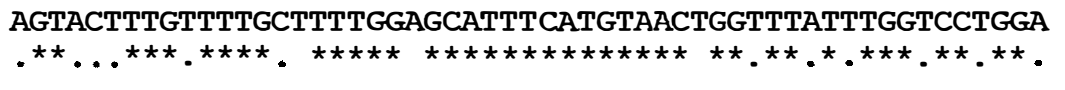 & 495 \\
\hline PSBBZM & АTATGGGTGTCCGATCCTTACGGACTCACTGGAAAAGTACAAGCTGTAAATCCTG & 550 \\
\hline PSBBOS & ATATGGGTGTCTGATCCTTATGGACTAACTGGAAAAGTACAAGCTGTAAATCCGG & 550 \\
\hline PSBBNT & ATATGGGTGTCCGACCCTTATGGACTAACGGGAAAAGTACAACCTGTAAATCCAG & 550 \\
\hline PSBBLE & ATATGGGTGTCCGATCCTTATGGACTAACGGGAAAAGTACAACCTGTAAATCCAG & 550 \\
\hline PSBBPT & ATATGGGTGTCTGATCCTTATGGACTAACTGGAAAAATACAACCAGTGGATCCAG & 550 \\
\hline PSBBMP & 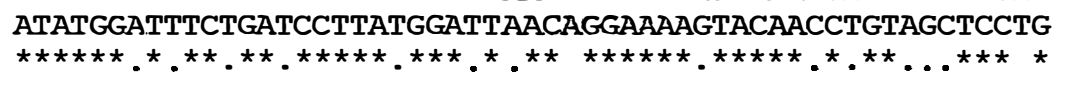 & 550 \\
\hline PSBBZM & CGTGGGGTGCAGAAGGTTTTGATCCTTTCGTTCCGGGAGGAATAGCTTCGCATCA & 605 \\
\hline PSBBOS & CGTGGGGTGCAGAAGGTTTTGATCCTTTTGTTCCGGGGGGAATAGCTTCTCATCA & 605 \\
\hline PSBBNT & CGTGGGGCGTGGAAGGTTTTGATCCTTTTGTTCCAGGAGGAATAGCCTCTCATCA & 605 \\
\hline PSBBLE & CGTGGGGCGTGGAAGGTTTTGATCCTTTTGTTCCAGGAGGAATAGCСTCTCATCA & 605 \\
\hline PSBBPT & CATGGGGAGCTGAAGGTTTTGATCCTTTTGTTCCAGGAGGAATAGCTTCTCATCA & 605 \\
\hline PSBBMP & 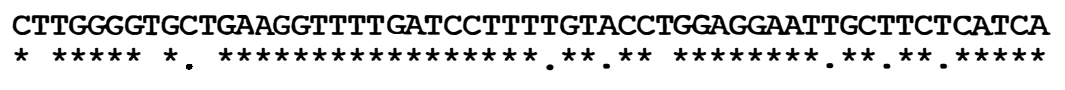 & 605 \\
\hline PSBBZM & TATTGCTGCGGGTATTCTGGGCATATTAGCGGGCCTATTCCATCTAAGTGTCCGT & 660 \\
\hline PSBBOS & TATTGCTGCGGGTACATTGGGCATATTAGCGGGCCTATTCСАTCTTAGTGTCCGT & 660 \\
\hline PSBBNT & TATTGCAGCAGGAACATTGGGCATATTAGCGGGCCTATTCCATCTTAGCGTCCGT & 660 \\
\hline PSBBLE & TATTGCAGCAGGAACATTGGGCATATTAGCGGGCCTATTCCATCTTAGCGTCCGT & 660 \\
\hline PSBBPT & TATAGCAGCGGGTATTTTGGGTATATTAGCAGGTCTATTCCATCTCAGTGTTCGT & 660 \\
\hline PSBBMP & 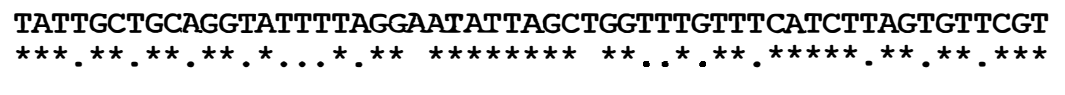 & 660 \\
\hline PSBBZM & ССGССТСАACGTCTATACAAAGGGTTACGTATGGGCAATATTGAAАCTGTACTTT & 715 \\
\hline PSBBOS & ССАССТСААСGTСТАТАСАAАGGATTACGTATGGGCAАTATTGAАACTGTACTTT & 715 \\
\hline PSBBNT & CCGCCACAACGTCTATACAAAGGATTGCGTATGGGAAATATTGAAACCGTCCTTT & 715 \\
\hline PSBBLE & CCGCCACAACGTCTATACAAAGGATTGCGTATGGGAAATATTGAAACCGTCCTTT & 715 \\
\hline PSBBPT & ССТСCССАACGTTTATACGTAGGATTACGCATGGGGAATATTGAAACGGTCCTAT & 715 \\
\hline PSBBMP & 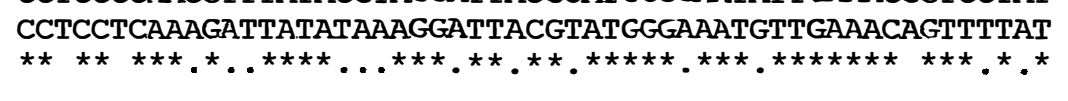 & 715 \\
\hline PSBBZM & CCAGTAGTATCGCTGCTGTTTTTTTTGCTGCTTTCGTAGTTGCCGGAACTATGTG & 770 \\
\hline PSBBOS & CCAGTAGTATCGCTGCTGTTTTTTTTGCAGCTTTCGTAGTTGCCGGAACTATGTG & 770 \\
\hline PSBBNT & CCAGTAGTATCGCTGCTGTCTTTTTTGCAGCTTTTGTTGTTGCCGGAACTATGTG & 770 \\
\hline PSBBLE & CCAGTAGTATCGCTGCTGTCTTTTTTGCAGCTTTTGTTGTTGCCGGAACTATGTG & 770 \\
\hline PSBBPT & CCAGCAGTATTGCTGCTGTGTTTTTTGCAGCTTTCATTGTTGCTGGGACCATGTG & 770 \\
\hline PSBBMP & 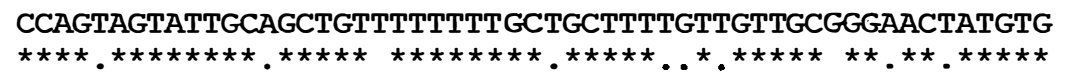 & 770 \\
\hline
\end{tabular}




\section{PSBBZM PSBBOS PSBBNT PSBBLE PSBBPT PSBBMP \\ PSBBZM PSBBOS PSBBNT PSBBLE PSBBPT PSBBMP}

PSBBZM PSBBOS PSBBNT PSBBLE PSBBPT PSBBMP

PSBBZM PSBBOS PSBBNT PSBBLE PSBBPT PSBBMP

PSBBZM PSBBOS PSBBNT PSBBLE PSBBPT PSBBMP

PSBBZM PSBBOS PSBBNT PSBBLE PSBBPT PSBBMP

PSBBZM PSBBOS PSBBNT PSBBLE PSBBPT PSBBMP

PSBBZM PSBBOS PSBBNT PSBBLE
GTATGGATCAGCAACTACCCCAATCGAATTATTTGGGCCTACTCGTTATCAGTGG GTATGGGTCAGCAACTACCCCAATTGAATTGTTTGGGCCTACTCGTTATCAGTGG GTATGGTTCGGCAACAACCCCGATTGAATTATTTGGGCCCACTCGTTACCAATGG GTATGGTTCGGCAACtACCCCGATTGAATTATTTGGGCCCACTCGTTALCAATGG GTATGGCTCCGCAACTACTCCGGTCGAATTATTCGGTCCCACTCGTTACCAGTGG GTACGGTTCTGCAGCAACTCCAATTGAATTATTTGGTCCTACTCGTTACCAATGG

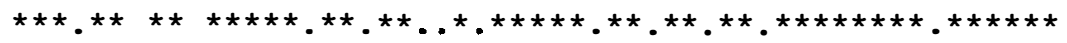

GATCAGGGATACTTTCAGCAAGAAATATATCGAAGAGTTAGCGATGGGTTAGCCG GATCAGGGATACTTTCAGCAAGAAATATATCGAAGAGTTAGTGATGGGTTAGCCG GATCAGGGGTACTTCCAGCAAGAAATATATCGAAGAGTTAGTGCTGGGCTAGCAG GATCAGGGGTACTTCCAGCAAGAAATATATCGAAGAGTTAGTGCTGGGCTAGCAG GATCAGGGATACTTCCAACAAGAAATAGATCGACGGGTTCGTGCCGGTCTGGCCG GATCAAGGATTTTTTCAGCAAGAAATAGATCGAAGAATTCGCTCTAGTAAAGCAG

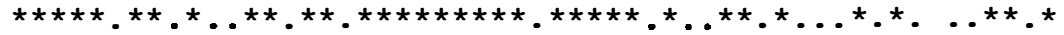

AAAATCTTAGTTTATCAGAAGCTTGGTCTAAAATTCCCGAAAAATTAGCCTTTTA AAAATCTCAGTTTATCAGAAGCTTGGTCTAAAATTCCCGAAAAATTAGCCTTTTA AAAATCAAAGTTTATCAGAAGCCTGGTCTAAAATTCCTGAAAAATTAGCTTTTTA AAAATCAAAGTTTATCAGAAGCCTGGTCTAAAATTCCTGAAAAATTAGCTTTTTA AAAATTTAAGCCTATCAGAAGCTTGGTCCAAAATTCCCGAGAAACTCGCTTTTTA AAAATTTAAGTTTATCAGAAGCTTGGTCTAAAATTCCTGAAAAATTAGCTTTTTA

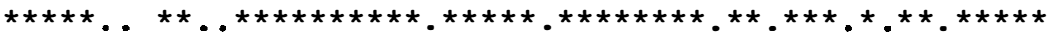

TGATTATATTGGTAATAATCCGGCAAAGGGGGGATTATTCAGAGCAGGCTCAATG TGATTATATTGGTAATAATCCGGCAAAGGGGGGATTATTCAGAGCAGGCTCAATG TGATTACATCGGCAATAATCCGGCAAAAGGGGGATTATTCAGAGCGGGCTCAATG TGATTACATCGGCAATAATCCGGCAAAAGGaGGATTATTCAGAGCaGGtTCAATG TGATTACATTGGTAATAATCCAGCTAAGGGGGGCTTATTCAGAGCAGGTGCAATG TGATTATATTGGTAATAATCCTGCTAAAGGAGGATTATTTAGAGCTGGAGCGATG

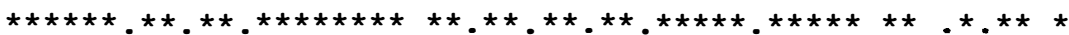

GACAATGGGGATGGCATAGCTGTTGGATGGTTAGGACATCCCGTCTTTAGAGATA GACAATGGGGATGGAATAGCTGTTGGATGGTTAGGACATCCTATCTTTAGAGATA GATAACGGGGATGGAATAGCGGTTGGATGGTTAGGACACCCTATCTTTAGAGATA GATAACGGGGATGGAATAGCGGTTGGATGGTTAGGACACCCTATCTTTAGAGATA GACAATGGAGATGGAATAGCTGTTGGTTGGTTAGGACACCCTATCTTCAAAGATA GATAATGGAGATGGTATAGCAGTTGGTTGGTTAGGCCATGCAGTTTTTAAAGATA

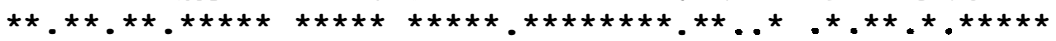

AAGAAGGACGCGAGCTTTTTGTACGTCGTATGCCTACTTTTTTTGAAACATTTCC AAGAAGGGCGCGAACTTTTTGTACGCCGTATGCCTACTTTTTTTGAAACATTTCC AAGAAGGCCGTGAACTTTTTGTACGTCGTATGCCTACTTTTTTTGAAACATTTCC AGGAAGGGCGTGAACTTTTTGTACGTCGTATGCCTACTTTTTTTGAAACATTTCC AGGAGGGAAATGAGCTTTTTGTACGTCGTATGCCTACCTTTTTCGAAACATTTCC AAGAAGGAAATGAGCTTTTCGTTCGTCGTATGCCTACTTTTTTTGAAACTTTTCC

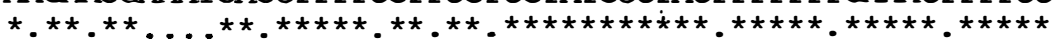

GGTCGTTTTGGTAGATGAAGAGGGAATTGTGAGAGCGGACGTTCCTTTTAGAAGA GGTTGTTTTGGTAGATGAAGAGGGAATTGTGAGAGCGGACGTTCCTTTTAGAAGA GGTCGTTTTGGTAGATGGCGATGGAATTGTTAGAGCCGATGTTCCTTTTAGAAGG GGTCGTTTTGGTAGACGGCGATGGgATTGTTAGAGCCGATGTTCCTTTTAGAAGG AGTAGTTCTGGTGGACAAAGAAGGAATTGTGAAAGCCGATGTTCCTTTTAGGAGG AGTTGTTTTGGTAGATGAACAAGGAATTGTTAGAGCTGATGTTCCATTTAGAAGA

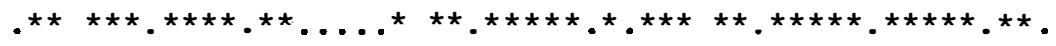

GCAGAATCCAAATATAGTGTTGAACAAGTAGGCGTAACGGTGGAGTTCTATGGTG GCAGAATCCAAATATAGTGTTGAACAAGTAGGCGTAACGGTGGAGTTCTATGGTG GCAGAATCGAAGTATAGTGTTGAACAAGTAGGTGTAACTGTTGAGTTCTACGGCG 


\begin{tabular}{|c|c|c|}
\hline PSBBPT & GCAGAATCAAAGTATAGTGTTGAACAAGTAGGTGTAACTGTTGAGTTCTATGGTG & 1210 \\
\hline PSBBMP & 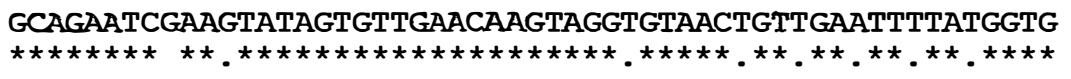 & 1210 \\
\hline PSBBZM & GCGAACTTAATGGAGTAAGTTATTCTGATCCTGCTACTGTAAAAAAATATGCGCG & 1265 \\
\hline PSBBOS & GCGAACTTAATGGAGTAAGTTATTCTGATCCTGCTACTGTAAAAAAATATGCGAG & 1265 \\
\hline PSBBNT & GTGAACTCAACGGCGTCAGTTATAGTGATCCTGCTACTGTGAAAAAATATGCTAG & 1265 \\
\hline PSBBLE & GTGAACTCAACGGCGTCAGTTATAGTGATCCTGCTACTGTGAAAAAATATGCTCG & 1265 \\
\hline PSBBPT & GTGGACTTGACAGGGTCAGTTTTGGTGATCCTGCTATAGTTAAAAAATACGCTAG & 1265 \\
\hline PSBBMP & 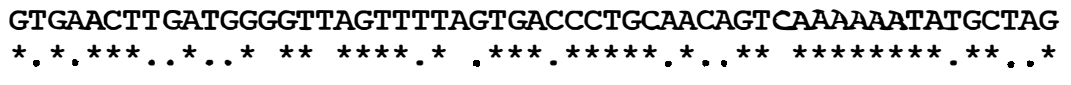 & 1265 \\
\hline PSBBZM & GCGTGCTCAATTAGGGGAAATTTTTGAATTAGATCGAGСTACTTTGAAATСAGAT & 1320 \\
\hline PSBBOS & GCGTTCCCAATTAGGGGAAATTTTTGAATTAGATCGGGCTACTTTGAAATCAGAT & 1320 \\
\hline PSBBNT & ACGTGCTCAATTGGGTGAAATTTTTGAATTAGATCGTGCTACTTTGAAATCCGAT & 1320 \\
\hline PSBBLE & ACGaGCTCAATTGGGTGAAATTTICGAATTAGATCGTGCTACTTTGAAATCCGAT & 1320 \\
\hline PSBBPT & ACGTGCTCAATTAGGTGAAATTTTTGAATTAGATCGTGCTACTCTAAAATCTGAT & 1320 \\
\hline PSBBMP & 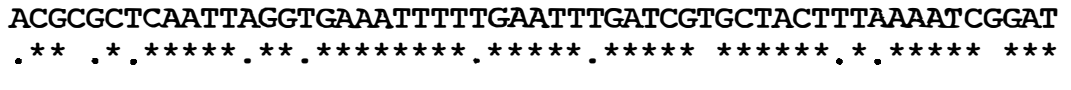 & 1320 \\
\hline PSBBZM & GGTGTTTTTCGCAGCAGTCCAAGGGGTTGGTTCACTTTTGGTCATGCTACCTTTG & 1375 \\
\hline PSBBOS & GGTGTTTTTCGCAGCAGTCCAAGGGGTTGGTTCACTTTTGGTCATGCTACCTTTG & 1375 \\
\hline PSBBNT & GGTGTTTTTCGTAGCAGTCCAAGGGGTTGGTTTACTTTTGGGCATGCTTCGTTTG & 1375 \\
\hline PSBBLE & GGTGTTTTTCGTAGCAGTCCAAGGGGTTGGTTTACTTTTGGGCATGCTTCGTTTG & 1375 \\
\hline PSBBPT & GGTGTTTTTCGTAGTAGTCCAAGGGGTTGGTTTACTTTTGGACATGCTACATTTG & 1375 \\
\hline PSBBMP & GGTGTTTTTCGAAGTAGTCCAAGAGGTTGGTTTACTTTTGGTCATGCTACATTTG & 1375 \\
\hline & 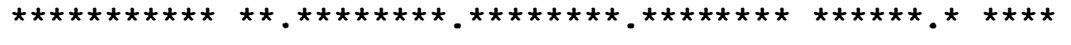 & \\
\hline PSBBZM & СTTTGCTCTTCTTTTTCGGACACATTTGGCATGGCGCTCGAACCTTGTTCCGAGA & 1430 \\
\hline PSBBOS & СTTTGCTCTTCTTTTTCGGACACATTTGGCATGGGGCTAGAACCTTGTTCGCAGA & 1430 \\
\hline PSBBNT & СTTTGCTCTTCTTCTTCGGACACATTTGGCATGGTGCTAGAACCTTGTTCAGAGA & 1430 \\
\hline PSBBLE & СTTTGCTCTTCTTCTTCGGACACATTTGGCATGGTGCTAGAACCTTGTTCAGAGA & 1430 \\
\hline PSBBPT & СTСTССTTTTCTTTTCTGGACACATTTGGCATGGTGCTAGGACCTTATTCAGAGA & 1430 \\
\hline PSBBMP & 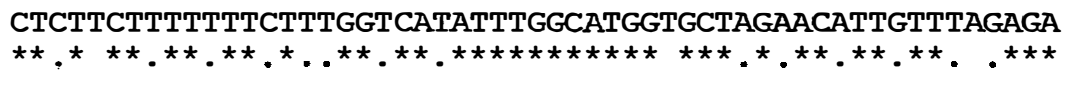 & 1430 \\
\hline PSBBZM & TGTTTTTGCTGGTATTGATCCAGACTTGGATGCTCAAGTGGAATTTGGAACATTC & 1485 \\
\hline PSBBOS & TGTTTTTGCTGGTATTGATCCAGACTTAGATGCTCAAGTGGAATTTGGAGCAATC & 1485 \\
\hline PSBBNT & TGTTTTTGCTGGTATTGACCCAGATTTAGATGCTCAAGTCGAATTTGGAGCATTC & 1485 \\
\hline PSBBLE & TGTTTTTGCTGGTATTGACCCAGATTTAGATGCTCAAGTCGAATTTGGAGCATTC & 1485 \\
\hline PSBBPT & TGTTTTTGCTGGTATCGACTCGGATCTGGATGATCGAATAGAATTTGGAGCATTC & 1485 \\
\hline PSBBMP & 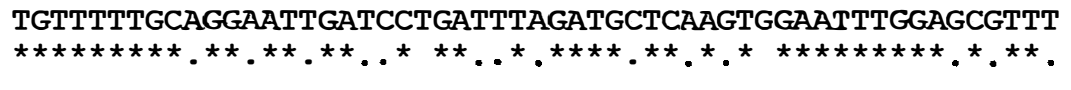 & 1485 \\
\hline PSBBZM & CAAAAAGTTGGAGATCCAACTACAAGGAGACAGGCAGCC--- & \\
\hline PSBBOS & CAAAAACGTGGAGATCCAACTACAGGGAGACAGCCAGTCTGA & \\
\hline PSBBNT & САAAAACTTGGAGATCCAACTACAAAAAGACAGGCAGCCTGA & \\
\hline PSBBLE & CAAAAACTTGGAGATCCAACTACAAAAAGACAGGCAGCCTGA & \\
\hline PSBBPT & СAAAAACTGGGAGATCCAACTACTAAAAGACAAGTGGTATGA & \\
\hline PSBBMP & 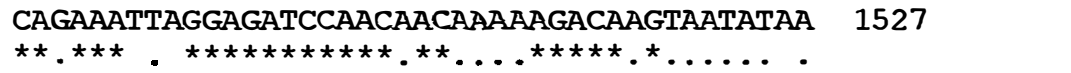 & \\
\hline
\end{tabular}

psbB: Aminoácidos

PSBBZM MGLPWYRVHTVVLNDPGRLLSVHIMHTALVSGWAGSMALYELAVFDPSDPVLDPM 55 PSBBOS MGLPWYRVHTVVLNDPGRLLSVHIMHTALVSGWAGSMALYELAVFDPSDPVLDPM PSBBNT MGLPWYRVHTVVLNDPGRLLSVHIMHTALVAGWAGSMALYELAVFDPSDPVIDPM 55 PSBBLE MGLPWYRVHTVVLNDPGRLLSVHIMHTALVAGWAGSMALYELAVFDPSDPVLDPM 


\begin{tabular}{|c|c|c|}
\hline PSBBPT & MGLPWYRVHTVVLNDPGRLISVHIMHTALVAGWAGSMTLYELAVFDPSDPVLDPM & 55 \\
\hline PSBBMP & 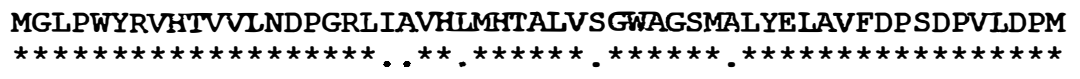 & 55 \\
\hline PSBBZM & WRQGMFVIP FMTRLGITNSWGGWSISGGTVTNPGIWSYEGVAGAHIVFSGLCFLA & 110 \\
\hline PSBBOS & WRQ̄GMFVIPFMTRLGITNSWGGWSISGGTVTNPGIWSYEGVAGAHIVFSGLCFLA & 110 \\
\hline PSBBNT & WRQGMFVI PFMTRLGITNSWGGWSITGGTVTNPGIWSYEGVAGAHIVFSGLCFLA & 110 \\
\hline PSBBLE & WRQ̄GMFVI PFMTRLGITNSWGGWSITGGTVTNPGIWSYEGVAGAHIVFSGLCFLA & 110 \\
\hline PSBBPT & WRQGMFVI PFMTRLGIKDSWSGWNITGETVINPGIWSYEGVAVAHIVFSGLCFLA & 110 \\
\hline PSBBMP & 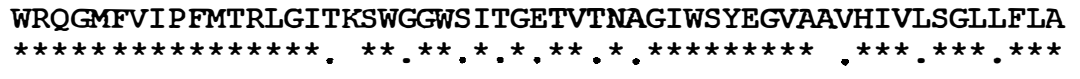 & 110 \\
\hline PSBBZM & AIWHWVYWDLE I FCDERTGKPSLDLPKIFGIHLFIAGVACFGFGAFHVTGLYGPG & 165 \\
\hline PSBBOS & AIWHWVYWDLE I FCDERTGKPSLDLPKIFGI HLFLAGVACFGFGAFHVTGLYGPG & 165 \\
\hline PSBBNT & AIWHWVYWDLE IFCDERTGKPSLDLPKIFGIHLFLSGVACFGFGAFHVTGLYGPG & 165 \\
\hline PSBBLE & AIWHWVYWDLE IFCDERTGKPSLDLPKIFGIHLFLSGVACFGFGAFHVTGLYGPG & 165 \\
\hline PSBBPT & AIWHWVYWDLDIFCDERTGKRCLDLPKVFGIHLFLSGVACFGFGAFHVTGLYGPG & 165 \\
\hline PSBBMP & 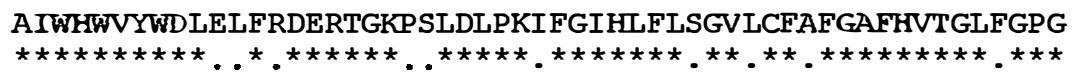 & 165 \\
\hline PSBBZM & IWVSDPYGLTGKVQAVNPAWGAEGFDPFVPGGIASHHLAAGILGILAGLFHLSVR & 220 \\
\hline PSBBOS & IWVSDPYGLTGKVQAVNPAWGAEGFDPFVPGGIASHHLAAGTLGILAGLFHLSVR & 220 \\
\hline PSBBNT & IWVSDPYGLTGKVQPVNPAWGVEGFDPFVPGGIASHHLAAGTLGILAGLFHLSVR & 220 \\
\hline PSBBLE & IWVSDPYGLTGKVQPVNPAWGVEGF DPFVPGGIASHHLAAGTLGI IAGLFHLSVR & 220 \\
\hline PSBBPT & IWVSDPYGLTGKIQPVDPAWGAEGFDPFVPGGIASHHIAAGILGILAGLFHLSVR & 220 \\
\hline PSBBMP & 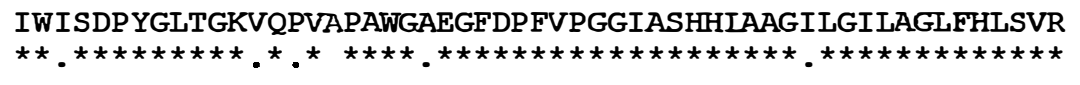 & 220 \\
\hline PSBBZM & PPQRLYKGLRMGNIETVLSSSIAAVFFAAFVVAGTMWYGSATTP IELFGPTRYQW & 275 \\
\hline PSBBOS & PPQRLYKGLRMGNIETVLSSS IAAVFFAAFVVAGTMWYGSATTP IELFGPTRYQW & 275 \\
\hline PSBBNT & PPQRIYKGLRMGNIETVLSSS IAAVFFAAFVVAGTMWYGSATTP IELFGPTRYQW & 275 \\
\hline PSBBLE & PPQRLYKGLRMGNIETVLSSS IAAVFFAAFVVAGTMWYGSATTPIELFGPTRYQW & 275 \\
\hline PSBBPT & PPQRLYVGLRMGNI ETVLSSS IAAVFFAAFIVAGTMWYGSATTPVELFGPTRYQW & 275 \\
\hline PSBBMP & 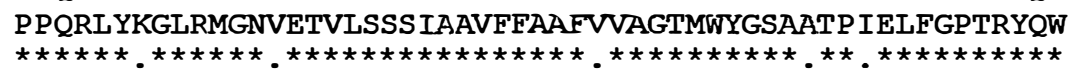 & 275 \\
\hline PSBBZM & DQGYFQQEI YRRVSDGLAENLSLSEAWSKI PEKLAFYDYIGNNPAKGGLFRAGSM & 330 \\
\hline PSBBOS & DQGYFQQEI YRRVSDGLAENLSLSEAWSKI PEKLAFYDYIGNNPAKGGLFRAGSM & 330 \\
\hline PSBBNT & DQGYFQQEI YRRVSAGLAENQSLSEAWSKI PEKIAFYDYIGNNPAKGGLFRAGSM & 330 \\
\hline PSBBLE & DQGYFQQE IYRRVSAGLAENQSLSEAWSKI PEKLAFYDYIGNNPAKGGLFRAGSM & 330 \\
\hline PSBBPT & DQGYFQQEIDRRVRAGLAENLSLSEAWSKI PEKLAFYDYIGNNPAKGGLFRAGAM & 330 \\
\hline PSBBMP & 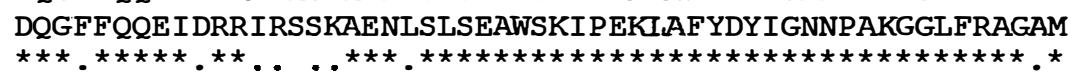 & 330 \\
\hline PSBBZM & DNGDGIAVGWLGHPVFRDKEGRELFVRRMPTFFETF PVVLVDEEGIVRADVPFRR & 385 \\
\hline PSBBOS & DNGDGIAVGWLGHPIFRDKEGRELFVRRMPTFFETFPVVLVDEEGIVRADVPFRR & 385 \\
\hline PSBBNT & DNGDGIAVGWLGHPIFRDKEGRELFVRRMPTFFETFPVVLVDGDGIVRADVPFRR & 385 \\
\hline PSBBLE & DNGDGIAVGWLGHP IFRDKEGRELFVPRMPTFFETFPVVLVDGDGIVRADVPFRR & 385 \\
\hline PSBBPT & DNGDGIAVGWLGHPIFKDKEGNELFVRRMPTFFETFPVVLVDKEGIVKADVPFRR & 385 \\
\hline PSBBMP & 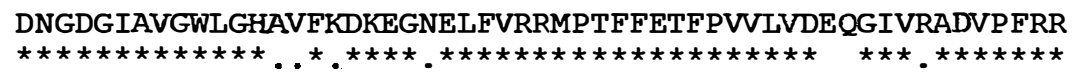 & 385 \\
\hline PSBBZM & AESKYSVEQVGVTVEFYGGELNGVSYSDPATVKKYARRAQLGEIFELDRATLKSD & 440 \\
\hline PSBBOS & AESKYSVEQVGVTVEFYGGELNGVSYSDPATVKKYARRSQLGE IFELDRATLKSD & 440 \\
\hline PSBBNT & AESKYSVEQVGVTVEFYGGELNGVSYSDPATVKKYARRAQLGEIFELDRATLKSD & 440 \\
\hline PSBBLE & AESKYSVEQVGVTVEFYGGELNGVSYSDPATVKKYARRAQLGEIFELDRATLKSD & 440 \\
\hline PSBBPT & AESKYSVEQVGVTVEFYGGGLDRVSFGDPAIVKKYARRAQLGE IFELDRATLKSD & 440 \\
\hline PSBBMP & 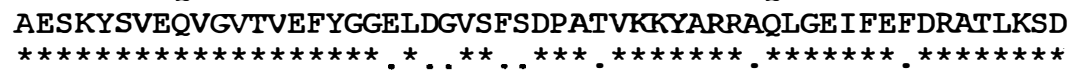 & 440 \\
\hline
\end{tabular}




\begin{tabular}{|c|c|c|c|}
\hline PSBBZM & \multicolumn{2}{|c|}{ GVFRSSPRGWFTFGHATFALLFFFGHIWHGARTLFRDVFAGIDPDLDAQVEFGTF } & 495 \\
\hline PSBBOS & \multicolumn{2}{|c|}{ GVFRSSPRGWFTFGHATFALLFFFGHIWHGARTLFADVFAGIDPDLDAQVEFGAI } & 495 \\
\hline PSBBNT & \multicolumn{2}{|c|}{ GVFRSSPRGWFTFGHASFALLFFFGHIWHGARTLFRDVFAGIDPDLDAQVEFGAF } & 495 \\
\hline PSBBLE & \multicolumn{2}{|c|}{ GVFRSSPRGWFTFGHASFALLFFFGHIWHGARTLFRDVFAGIDPDLDAQVEFGAF } & 495 \\
\hline PSBBPT & \multicolumn{2}{|c|}{ GVFRSSPRGWFTFGHATFALLFFSGHIWHGARTLFRDVFAGIDSDLDDRIEFGAF } & 495 \\
\hline PSBBMP & \multicolumn{2}{|c|}{ 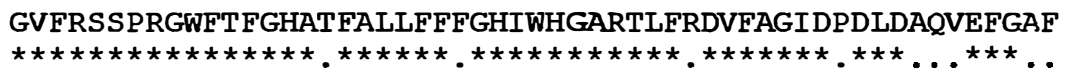 } & 495 \\
\hline PSBBZM & QKVGDPTTRRQAA & 508 & \\
\hline PSBBOS & QKRGDPTTGRQPV & 508 & \\
\hline PSBBNT & QKLGDPTTKRQAA & 508 & \\
\hline PSBBLE & QKLGDPTTKRQAA & 508 & \\
\hline PSBBPT & QKLGDPTTKRQVV & 508 & \\
\hline PSBBMP & $\begin{array}{l}\text { QKLGDPTTKRQVI } \\
\star \star \star \star \star \star \star \star \star \star\end{array}$ & 508 & \\
\hline
\end{tabular}

psbT: Nucleotídeos

PSBTZM ATGGAAGCATTGGTTTATACGTTCCTTTTAGTTTCGACTTTAGGGATAATTTTTT PSBTOS ATGGAAGCATTGGTTTATACGTTCCTTTTAGTTTCGACTTTAGGGATAATTTTTT PSBTNT PSBTLE PSBTPT PSBTMP ATGGAAGCATTGGTTTATACATTCCTCTTAGTCTCGACTCTAGGGATAATTTTTT ATGGAAGCATTGGTTTATACATTCCTCTTAGTCTCGACTCTAGGGATAATTTTTT ATGGAAGCATTGGTTTATACATTCCTGTTGGTATCGACCCTAGGGATAATCTTTT ATGGAAGCATTAGTTTATACATTTTTGTTGGTAGGTACTTTAGGAATCATTTTTT

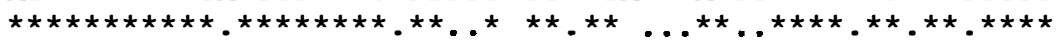

PSBTZM PSBTOS TCGCTATCTTCTTCCGAGAACCACCTAAGGTTCCGACTAAGAAA-------TCGCTATCTTCTTCCGAGAACCACCTAAGGTTCCGACTAAAAAAGTGAAATAA TCGCTATCTTTTTTCGAGAACCGCCTAAAGTTCCAACTAAAAA---GAACTAA TCGCTATCTTTTTTCGAGAACCGCCTACAaTTCGAACTAAAAA---GAACTAA TCGCTATT"TCTTCCGAGAACCACCCAAACTTCCGACTAAAG GGG GAAATAA TTGCTATTTTTTTTAGAGAACCACCTAAAGTACCAAGTAAAGCAAAAAAATAA

PSBTMP

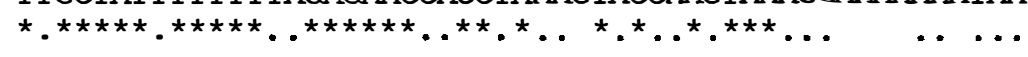

psbr: Aminoácidos

\begin{tabular}{|c|c|}
\hline PSBT ZM & MEALVYTFLLVSTLGI I FFA IFFREPPKVPTKKVK \\
\hline PSBTOS & MEALVYTFLLVSTLGI IFFAIFFREPPKVPTKKVK \\
\hline PSBTNT & MEALVYTFLLVSTLGI IFFAI FFREPPKVPTKKN- \\
\hline PSBTLE & MEALVYTFLLVSTLGI IFFAIFFREPPTIRTKKN- \\
\hline PSBTPT & MEALVYTFLLVSTLGI IFFAIFFREPP $\overline{\mathrm{KLPTKGGK}}$ \\
\hline PSBTMP & 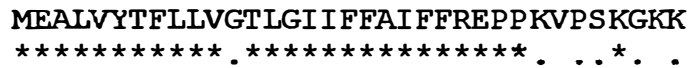 \\
\hline
\end{tabular}

pshN : Nucleotídeos

PSBNZM ATGGAAACAGCAACTTTAGTCGCCATCTCCATATCTGGTTTACTTGTAAGCTTTA PSBNOS ATGGAAACAGCAACTTTAGTCGCCATCTCCATATCTGGTTTACTTGTAAGCTTTA PSBNNT PSBNLE PSBNPT ORF27MP ATGGAAACAGCAACCCTAGTCGCCATCTTTATATCTGGTTTACTTGTAAGTTTTA ATGGAAACAGCAACCCTAGTCGCCATCTTTATATCTGGTTTACTTGTAAGTTTTA ATGGAAACTGCAACCTTAGTCACCATCTCCATATCTTGTTTACTTGTAAGCTTTA ATG-- - TTCTTCAAATGGATC-- - - -TCTAAGTT--- -- САTTA

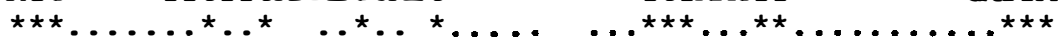
CTGGGTATGCCTTATATACCGCGTTTGGGCAACCCTCTCAACAATTAAGAGATCC CTGGGTACGCCTTATATACCGCTTTTGGGCAACCTTCTCAACAACTAAGAGATCC PSBNNT PSBNLE CTGGGTACGCCTTATATACCGCTTTTGGGCAACCTTCTCAACAACTAAGAGATCC 


\begin{tabular}{|c|c|c|c|c|}
\hline \multirow[t]{2}{*}{ ORF27MP } & \multicolumn{3}{|c|}{ GAAGGTTGTCCAAAT-----GCGGTATAAAGAGCAT---------------AACC } & 66 \\
\hline & $\ldots *^{*} \cdot *^{\star \star} \cdot{ }^{\star \star} \cdot \ldots{ }^{* \star}$ & $\star \ldots \ldots \star^{*} \star^{*} \ldots \ldots \ldots$ & $\cdot \ldots . * * \star$ & \\
\hline PSBNZM & ATTCGAAGAACATGGGGAC--- & 129 & & \\
\hline PSBNOS & ATTCGAAGAACACGGGGACTAA & 132 & & \\
\hline PSBNNT & ATTCGAGGAACATGGAGACTAG & 132 & & \\
\hline PSBNLE & ATTCGAGGAACATGGAGACTAG & 132 & & \\
\hline PSBNPT & TTTTGAGGATCACGAGGACTAA & 132 & & \\
\hline \multirow[t]{2}{*}{ ORF27MP } & A---GTAAAGCTTATAAG-TAA & 84 & & \\
\hline & $\ldots \star \ldots \star \star \star \ldots \ldots \ldots$ & & & \\
\hline \multicolumn{5}{|c|}{ psb̂: Aminoácidos } \\
\hline PSBNZM & \multicolumn{2}{|c|}{ METATLVAISISGLLVSFTGYALYTAFGQPSQQLRDPFEEHGD } & 43 & \\
\hline PSBNOS & \multicolumn{2}{|c|}{ METATLVAISISGLLVSFTGYALYTAFGQPSQQLRDPFEEHGD } & 43 & \\
\hline PSBNNT & \multicolumn{2}{|c|}{ METATLVAIFISGLLVSFTGYALYTAFGQP SQQLRDPFEEHGD } & 43 & \\
\hline PSBNLE & \multicolumn{2}{|c|}{ METATLVAIFISGLLVSFTGYALYTAFGQPSQQLRDPFEEHGD } & 43 & \\
\hline PSBNPT & \multicolumn{2}{|c|}{ METATLVTISISCLLVSFTGYALYTAFGQPSKQLRDPFEDHED } & 43 & \\
\hline PSBNMP & \multicolumn{3}{|c|}{ 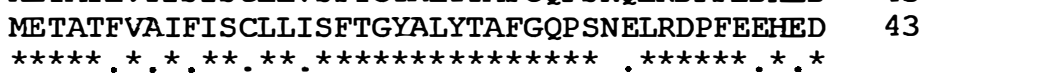 } & \\
\hline
\end{tabular}

Quadro 4. Alinhamento e homologia.na região espaçadora entre os genes $t r n \mathrm{E}-\mathrm{tr}$ T $\mathrm{T}$ de tabaco e tomate apresentando uma deleção de $437 \mathrm{pb}$ na seqüência de tomate. Asteriscos indicam homologia; letras minúsculas representam ausência de identidade entre os nucleotídeos. Traços (-) representam ausência de nucleotideos (Morgenstern, 1999).

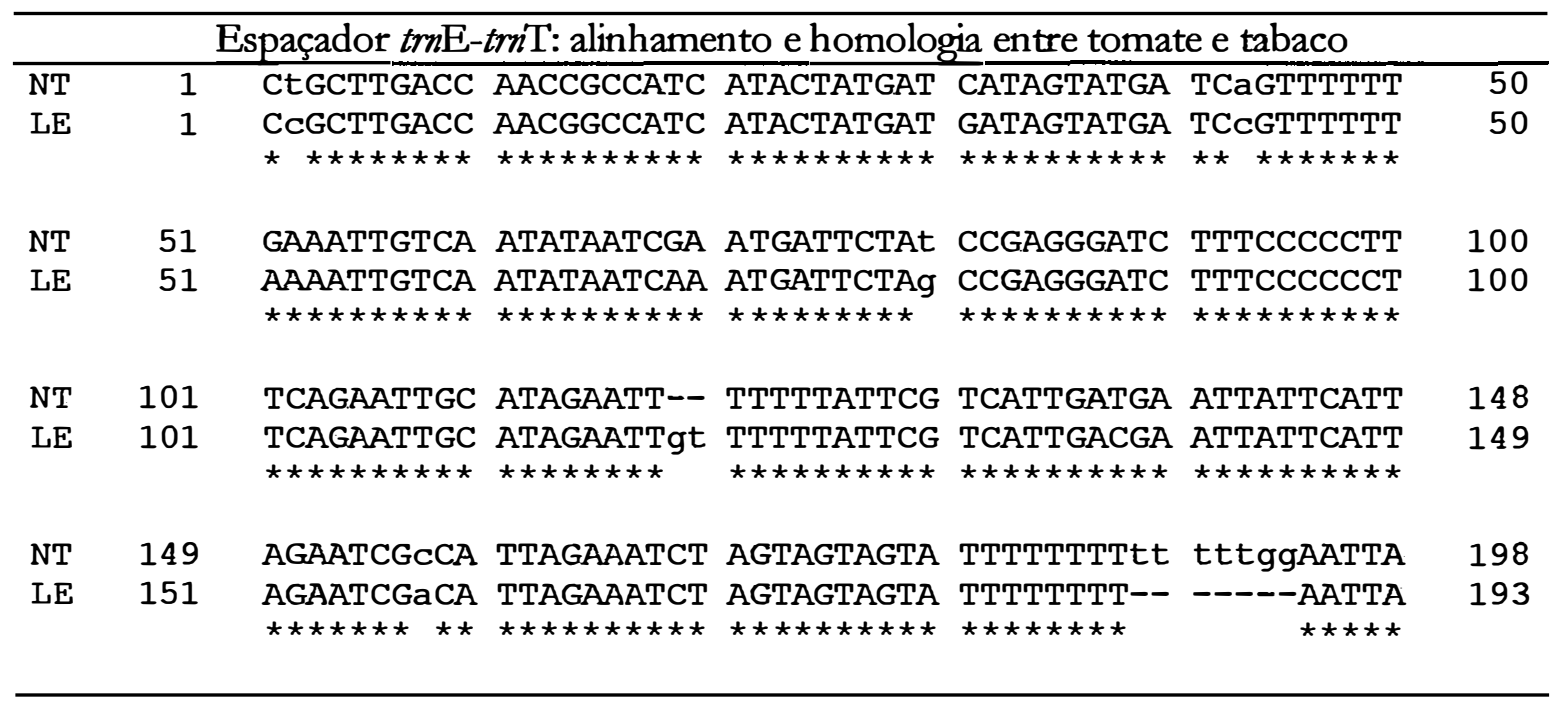




\begin{tabular}{|c|c|c|c|c|c|c|c|}
\hline $\mathrm{NT}$ & 199 & TTTCAATTGA & АТTTСТTTCg & attattttag & tttagattat & ttagtattta & 248 \\
\hline $\mathrm{LE}$ & 194 & 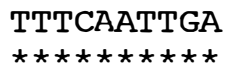 & 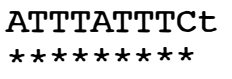 & -ーーーーーー-ーー & -ーーーーーー-ー- & -ーーーーーーーーー & 214 \\
\hline NT & 249 & gaattttctt & tttttattat & aaataaaaa & aaaattaata & aatacaaaaa & 298 \\
\hline LE & 214 & -ーーーーーーーーー & -ーーーーーーーーー & ーーーーーーーーーー & -ーーーーーーーーー & -ーーーーーーーーー & 214 \\
\hline NT & 299 & atagaaataa & taaggaagag & taggattttt & gcagggaatg & attggtccgt & 348 \\
\hline LE & 214 & -ーーーーーーーーー & -ーーーーーーーーー & -ーーーーーーーーー & -ーーーー-ー-ー- & -ーーーーーー-ー- & 214 \\
\hline NT & 349 & cagaaaagga & aaaaggtgtg & aaattctatt & tctttcactt & tcatttgatt & 398 \\
\hline LE & 214 & -ーーーーーーーーー & -ーーーーーーーーー & -ー-ー-ー-ー-ー & -ーーーーーーー-ー & -ー-ー-ー-ー-ー & 214 \\
\hline NT & 399 & cattgttaag & acgagatatc & cttatctccc & tcccaccaag & acaggaaatt & 448 \\
\hline LE & 214 & -ーーーーーーーーー & ーーーーーーーーーー & -ーーーーーーーーー & -ーーーーーーーーー & -ーーーーーーーーー & 214 \\
\hline $\mathrm{NT}$ & 449 & aacaaacgag & aaatctagta & agcgggatca & agaagaaaat & tcttttttct & 498 \\
\hline LE & 214 & -ーーーーーーーー & ーーーーーーーーーー & -ー--ー----- & -ーーーーーー-ーー & -ーーーーー-ーーー & 214 \\
\hline NT & 499 & ccaagaattt & agttcaggag & acaagtagaa & tctcttcatt & ccatgattcg & 548 \\
\hline LE & 214 & ーーーーーーーーーー & -ーーーーーーーーー & -ーーーーーーーーー & -ーーーーーーーーー & -ーーーーーーーーー & 214 \\
\hline NT & 549 & atgaaatatc & ttgaatttta & tgttgaattg & ctaggtgtat & gtacatgtat & \\
\hline $\mathrm{LE}$ & 214 & ーーーーーーーーーー & ーーーーーーーーーー & ーーーーーーーーーー & ーーーーーーーーーー & ーーーーーーーーーー & 214 \\
\hline NT & 599 & caatcaagtg & aattttgttc & tggtgggatc & aattcaataa & aagaaaaaaa & 648 \\
\hline LE & 214 & --ー-ー-ー--- & ---ー-ー-ー-- & ------- & ---------- & --ー-ー----- & 214 \\
\hline NT & 649 & gсаATTCGAG & TCGGTCTTGA & ААСАATTСАТ & TGCATTTTCT & ССТАgАСТTС & 698 \\
\hline LE & 214 & $\begin{array}{r}-- \text { ATTCGAG } \\
\star \star \star \star \star \star \star \star\end{array}$ & 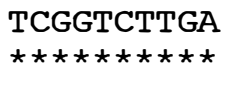 & 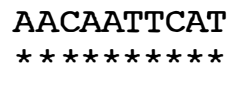 & 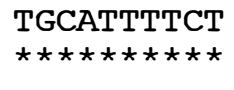 & 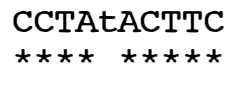 & 260 \\
\hline NT & 699 & СTAGGTAAAT & ССАТTTТАТT & АТТСААСААТ & GAGCCACTAG & АСАСТАTGTA & 748 \\
\hline $\mathrm{LE}$ & 261 & 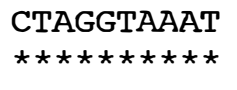 & $\begin{array}{l}\text { CCATTTTATT } \\
\star \star \star \star \star \star \star \star \star \star\end{array}$ & 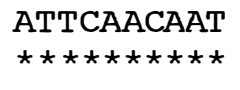 & 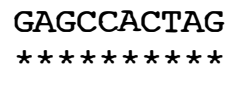 & 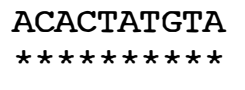 & 310 \\
\hline NT & 749 & TCTACTGCAT & GTACTTA-TG & САТАТАТАСТ & TATGTTTATA & ATATATGTAC & 797 \\
\hline LE & 311 & 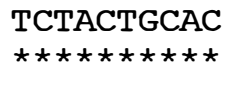 & $\begin{array}{l}\text { GTACTTAaTG } \\
\star \star \star \star \star \star \star \star \star \star ~\end{array}$ & 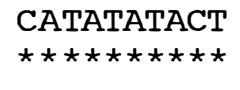 & 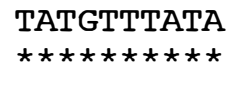 & $\begin{array}{l}\text { ATATAAGTAC } \\
\star \star \star \star \star \star \star \star \star \star \star\end{array}$ & 360 \\
\hline NT & 798 & СTATAGATAT & TTtATCCACA & TAGTGAATAA & TTCCGGAATT & AAAT CAAAAA & 848 \\
\hline LE & 361 & $\begin{array}{l}\text { ATATAGATAT } \\
\star \star \star \star \star \star \star \star \star \star \star\end{array}$ & $\begin{array}{l}\text { TTaATCCACA } \\
\star \star \star \star \star \star \star \star \star\end{array}$ & 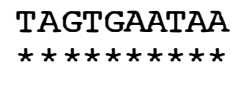 & 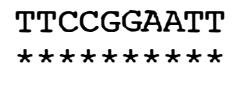 & $\begin{array}{l}\text { AАATAAAAAA } \\
\star \star \star \star \star \star \star * \star * \star *\end{array}$ & 410 \\
\hline NT & 849 & G & & & & & \\
\hline $\mathrm{LE}$ & 411 & $\begin{array}{l}\text { G } \\
\star\end{array}$ & & & & & \\
\hline
\end{tabular}


Análise de restrição de ambas as seqüências gerou os mapas de restrição para os fragmentos cloroplastidiais de tomate clonados em pIJB1 e pIJB2 apresentos nas Figuras 22 e 23. Os mapas apresentam predominantemente enzimas de restrição que possuem somente um ou dois sítios de reconhecimento na seqüência.
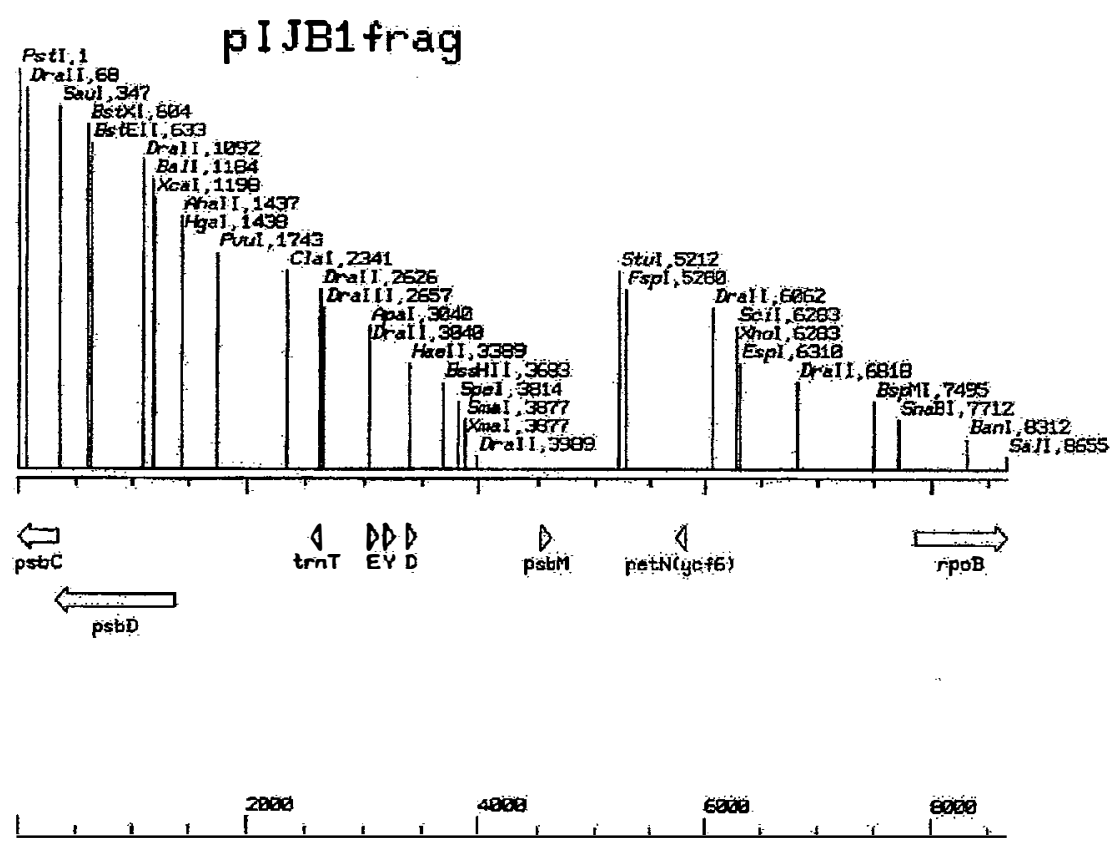

Figura 16. Mapa de restrição do fragmento cloroplastidial de tomate de 8.660 pb clonado em pIJB1. Setas indicam o sentido de transcrição dos genes. 


\section{pIJB2frag}
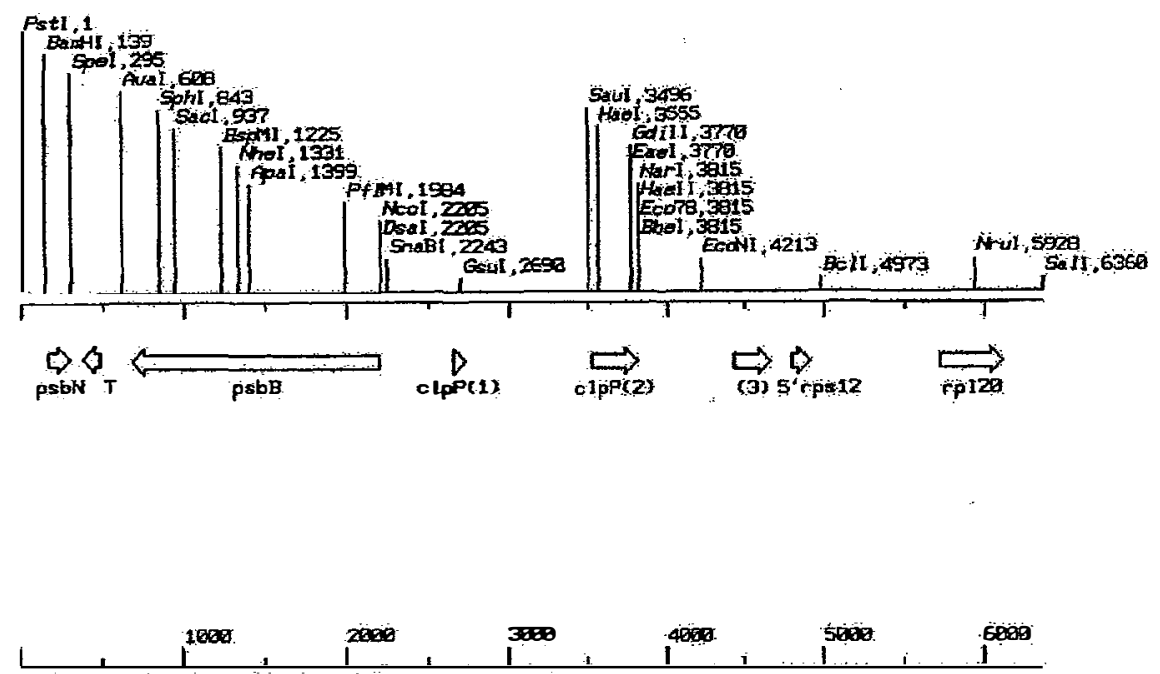

Figura 17. Mapa de restrição do fragmento cloroplastidial de tomate de 6.366 pb clonado em pIJB2. Setas indicam o sentido de transcrição dos genes.

Em concordância com a alta homologia encontrada, a posição relativa dos genes nos fragmentos sequenciados foi exatamente aquela encontrada na seqüência de tabaco (Shinozaki et al., 1986). Mapas gênicos dos fragmentos estudados estão esquematizados nas Figuras 18 e 19, e a posição exata de cada uma das seqüências codificadoras pode ser visualizada nos Quadros 1 e 2 em negrito. Em adição, o conteúdo de GC nos fragmentos de $8.660 \mathrm{pb}$ e $6.366 \mathrm{pb}$ foram calculados como sendo $35,13 \%$ e $36,94 \%$ respectivamente. $\mathrm{O}$ conteúdo de GC das respectivas seqüências no plastoma de tabaco, calculado em 37,9\% para o genoma completo, é de 34,75\% e 37\% (Shimada \& Sugiura, 1991). Estes resultados refletem a alta homologia das sequências e indicam, conforme verificado, o mesmo padrão de uso preferencial de códons em tomate e tabaco, contendo A ou U na terceira posição (Shimada \& Sugiura, 1991). 


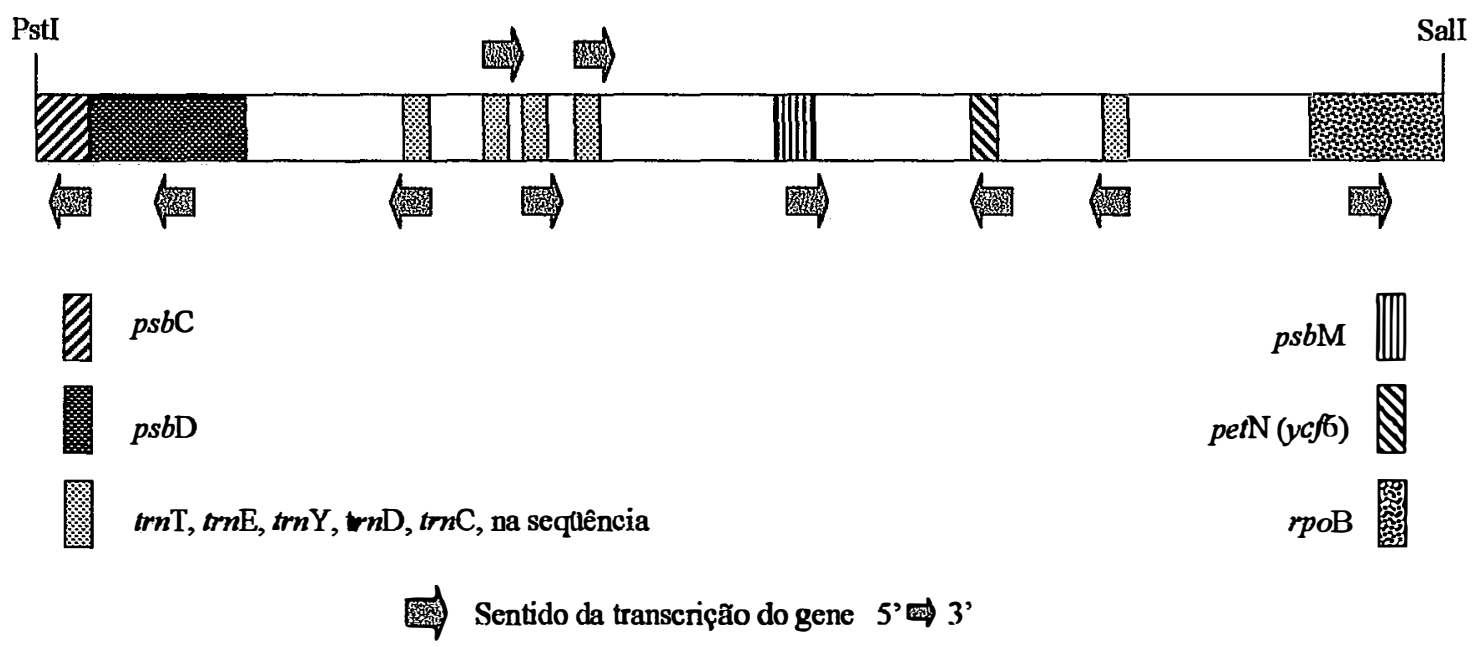

Figura 18. Mapa gênico esquemático do fragmento cloroplastial de tomate de $8.660 \mathrm{pb}$ clonado no plasmídio pIJB1.

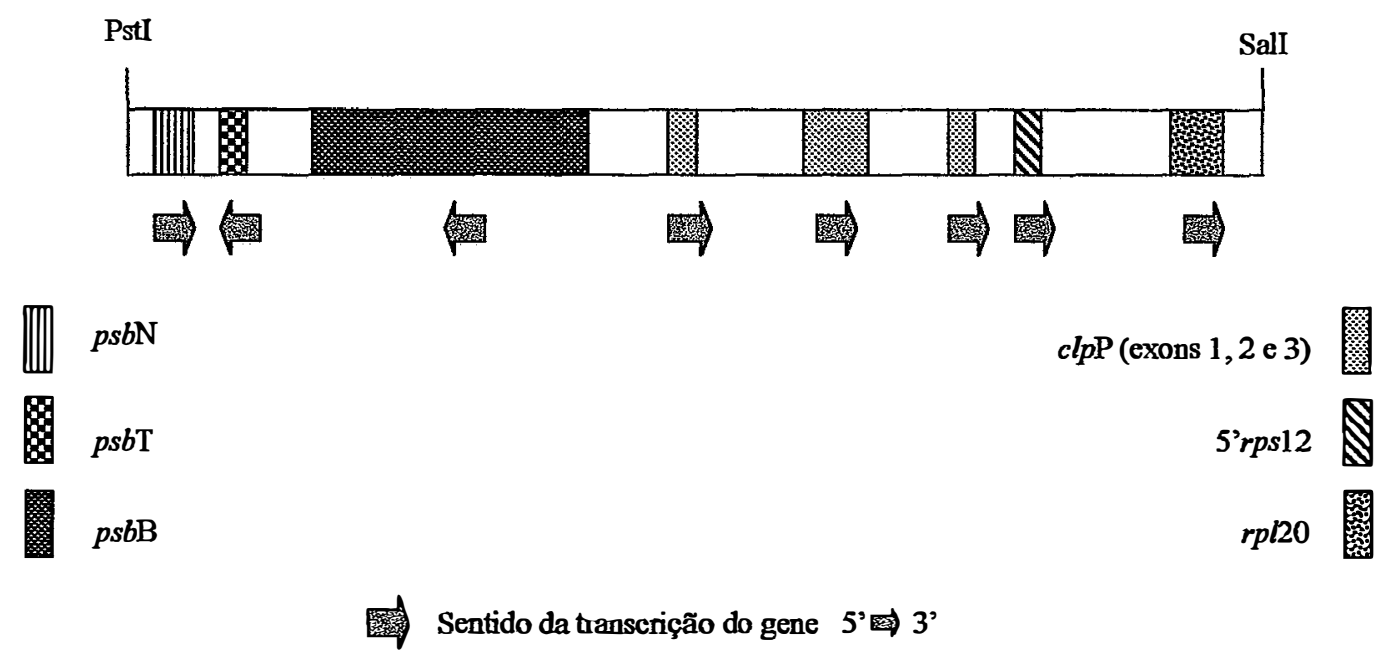

Figura 19. Mapa gênico esquemático do fragmento cloroplastial de tomate de $6.366 \mathrm{pb}$ clonado no plasmídio pIJB2.

A alta homologia entre tabaco e tomate, o posicionamento conservado de genes, o conteúdo em GC, assim como o elevado grau de conservação dos produtos gênicos entre as espécies sugerem que o padrão genético de cloroplastos de tabaco é altamente conservado em tomate, em concordância com o esperado, uma vez que ambos, tomate e tabaco, pertencem a família das solanáceas, extensa família de dicotiledôneas evolutivamente relacionadas. 


\subsection{Identificação de sítios únicos de restrição para construção de vetores de transformação via recombinação homóloga}

Análise das seqüências completas dos fragmentos cloroplastidiais de pIJB1 e pIJB2 permitiu a construção de mapas de restrição detalhados e a determinação de potenciais sítios para introdução de genes de interesse no genoma cloroplastidial de tomate via recombinação homóloga através da construção de vetores de transformação. Os mapas de restrição estão mostrados nas Figuras 22 e 23, apresentando as enzimas com sítio único de reconhecimento na sequência e algumas outras com dois ou três sítios. A análise minuciosa das sequências visando a construção de vetores de transformação de cloroplastos de tomate via recombinação homóloga levou à maior atenção ao fragmento de $8.660 \mathrm{pb}$, onde as regiões intergências se mostram mais extensas e apresentam maior número de sítios únicos de restrição. Três sítios de restrição foram inicialmente apontados como potenciais sítios para futura introdução de genes de interesse: $X b a \mathrm{I}$ entre os genes $p s b \mathrm{D}$ e $t r m \mathrm{~T}$, StuI entre os genes $p s b \mathrm{M}$ e $p e t \mathrm{~N}(y c \sigma)$ e EcoRV entre os genes $t m \mathrm{C}$ e $r p o \mathrm{~B}$.

A introdução de genes exógenos no plastoma não deve afetar o funcionamento normal do sistema genético cloroplastidial (Maliga, 1993; Bock \& Hagemann, 1999), c portanto, não deve afetar a expressão de genes individuais. $\mathrm{O}$ sítio $\mathrm{XbaI}$ foi descartado pois encontra-se na região promotora do gene $p s b \mathrm{D}$, a qual foi caracterizada por apresentar elementos procarióticos promotores "-10" e "-35" a cerca de $900 \mathrm{pb}$ do códon de iniciação da tradução (Christopher et al., 1992). Observou-se que existem dois sítios próximos para $\mathrm{E} c o \mathrm{RV}$ (distanciados entre si por apenas $147 \mathrm{pb}$ ) no espaço intergênico entre $t r m \mathrm{C}$ e $r p o \mathrm{~B}$ e o uso da enzima resultaria em potencial perda deste segmento, sem que se saiba se haveria algum prejuízo, adotou-se como sítio alvo o sítio único de restrição para a enzima StuI contido entre os genes $p s b \mathrm{M}$ e pet $\mathrm{N}(y c f)$. Como estes genes em questão são transcritos em sentidos opostos (Figura 18), o sítio StuI encontra-se especificamente na região 3 ' ̀̀ região codificadora de ambos os genes e a uma distância superior a cerca de $200 \mathrm{pb}$, o que pode garantir a integridade dos transcritos originais no caso da clivagem e inserção do gene marcador seletivo na referida localização (Bock, 2000).

Admitido como sítio alvo o sítio de restrição $S t u$ localizado no espaço intergênico entre os genes $p s b \mathrm{M}$ e $p e t \mathrm{~N}(y c f)$, adotou-se como estratégia o isolamento e subclonagem do 
sub-fragmento SmaI/XboI de pIJB1 (Figura 17). Desta forma, obteve-se o plasmídio p'T'T'J2 no vetor pBS KS(-) contendo um fragmento cloroplastidial de 2404 pb, com sítio único de restrição para a enzima StuI entre os genes $p s b \mathrm{M}$ e peț (ycfo), como esquematizado na Figura 20.

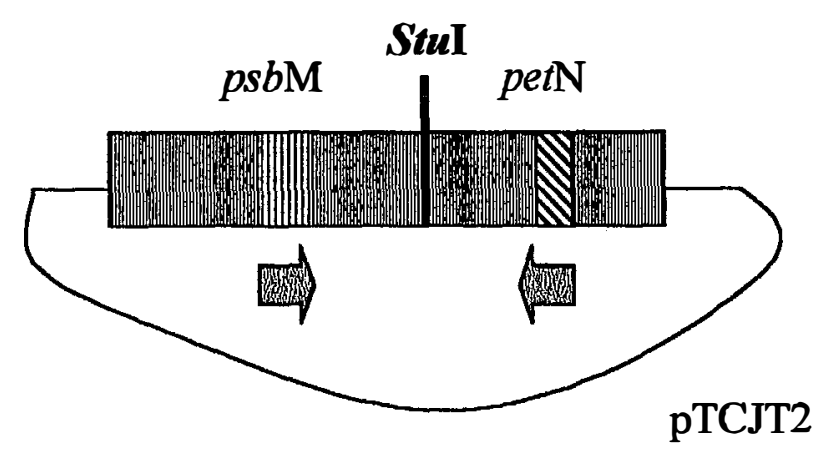

Figura 20. Plasmídio p'TCJT2 contendo a seqüência alvo de tomate para construção de vetores de transformação de cloroplastos.

\subsection{Construção do gene marcador seletivo}

A amplificação via PCR do promotor PatpI e terminalizador Trps14 de tomate utilizando primers baseados na seqüência de tabaco (Tabela 3) gerou respectivamente as seqüências de 281 e $150 \mathrm{pb}$, as quais incluem a seqüência dos primers utilizados, estão mostradas no Quadro 5. A região do promotor PatpI foi obtida através de digestão com as enzimas de restrição EcoRI (SacI)/NcoI, obtendo-se um fragmento de $270 \mathrm{pb}$. A região do terminalizador Trps14 foi obtida através de digestão com as enzimas de restrição SpbI/Sall, obtendo-se um fragmento de $140 \mathrm{pb}$. Análise de homologia entre as sequências amplificadas e as seqüências originalmente conhecidas em tabaco pode ser visualizada também no Quadro 5. A seqüência promotora de tomate difere da de tabaco por apresentar um duplicação da seqüência de 10 bases AGAAATCCCT presente em cópia única em 
tabaco. Por sua vez, a seqüência terminalizadora de tomate apresenta uma substituição de T (em tabaco) por C (em tomate), como destacado em negrito no Quadro 5.

Uma vez isolados e clonados os sinais de controle de expressão PatpI e Trps14 de tomate, fez-se a substituição dos sinais originalmente presentes na construção pUC-16Saad (ccdida por Ulrich-H. Koop / Universidade de Munique, Alemanha) a qual deu origem ao cassete atpI-aadA-rps14 clonado no plasmídio pIJB13, conforme esquematizado na Figura 21.

Originalmente em tabaco o promotor PatpI apresenta dois sítios de iniciação da transcrição, -131 e -208, o primeiro promovido por uma seqüência promotora consenso "-35" tipicamente procariótica (-35 consensus-type promoters - CT) responsável pela promoção da expressão em cloroplastos, e o segundo promovido por uma seqüência promotora não-consenso (non-consensus type promoter - NCII) responsável pela expressão em plastídios não-verdes (Miyagi et al., 1998). A amplificação em tomate de toda a região intergênica $5^{\prime}$ à região codificadora do gene atpI, somada à elevada homologia verificada, com a existência dos citados sítios de iniciação da transcrição, permitem supor que a construção de um gene marcador sob controle de tal seqüência resultará na expressão do fenótipo marcador em plastídios verdes ou não-verdes. Interessante indicativo da atividade promotora do PatpI pôde ser verificada pela expressão de resistência ao antibiótico espectinomicina em Escherichia coli contendo o cassete de expressão PatpI-aadATrps14 (dados não mostrados, verificação rotineira no decorrer das clonagens), uma vez que, apresentando um promotor tipicamente procariótico (tipo $\sigma^{79}$ ) sua expressão seria esperada em E. coli. 
Quadro 5. Seqüências e análise de homologia entre as regiões promotoras dos gene atpl I e terminalizadoras dos gene $p s 14$ de tomate (Tom) e tabaco (Tab). Em negrito e itálico encontram-se destacados os sítios de restrição inseridos via primers. Letras minúsculas representam os primers utilizados na amplificação. Setas indicam sítios de iniciação da trascrição (transcritos primários).

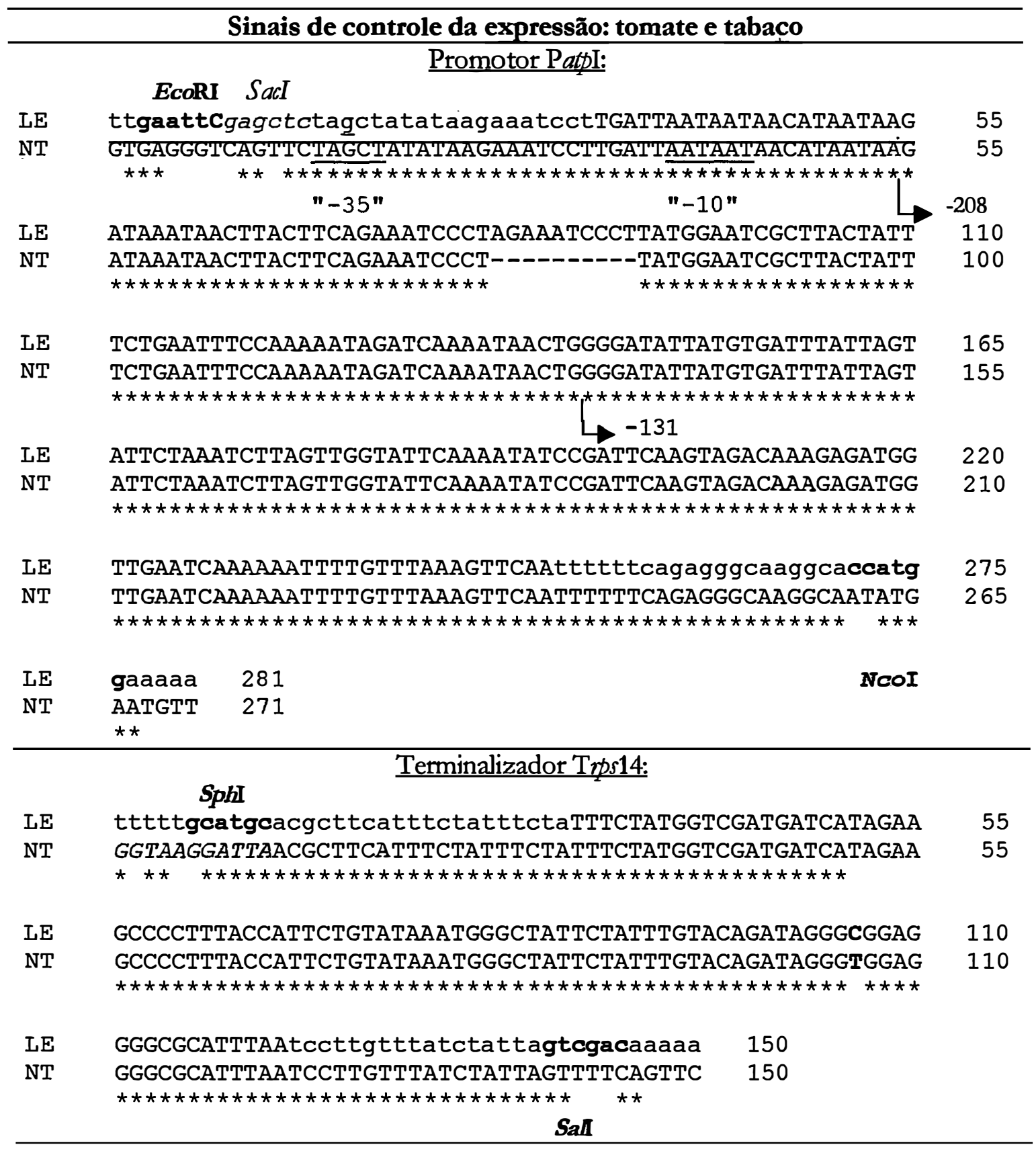




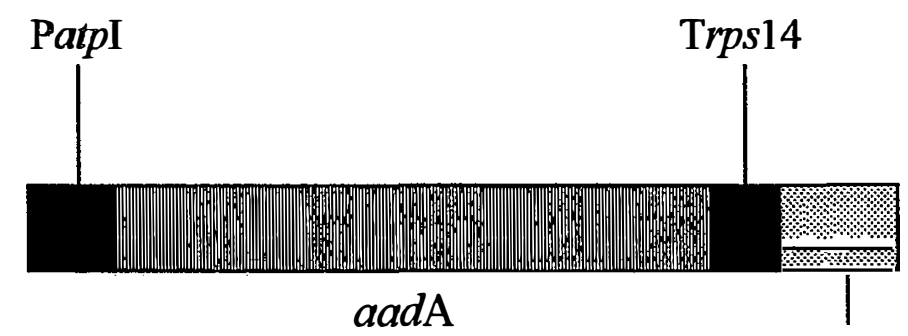

Múltiplos

Sítios de

Clonagem

XbaI, SpeI, BamHI, SmaI, PstI, EcoRI, EcoRV, HindIII, ClaI, SalI, HincII, XhoI, Eco0109I, KpnI

Figura 21. Cassete atpI-aadA-rps14 (gene marcador) clonado no plasmídio pIJB13, construído com sinais plastídio-específicos de tomate para expressão do gene quimérico aadA em cloroplastos e plastídios não-verdes.

\subsection{Construção de vetores de transformação de cloroplasto de tomate via recombinação homóloga}

Para a construção de vetores de transformação, ou seja, o gene marcador flanqueado por seqüências homólogas de DNA cloroplastidial, o cassete atpI-aadA-rps14 (gene marcador), junto a uma seqüência 3' ('polylinker' ou 'multicloning site') foi isolado do plasmídio pIJB13 (Figura 8), gerando os vetores pIJB18 e pIJB20 para transformação de cloroplastos de tomate via recombinação homóloga. Os vetores para transformação pIJB18 e pIJB20 estão apresentados nas Figuras 28 e 29 respectivamente. A distinção entre os vetores está na existência de dois (2) sítios de restrição adicionais no vetor pIJB20, o que pode ser de grande interesse para futuras clonagens e inserção de genes de interesse no respectivo vetor. Como pode ser visto na Figuras 28 e 29, o vetor pIJB20 apresenta os sítios de restrição EcoO109I e KpnI além daqueles presentes em pIJB18: XbaI, SpeI, BamHI, SmaI, PstI, EcoRI, EcoRV, HindIII, ClaI, Sall, HincII e XhoI. 
Devido à presença de sítios de reconhecimento para as enzimas de restrição $X b a I$, BamHI, HincII e EcoO109I na seqüência flanqueadora do gene marcador aadA (pTCTJ2), estes sítios não estão disponíveis para introdução de genes de interesse nos vetores para transformação de cloroplastos.

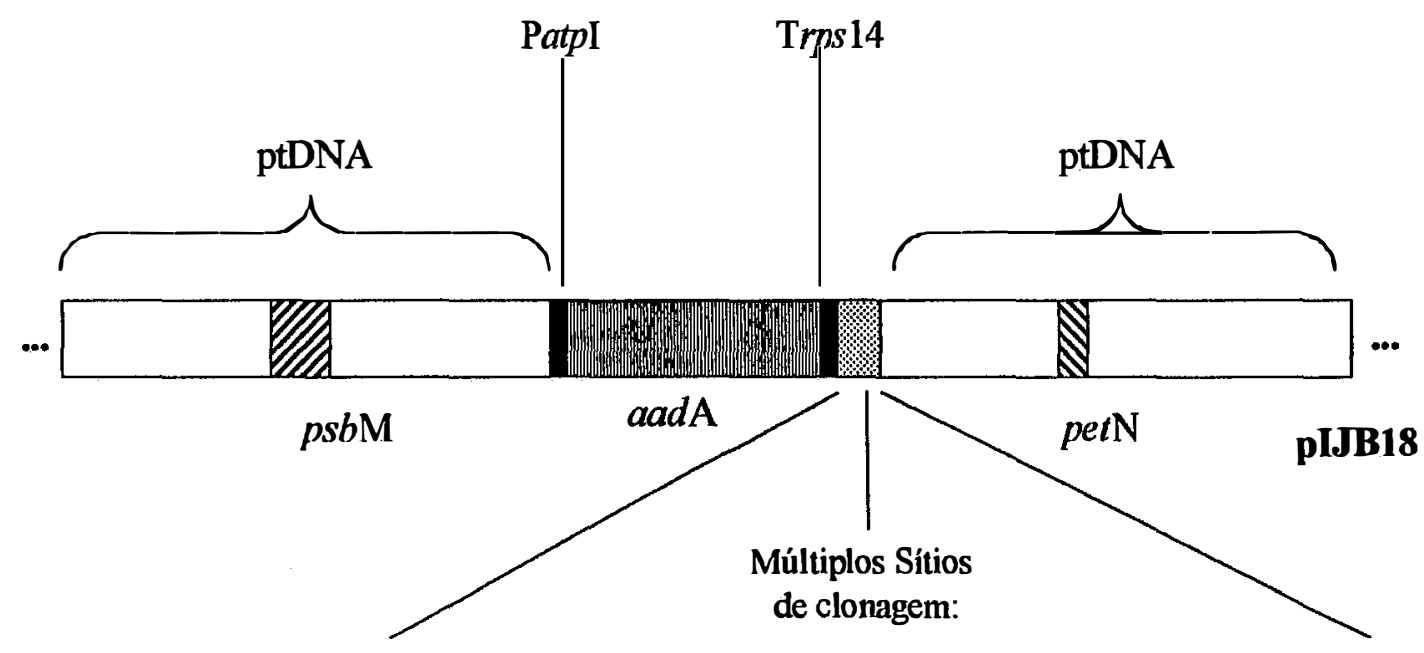

Xbal, SpeI, BamHI, SmaI, PstI, EcoRI, EcoRV, HindIII, ClaI, SalI, HincII, Xhol

Figura 22. Vetor final de transformação de cloroplastos de tomate pIJB18 em pBS KS (-).

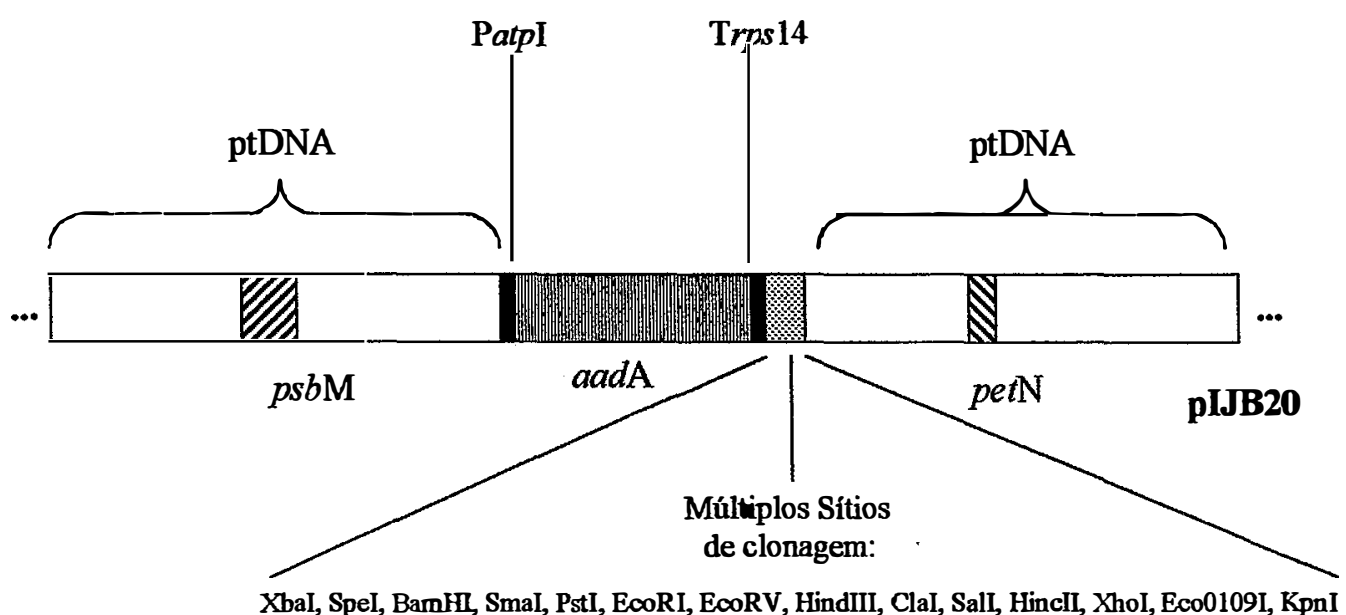

Figura 23. Vetor final de transformação de cloroplastos de tomate pIJB20 em pBS KS (-). 
A tecnologia de transformação de cloroplastos promete ser bastante útil no auxílio a programas de melhoramento genético. A transformação do genoma cloroplastidial torna possível a obtenção de plantas apresentando elevados níveis de expressão de transgenes e acúmulo de proteínas exógenas, garante transformação dirigida, segurança ambiental e ausência de efeitos epigenéticos, assim como permite a expressão de mais de um gene através de um único evento de transformação (como "operons"). Conforme discutido por Bock \& Hagemann (1999), por meio da transformação de cloroplastos um grande número de genes metabólicos bacterianos e "operons" completos podem ser potencialmente explorados para melhorar o valor nutricional de espécies cultivadas, para gerar plantas resistentes ao estresse e a doenças ou mesmo para produzir enzimas e farmacêuticos em plantas. 


\section{CONCLUSÕES}

Com base nos resultados apresentados, pode-se concluir:

- Ás seqüências cloroplastidiais dos fragmentos de tomate estudados (6.366 pb e 8.660 pb) quando comparadas com as correspondentes seqüências em tabaco apresentaram alta homologia, sendo o padrão genético do genoma cloroplastidial de tabaco bastante conservado em tomate;

- A análise de homologia dos espaços intergênicos entre os fragmentos cloroplastidiais de tabaco e tomate é menor quando comparada à homologia entre as regiões codificadoras, de modo que deleções, inserções, duplicações e substituições são freqüentemente encontradas;

- A existência de diversos espaços intergênicos nos fragmentos clonados e seqüenciados, os quais apresentam sítios únicos de restrição, potencializa a introdução de genes de interesse em cloroplastos, disponibilizando o desenvolvimento da tecnologia de transformação de cloroplastos de tomate (Lycopersicon esculentum L.);

- A construção dos vetores de transformação pIJB18 e pIJB20 tomou disponível a possibilidade de estabelecimento da tecnologia de transformação de cloroplastos de tomate. 


\begin{abstract}
ANEXO A: fragmento do genoma cloroplastidial de tabaco

\author{
Formato DIALIGN 2.1

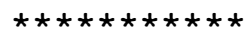 \\ Burkhard Morgenstern (1999)
}

Seqüências Alinhadas: tamanho (bases):

$\begin{array}{ccr}== & === \\ \text { 1) } & \text { LEpIJB1 } & ====== \\ \text { 2) } & \text { NT } & 8660 \\ & & 9127\end{array}$
\end{abstract}

Alinhamento do fragmento cloroplastidial de tomate de $8.660 \mathrm{pb}$ com o respectivo

Somente letras maiúsculas devem ser consideradas alinhadas Asteriscos confirmam identidade

\begin{tabular}{|c|c|c|c|c|c|c|}
\hline LEpI JBI & 1 & GTCGACCAAT & ССТТССТААТ & ТСАСАТСТTT & GTTGAAAGAA & TTTCTTTTGT \\
\hline NT & 26722 & 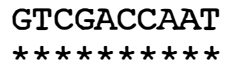 & 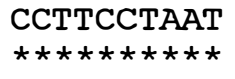 & 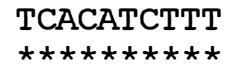 & 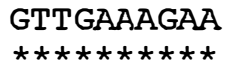 & 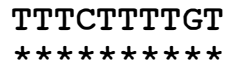 \\
\hline $\begin{array}{l}\text { LEpIJBI } \\
\text { NT }\end{array}$ & $\begin{array}{r}51 \\
+51\end{array}$ & 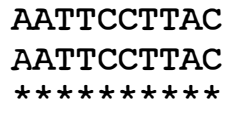 & 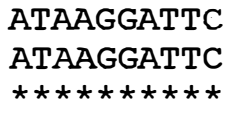 & 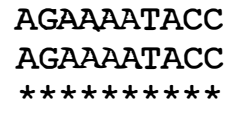 & $\begin{array}{l}\text { GGATCGCCAC } \\
\text { GGATCGCCAC } \\
\star \star \star \star \star \star \star \star \star \star\end{array}$ & 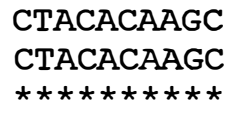 \\
\hline $\begin{array}{l}\text { LEpI JBI } \\
\text { NT }\end{array}$ & $\begin{array}{r}101 \\
+101\end{array}$ & 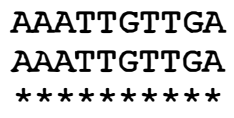 & 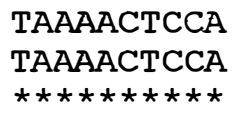 & $\begin{array}{l}\text { AAATGGAATT } \\
\text { AAATGGCATT } \\
\star \star \star \star \star \star \star \star \star \star\end{array}$ & 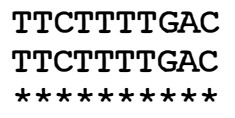 & 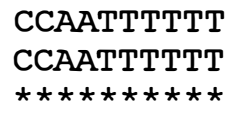 \\
\hline $\begin{array}{l}\text { LEpI JBI } \\
\text { NT }\end{array}$ & $\begin{array}{r}151 \\
+151\end{array}$ & 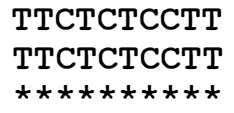 & $\begin{array}{l}\text { ATCATTCAGA } \\
\text { ATCACTCAGA } \\
\star \star \star \star \star \star \star \star \star \star ~\end{array}$ & 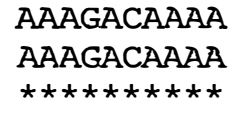 & 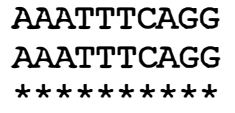 & $\begin{array}{l}\text { ATAGCAAACA } \\
\text { ATAGCAAACA } \\
\star \star \star \star \star \star \star \star \star \star ~\end{array}$ \\
\hline $\begin{array}{l}\text { LEpIJBI } \\
\mathrm{NT}\end{array}$ & $\begin{array}{r}201 \\
+201\end{array}$ & 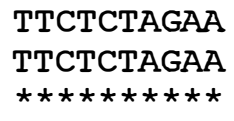 & 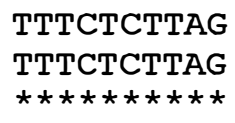 & 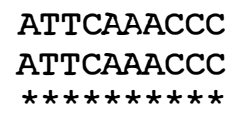 & 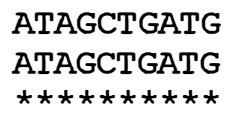 & 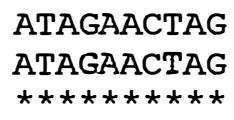 \\
\hline $\begin{array}{l}\text { LEpIJBI } \\
\mathrm{NT}\end{array}$ & $\begin{array}{r}251 \\
+251\end{array}$ & 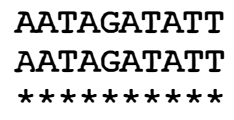 & 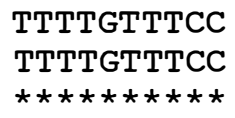 & 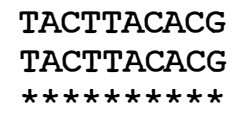 & 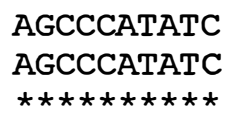 & 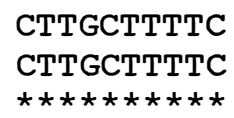 \\
\hline $\begin{array}{l}\text { LEpIJB1 } \\
\mathrm{NT}\end{array}$ & $\begin{array}{r}301 \\
+301\end{array}$ & 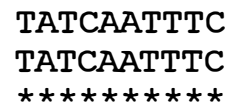 & 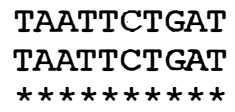 & 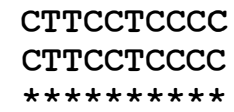 & $\begin{array}{l}\text { AATCTGATAT } \\
\text { AATCTGATAT } \\
\star \star \star \star \star \star \star \star \star \star ~\end{array}$ & 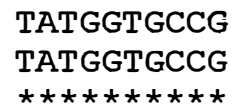 \\
\hline
\end{tabular}


LEPIJB1 35 NT +351

LEpIJB1

LEpIJB1 451 NT +451

LEpIJB1 $\quad 501$ NT +501

$\begin{array}{lr}\text { LEpIJB1 } & 551 \\ \text { NT } & +551\end{array}$

LEpIJB1 601 NT +601

LEPIJBI 651

NT +651

$\begin{array}{lr}\text { LEpIJB1 } & 701 \\ \text { NT } & +701\end{array}$

LEPIJB1 751

NT $+751$

LEPIJB1 801 NT $\quad+801$

LEPIJB1 851 NT $\quad+851$

$\begin{array}{lr}\text { LEpIJB1 } & 901 \\ \mathrm{NT} & +901\end{array}$

LEpIJB1 951 NT +951
GTATAGACCG AAATTCCGTT ATGGTCCAAT TCTGATCGGT AATAAATACC GTATAGACCG AAATTCCGTT ATGGTCCAAT TCTGATCGGT AATAAATACC

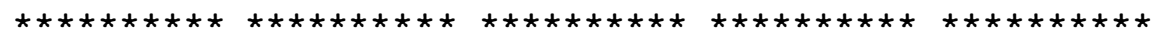

GGGACTTTGC AATATTTGAT TGATCACAAT TCTATATATT CCATTGACTA GGGACTTTGC AATATTTGAT TGATCACAAT TCTATATATT CCATTGACTA

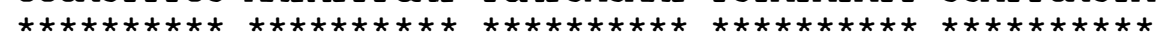

TAGAAGTTCC CAGGGAATTC ATTAGAGGAA TGTTTCCGAT AAAAATTGTT TAGAAGTTCC CAGGGAATTC ATTAGAGGAA TGTTTCCGAT AAAAATTGTT

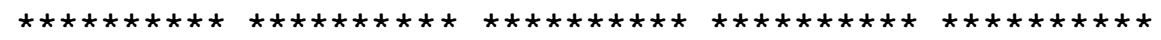

TGTTCTTGCA TATCCCTACT GTTTTTCCAA ATTAATCCCG CGGATACATA TGTTCTTGCA TATCCCTACT GTTTTTCCAA ATTAATCCCG CGGATACATA

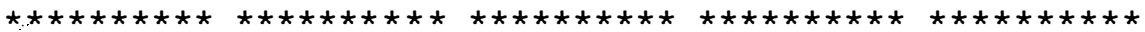

TAATTCAGAA GAATATGTGA GTGATTCATA CACAGCATCT CTTTCCTTTA TAATTCAGAA GAATATGTGA GTGATTCATA CACAGCATCT CTTTCCTTTA

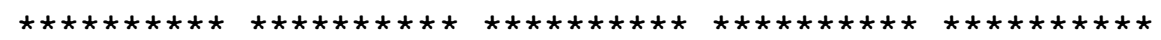

TCAAGGGTTC GACCAATTGA TATGTTTCCA CAAATAATTG AAATTCAATT TCAAGGGTTC GACCAATTGA TATGTTTCCA CAAATAATTG AAATTCAATT

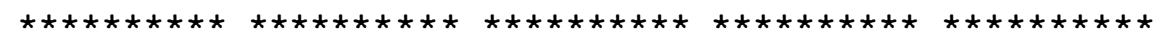

TCTTGATCTG TATCTTCAAT TTTTGGAAAC TTATAAAGTT CTTCCGTCAA TCTTGATCTG TATCTTCAAT TTTTGGAAAC TTATAAAGTT CTTCCGTCAA

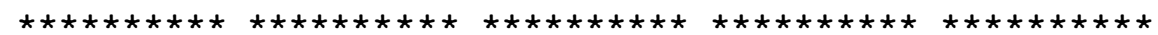

ACCTTGATCA ATGAACCTAC AAAATCCTTC AAATTGTATC TGATTAAATC ACCTTGATCA ATGAACCTAC AAAATCCTTC AAATTGTATC TGATTAAATC

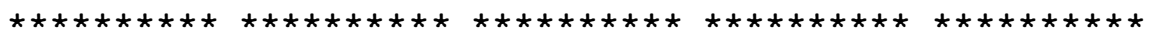

CAGGTATTGT AGATATTCCC TCATTTCCAT CCCCGAGCAT TTTaAATTTC CAGGTATTGT AGATATTCCC TCATTTCCAT CCCCGAGCAT TTTtAATTTC

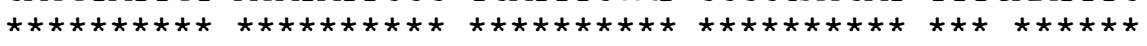

CCATTTAGCA AAAAATCCCA CTATTGGTTC ATTCTgLATC TAATTAGATA CCATTTATCA AAAAATACCA CTATTGGTTC ATTCT LCATC TAATTAGATA

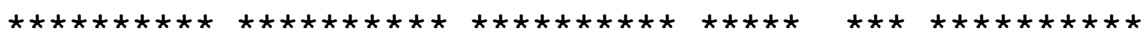

GATTAGATAA ATGATCTAGC AATGATGGCA TTTCTATTTT GTTTACCGAA GATTAGATAA ATGATCTAGC AATGATGGCA TTTCTATTTT GTTTACCGAA

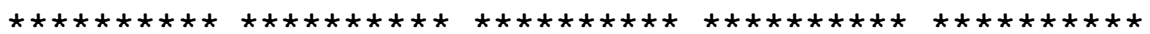

TCACATGAAA TTTTACCCAA CTCCATATCT GGAATGTATG AAATACGTAT TCACATGAAA TTTTACCCAA CTCCATATCT GGAATGTATG AAATACGTAT

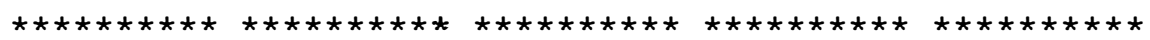

GAACGGAGGA AGAAGGAGAA TTTTCTACTT AAATTttaAA TTGaatTgaA GAACGGAGGA AGAAAGAGAA TTTTCTACTT AAATT--gAA TTGgaaTttA

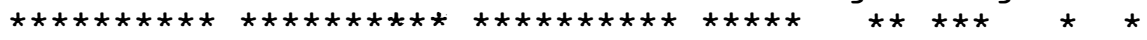




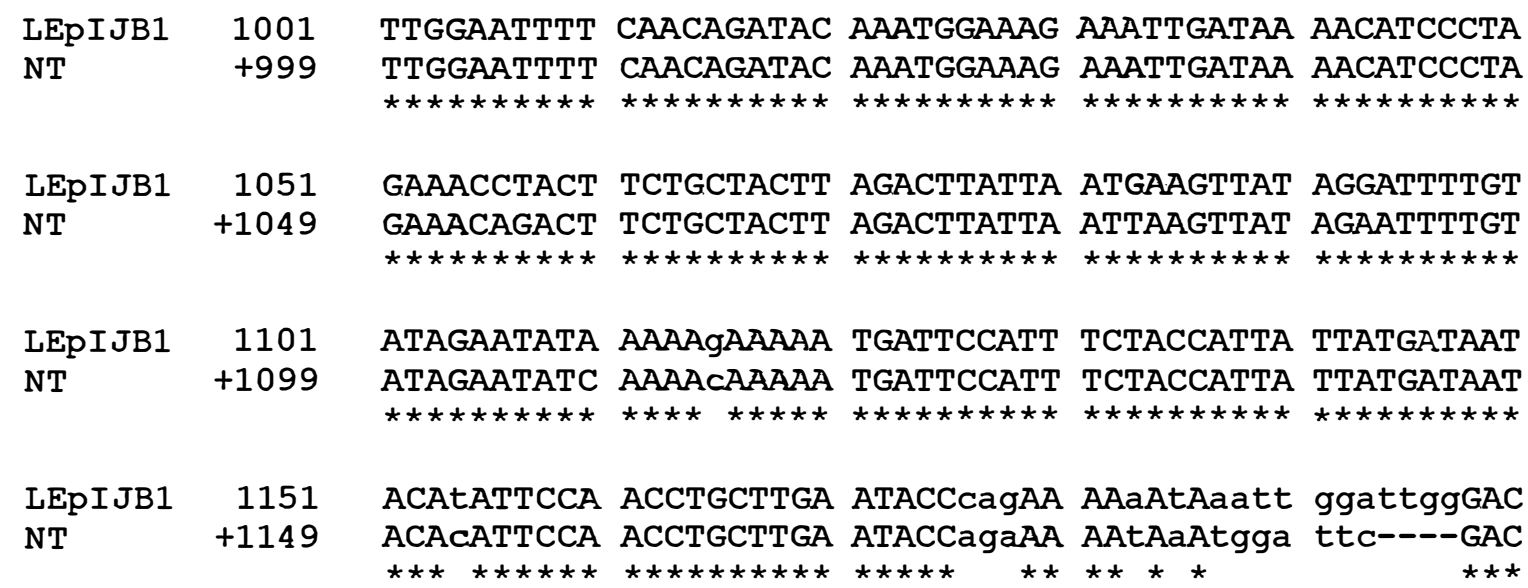

LEpIJB1 1201 ATTTGATCTT TTCgGCTGAg ATAAAgGCAT AAAAAatcAG AAAGAATATA NT +1195 ATTTGATCTT TTC-GCTGAG ATAAAGGCAT AAAAAta-AG AAAGAATATA

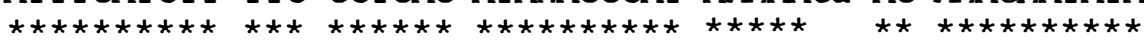

LEpIJB1 1300 TTCaattgTt CAAAAAATGA TTCGCAGAGA AGAGAGATAT TTTGTTTACG NT +1293

LEpI JB1 1350

NT +1342

LEpI JB1 1400 NT +1392

LEpIJB1 1450 NT +1442

LEpIJB1 1500 NT +1492

LEpIJB1 1550 NT +1542

LEpIJBI 1600 NT +1591

TAGAATTAGA ATCGGTTTTT TAGCATTTAA -CCCCCCTTA TGTTATGGAT TAGAATTAGA ATCGGTTTTT TAGCATTTAA CCCCCTTTTC TGTTATGGAT

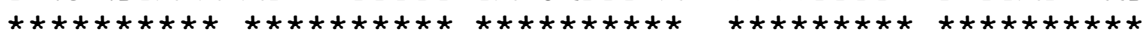
TTCgtTgcTa -AAAAAATGA TTTGTAGAGA AGAGAGAGAT TTTGTTTACG

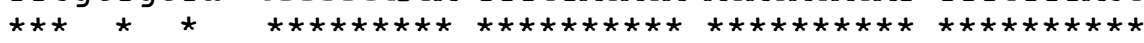

GATTTTTGA TAGAATACGA TTGTGAAGTG GATAAGAAAA GAAGGTTTGT GATTTTTGAA TAGAATACGA TTGTGAAGTG TATAAGAAAA GAAGGTTTGT

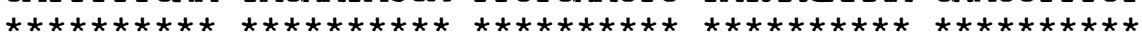

ATGGCTTAAA CACGTGTGGA GATATCTATA ATATCTGTCT TTCTTCTCTT ATGGCTTAAC CACGTGTGGA GATATCTATA ATATCCGTCT TTCTTCTCTT

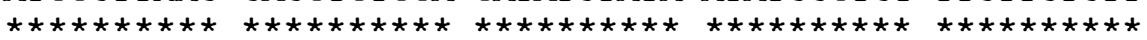

TTATTGTTT ATTGTCGTTt TaTGTTCTAT TCGgGGCAAC ACAGGTTGTG TTATTGTTTT ATTGTCGTTC TCTGTTCTAT TCGGGGCAAC CCGGGTTGTG

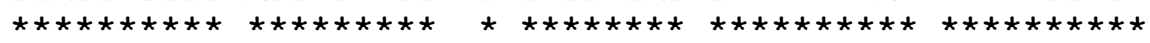

CTCTCCGAAA ACATAATTTC AАTTTTCTAT TCAATTCAAA ATTCAAATTG CTCTatgAAA ACAGAATTTC AATTTTCTAT TCAATTCAAA ATTCAAATTG

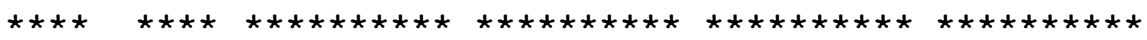

AAGTATGATA CTTTTCTGAT ATCTGATAAT TCTaTATCgG GAACATATAT AAGTATGATA CTTTTCTGAT ATCTGATAAT TCTCTATC-G GAACATATAT

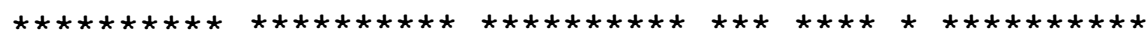

AAATAATATA TAtCCGTCTA ACAATTTATC TTttggggg TTTACATATA AAATAATATA TA-CCGTCTA ACAATTTCTC TT---GGGGG TTTACATATA

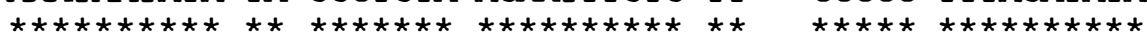


$\begin{array}{lr}\text { LEpIJB1 } & 1650 \\ \text { NT } & +1637\end{array}$

NT +1637

$\begin{array}{lr}\text { LEpIJB1 } & 1700 \\ \text { NT } & +1674\end{array}$

LEpIJB1 1750

NT $\quad+1712$

$\begin{array}{lr}\text { LEpIJB1 } & 1800 \\ +1762\end{array}$

LEpIJB1 1850

NT $\quad+1812$

LEpIJB1 1900

NT $\quad+1862$

$\begin{array}{lr}\text { LEpIJB1 } & 1950 \\ \text { NT } & +1907\end{array}$

LEpIJB1 2000

NT +1953

LEpIJB1 2050

NT +2003

LEpIJB1 2100

NT 2053

LEpIJB1 2150

NT 2103

LEpIJB1 2200

NT 2153

LEpIJB1 2245

NT 2203
CTGATAATTG TTGTTATAAT TAttattaat aatgaAAATT GAGAAGGATT CTCATAATTG TTGTTATAAT TA---_--- ----AAATT GAGAAGGATT

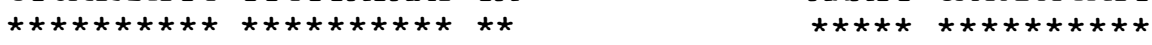

TTTTGATTGC AAAAATCCAT ACTGAactga TTgGTTatat atcATATATC TTTTGATTGA AAAAATCCAT ACTGA----- TTaGTT---- ---ATATATC

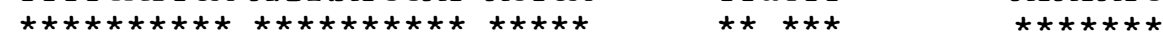

AAGTTGTATT TTCTTATGTC ATTAGGAAAC CAAAATTgGG AGATTCAAAT AAGTTGTATT TTCTTATGTC ATTAGGAAAA CAAAATTtGG AGATTCAAAT

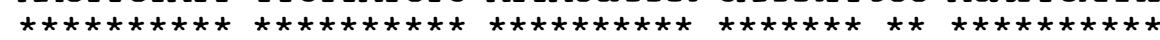

CCAAGAATCA TTCATGCATT CTAAggCAAT AgTTACTGGG TCCTATTTTC CCAAGAATCA TTCATGCATT CTAAGtCAAT AGTTAATGGT TCCGATTTTC

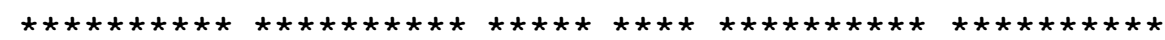

TGAAAGTTGA ATTTTGtATT TTGCGAATGA AAATCCACAT TTGATTTTTC AGAAATTTGA ATTTTGgATT TTGCGACTGA AAATCCACAT TTGATTTTTC

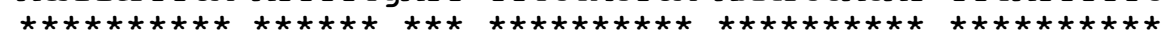

AATAGAAAGg TAAGAGAAAG TTTTGAACAT TATGAATTTG GAGATagact AATAGAAAGG TAAGAGAAAG CTTTGAACAT TATGAATTTG GAGAT-----

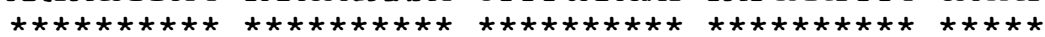

caatCGAAAT TGAAAGGATG AATCAAACCC AATCAAAAGG GAAGAAGGAT ---CGAAAT TGAAAGGATG AATCAAACCC AATCAAAAGG GAAGAAGGAT

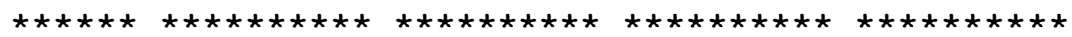

TAGGATTTCT TTGACTTTTA GGAAAAATTA AgGAAAACAG AACTCAAGGT TAGGATTTCT TTGACTTTTA GGAAAAATTA AGGAAAACAG AACTCAAGGT

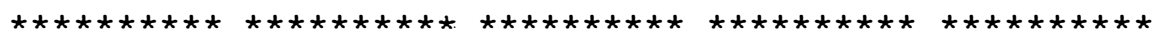

GCAAGTACAA TAAAAAAGCA GTTCAGTAAT CCGGGAAAGT TTTCATCTAT GCAAGTACAA TAAAAAAGCA GTTCAGTAAT CCTGGAAAGT TTTCATCTAT

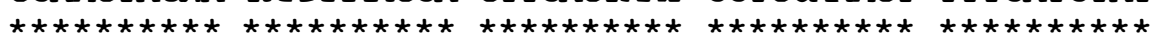

TTTGTATTTG TAGCATTTTG GCGACATGGC CGAGTGGTAA GGCAGAGGAC TTTGTATTTG TAGCATTTTG GCGACATGGC CGAGTGGTAA GGCAGAGGAC

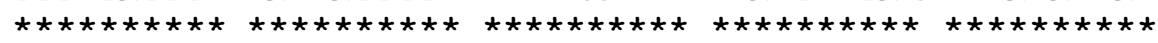

TGCAAATCCT TTTTTCCCCA GTTCAAATCC GGGTGTCGCC TGATCAACAA TGCAAATCCT TTTTTCCCCA GTTCAAATCC GGGTGTCGCC TGATCAACAA

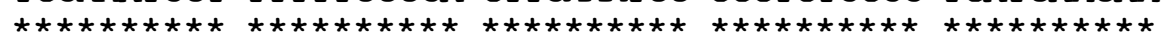

AAAACTGGAA ATCTCTTTTT TTC-----TT CTGTTGATAT AACCCGCCGA AAAACTCGAA ATCTCTTCTT TTCttctgTT CTGTTGATAT AACCCGCCGA

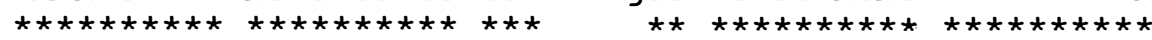

ATGATTCgCC AGCAGAAGCA GAGAAAgCAg ACTGTTGATA CTTGTTT--ATGATTCCCC AGCAGAAGCA GAGAAAGCAG ACTGTTGATA CTTGTTTgat

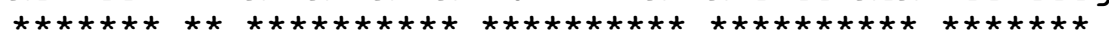




\begin{tabular}{|c|c|c|c|c|c|c|}
\hline LEpIJB1 & 2292 & -ー-ー-ー-ー- & TGGTCTGGGT & GTTTTTagAA & AAAATTGTAA & АTATCCTTGC \\
\hline $\mathrm{NT}$ & 2253 & tctaaacatc & TGGTCTGGGG & GTTTTTCtAA & AAAATTGTAA & АTATСTTTGC \\
\hline & & & 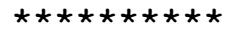 & $\star \star \star \star \star \star \star ~$ & 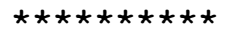 & 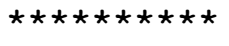 \\
\hline LEpIJBI & 2332 & АTTGCATATT & TAGGCTTagc & tttCAAGTAA & АTATTCGAAT & GCTCGAGGGG \\
\hline NT & 2303 & 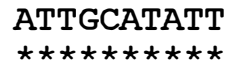 & $\begin{array}{l}\text { TAGGCTT--- } \\
\star \star \star \star \star \star \star\end{array}$ & 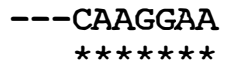 & 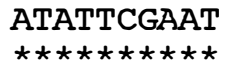 & 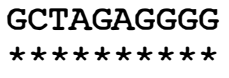 \\
\hline LEpIJBI & 2382 & СТАTСAAGAC & TTCGCAATTA & ССТТСТАСТА & CAAATCAAAA & ТTТТСТАТТА \\
\hline NT & 347 & $\begin{array}{l}\text { CTATCAAGAC } \\
\star \star \star \star \star \star \star \star \star \star \star\end{array}$ & 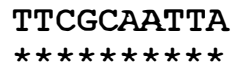 & 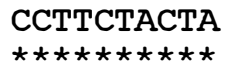 & $\begin{array}{l}\text { CAAATCAAAA } \\
\star \star \star \star \star \star \star \star \star \star * \star\end{array}$ & 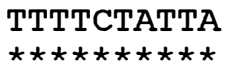 \\
\hline LEpIJBI & 2432 & TТАATССАТT & GTATAATGAC & TGGACCT--- & -------TGG & AGAGCCCGAT \\
\hline $\mathrm{NT}$ & 2397 & 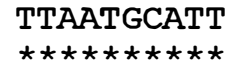 & 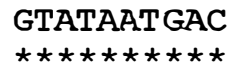 & $\begin{array}{l}\text { TGGACCTtga } \\
\star \star \star \star \star \star \star \star \star\end{array}$ & $\begin{array}{r}\text { attagatTGG } \\
\star \star \star\end{array}$ & 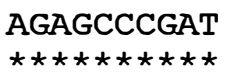 \\
\hline LEpIJBI & 2472 & AGGAAATCGA & AATAGTTGTG & GAAGGGGGCG & GAAGATACTT & TATTATATAC \\
\hline NT & 2447 & $\begin{array}{l}\text { AGGAAATCTA } \\
\star \star \star \star \star \star \star \star \star \star \star *\end{array}$ & 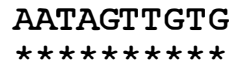 & 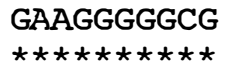 & 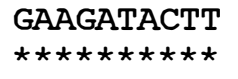 & 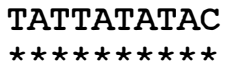 \\
\hline LEpI JBI & 522 & GAGGAACTCA & CGAAAATaTC & TCAGTGCTCA & AGCATCCAAT & CAATTCAAAT \\
\hline $\mathrm{NT}$ & 2497 & $\begin{array}{l}\text { GAGGAACTCA } \\
\star \star \star \star \star \star \star \star \star \star \star\end{array}$ & $\begin{array}{l}\text { CGAAAATCTC } \\
\star \star \star \star \star \star \star \star \star \star ~\end{array}$ & 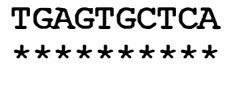 & $\begin{array}{l}\text { AGCATCCAAT } \\
\star \star \star \star \star \star \star \star \star \star \star \star\end{array}$ & $\begin{array}{l}\text { CAATTGAAAT } \\
\star \star \star \star \star \star \star \star \star \star \star *\end{array}$ \\
\hline LEpI JBI & 2572 & GAGGGTCAAC & AAAAAAAGAA & TAGGACCTAT & ТАТТССТАСА & TGTTCCATTA \\
\hline $\mathrm{NT}$ & 2547 & 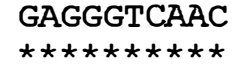 & 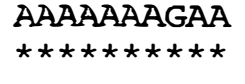 & 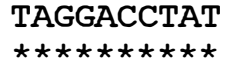 & 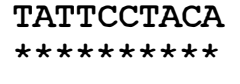 & 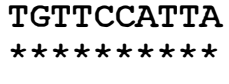 \\
\hline LEpI JBI & 2622 & GTAACATTCC & CTTGAGATGT & TACTGCGGAT & TTTGCTTGgG & TTTAАТСТTT \\
\hline NT & 2597 & $\begin{array}{l}\text { GTAACATTCC } \\
\star \star \star \star \star \star \star \star \star \star \star \star *\end{array}$ & 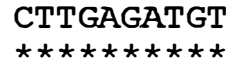 & $\begin{array}{l}\text { TACTGCAGAT } \\
\star \star \star \star \star \star \star \star \star \star \star \star *\end{array}$ & 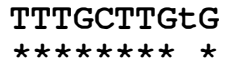 & $\begin{array}{l}\text { TTTAATCTTT } \\
\star \star \star \star \star \star \star \star \star \star \star * \star\end{array}$ \\
\hline LEpI JBI & 2672 & CCCGATTATA & АATCATATAG & МААТTТСТТА & TAAAATGAGC & GAАTTTATTG \\
\hline $\mathrm{NT}$ & 2647 & 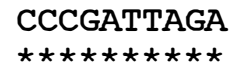 & 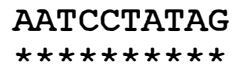 & $\begin{array}{l}\text { gAATTTCTTA } \\
\star \star \star \star \star \star \star \star \star \star * \star *\end{array}$ & 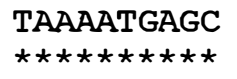 & 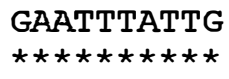 \\
\hline LEpIJBI & 2722 & GATTGGTTTA & TTAATAGTCT & TCGTTCTTTT & TGACTCTGCG & ССАTTGATTC \\
\hline $\mathrm{NT}$ & 2697 & 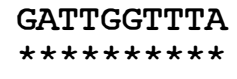 & $\begin{array}{l}\text { TTAATAGTCT } \\
\star \star \star \star \star \star \star \star \star \star \star\end{array}$ & 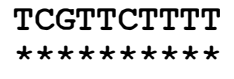 & 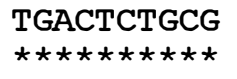 & 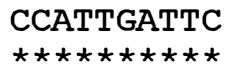 \\
\hline LEpIJBI & 2772 & ŁACTATTATT & AGTGAGGAAT & AATGGAACAA & ТTССТTTATA & TTTATAGAGA \\
\hline $\mathrm{NT}$ & 2747 & $\begin{array}{l}\text { CACTATTATT } \\
\star \star \star \star \star \star \star \star \star \star\end{array}$ & 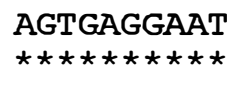 & 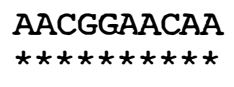 & 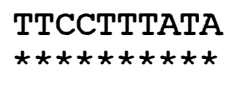 & 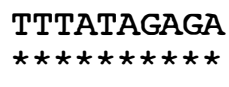 \\
\hline LEpI JBI & 2822 & TAGGGGACAT & АATTCATATG & GATATAGTAA & GTCTTGCTTG & GGCTGCTTTA \\
\hline $\mathrm{NT}$ & 2797 & 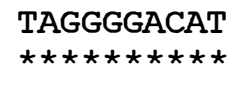 & 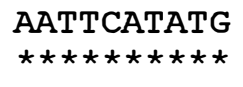 & 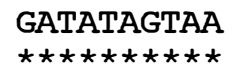 & 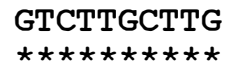 & 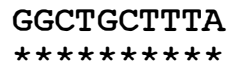 \\
\hline LEpIJBI & 2872 & ATGGTAGTCT & TTACTTTTTC & ССТТТСАСТС & GTAGTGTGGG & GAAGGAGTGG \\
\hline $\mathrm{NT}$ & 2847 & 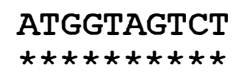 & $\begin{array}{l}\text { TTACTTTTTC } \\
\star \star \star \star \star \star \star \star \star \star \star * \star * t\end{array}$ & $\begin{array}{l}\text { ССТТТСАСТC } \\
\star \star \star \star \star \star \star \star * t * t * t\end{array}$ & 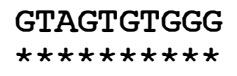 & 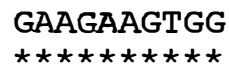 \\
\hline
\end{tabular}




\begin{abstract}
LEpIJB1 2922 ACTCTAGgg TtCTgCtAAT TGAgTtAAgg AAgCAAACTg TATCATTATC NT 2897 ACTCTAGGGg TCCTaCTAAT TGAGTTAAGG AAGCAAACTG TATCAATATC

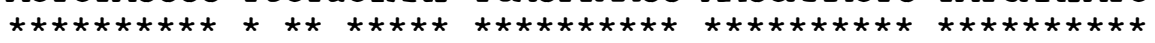

LEpIJB1 2972 AATTGCTTC TAGATGGTTC TGCAACACGT TTGGAACAAA ATaAAAATAT NT 2947

AATTGCTTTC GAGATCGTTC TGCAACACGT TTTGAACAAA ATCAAAATAT

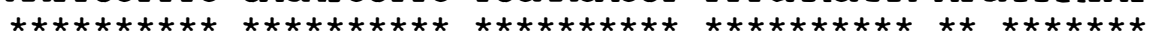

LEpIJB1 3022 CTTCATTTTG AAATTCCATT GGACTCGACT GGAGTAATGT ATTATAGGAA NT 2997

CTTCATTTTG AAATTCCATT GGACTCGACT GGAGTAATGT ATTATAGGAA

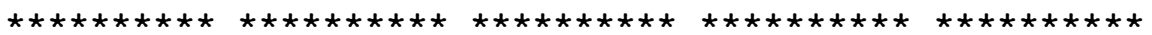

LEpIJB1 3072 TCAGCCTCTT TCAATCAAAg AaCTATTTCA ACGATTCCCA TGTTTGTAGT NT 3047 TCATCCTCTT TCAATCAAAG AgCTATTTCA ACGATTCCCA TGTTTGTAGT

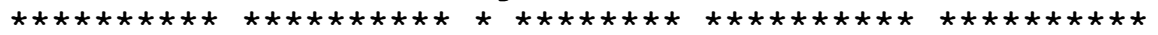

$\begin{array}{ll}\text { LEpIJB1 } & 3122 \\ \text { NT } & 3097\end{array}$

LEpIJBI 3172

NT 3147

LEpIJB1 3222

NT 3196

$\begin{array}{ll}\text { LEpI JB1 } & 3272 \\ \text { NT } & 3246\end{array}$

LEpIJB1 3322

NT

3296

LEpIJB1 3372

NT 3346

LEpIJB1 3420

NT 3396

LEpI JBI 3470

NT 3446

LEpIJB1 3512

NT 3496
TCGAAAGGAA aAgGATCCCA GgAAATTTAT TCGAACCTAA TTCTTaCtAA TCGAAAGGAA gAGGATCCCA GGAAATTTAT TCGAACCTAA TTCTTCCgAA

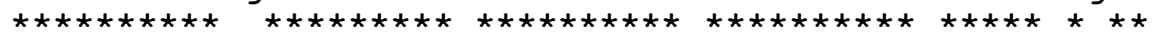

ATTTTCTATT CCAATCAATG GCCTCTTCCt AGGTGATACT GAGGAGGGCC ATTTTCTATT CCAATCAACG GCCTCTTaC- AGGTGATACT GAGGAGGGCC

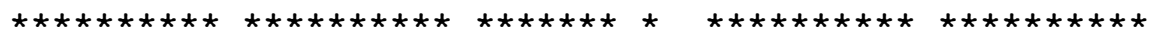

GGACCCGTTT TTTATTTggT TCTCTCTTTA CTGTTCAAAG AAaAaGTGGT GGACCCTTTT TTTATTTCtT TCTCTCTTTA CTGTTCAAAG AAgAgGTAGT

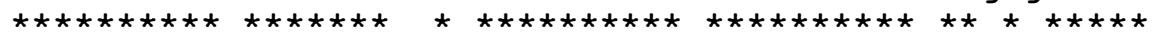

TTTGTTAAGT GTATAAGCAC TTTGTATGAg AAAGAAAGGA TATAAACATA TTTGTTAAGT GTATACGCAC TTTGTATGAG AAAGAAAGGA TATAAACATA

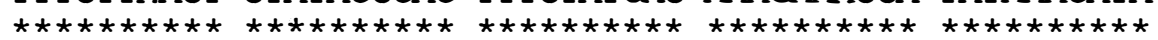

GTGGTTGTCT AACGAGATAC TATttAGAAT AAGATCGTCA GGTGAGTCAC GTGGTTGTCT AACGAGATAC TATgCAGAAT AAGATCTTCA GATGAGTCAC

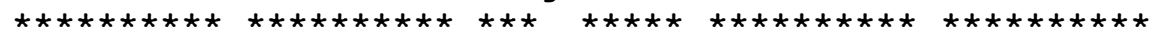

ATATTGCGCA TTTAC--CTT TCGAATTTTG GAAATTGGAT TTAGACTTTA ATATTGCGCA TTTACcgCTT TCGAATTTTT GAAATTGGAT TTATGCTTTA

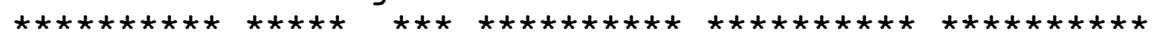

TCGACTTATT TCATATCATG GTTCAGGCCT TAAAAATCAG TGAGGTTTAC TCGACTTATT TCATATCATG GTTCAGGCGT TAAAAATCGG TGAGGTTTAC

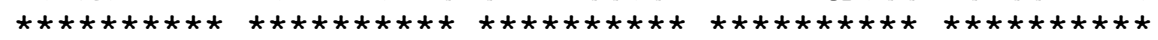

TCTTCCTTTT CGATGCCCGT GGAACTACTG TCAATGGT-- ------TTAC TCTTCCTTTT CGATGCCCGT GGAACTACTG TCAATGGTtt actcaaTTAC

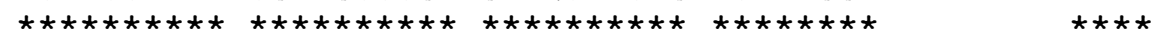

TTCTTAGGAA TGTTAAAAAA AAaaagATTA CTACGTGATT TTTTGAATAT TTCTTGGGAA TGTTAAAAAA AA---GATTA CTACGTGATT TTTTGAATCT

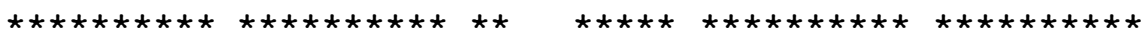




\begin{abstract}
LEpIJB1 3562 NT 3543

LEpIJB1 3612 NT 3593

LEpIJB1 3662

NT 3643

LEpIJB1 3712 NT 3693

LEpIJB1 3762

NT 3743

LEpIJB1 3798 NT 3793

LEpIJB1 3848 NT 3843

GCCTATATCT ATCGCTTTTg CTTCATTGAT TTGATTCTCT CAATAGATAC GCCTATATCT ATCGCTTTTC CTTCATTGAT TTGATTCTTT CAATAGATAC

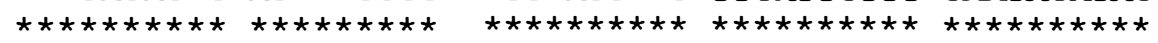

TGAGATTCAt ATTGgAAATC AAAAATATAG TAATTCAAAC TATAAGACAT CGAGATTCAg ATTGGAAATC AAAAATCTAG TAATTCAAAC TATAAGACAT

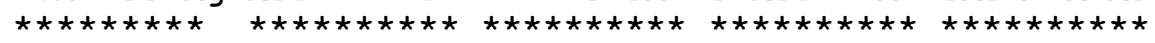

AggagtAatT CAGATTGATC AgAaCAAATA GATATAgCAA ATAAATGgAA AagAGTAATT TAGATTGATC AGAACAAATA GATATAGCAA ATAAATGGAA

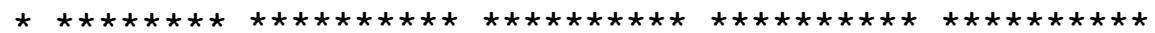

TTGGATGCTA TGTCAATCCC ATATATGGAA TTGATATTCA CATATATCAA TTGGATGCTA TGTCAATCCC ATATATGGAA TTGATATTCA CATATATCAA

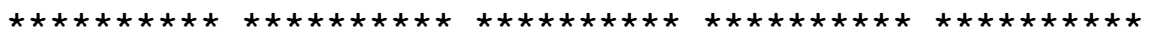

GATAATATTG TAGATTGATa Tat------ ------AGA TCCATATCAA GATAATATTG TAGATTGATC TATagatcca tatcaaaAGA TCCATATCAA

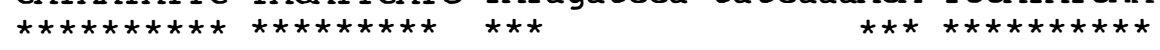

ATGCAGCCTC TATCTTTATT TTATTCCAGg GgGCAGCTTT ATAACAAGAA ATGCAGCCTC TATCTTTATT TTATTCCAGG GGGCAGCTTT ATAACTACAA

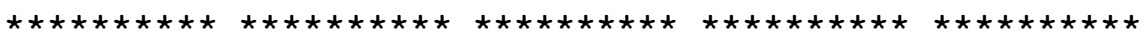

TCTAACTAAT AAATAGTATG GTAGAAAGAA ATAGATGAAT CTTTCT---TCTAACTAAT AAATAGTATG GTAGAAAGAA ATAGATGAAT CTTTCTttct

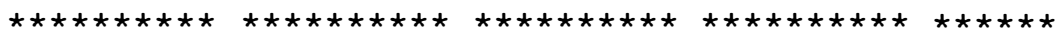

LEPIJB1 3894 NT 3893

LEpIJB1 3943 NT 3943

LEpIJB1 3993 NT 3993

LEpIJB1 4043 NT 4043

LEpIJB1 4093 NT 4093

LEpIJB1 4143 NT 4143

ACCATACTAT CTATCTATTA GAATACTGCC GATTCTAGTC CACtCA-TTT ACCATACTAT CTATCTATTA GAATACTGCC GATTCTAGTC CAtaCAtTTT

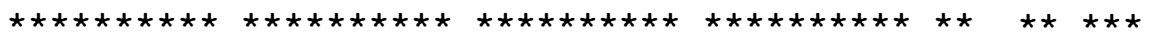

CATTTAAGAC ATGAAATTGG AATCTTTTTC ATTTTATTTC GTCAATTTTG CATTTAAGAC ATGAAATTA AATCTTTTTC ATTTTATTTC GTCAATTTTG

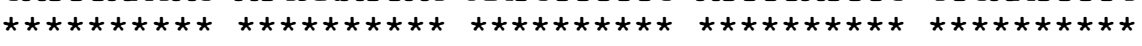

GCTAAGAACT CAGAAGTCAA GTTTCATTCA AATTAGTTAA TAATTAATCG GCTAAGAACT CAGAAGTCAA GTTTCATTCA AATTAGTTAA TAATTAATCG

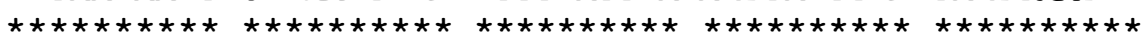

TTTTGACTGA CTGTTTTTAC ATAAATGATA AGTAGAAAAG CGGTAGgAAC TTTTGACTGA CTGTTTTTAC GTAAATGATA AGTAGAAAAG CGGTAGGAAC

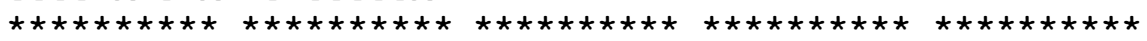

TAGAATAAAT AGTGCAGTAG CAATAAATGC AAGAATATTT ACTTCCATAA TAGAATAAAT AGTGCAGTAG CAATAAATGC AAGAATATTT ACTTCCATAA

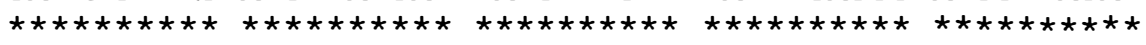

TCTCATCGGT TTTTTACTTC GCAATAACTC GGGATTTAAT CCCATAGAGA TCTCATCGGT TTTTTACTTC GCAATAACTC GGGATTTAAT CCCATAGAGA

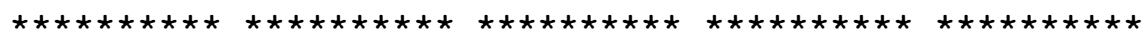


$\begin{array}{ll}\text { LEpIJB1 } & 4193 \\ \text { NT } & 4193\end{array}$

LEpIJB1 4243

NT

LEpIJB

NT

LEpIJB1 4343

NT

4343

$\begin{array}{ll}\text { LEpIJB1 } & 4393 \\ \text { NT } & 4393\end{array}$

LEpIJB1 4437

NT

4443

LEpIJB1 4487

NT

LEpIJB1

NT

$\begin{array}{ll}\text { LEpIJB1 } & 4585 \\ \text { NT } & 4593\end{array}$

LEpIJB1 4635

NT

4643

LEpIJB1 4685

NT

4693

LEpIJB1 4735

NT

4742

LEpIJB1 4785

NT
TGATAAATCT TTGGCCTGTA AATTCAATGA ATGAATATTA CCTCTCGATG TGATAAATCT TTGGCCTGTA AATTCAATGA ATGAATATTA CCTCTCGATG

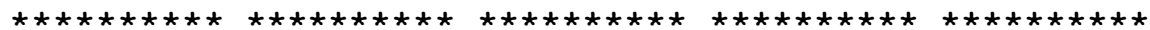

ATCTTGAATC aGATCAATAT CATGAATAAC AATATCTGAA CTATCAAATa ATCTTGAATC gGATCAATAT CATGAATAAC AATATCTGAA CTATCAAATC

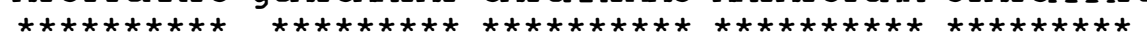

AATTCGTCGT CGAGAATTGA ATAGTATAAC ATAGGAAGTT CTTTTATCCA AATTCGTCGT CGAGAATTGA ATAGTATAAC ATAGGAAGTT CTTTTATCCA

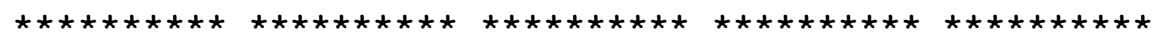

TACCGCCCCA AACTCGGATT GCTGACCTAA CCCAAAATTC CTTTATTTAT TACCGCCCCA AACTTGGATT CCTGACCCAA tCCAAAATTC CTTTATTTAT

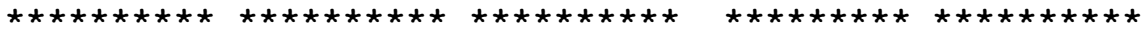

TTATCATT-- ----TTTTAT TATCTGTTCT TTTTTTCTCT CTAATCTATC TTATCATTat cattTTTTCT CATCTGTTCT TTTTTTCTCT CTAATCTATC

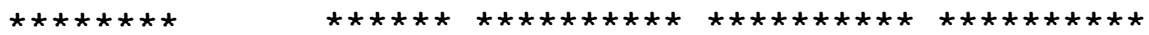

TAGTTCCTTC TTGTACAATC ATCTGATGAA GTCTCATCAA ATAGCTCTTC TAGTTCCTTC TTGTACAATC ATCTGATGAA GTCTCATCAA ATAGCTCTTC

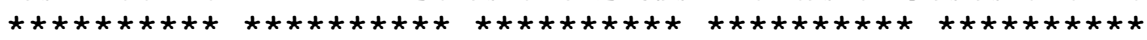

CACTTCCAGT GGT--CACAT AGTTACAAAC CCAAACAAAC AATAAAAGCT CACTTCCAGT GGTCaCACAT AGTTACAAAC CCAAACAAAC AATAAAAGCT

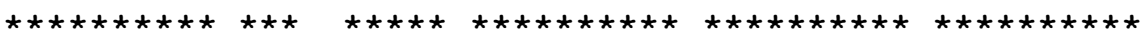

AAATGGAAAA AGAAAGGAGT TTAGAACGAA ACTATTTTTG ACTTGGAAGA AAATGGAAAA AGAAAGGAGT TTAGAACTAA ACTATTTTTG ACTTGGAAGA

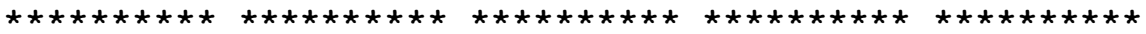

CAAAGAAGTG TGATAAAGAT GAGACCGTAT AAAATGAATA TTCATCAAAT CAAAGAAGTG TGATAAAGAT GAGACCGTAT AAAATGAATA TTCATCAAAT

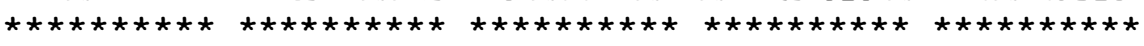

TGACTATTTT CCGATTTGTT CggTCGTCGA TGGGGCCTTA AAACAAAATG TGACTATTTT CCGATTTGTT CttTCGTCGA TGGGGCCTTA AAACAAAATG

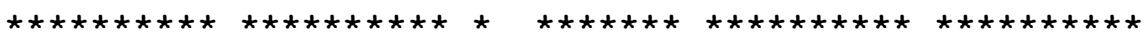

AAAAATaGGA AAAATGATTC ATTCGCCTTT CTAAGAGGAG TAGGATCTTt AAAAATCGGA AAAATGATTC ATTCCCCTTT CTAAGAGGAG TAGGATCTT-

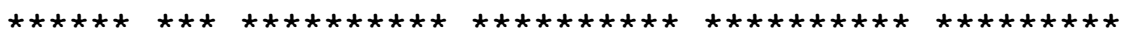

ggttgatctg TCCTTCCCCC TCCTTTCTTC GTCGATTATT AGCCCCCGGG -------- TCCTTTCCCC TCCTTTCTTC GTAGATTATT AG-CCCCGGG

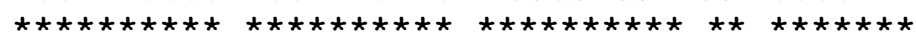

ACACCTATAC CAAAAGCTCA GTGTGCAATT TGCATGAAAT CTATTTTGCA ACACCTATAC CAAAAGCTCA GTGTGCAATT TGCATGAAAT CTATTTTTCA

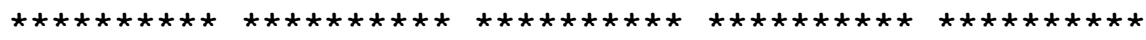




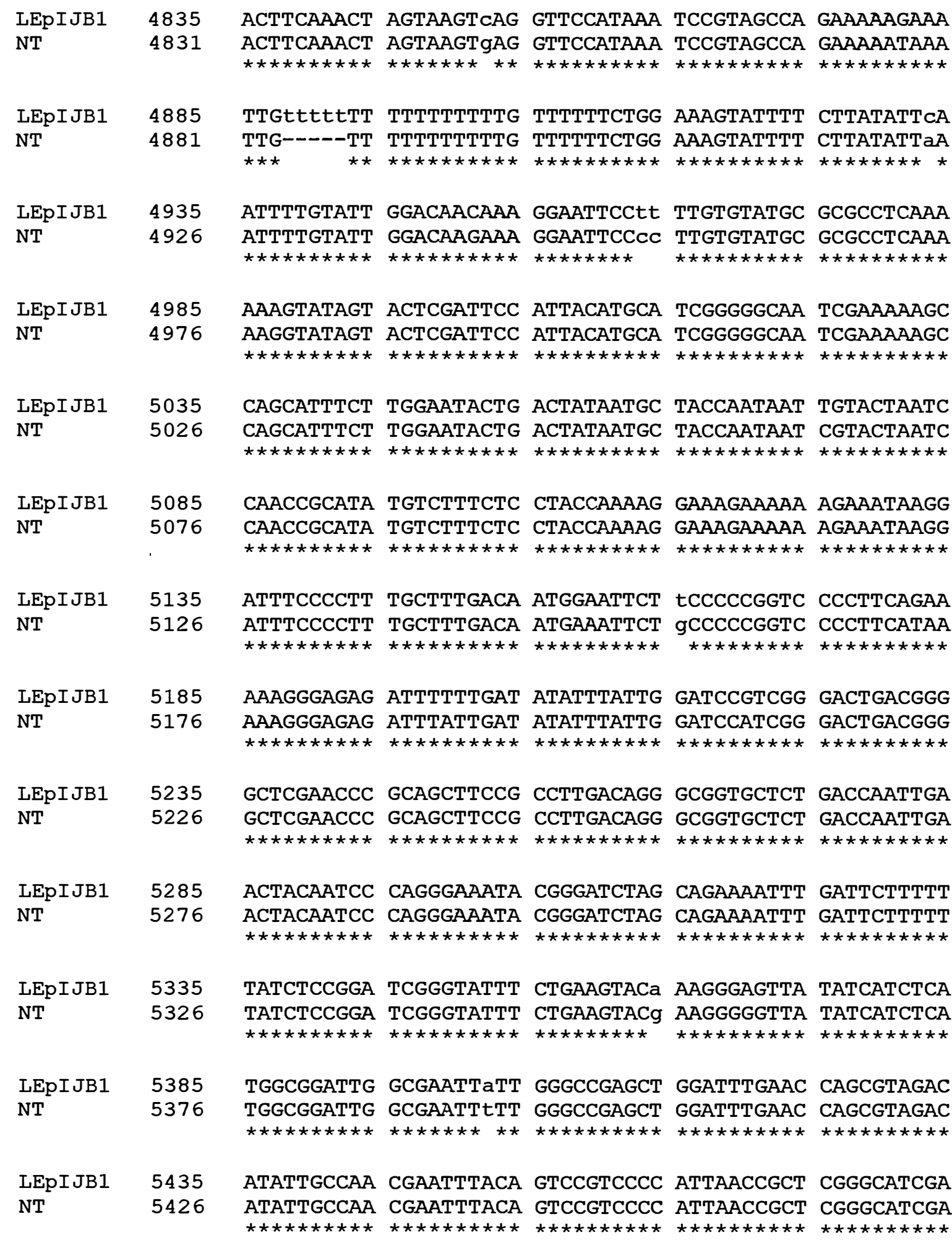




\begin{tabular}{|c|c|c|c|c|c|c|}
\hline LEpIJBI & 5485 & CCCAGGAAGA & АТСААТТТТС & аAСTTATTGG & TAATCCATGA & ТСААТТТССТ \\
\hline $\mathrm{NT}$ & 5476 & $\begin{array}{l}\text { CCCAAGAAGA } \\
\star \star \star \star \star \star \star \star \star \star \star * \star\end{array}$ & 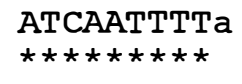 & $\begin{array}{c}\text { gACTTATTGG } \\
\star \star \star \star \star \star \star \star \star \star * t\end{array}$ & 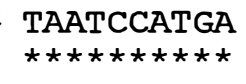 & $\begin{array}{l}\text { TCAАCTTCCT } \\
\star \star \star \star \star \star \star \star \star \star \star * \star\end{array}$ \\
\hline $\begin{array}{l}\text { LEpIJB1 } \\
\text { NT }\end{array}$ & $\begin{array}{l}5535 \\
5526\end{array}$ & $\begin{array}{l}\text { TTCGTAGTAC } \\
\text { TTCGTAGTAC } \\
\star \star \star \star \star \star \star \star \star \star\end{array}$ & $\begin{array}{l}\text { ССТАСССССА } \\
\text { ССТАCССССA } \\
\star \star \star \star \star \star \star \star \star \star\end{array}$ & $\begin{array}{l}\text { GGGGAATTCG } \\
\text { GGGGAATTCG } \\
\star \star \star \star \star \star \star \star \star \star\end{array}$ & $\begin{array}{l}\text { AATCCCCGCT } \\
\text { AATCCCCGCT } \\
\star \star \star \star \star \star \star \star \star \star\end{array}$ & $\begin{array}{l}\text { GCCTCCTTGA } \\
\text { GCCTCCTTGA } \\
\star \star \star \star \star \star \star \star \star \star\end{array}$ \\
\hline $\begin{array}{l}\text { LEpIJBI } \\
\text { NT }\end{array}$ & $\begin{array}{l}5585 \\
5576\end{array}$ & 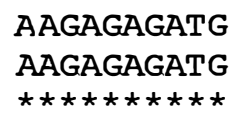 & 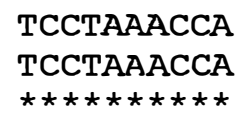 & 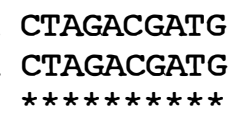 & 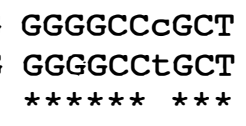 & 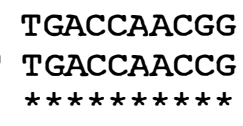 \\
\hline $\begin{array}{l}\text { LEpIJBI } \\
\mathrm{NT}\end{array}$ & $\begin{array}{l}5635 \\
5626\end{array}$ & 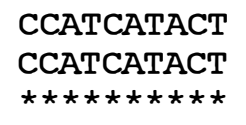 & 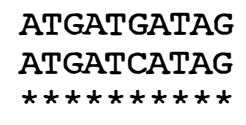 & $\begin{array}{l}\text { TATGATCCGT } \\
\text { TATGATCaGT } \\
\star \star \star \star \star \star \star \star \star \star\end{array}$ & 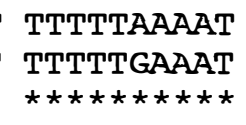 & 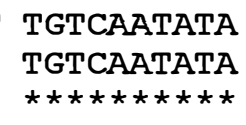 \\
\hline $\begin{array}{l}\text { LEpIJB1 } \\
\text { NT }\end{array}$ & $\begin{array}{l}5685 \\
5676\end{array}$ & 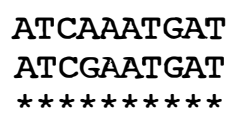 & 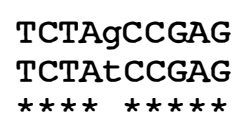 & 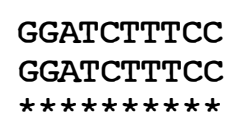 & $\begin{array}{l}\text { ССССТTCAGA } \\
\text { CССTTTCAGA } \\
\star \star \star \star \star \star \star \star \star \star\end{array}$ & $\begin{array}{l}\text { ATTGCATAGA } \\
\text { ATTGCATAGA } \\
\star \star \star \star \star \star \star \star \star \star\end{array}$ \\
\hline $\begin{array}{l}\text { LEpIJB1 } \\
\text { NT }\end{array}$ & $\begin{array}{l}5735 \\
5726\end{array}$ & $\begin{array}{l}\text { ATTgtTTTTT } \\
\text { ATT--TTTTT } \\
\star \star \star \\
\star \star \star \star \star \star \star\end{array}$ & 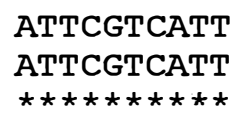 & $\begin{array}{l}\text { GACGAATTAT } \\
\text { GATGAATTAT } \\
\star \star \star \star \star \star \star \star \star \star \star *\end{array}$ & 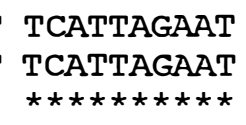 & $\begin{array}{l}\text { CGaCATTAGA } \\
\text { CGCCATTAGA } \\
\star \star \star \star \star \star \star \star \star \star *\end{array}$ \\
\hline $\begin{array}{l}\text { LEpIJB1 } \\
\text { NT }\end{array}$ & $\begin{array}{l}5785 \\
5774\end{array}$ & $\begin{array}{l}\text { AATCTAGTAG } \\
\text { AATCTAGTAG } \\
\star \star \star \star \star \star \star \star \star \star \star\end{array}$ & 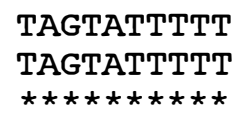 & $\begin{array}{l}\text { TTT------- } \\
\text { TTTtttttgg } \\
\star \star \star\end{array}$ & 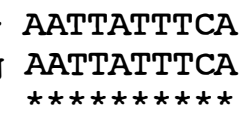 & $\begin{array}{l}\text { ATTGAATTTA } \\
\text { ATTGAATTTC } \\
\star \star \star \star \star \star \star \star \star \star \star *\end{array}$ \\
\hline $\begin{array}{l}\text { LEpIJB1 } \\
\text { NT }\end{array}$ & $\begin{array}{l}5828 \\
5824\end{array}$ & $\begin{array}{l}\text { TTTCt----- } \\
\text { TTTCgattat } \\
\star \star \star \star\end{array}$ & $\begin{array}{l}-------- \\
\text { tttagtttag }\end{array}$ & --------- & atttagaatt & $\begin{array}{l}-------- \\
\text { ttctttttt }\end{array}$ \\
\hline $\begin{array}{l}\text { LEpIJB1 } \\
\mathrm{NT}\end{array}$ & $\begin{array}{l}5833 \\
5874\end{array}$ & attataaata & aaaaaaaat & taataaatac & aaaaataga & aataataagg \\
\hline $\begin{array}{l}\text { LEpIJB1 } \\
\text { NT }\end{array}$ & $\begin{array}{l}5833 \\
5924\end{array}$ & --------- & $\begin{array}{l}-------- \\
\text { tttttgcagg }\end{array}$ & gaatgattgg & tccgtcagaa & aaggaaaaag \\
\hline $\begin{array}{l}\text { LEpIJB1 } \\
\mathrm{NT}\end{array}$ & $\begin{array}{l}5833 \\
5974\end{array}$ & gtgtgaaatt & ctatttcttt & cactttcatt & tgattcattg & ttaagacgag \\
\hline $\begin{array}{l}\text { LEpIJB1 } \\
\text { NT }\end{array}$ & $\begin{array}{l}5833 \\
6024\end{array}$ & atatccttat & ctccetcca & ccaagacagg & aaattaacaa & acgagaaatc \\
\hline $\begin{array}{l}\text { LEpIJB1 } \\
\mathrm{NT}\end{array}$ & $\begin{array}{l}5833 \\
6074\end{array}$ & tagtaagcgg & gatcaagaag & aaaattcttt & tttctccaag & aatttagttc \\
\hline $\begin{array}{l}\text { LEpIJB1 } \\
\text { NT }\end{array}$ & $\begin{array}{l}5833 \\
6124\end{array}$ & aggagacaag & tagaatctct & tcattccatg & attcgatgaa & atatcttgaa \\
\hline
\end{tabular}




\begin{tabular}{|c|c|c|c|c|c|c|}
\hline LEpIJB1 & 5833 & -ーーーーーーーーー & -ーーーーーーー- & -ーーーーーーーーー & ーーーーーーーーーー & -ーーーーーーーー \\
\hline $\mathrm{NT}$ & 6174 & ttttatgttg & aattgctagg & tgtatgtaca & tgtatcaatc & aagtgaattt \\
\hline LEpIJB1 & 5833 & ---ー--ー--- & ----- & ---- & $--------\mathrm{AT}$ & TCGAGTCGGT \\
\hline $\mathrm{NT}$ & 6224 & tgttctggtg & ggatcaattc & aataaaagaa & $\begin{array}{r}\text { aaaaagcaAT } \\
\star \star\end{array}$ & 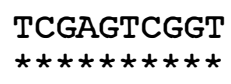 \\
\hline LEpIJB1 & 5845 & СTTGAAACAA & TTCATTGCAT & TTТСТССТАТ & ACTTCCTAGG & TAAATCCATT \\
\hline $\mathrm{NT}$ & 6274 & 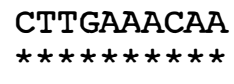 & 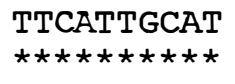 & 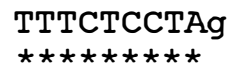 & 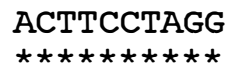 & 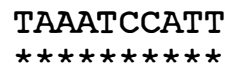 \\
\hline LEpIJB1 & 5895 & ТТАТТАТТСА & ACAATGAGCC & ACTAGACACT & АTGTATСTAC & TGCACGTACT \\
\hline $\mathrm{NT}$ & 6324 & 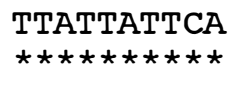 & 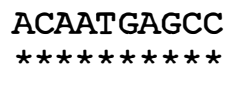 & 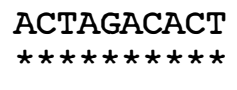 & 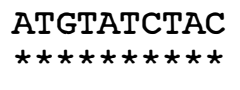 & 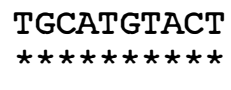 \\
\hline LEpIJB1 & 5945 & TAаTGCATAT & АTACTTATGT & ТTATAАTATA & AGTACATATA & GATATTTaAT \\
\hline $\mathrm{NT}$ & 6374 & 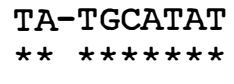 & 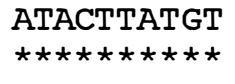 & 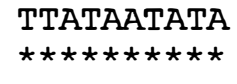 & 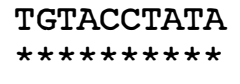 & 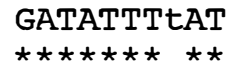 \\
\hline LEpIJB1 & 5995 & CCACATAGTG & АATAATTCCG & GAATTAAATA & AAAAAGGCCC & ТTTTAАСТСА \\
\hline $\mathrm{NT}$ & 6423 & 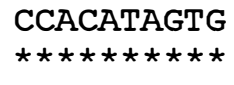 & 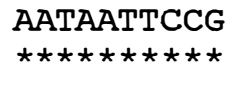 & 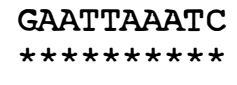 & 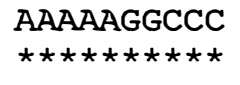 & 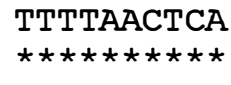 \\
\hline LEpIJB1 & 6045 & GTGGTAGAGT & AACGCCATGG & TAAGGCGTAA & GTCATCGGTT & CAAATCCGAT \\
\hline $\mathrm{NT}$ & 6473 & 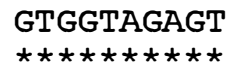 & 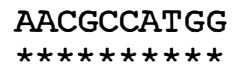 & 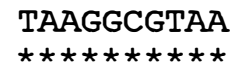 & 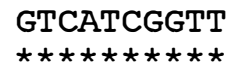 & 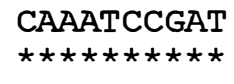 \\
\hline LEpIJB1 & 6095 & AAGGGGCTTT & GTAAAACCCC & AATCTAGTAT & TСATATTTGA & TGGGAGAATT \\
\hline NT & 6523 & 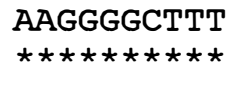 & 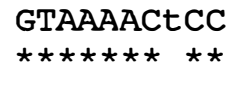 & 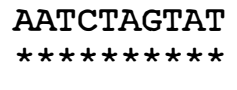 & 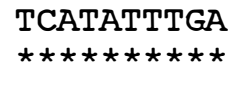 & 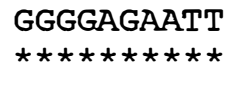 \\
\hline LEpIJB1 & 6145 & TTСТTTTАТ & TTGTAATAAA & АAAAGTAACT & AACTGGATAA & TACATTATC- \\
\hline $\mathrm{NT}$ & 6573 & 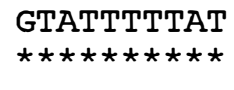 & 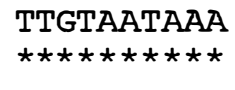 & 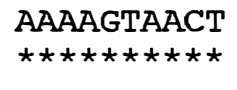 & 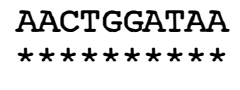 & 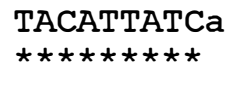 \\
\hline LEpIJB1 & 6194 & -ーー-ーーーー-ー & --АТТАТАСТ & TAGTTATAAA & GTTGAACATT & TGTTTAGTCA \\
\hline $\mathrm{NT}$ & 6623 & ttatacttaa & 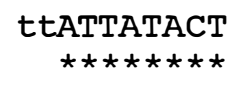 & 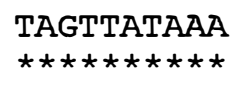 & 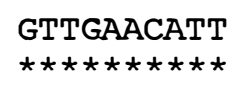 & 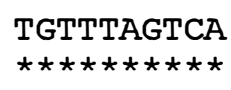 \\
\hline LEpIJB1 & 6232 & АТTTTСАTТА & GTATGAATTT & AGGAATAATG & AAAAGTCACT & TCTTGAA-TC \\
\hline $\mathrm{NT}$ & 6673 & 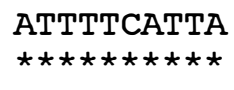 & 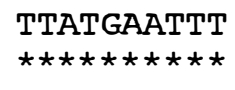 & 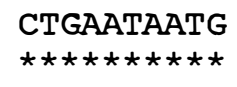 & 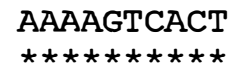 & $\begin{array}{l}\text { TCTTGAACTC } \\
\star \star \star \star \star \star \star \star \star \star ~\end{array}$ \\
\hline LEpIJB1 & 6281 & ACCGAATATT & ССТАТТTТСС & АТTATACCAA & ССАААТСgAT & TCGAAAGGTT \\
\hline $\mathrm{NT}$ & 6723 & 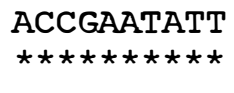 & 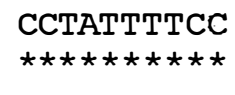 & 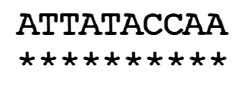 & 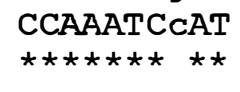 & 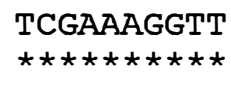 \\
\hline LEpIJB1 & 63 & AGAAATCAAC & AAAAGAAAAA & GTAAaaagta & aGTGGACCTG & ACCTATTGAA \\
\hline NT & 6773 & $\begin{array}{l}\text { AGAAATCAAC } \\
\star \star \star \star \star \star \star \star \star \star \star \star * \star\end{array}$ & $\begin{array}{l}\text { AAAAGAAAAA } \\
\star \star \star \star \star \star \star \star \star \star \star * \star\end{array}$ & $\begin{array}{l}\text { GTAA------ } \\
\star \star \star \star\end{array}$ & 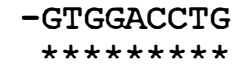 & 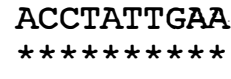 \\
\hline
\end{tabular}




\begin{abstract}
LEpIJB1 6381 TCATGACTAT ATCCGCTATT CTGATATTAA AATTCGATAG AGATGAAAT NT 6816 TCATGACTAT ATCCGCTATT CTGATATTAA AATTCGATAG AGATGAAATT

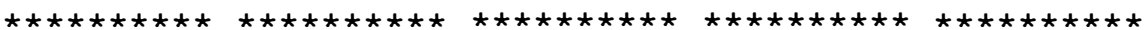

LEpIJB1 6431 NT 6866

LEpI JB1 6479

NT 6916

LEpI JB1 NT

6529 6966

LEpIJB1 6579

NT 7016

$\begin{array}{ll}\text { LEpIJB1 } & 6629 \\ \text { NT } & 7066\end{array}$

GGAGCAGTTG A--TTTTTTT TATTTCATTT TTTTGTTTTG GACTCCACAA GGAGCAGTTG AttTTTTTTT AATTTCATTT TTTTGTTTTG GAtTCCACAA

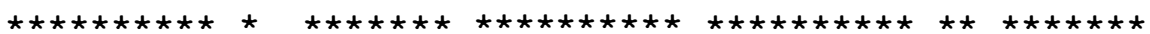

GAATTTGCG ATATTTCCGA TTAAATCTTC TTGTTACTAG ATTTTCTATA GAATTTTCG ATATTTCCGA TTAAATCTTC TTGTTACTAG ATTTTCTATA

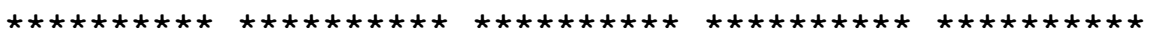

GGAAAAATTA TCGGAATAAt TTGTTATTCC TTTCCTCTAC AGAGAAACCT GGAAAAATTA TAGGAATAAa TTGTTATTCC TTTCCTCTAC AGAGAAACCT

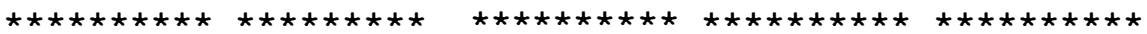

TTCTTCCAAG gCACACCATA AGAGCCATTT ATTATtTTTC TTTGATTCTA TTCTTCCAAG tCACACCATA AGAGCCATTT ATTATCTTTC TTTGATTCCA

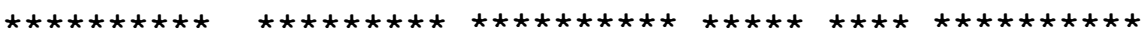

GATCAAAGAT TAATTTCATC taTAt---- --GATCAAAGAT TAATTTCATC atTAattct atctagatta TATATCTATA

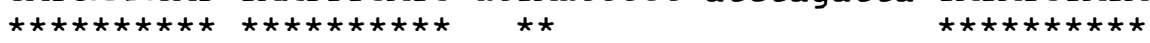

LEpIJB1 6664

NT

7116

LEpIJB1 6714

NT 7162

LEpIJB1 6764 NT 7212

LEpIJB1 $\quad 6814$ NT 7261

LEpIJB1 6857 NT 7311

LEpIJB1 6894 NT 7361

LEpIJBI 6944 NT 7411
TTATATTAAG TAGATTGTAg attgATTTCG ATGTATATCT ATCAGATCaT TTATATTAAG TAGATTGTA- ---GATTTCG ATGTATATCT ATCAGATCgT

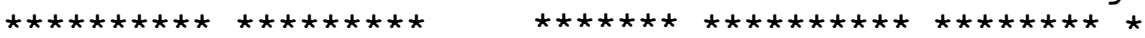

GGCTTCATGT ACCAAATATT TCAATATCGT TGCATCCGGT ATTTTTGTTT GGCTTCATGT ACCAAATATT TCAATATCGT TGCATCCGGT ATTTTTGTTT

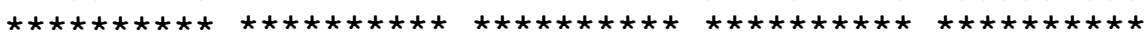

TGTTCCACCA GTGTGATGAA GAATAGATCC CGAGAAAGAG ACTTTCATTT TGTTCCAACA GTGTGATGAA GAATAGATC- CGAGAAAGAG ACTTTCATTT

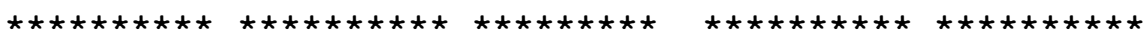

CCAGTCTCCT ATTTA---- --TTTATTGA ATTTTAGATT TTCTAAAAGG TCAGTCTCTT ATTTAttta ttTTTATTGA ATTTTCGATT TTCTAAAAGG

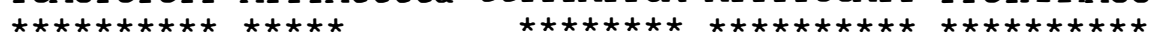

АААA----- ------ATA GTAGATTATC TCTTTTTCTA АCAGATAAAA AAAAtctaaa aggaaaaATA GTAGATTATC TCTTTTTCTA ACAGATAAAA

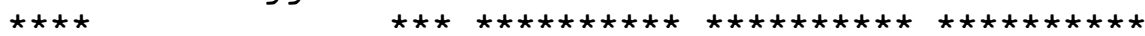

GAATCTAAAA ATCAATATTC GATCGAACTG TCTTTTTTCC TTCGATCCGg GAATCTAAAA ATAAATATTC GATCGAACTG TCTTTTTTCC TTCGATCCGt

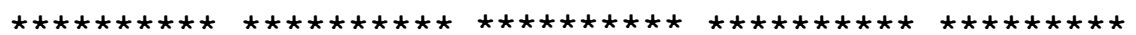

GGAAAGATAT ACTCTGGgGT TTTCGATTTA TTTATATGAA GTATGAAGGA GGAAAGATAT ACTCTGGGGT TTTAGATTTA TTTATATGAA GTATGAAGGA

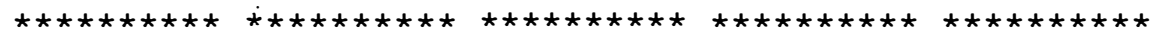


$\begin{array}{llll}\text { LEpIJB1 } & 6994 & \text { AAgGGACCGT } & \text { TTGGTCCTTG AAGAGTTCTT TCAAAACAAG GGATTGATTG } \\ \text { NT } & 7461 & \text { AAGGGATCGC } & \text { TTGGTCCTTG AAGAGTTCTT } \\ & \text { TCAAAACAAA GGATTGATTG }\end{array}$

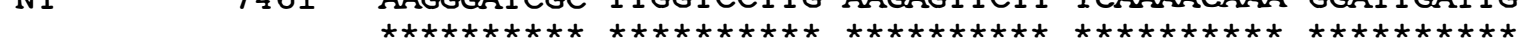

LEpIJB1 7044 AATTATCTTA TTAAGACAAT TCATGGTTCA TATGCTTAGT CAGAAGGAAT NT $\quad 7511$

AATTGTCTTA TTAGGACAAT TAATGGTTCA TATGCTTAGT CAGAAGGAAT

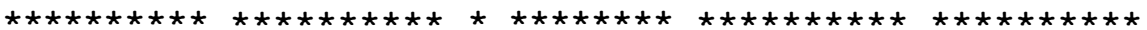

LEpIJB1 7094 AATCCAATG AGTTCATGGA TTTACCTAGg TCAGTTTATG GgCTAATCAA NT $\quad 7561$

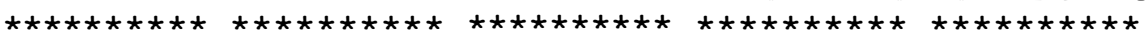

LEpIJB1 7144 TAAAGgATTT TTATCTTCGA AACCCATTGG GAAGgGCAGT GCAAGAGAAA NT $\quad 7611$ TAAAGCATTT TTATCTTCGA AACCCATTGG AAAGGGCAGT GCAAGAGAAA

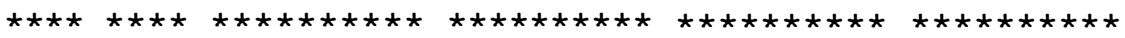

LEpIJB1 7194 TCAGACAAAA ATGATCGGAT CTTGGGACGC CCCGAAAAAG ATATGAGGTG NT $\quad 7661$

TCATACAAAA ATGATCGAAT CTTCGGACGC CCCGAAAAAG ATATGAGGTG

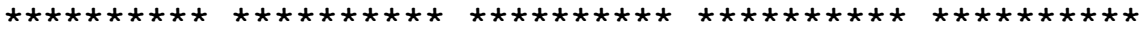

LEpIJB1 7244 CTCGGAAATG GTCGAAGTAG TTGAATAGGA GGATCACTAT GACTATAGCC NT $\quad 7711$

CTCGGAAATG GTCGAAGTAG TTGAATAGGA GGATCACTAT GACTATAGCC

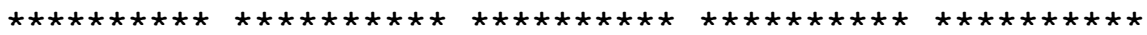

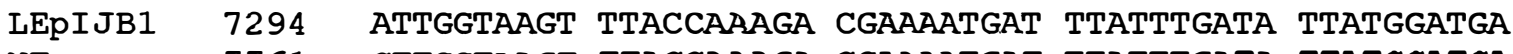
NT $\quad 7761$

CTTGGTAAGT TTACCAAAGA CGAAAATGAT TTATTTGATA TTATGGATGA

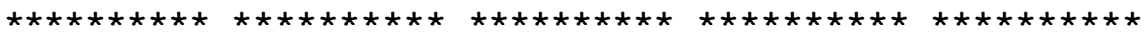

LEpIJB1 7344 CTGGTTACGg AGGGACCGTT TCGTTTTTGT AGGCTGGTCC GGTCTATTGC NT $\quad 7811$

CTGGTTACGG AGGGACCGTT TCGTTTTTGT AGGCTGGTCC GGTCTATTGC

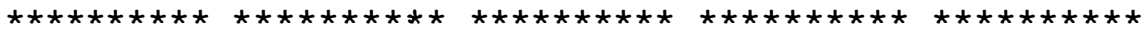

LEpIJB1 7394 TCTTTCCTTG TGCCTATTTC GCTGTAGGG GTTGGTTCAC AGGTACAACC NT $\quad 7861$

TCTTTCCTTG TGCCTATTTC GCTGTAGGGG GTTGGTTCAC AGGTACAACC

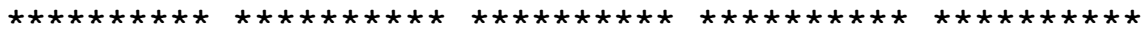

LEpIJB1 7444 TTTGTAACTT CATGGTATAC CCATGGATTG GCCAGTTCTT ATTTGGAAGG NT $\quad 7911$

TTTGTAACTT CATGGTATAC CCATGGATTG GCCAGTTCTT ATTTGGAAGG

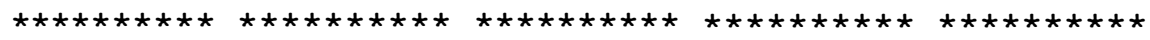

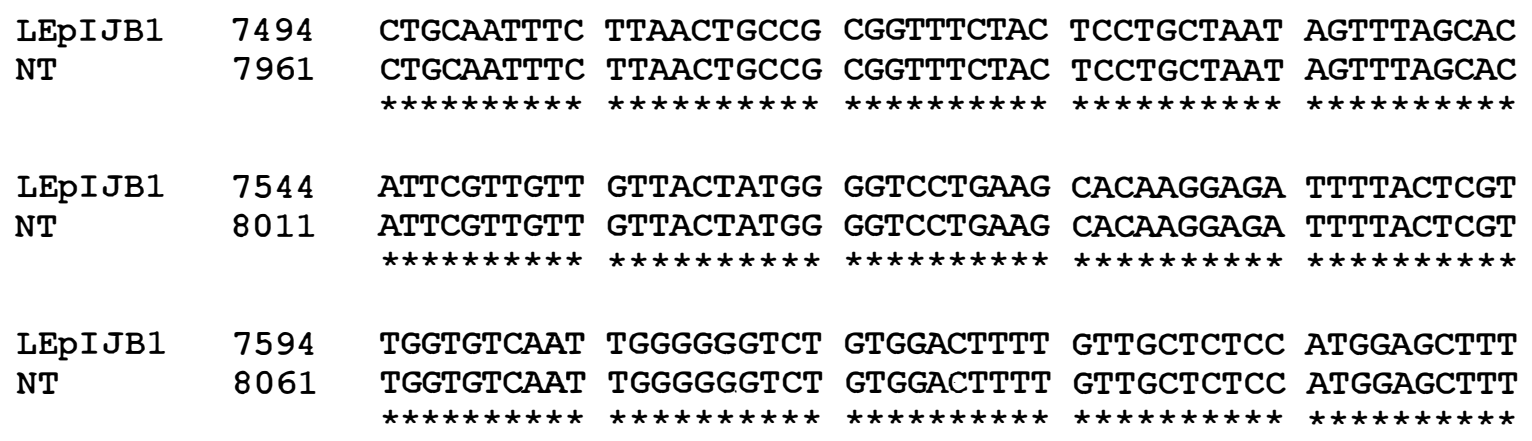




\begin{abstract}
LEpIJB1 7644 TGGCCTAATA GGTTCATGT TACGTCAATT CGAGCTTGCT CGATCTGTTC NT 8111 TGGCCTAATA GGTTTCATGT TACGTCAATT CGAGCTTGCT CGATCTGTTC

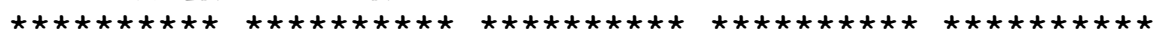

LEpIJB1 7694 AATTGAGACC TTATAATGCA ATCGCATTCT CTGGTCCAAT TGCTGTTTTT NT 8161 AATTGAGACC TTATAATGCA ATCGCATTCT CTGGTCCAAT TGCTGTTTTT

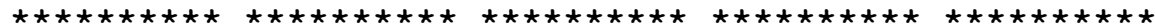

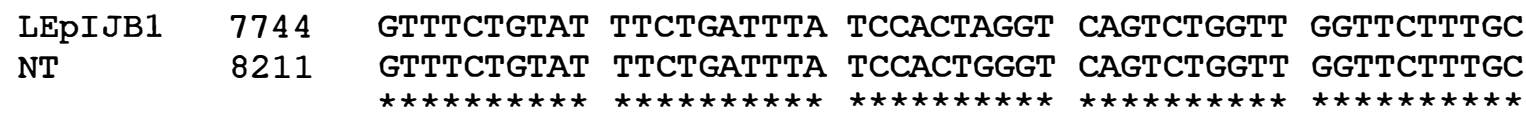

LEpIJB1 7794 ACCTAGTTTT GGTGTAGCAG CTATATTTCG ATTCATCCTA TTTTTTCAAG NT 8261 ACCTAGTTTT GGTGTAGCAG CTATATTTCG ATTCATCCTC TTTTTTCAAG

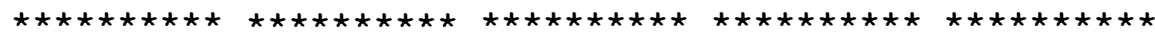

LEpIJB1 7844 GGTTTCATAA TTGGACCTTG AACCCCTTTC ATATGATGGg AGTTGCCGGT NT 8311 GGTTTCATAA TTGGACGTTG AACCCaTTTC ATATGATGGG AGTTGCCGGT

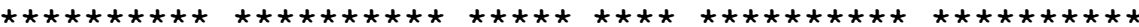

$\begin{array}{ll}\text { LEpIJB1 } & 7894 \\ \text { NT } & 8361\end{array}$

LEPIJB1 7944

NT

8411

LEPIJB1 7994

NT

8461

LEpIJB1 8044

NT

8511

LEPIJB1 $\quad 8094$

NT

LEpIJB1 8144

NT

8611

LEpI JB1 8194

NT

8661

LEpIJB1 8244

NT $\quad 8711$
GTATTGGGgG CTGCTTTGCT ATGCGCCATT CATGGTGCTA CCGTAGAAAA GTATTGGGCG CTGCTTTGCT ATGCGCCATT CATGGTGCTA CCGTAGAAAA

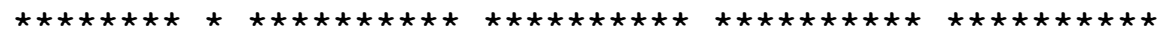

TACTTTATTT GAAGACGGTG ATGGTGCAAA TACATTCCGT GCTTTTAACC TACTTTATTT GAAGACGGTG ATGGTGCAAA TACATTCCGT GCTTTTAACC

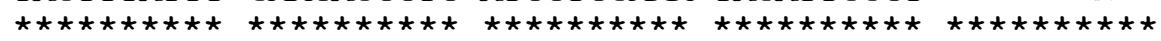

CAACTCAAGC CGAAGAAACT TATTCAATGG TCACCGCTAA CCGCTTTTGG CAACTCAAGC CGAAGAAACT TATTCAATGG TCACCGCTAA CCGCTTTTGG

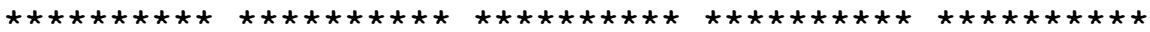

TCCCAAATCT TTGGGGTTGC TTTTTCCAAT AAACGTTGGT TACATTTCTT TCCCAAATCT TTGGGGTTGC TTTTTCCAAT AAACGTTGGT TACATTTCTT

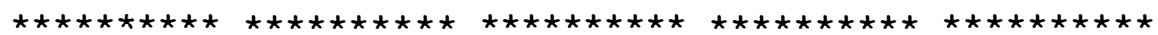

TATGTTATTT GTACCAGTGA CCGGTTTATG GATGAGTGCT CTTGGAGTAG TATGTTATTT GTACCAGTAA CCGGTTTATG GATGAGTGCT CTTGGAGTAG

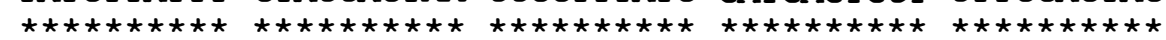

TCGGTCTAGC TCTGAACCTA CGTGCCTATG ACTTCGTTTC TCAGGAAATT TCGGTCTAGC CCTGAACCTA CGTGCCTATG ACTTCGTTTC TCAGGAAATT

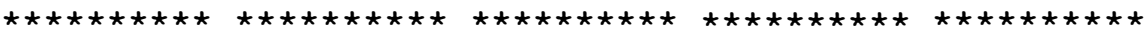

CGCGCAGCGG AAGATCCTGA ATTTGAGACT TTCTACACCA AAAATATTCT CGCGCAGCGG AAGATCCTGA ATTTGAGACT TTCTACACCA AAAATATTCT

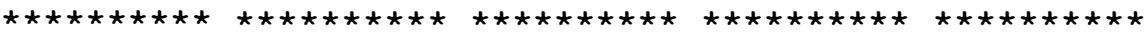

CTTAAACGAA GGTATTCGCG CTTGGATGGC GGCTCAAGAT CAGCCTCATG CTTAAACGAA GGTATTCGCG CTTGGATGGC GGCTCAAGAT CAGCCTCATG

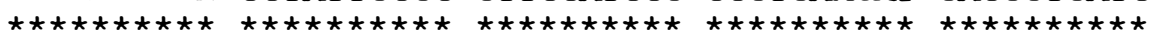




\begin{tabular}{|c|c|c|c|c|c|c|}
\hline LEpIJB1 & 8294 & АAAACCTTAT & АTTCССТGAG & GAGGTTCTAC & CACGTGGAAA & СGСТСТTTAA \\
\hline $\mathrm{NT}$ & 8761 & 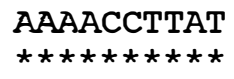 & 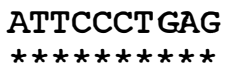 & 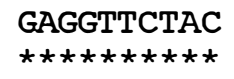 & 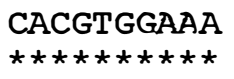 & $\begin{array}{l}\text { CGCTCTTTAA } \\
\star \star \star \star \star \star \star \star \star \star * t * t\end{array}$ \\
\hline $\begin{array}{l}\text { LEpI JB1 } \\
\mathrm{NT}\end{array}$ & $\begin{array}{l}8344 \\
8811\end{array}$ & 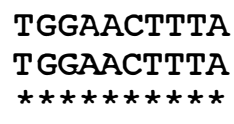 & 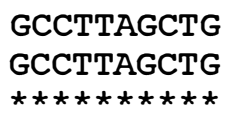 & 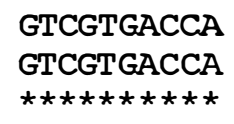 & 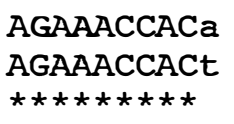 & 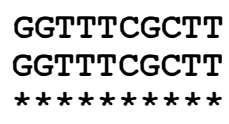 \\
\hline $\begin{array}{l}\text { LEpI JB1 } \\
\text { NT }\end{array}$ & $\begin{array}{l}8394 \\
8861\end{array}$ & 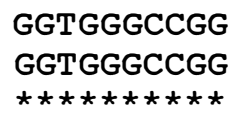 & 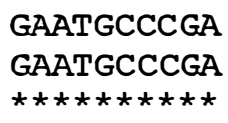 & 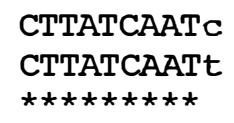 & 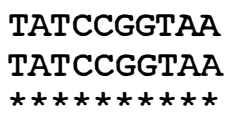 & 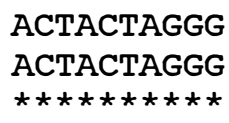 \\
\hline $\begin{array}{l}\text { LEpIJB1 } \\
\text { NT }\end{array}$ & $\begin{array}{l}8444 \\
8911\end{array}$ & 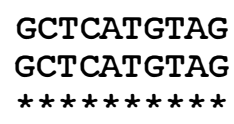 & 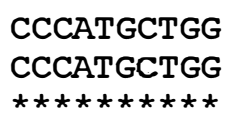 & 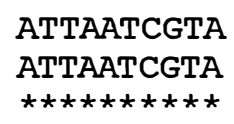 & 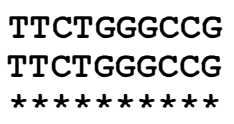 & 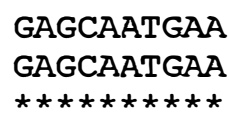 \\
\hline $\begin{array}{l}\text { LEpI JB1 } \\
\text { NT }\end{array}$ & $\begin{array}{l}8494 \\
8961\end{array}$ & 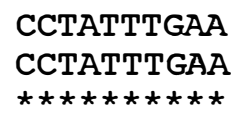 & 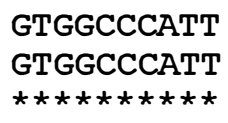 & 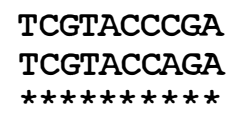 & 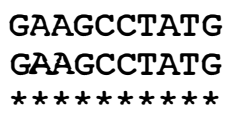 & 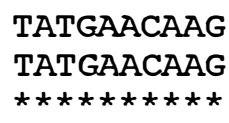 \\
\hline $\begin{array}{l}\text { LEpIJB1 } \\
\text { NT }\end{array}$ & $\begin{array}{l}8544 \\
9011\end{array}$ & 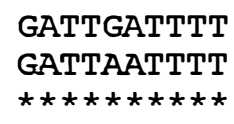 & 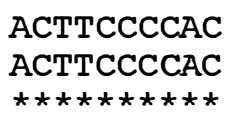 & 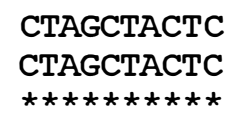 & 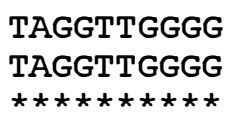 & $\begin{array}{l}\text { GGTAGGCCCT } \\
\text { GGTAGGCCCT } \\
\star \star \star \star \star \star \star \star \star \star ~\end{array}$ \\
\hline $\begin{array}{l}\text { LEpI JB1 } \\
\mathrm{NT}\end{array}$ & $\begin{array}{l}8594 \\
9061\end{array}$ & 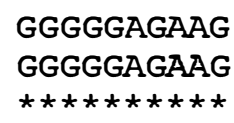 & 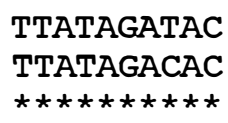 & 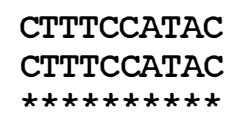 & 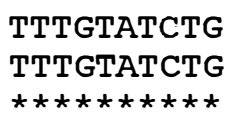 & 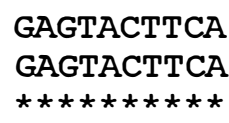 \\
\hline $\begin{array}{l}\text { LEpIJB1 } \\
\mathrm{NT}\end{array}$ & $\begin{array}{l}8644 \\
9111\end{array}$ & $\begin{array}{l}\text { TTTAATTTCT } \\
\text { TTTAATTTCT } \\
\star \star \star \star \star \star \star \star \star \star ~\end{array}$ & 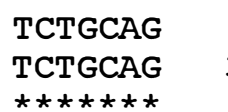 & 35848 & & \\
\hline
\end{tabular}




\begin{abstract}
ANEXO B: fragmento do genoma cloroplastidial de abaco

Formato DIALIGN 2.1

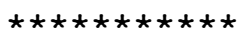

Burkhard Morgenstern (1999)

Sequiências Alinhadas: tamanho (bases):

\begin{tabular}{|c|c|}
\hline 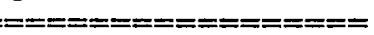 & $=====$ \\
\hline 1) LEpIJB2 & 6366 \\
\hline 2) NT & 6375 \\
\hline
\end{tabular}
\end{abstract}

Alinhamento do fragmento cloroplastidial de tomate de $6.366 \mathrm{pb}$ com o respectivo

Somente letras maiúsculas devem ser consideradas alinhadas Asteriscos confirmam identidade

\footnotetext{
Alinhamento:

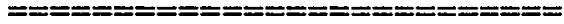

LEpIJB2 1 GTCGACCGCT AGAACTACTG GTTTTAAAGC CCGAAATAAA TAGGCTTACT NT 70781 GTCGACCGCT AGAACTACTG GTTTTAAAGC CCGAAATAAA TAGGCTTACT

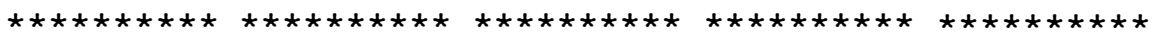

LEpIJB2 51 TTTTCTTCAC TTGAATCATA ATTACAAGAA tctagatttg agtgaaTCTA NT +51 TTTTCTTCAC TTGAATCATA ATTACAAGAA -------- $-----T C T A$

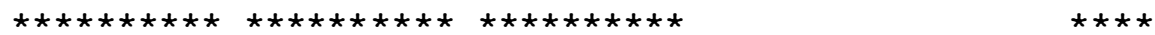

LEpIJB2 101 GATTTGAGTA TCGTGTCCTA AGAAAAAAA- TGAATCGGAA AAAAAGAAAT NT +85 GATTTGAGTA TCGTGTCGTA AGAAAAAAAa TGAATCGGAA AAAAAGATTT

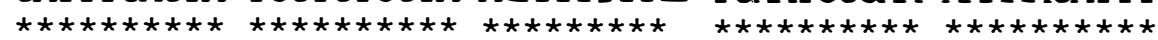

LEpIJB2 150 CTGTTTTTAT TGAATTAAC GTGTTCATTC ATTTTGACTA CTTTAGTATA NT +135 CTTTTTTTAT TGAATTGAAC GTGTTCATTC ATTTTGACTA CTTTAGCATA

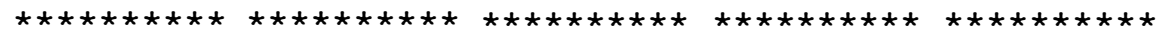

LEpIJB2 200 TTTTCTCATA ctAATTTCTA CTCTACCTTC CCGGAGTTCA TTCTCCGGGt NT +185 TTTTCTCATA gaAATTTCTA CTCTACCTTC CCGGAGTTCA TTCTCCGGGg

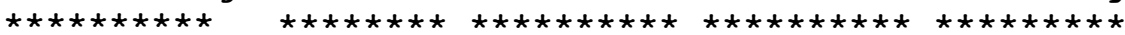

LEpIJB2 250 AACTCCATTT AAATTATTCT GGTGGATTCT TTCCAATCTA CTTCCTTTAT NT +235 AACTCCATTT AAATTATTCT GGTGGATTCT TTCCAATCTA CTTCCTTTAT

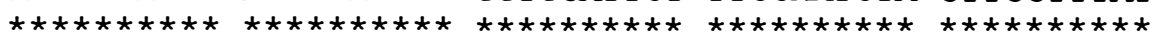

LEpIJB2 300 GATTTCGTTC GAAATCATAT AAAGACAATT CCTATTTGAT ATAGCTATTT NT +285 GATTTCGTC GAAATCATAT AAAGACAATT CCTATTTGAT ATAGCTATTT
} 


\begin{tabular}{|c|c|c|c|c|c|c|}
\hline LEpIJB2 & 350 & GTGCAAGTAT & TTTACGGTTA & AGAAGCAACT & GTCTCTTGTA & CAGATCGTGT \\
\hline $\mathrm{NT}$ & +335 & 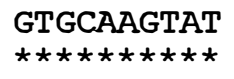 & 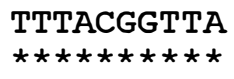 & 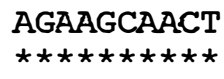 & 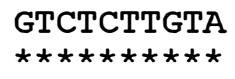 & 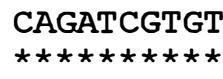 \\
\hline $\begin{array}{l}\text { LEpIJB2 } \\
\text { NT }\end{array}$ & $\begin{array}{r}400 \\
+385\end{array}$ & 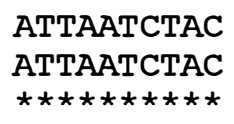 & 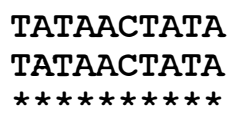 & 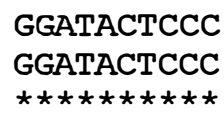 & 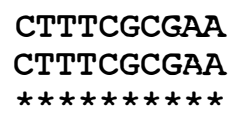 & 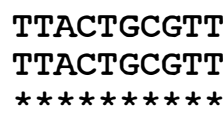 \\
\hline $\begin{array}{l}\text { LEpI JB2 } \\
\mathrm{NT}\end{array}$ & $\begin{array}{r}450 \\
+435\end{array}$ & 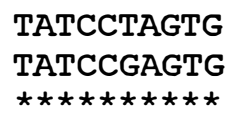 & 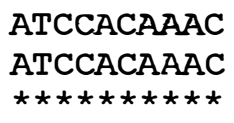 & 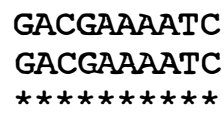 & 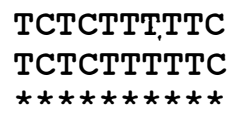 & 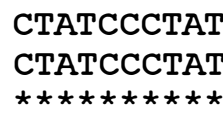 \\
\hline $\begin{array}{l}\text { LEpIJB2 } \\
\text { NT }\end{array}$ & $\begin{array}{r}500 \\
+485\end{array}$ & 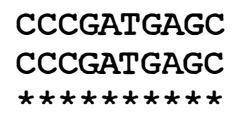 & 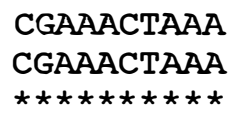 & 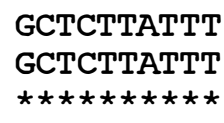 & 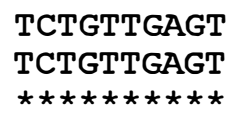 & 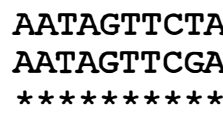 \\
\hline $\begin{array}{l}\text { LEpIJB2 } \\
\text { NT }\end{array}$ & $\begin{array}{r}550 \\
+535\end{array}$ & 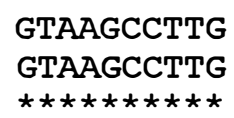 & 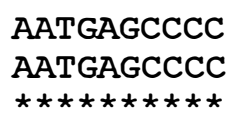 & 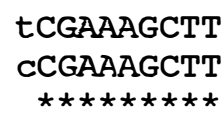 & 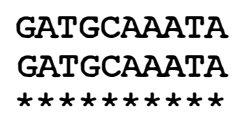 & 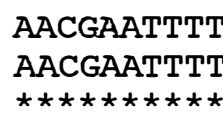 \\
\hline $\begin{array}{l}\text { LEpI JB2 } \\
\mathrm{NT}\end{array}$ & $\begin{array}{r}600 \\
+585\end{array}$ & 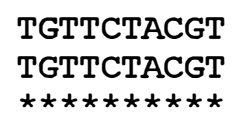 & 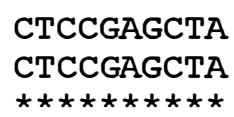 & 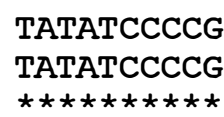 & 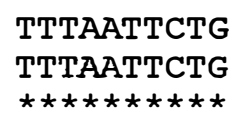 & 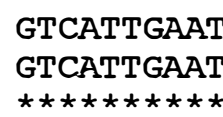 \\
\hline
\end{tabular}

\begin{tabular}{|c|c|c|c|c|c|c|}
\hline LEpIJB2 & 650 & AAATGAAACT & TTGACGAATA & ACTAATEGAT & TGCCTTTCTT & GTTATTC \\
\hline $\mathrm{NT}$ & +635 & AAATGAAACT & TTGACGAATA & ACTAATCGAT & TGCCTTTCTT & TCAGTTATT \\
\hline
\end{tabular}

LEpIJB2 700 TTTTCCCCCT TCCTAGTCTA TTAATAACAA AACGGATTTT TCCAATGTAT NT +685 TTTTCCCCCT TCCTAGTCTA TTAATAACAA AACGGATTTT TCCAATGTAT

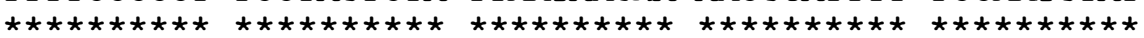

LEpIJB2 750 AAAATCAAAA TTCCAATGGC TTTGGCTACT CTAACCTTCC CGACCACGANT $\quad+735$ AAAATAAAAA TTCCAATGGC TTTGGCTACT CTAACCTTCC CGACCACGAt

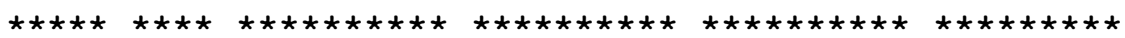

- - - - - TTTTTTTTT AGGTATTTCA CTGCGAAATA AGACAGAACT ttttctttt tTTTTTTTTT AGGTATTTCA CTGCGAAATA AGAaAGAAAT

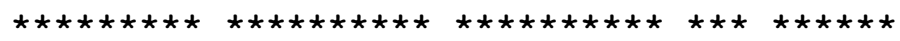

\begin{tabular}{|c|c|c|c|c|c|c|}
\hline LEpI JB2 & 838 & AAGAAATTGT & АTTTTССТАG & GTATCAAAAA & TaTAGTAAAT & AAAAGAAATA \\
\hline $\mathrm{NT}$ & +8 & 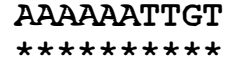 & 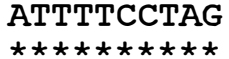 & 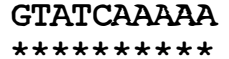 & 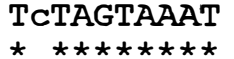 & \\
\hline
\end{tabular}
LEpIJB2 888 AAAAAAGAAA -TAGTGGGTT CCTTCGTTTC TATGGTTACT TCTTAAACGG NT +885 AAAAAATAAA gTAGTGGGTT CCTTCGTTTC TATGGTTACT TCTTAAACGG 


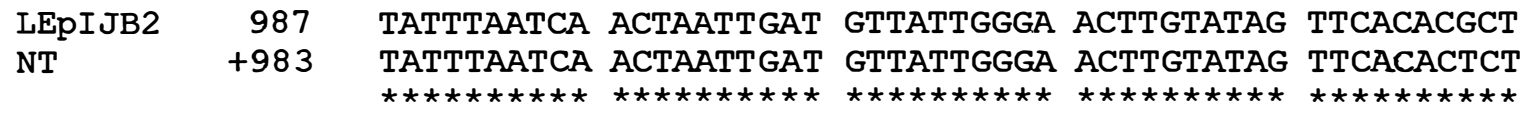

LEpIJB2 1037 TTGGCTCTAC CCATGAATTG TCCAGTAATA GGTCTTTCAC AATCAGATCT NT +1033 TTGGCTCTAC CCATGAATTA TCCAGTAATA GGTCTTTCAC AATCAGATCT

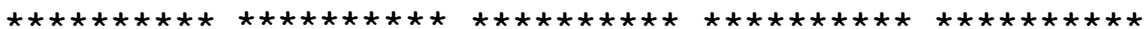

LEpIJB2 1087 ACCTATACAG TAA-CGGTAT TTAATTATGA AAGTTTGCTG GGTAGCTGAC NT +1083

LEpIJB2 1136

NT +1133

LEpIJB2 1186

NT +1183

LEpIJB2 1236

NT +1233

$\begin{array}{lr}\text { LEpIJB2 } & 1286 \\ \text { NT } & +1274\end{array}$

LEpIJB2 1336

NT +1322

LEpIJB2 1386

NT +1372

LEpIJB2 1436

NT +1421

LEpIJB2 1486

NT +1471

LEpIJB2 1536

NT +1521

LEpIJB2 1586 NT +1571
ACCTATACAG TAAgCGGTAT TTAATTATGA AAGTTTGCTG GGTAGCTGAC

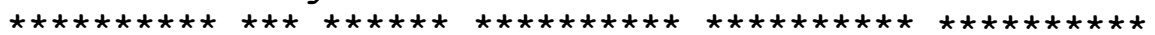

CCTCTTAGTC CGTTCTTGCC AGATTGGGAG CCTACCTAAT CTTTATGTTT CCTCTTAGTC CGTTCTTGCC AGAGTGGGAG CCTGCCTAAT CTTTATGTTT

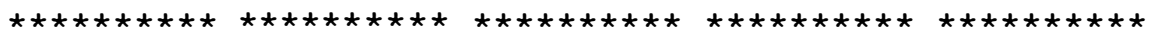

TATGCTTTTT AAATAAGATT TCCTCCGCTT AATGGATAAC CATTTGTTAC TATGCTTTTT AAATAAGATT TCCTCCGCTT AATGGATAAC CATTTGTTAC

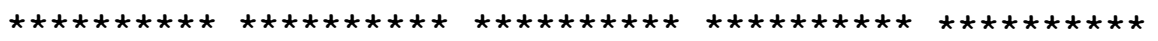

CAATGGAGAA TTTCTTATCA TCTtaaattc agGTGATTGG ATTTACACCA CAATGGAGAA TTTCTTATCA TCT------ --GTGATTGG ATTTACACCA

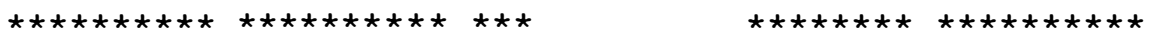

ACGGAAACCA TAAACTTCAT ACACAATagA GGGGGATATG GTAGAGTTTT ACGGAAACCA TAAACTTCAT ACACAAT--A GAGGGATATG AGAGAGTTTT

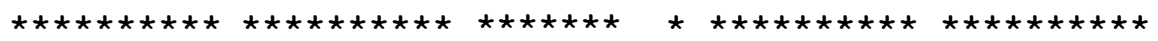

TTTTTTATAA TGgATGGAGT TCCTTTTTCC ATCCTATCCC ATTCACCGGT TTTTAAATAA TGaATGGAGT TCCTTCTTCC ATCCTATCCC ATTCACCGGT

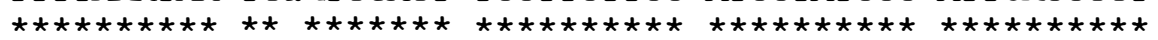

ACTGATCATT GATACTGTAA AAGTAGTTTT CTTGCTTTTt GTGCCAGCTC ACTGATCATT GATACTGTAA AAGTCGTTTT CTTGCTTTT- GTGCCAGCTC

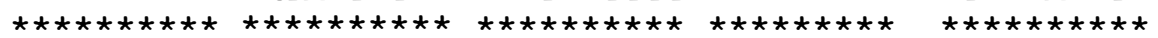

ATGATCTAAA CGAGTCGCAC ATACACCCTA GTACATGTTC CTCGACGCTG ATGATCTAAA CGAGTCGCAC ATACACCCTA GTACATGTTC CTCGACGCTG

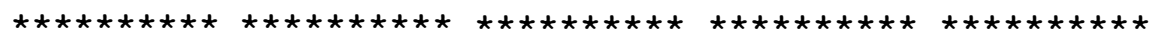

AGGGCACCCC CGAAGAGCGG GGGATTTCGT GACATTTCTG ATTGGCTGTC AGGACAGCCC CGAAGAGCGG GGGATTTCGT GACATTTCTG ATTGGCTGTC

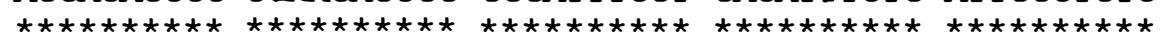

TTGTATTTCT AATAAGTTGT TTAATAGTTG GCATGTTGAA TCGTATACAT TTGTATTTCT AATAAGTTGT TTAATAGTTG GCATGTTGAA TCGTATACAT

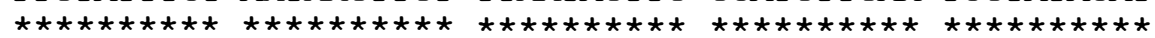

AATATGATGG GTTGGTTTAG ATTGATCCTA ACCGAATGAT GgTGAATTAC AATATGATGG GTTGGTTTAG ATTGATCCTA ACCGAATGAT GaTGAATTAC

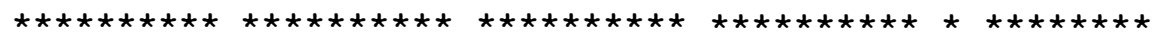


LEPIJB2 1636

NT +1621

LEpIJB2 1686

NT +1671

$\begin{array}{lr}\text { LEpIJB2 } & 1736 \\ \text { NT } & +1721\end{array}$

LEPIJB2 1786

NT +1771

LEpIJB2 1836

NT +1821

LEPIJB2 1886

NT +1871

LEPIJB2 1936

NT +1921

LEpIJB2 1986

NT $\quad+1971$

LEpIJB2 2036

NT +2021

$\begin{array}{lr}\text { LEpIJB2 } & 2078 \\ \text { NT } & +2071\end{array}$

LEpIJB2 2126

NT +2121

LEpIJB2 2176

NT +2171

LEpIJB2 2221

NT +2221
TTCTATTTAA TAGAATATTC AATTCGAAGA TAAAATCTCA AATCATAGAT TTCTATTTAA TAGAATATTC AATTCGAAGA TAAAATCTCA AATCACAGAT

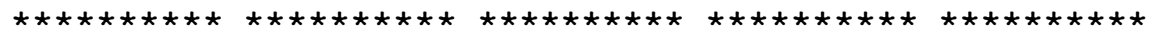

CTGCGTGAAA TCCATGTTCT TTTCCTTGAA CCGCTACAAA ATCAACAATT TTGCGCGAAA TCCATGTTAT TTTCaTTCAA CCGCTACAAG ATCAACAATT

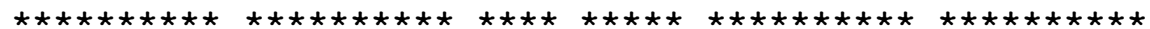

CCATAAGCTT GGGCTTCTGT TGCTGACATA AAAATATCTC TTTCCATATC CCATAAGCTT GGGCTTCTGT TGCTGACATA AAAACATCTC TTTCCATATC

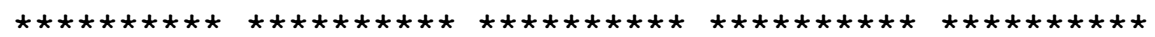

TTCGtgTATA ACCCACACGG GTTGGCCCGT TTTTTCTgCA TAAACCCTTG TTCGgaTACA ACCCATAAGG GTTTCCCCGT TCTTTgTaCA TAAACCCTTG

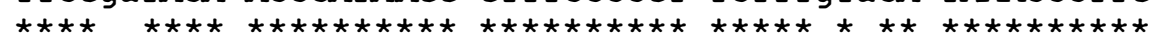

TGAGGGTTTC ACGCAGTTTC gCCAtTTCTa tCGCTTCCAG GACAAATTCG TGAGGGTTTC ACGCAGTTTC agCAgTTCTt CCGCTTCCAG GACAAATTCG

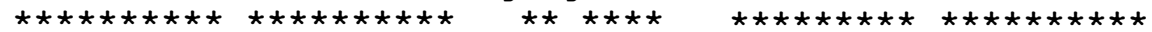

CCTACTTGTG CCATATAAAA ACCACTALAA GGTTCATGTA TCATTACCCT CCTGTTTGTG CCTCATAAAA AgaACTAgCA GGTTGATGGA TCATTACCCT

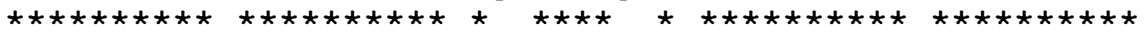

GATGATATAA CAAAATAAAA GCTTCCCCTA TCTCGCATGA TAAAGCAAAG GATGATATAA CAAAATAAAA GCTTCCCCTA TCTCGCATGA TAAAGCAAAG

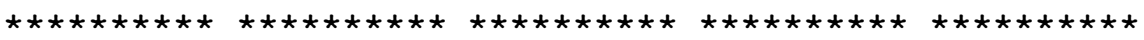

AAAAAAGAAA GATAAAGAAT AGAAAAAAGA TAGAATTGAA CAACCGTACA AGAAAAGAAA GATAAAGAAT AGAAAAAAGA TAGAATTGAA CAACCGTACA

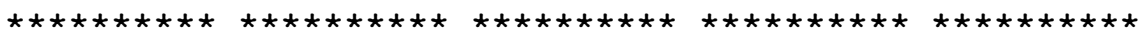

GGCATCTTTT GTGCATACGG CTCTACAAGA AAATTGACCC CC-------GGCATCTTTT GTGCATACGG CTCTACAAGA AAATTGACCt cCcctcctt

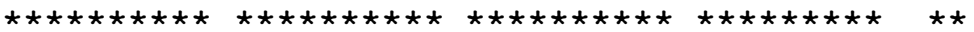

--ATTGAAGA AAGAGAAAAA TAGAATCTAT CAGACTCAGA TGGGTAAATA CtATTGAAGA AAGAGAAAAA TAGAATCTAT CAGACTCAGA TGGGTAAATG

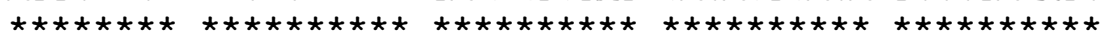

ATCAAATTGC CATCCTTCCT TTCGGAGGAA TTCAAAAATA CTATGATGGC ATCAAATTGC CATCCTTCCT TTCGGAGGA TTaAAAAATA CTATGATGGC

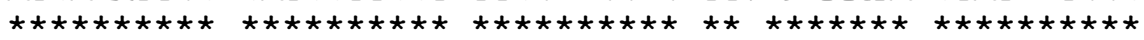

TCCGTTGCTT TATATGTTTA TTTTTTCTTT -----TTTTT GTCTGTGATT TCCGTTGCTT TATATGTTTA TTTTTTCTTT tttttTTTTT GTCTGTGATT

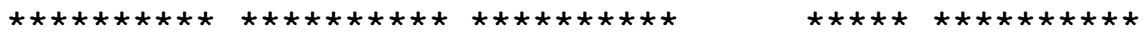

CAGCAATCCC AAAGTTTCTT TTTAATCCGA TCAAATAAGG AAAAAtTa-CAGCAATCCC AAAGTTTCTT TTTAATCCGA TCAAATAAGG AAAAAaTctt

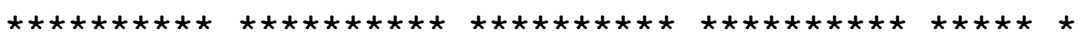




\begin{abstract}
LEpI JB2 2269
NT $\quad+2271$

LEpIJB2 2315

NT +2321

LEpIJB2 2364

NT +2371

LEpIJB2 2414

NT $\quad+2421$

LEpIJB2 2464

$+2469$

LEpIJB2 2514

NT +2519

LEpIJB2 2564

NT +2569

LEpI JB2 2614

NT +2619

LEpIJB2 2664

NT +2669

LEpIJB2 2714

NT +2719

LEpIJB2 2764

NT +2769

ATAAGACCAA TAAGTTGATT CGAAAGCTCG GTACCAAtCc CTTGGCCTAA ATAAGACCAA TAAGTTGATT CGAAATCTCG CTATCAACCt CTTGGCCTAA

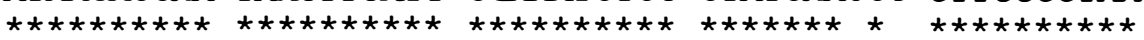

LEpIJB2 2814 AAAAAGTAA CTTTCTCGAT AAAGTCGGTT GATTAGGGTA AAATTGTATC NT +2819

AAAAAGTAAT CTTTCTCGAT AAAGTCGGTT GATTAGGGTA AAATTGTATC

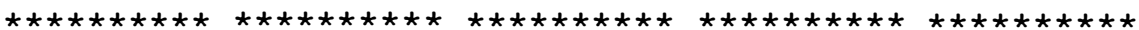

LEpIJB2 2864 NT +2869

----TTTTTT TTTCGTACTC TTTCATAACA TAAATATTGT TAAGAACTCT ttttTTTTTT TTTCGTACTC TTTCATAACA TAAATATTGT TAAGAACTCT

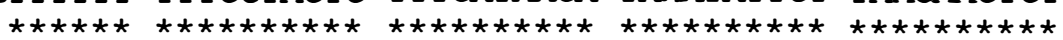

CCGGCATGAA AAC-AAAAAG TTTGTGACGC TGAACTGAAC TCCCGATAtA CCGGCATGAA AACaAAAAAG TTTGTGACGC TGAACTGAAC TCCCGATAgA

TAATAGAAAA TCGGAAATAC CCCTTATCTC ATACTACTCT CTCGATACAG TAAGAGAAAA TCGGAAATAC CCCTTATCTC ATACTACTCT CTCGATACAG

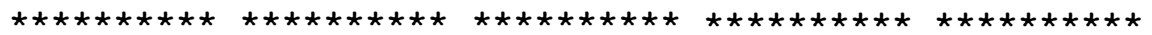

AATCTAATGT TTTGAAAAAA AAAaaCAATA CAAAAATTTC TCATATCGAA AATCTAATGT TTTGAAAAAA AAA--CAATA CAAAAATTTC TCATATCGAA

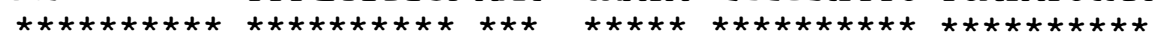

TTCGAAGTGC CATGCTATTA TTACTTAGTA TTCATATgGC GAAGgCATAG TTCGAAGTGC CATGCTATTA TTACTTAGTA TTCATATGGC GAAGGCATAG

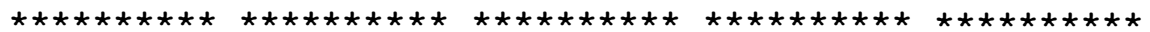

TCTTCTTTTT TTTCTCAAAT AAAAACCTCA TTGGCGCCAA GCGTGAGgGA TCTTCTTTTT TCTCTCAAAT AAAAACCTCA TTGGCGCCAA GCGTGAGGGA

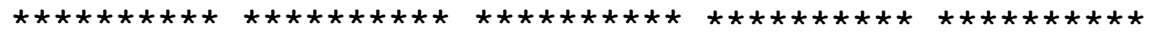

ATgCTATACG TTTGgtAAgT TGTCCTCCGg CCAgGATAAA AGATCCCATT ATGCTAGACG TTTGGTAATT TCTCCTCCGA CCAGGATAAA AGATCCCATT

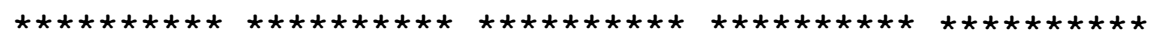

GAAGCAGCTA ATCCTAGGCA TATTGTATGg ATATCTGGTC GCACAAATTG GAAGCGGCTA ATCCCATGCA TATTGTATGG ACATCTGGTC GCACAAATTG

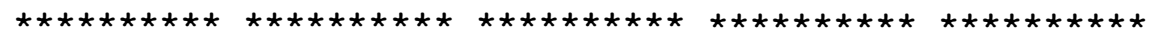

CATAGTATCA TAAATgGCgA tCCCAGGTAT TACCCAGCCC CCAGGAGAGT CATAGTATCA TAAATaGCCA CCCCAGGTAT TACCCAGCCC CCAGGAGAGT

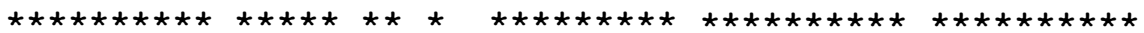

TTACAAACAA ATACAGGTCT TTGTTCTCAT CCTCCATACT GAGATACAaC TTALAAACAA ATACAGATCT TTGGTCTCAT CCTCGATACT GAGATAtACC

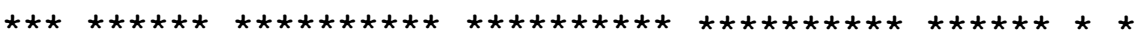

CCTTAGgAAC CGTACATGCG CCTTTTGATG CATACGgTTC AAAAAAA--CCTTAGGAAC CGTACATGCG CCTTTTGATG CATACGGTTC AAAAAAAaaa

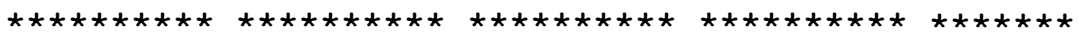




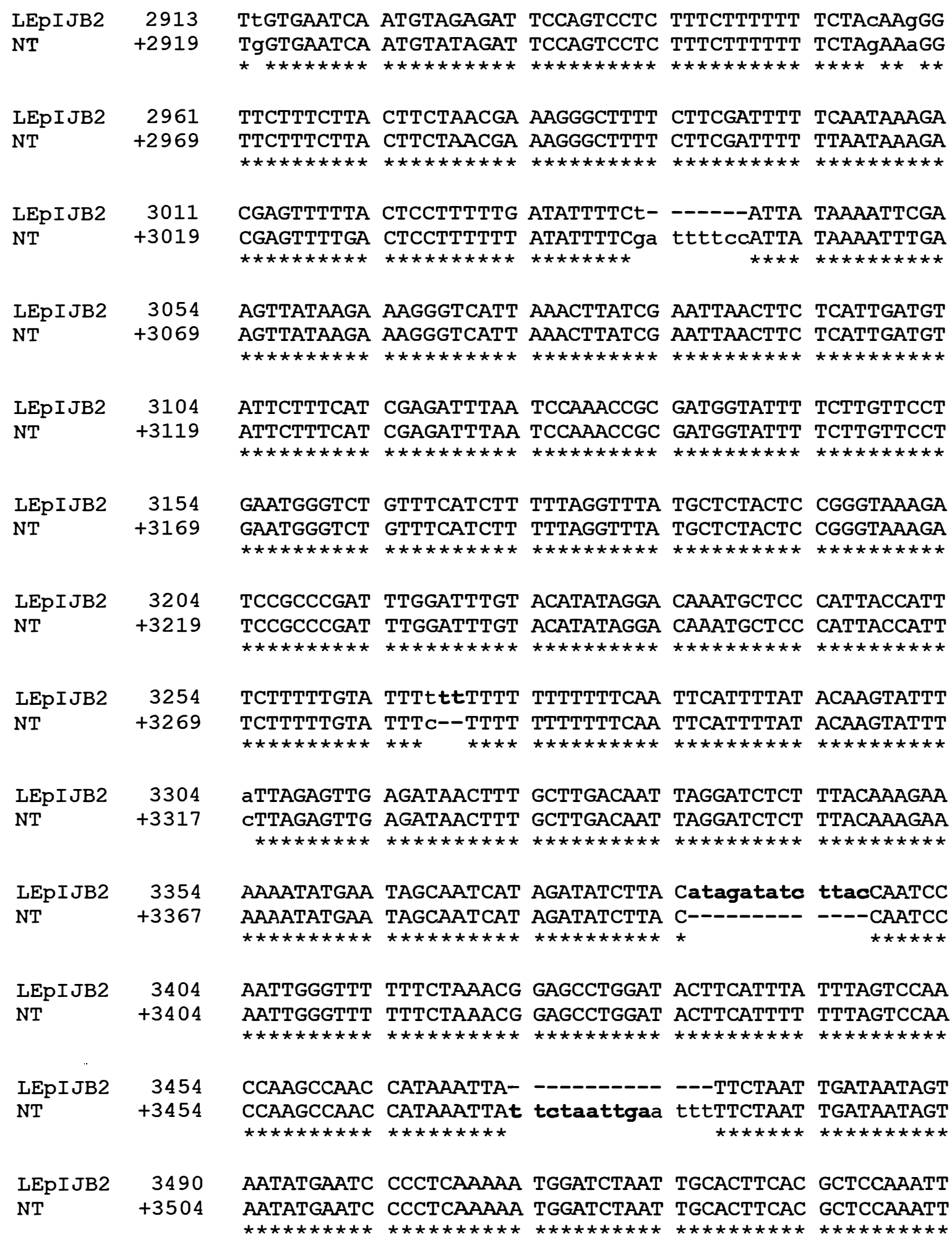




\begin{tabular}{|c|c|c|c|c|c|c|}
\hline \multirow{3}{*}{$\begin{array}{l}\text { LEpI JB2 } \\
\text { NT }\end{array}$} & 3540 & TTTGATGATT & сAATTTATCT & TTCTTGGGCG & AAACGGGGGA & TATCTCGATC \\
\hline & +3554 & TTTGATGATT & AАATTTATCT & TTCTTGGGTG & AAACGGGGGA & TATCTCGATC \\
\hline & & 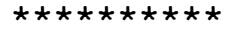 & 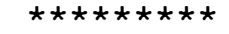 & 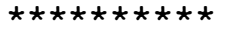 & 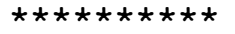 & 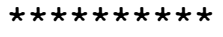 \\
\hline $\mathrm{Ep}$ & & GGGGAGAGA & ACGGGGAAAT & $\mathrm{ACC}$ & $\mathrm{CCA}$ & TGACAAGTCC \\
\hline Tा & 3 & 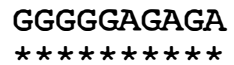 & 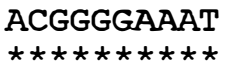 & 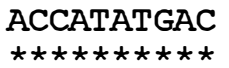 & 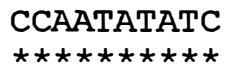 & ACAAGTCG \\
\hline
\end{tabular}

LEpIJB2 3640 $+3654$

LEpIJB2 3690

NT +3704

LEpIJB2 3740

NT +3754

LEpIJB2 3790 $+3804$

LEpIJB2 3840 NT +3854

$\begin{array}{lr}\text { LEpIJB2 } & 3890 \\ + & +3904\end{array}$

LEpIJB2 3940 NT +3954

LEpIJB2 3990 NT +4004

$\begin{array}{lr}\text { LEpIJB2 } & 4039 \\ \mathrm{NT} & +4054\end{array}$

LEpIJB2 4089 NT +4104

LEPIJB2 4139 NT
CACTATATGT CAACCCAAGA TGaAatTgga TCTCCAGGAT TTCGGAATAC CACTATACGT CAACCCAAGA TGcAtcTtCC TCTCCAGGAC TTCGGAAAGG

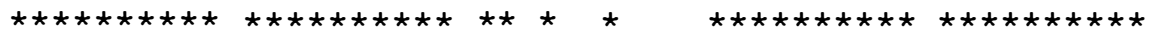

AACTCTTGGA ACACCAATAG GCATTAAATG AAAGAACGAA TTAAATACTA GACTTTTGGA ACACCAATAG GCATTAAATG AAAGAAAGAA CTAAATACTA

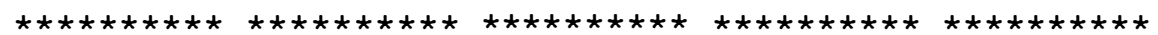

TATTTCACTT TGAGGTGGAA ACGTAACAAT TTTTTTTATT GTCTTTATAA TATTTCACTT TGAGGTGGAA ACGTAACAAT TTTTTTTATT GTCTTTATAA

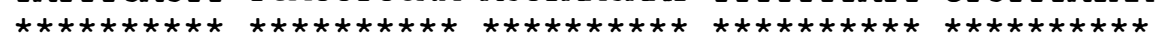

TATgaATATT GGTTTTTATC GTATTTCTTT TATCCATAGA TTCTCAAAAT TATtcATATT GGTTTTTATC GTATTTATTT TATCCATAGA TTaTaAAAAT

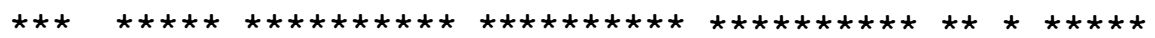

TCATAAAGAA AGACAGAATG AATAAACTCA AATTATTACG AATAGGTCTT TCATAAAGAA AGACAGAATG AATAAACTCA AATTATTACG AATAGGTCTT

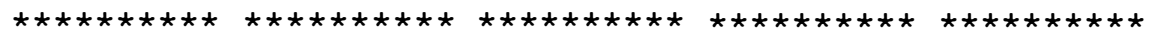

TCTAATGATA AATAAGTATG GACTCATTCG CTCATAGAAA ATGGGATCAA TCTAATGATA AATAAGTATG GACTCATTCG CTCATAGAAA ATGGGATCAA

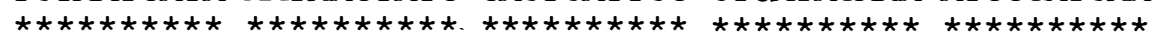

CTCCCCCATT GCGTATTGGT ACTTATCGAG TATAGAATAA ATCTGCTTCT CTCCCCCATT GCGTATTGGT ACTTATCGAG TATAGAATAA ATCTGCTTCT

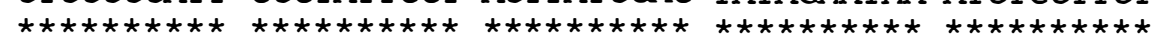

CTTTGTTCCT ACGAACAGAA TTGTTCCATT ATTACCAACA GAATAGAA-A CTTTGTTCCT ACGAACAGAA TTGTTCCATT ATTACCAACA GAATAGAACA

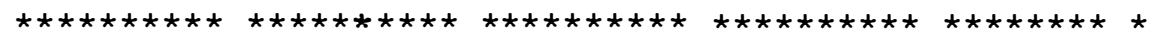

CCCTTGTTCG GAAATAATTG ACTCAACAAG AGTGGTCCAT AGGATAGTCA CCCTTGTTCG GAAATAATCG ACTGAACAAG AGTGGTCCAT AGGATAGTCA

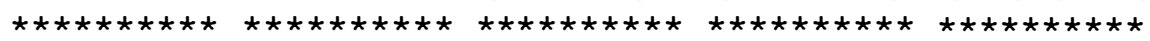

TATTATAGTC TTTTCCAATG CAATAAAGTT ACGTAGTGTT CATTTATCTT TATTATAGTC TTTTCCAATG CAATAAAGTT ACGTAGTGTC TATTTATCTT

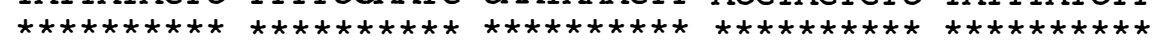

TGATATAAGG GGTATTTCCA TGGGTTTGCC TTGGTATCGT GTTCATACCG TGATATAAGG GGTATTTCCA TGGGTTTGCC TTGGTATCGT GTTCATACCG

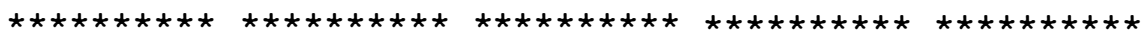




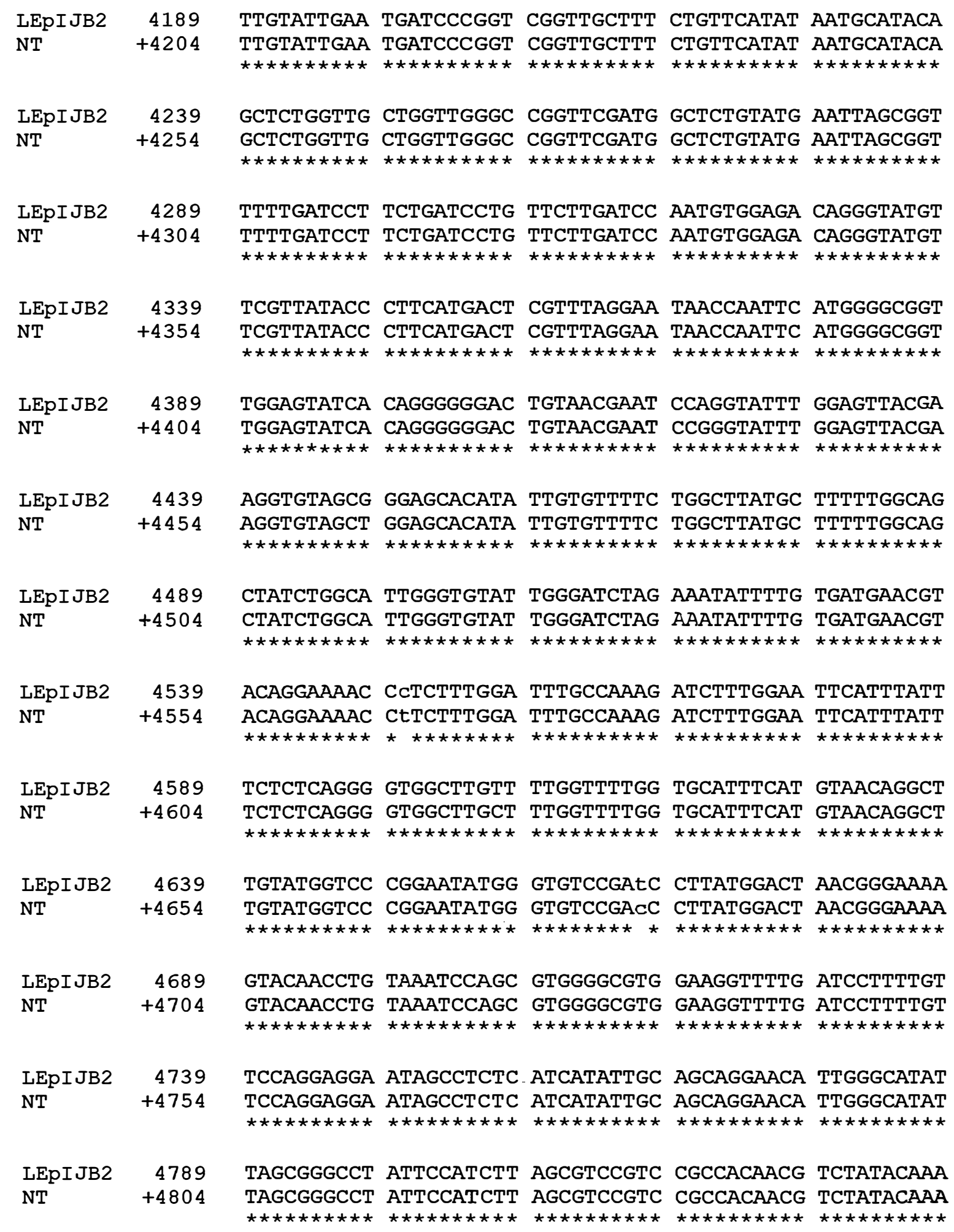




\begin{tabular}{|c|c|c|c|c|c|c|}
\hline $\begin{array}{l}\text { LEpI JB2 } \\
\text { NT }\end{array}$ & $\begin{array}{r}4839 \\
+4854\end{array}$ & $\begin{array}{l}\text { GGATTGCGTA } \\
\text { GGATTGCGTA } \\
\star \star \star \star \star \star \star \star \star \star ~\end{array}$ & $\begin{array}{l}\text { TGGGAAATAT } \\
\text { TGGGAAATAT } \\
\star \star \star \star \star \star \star \star \star \star\end{array}$ & $\begin{array}{l}\text { TGAAACCGTC } \\
\text { TGAAACCGTC } \\
\star \star \star \star \star \star \star \star \star \star\end{array}$ & $\begin{array}{l}\text { CTTTCCAGTA } \\
\text { CTTTCCAGTA } \\
\star \star \star \star \star \star \star \star \star \star\end{array}$ & 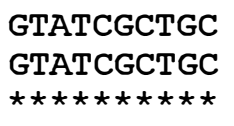 \\
\hline $\begin{array}{l}\text { LEpI JB2 } \\
\text { NT }\end{array}$ & $\begin{array}{r}4889 \\
+4904\end{array}$ & 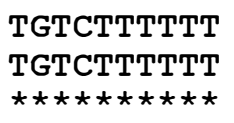 & $\begin{array}{l}\text { GCAGCTTTTG } \\
\text { GCAGCTTTTG } \\
\star \star \star \star \star \star \star \star \star \star ~\end{array}$ & 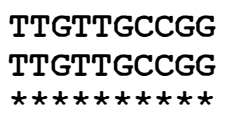 & $\begin{array}{l}\text { AACTATGTGG } \\
\text { AACTATGTGG } \\
\star \star \star \star \star \star \star \star \star \star ~\end{array}$ & 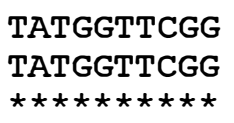 \\
\hline $\begin{array}{l}\text { LEpIJB2 } \\
\text { NT }\end{array}$ & $\begin{array}{r}4939 \\
+4954\end{array}$ & 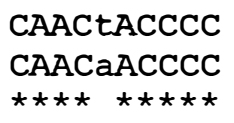 & 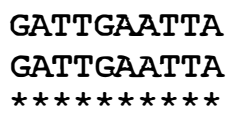 & 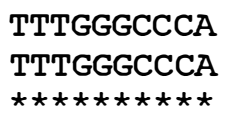 & 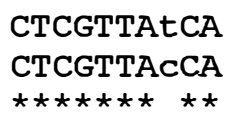 & 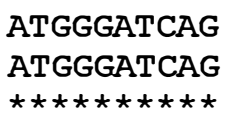 \\
\hline $\begin{array}{l}\text { LEpI JB2 } \\
\text { NT }\end{array}$ & $\begin{array}{r}4989 \\
+5004\end{array}$ & 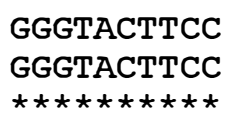 & 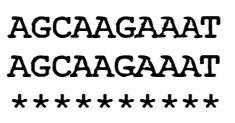 & $\begin{array}{l}\text { ATATCGAAGA } \\
\text { ATATCGAAGA } \\
\star \star \star \star \star \star \star \star \star \star\end{array}$ & 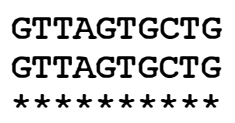 & 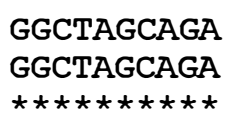 \\
\hline $\begin{array}{l}\text { LEpI JB2 } \\
\text { NT }\end{array}$ & $\begin{array}{r}5039 \\
+5054\end{array}$ & 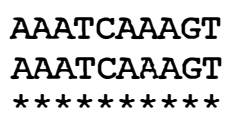 & 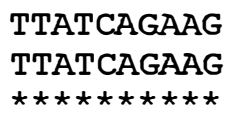 & 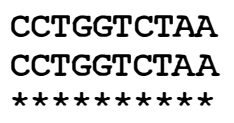 & 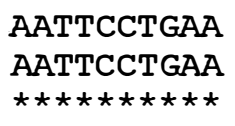 & 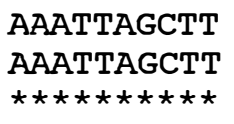 \\
\hline $\begin{array}{l}\text { LEpIJB2 } \\
\text { NT }\end{array}$ & $\begin{array}{r}5089 \\
+5104\end{array}$ & 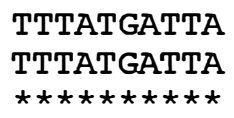 & 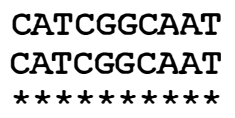 & 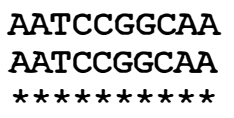 & 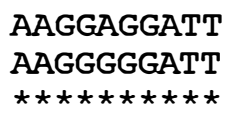 & $\begin{array}{l}\text { ATTCAGAGCa } \\
\text { ATTCAGAGCg } \\
\star \star \star \star \star \star \star \star \star\end{array}$ \\
\hline $\begin{array}{l}\text { LEpI JB2 } \\
\text { NT }\end{array}$ & $\begin{array}{r}5139 \\
+5154\end{array}$ & 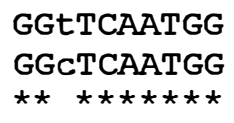 & 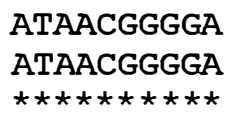 & 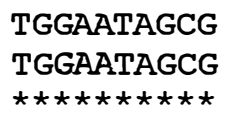 & 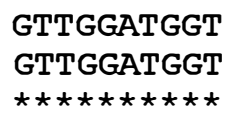 & 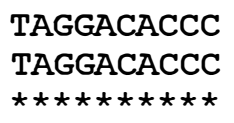 \\
\hline $\begin{array}{l}\text { LEpI JB2 } \\
\text { NT }\end{array}$ & $\begin{array}{r}5189 \\
+5204\end{array}$ & 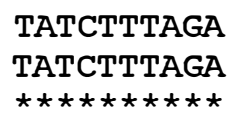 & 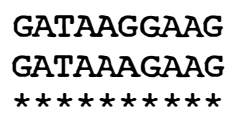 & 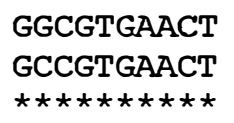 & 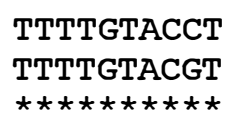 & 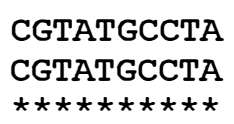 \\
\hline $\begin{array}{l}\text { LEpI JB2 } \\
\mathrm{NT}\end{array}$ & $\begin{array}{r}5239 \\
+5254\end{array}$ & 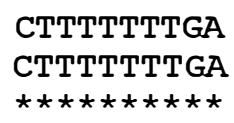 & 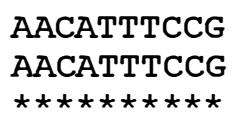 & 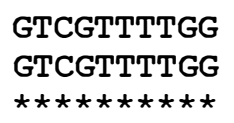 & 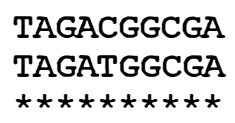 & 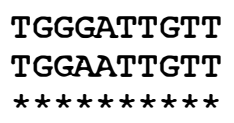 \\
\hline $\begin{array}{l}\text { LEpIJB2 } \\
\text { NT }\end{array}$ & $\begin{array}{r}5289 \\
+5304\end{array}$ & 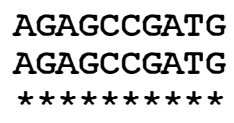 & 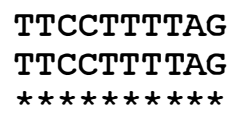 & 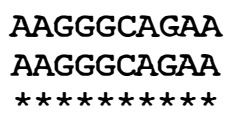 & $\begin{array}{l}\text { TCGAAGTATA } \\
\text { TCGAAGTATA } \\
\star \star \star \star \star \star \star \star \star \star ~\end{array}$ & 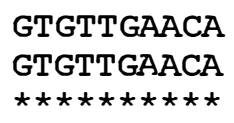 \\
\hline $\begin{array}{l}\text { LEpIJB2 } \\
\text { NT }\end{array}$ & $\begin{array}{r}5339 \\
+5354\end{array}$ & 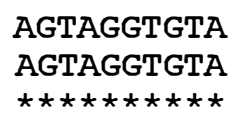 & 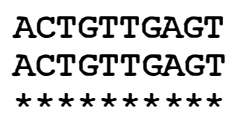 & 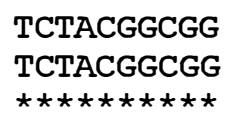 & $\begin{array}{l}\text { TGAACTCAAC } \\
\text { TGAACTCAAC } \\
\star \star \star \star \star \star \star \star \star \star ~\end{array}$ & 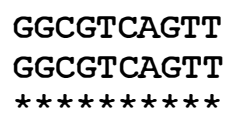 \\
\hline $\begin{array}{l}\text { LEpI JB2 } \\
\text { NT }\end{array}$ & $\begin{array}{r}5389 \\
+5404\end{array}$ & 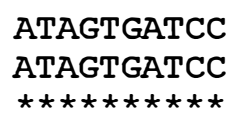 & 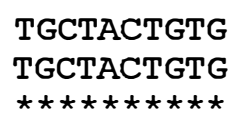 & 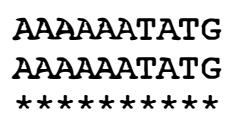 & 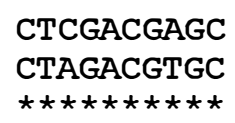 & $\begin{array}{l}\text { TCAATTGGGT } \\
\text { TCAATTGGGT } \\
\star \star \star \star \star \star \star \star \star \star ~\end{array}$ \\
\hline $\begin{array}{l}\text { LEpI JB2 } \\
\text { NT }\end{array}$ & $\begin{array}{r}5439 \\
+5454\end{array}$ & $\begin{array}{l}\text { GAAATTTTCG } \\
\text { GAAATTTTEG } \\
\star \star \star \star \star \star \star \star \star ~\end{array}$ & 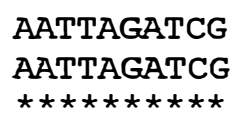 & $\begin{array}{l}\text { TGCTACTTTG } \\
\text { TGCTACTTTG } \\
\star \star \star \star \star \star \star \star \star \star ~\end{array}$ & 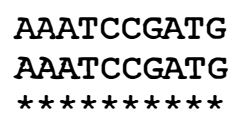 & $\begin{array}{l}\text { GTGTTTTTCG } \\
\text { GTGTTTTTCG } \\
\star \star \star \star \star \star \star \star \star \star ~\end{array}$ \\
\hline
\end{tabular}




\begin{tabular}{|c|c|c|c|c|c|c|}
\hline $\begin{array}{l}\text { LEpI JB2 } \\
\text { NT }\end{array}$ & $\begin{array}{r}5489 \\
+5504\end{array}$ & 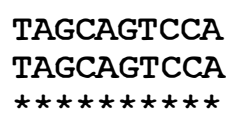 & 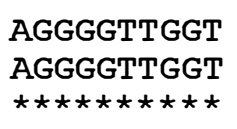 & 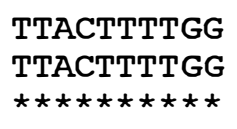 & 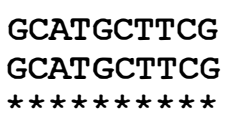 & $\begin{array}{l}\text { TTTGCTTTGC } \\
\text { TTTGCTTTGC } \\
\star \star \star \star \star \star \star \star \star \star ~\end{array}$ \\
\hline $\begin{array}{l}\text { LEpIJB2 } \\
\text { NT }\end{array}$ & $\begin{array}{r}5539 \\
+5554\end{array}$ & 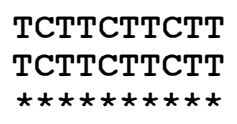 & 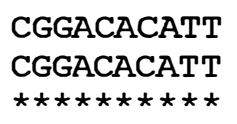 & $\begin{array}{l}\text { TGGCATGGTG } \\
\text { TGGCATGGTG } \\
\star \star \star \star \star \star \star \star \star \star ~\end{array}$ & 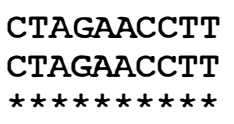 & 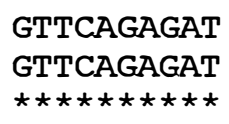 \\
\hline $\begin{array}{l}\text { LEpIJB2 } \\
\text { NT }\end{array}$ & $\begin{array}{r}5589 \\
+5604\end{array}$ & 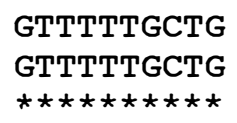 & 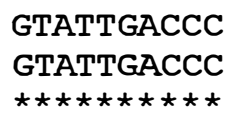 & 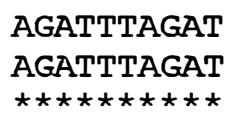 & $\begin{array}{l}\text { GCTCAAGTCG } \\
\text { GCTCAAGTCG } \\
\star \star \star \star \star \star \star \star \star \star ~\end{array}$ & 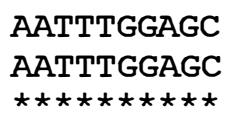 \\
\hline $\begin{array}{l}\text { LEpIJB2 } \\
\text { NT }\end{array}$ & $\begin{array}{r}5639 \\
+5654\end{array}$ & 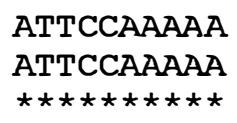 & 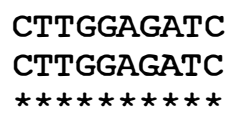 & 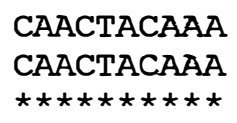 & 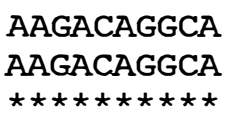 & 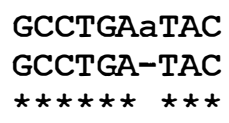 \\
\hline $\begin{array}{l}\text { LEpIJB2 } \\
\text { NT }\end{array}$ & $\begin{array}{r}5689 \\
+5703\end{array}$ & $\begin{array}{l}\text { AACATTGCTT } \\
\text { AACATTACTT } \\
\star \star \star \star \star \star \star \star \star \star ~\end{array}$ & 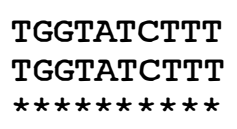 & 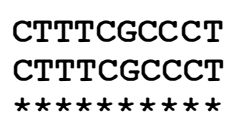 & 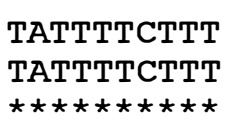 & 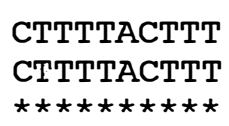 \\
\hline $\begin{array}{l}\text { LEpI JB2 } \\
\text { NT }\end{array}$ & $\begin{array}{r}5739 \\
+5753\end{array}$ & 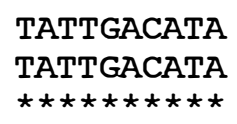 & 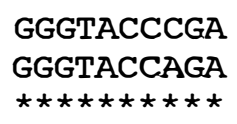 & $\begin{array}{l}\text { GAAATCTTTA } \\
\text { GAAATCTTTA } \\
\star \star \star \star \star \star \star \star \star \star ~\end{array}$ & 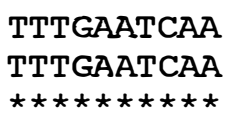 & 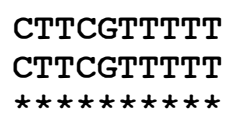 \\
\hline $\begin{array}{l}\text { LEpI JB2 } \\
\text { NT }\end{array}$ & $\begin{array}{r}5789 \\
+5803\end{array}$ & 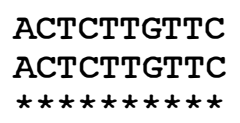 & 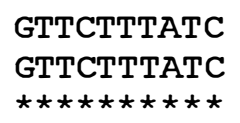 & 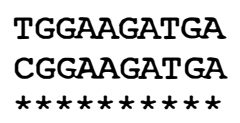 & 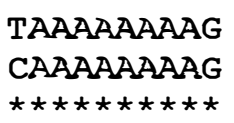 & 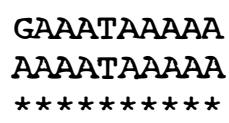 \\
\hline $\begin{array}{l}\text { LEpIJB2 } \\
\text { NT }\end{array}$ & $\begin{array}{r}5839 \\
+5853\end{array}$ & 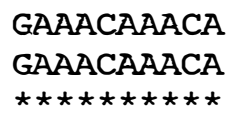 & $\begin{array}{l}\text { GGTATGAAAG } \\
\text { GGTATGAAAG } \\
\star \star \star \star \star \star \star \star \star \star\end{array}$ & 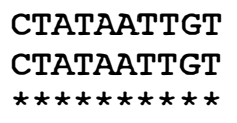 & $\begin{array}{l}\text { AAACCACGAT } \\
\text { AAACCACGAT } \\
\star \star \star \star \star \star \star \star \star \star ~\end{array}$ & 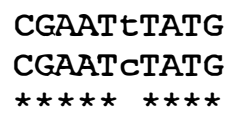 \\
\hline $\begin{array}{l}\text { LEpI JB2 } \\
\text { NT }\end{array}$ & $\begin{array}{r}5889 \\
+5903\end{array}$ & 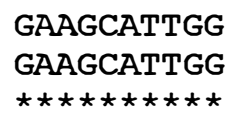 & 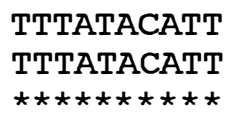 & 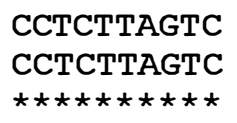 & $\begin{array}{l}\text { TCGACTCTAG } \\
\text { TCGACTCTAG } \\
\star \star \star \star \star \star \star \star \star \star ~\end{array}$ & $\begin{array}{l}\text { GGATAATTTT } \\
\text { GGATAATTTT } \\
\star \star \star \star \star \star \star \star \star \star ~\end{array}$ \\
\hline $\begin{array}{l}\text { LEpIJB2 } \\
\text { NT }\end{array}$ & $\begin{array}{r}5939 \\
+5953\end{array}$ & $\begin{array}{l}\text { TTTCGCTATC } \\
\text { TTTCGCTATC } \\
\star \star \star \star \star \star \star \star \star \star ~\end{array}$ & 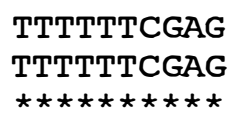 & 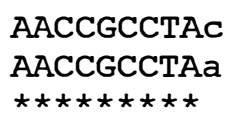 & $\begin{array}{l}\text { AaTTCGAACT } \\
\text { AgTTCCAACT } \\
\star \star \star \star \star \star \star \star \star ~\end{array}$ & 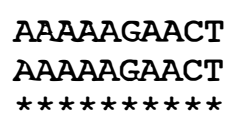 \\
\hline $\begin{array}{l}\text { LEpI JB2 } \\
\text { NT }\end{array}$ & $\begin{array}{r}5989 \\
+6003\end{array}$ & 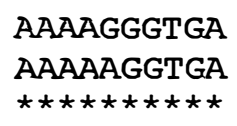 & 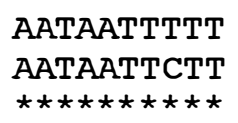 & $\begin{array}{r}\text { ttttCATTAT } \\
----\mathrm{CATTAT} \\
\star \star \star \star \star \star\end{array}$ & 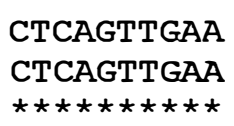 & 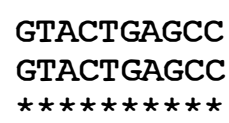 \\
\hline $\begin{array}{l}\text { LEpIJB2 } \\
\text { NT }\end{array}$ & $\begin{array}{r}6039 \\
+6049\end{array}$ & $\begin{array}{l}\text { TCCCGATATC } \\
\text { TCCCGATACC } \\
\star \star \star \star \star \star \star \star \star \star ~\end{array}$ & $\begin{array}{l}\text { GGGAGGCTCA } \\
\text { GGGAGGCTCA } \\
\star \star \star \star \star \star \star \star \star \star ~\end{array}$ & 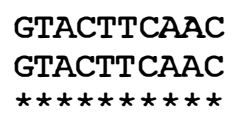 & 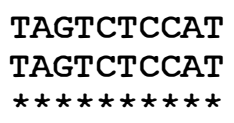 & 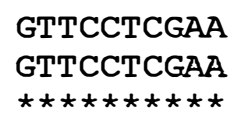 \\
\hline $\begin{array}{l}\text { LEpI JB2 } \\
N T\end{array}$ & $\begin{array}{r}6089 \\
+6099\end{array}$ & $\begin{array}{l}\text { TGGATCTCTT } \\
\text { TGGATCTCTT } \\
\star \star \star \star \star \star \star \star * \star * \star * \star\end{array}$ & 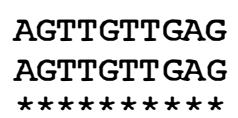 & 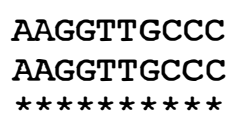 & 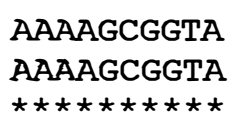 & 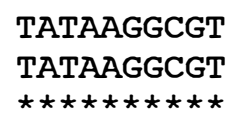 \\
\hline
\end{tabular}




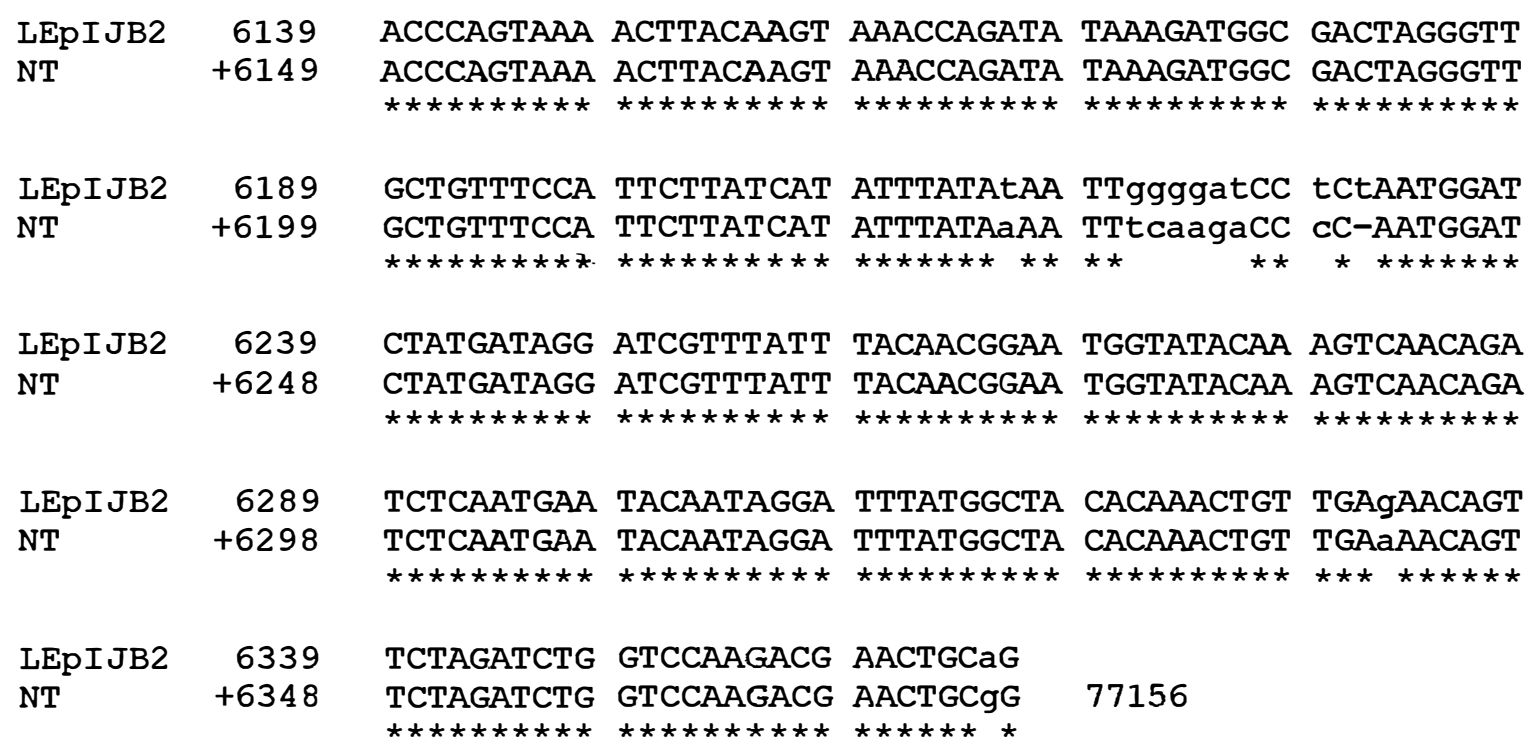




\section{REFERÊNCIAS BIBLIOGRÁFICAS}

AUSUBEL, F.M.; BRENT, R.; KINGSTON, R.E.; MOORE, D.D.; SEIDMAN, J.G.; SMITH, J.A. \& STRUHL, K. Current protocols in molecular biology. USA: John Wiley \& Sons, Inc., vol. 1, 2000.

BENDICH, A.J. Why do chloroplasts and mitochondria contain so many copies of their genome? Bioessays, v.6, p.279-282, 1987.

BOCK, R. Analysis of RNA editing in plastids. METHODS: A Companion to Methods in Enzimology. v.15, p.75-83, 1998.

BOCK, R. Analysis of RNA Editing in Plastids. METHODS: A Companion to Methods in Enzimology, v.15, p.75-83, 1998 b.

BOCK, R. \& HAGEMANN, R. Plastid genetics: Manipulation of plastid genomes and biotechnological applications. Progress in Botany, v.61, p.76-90, 1999.

BOCK, R.; HERMANN, M. \& KÖSSEL, H. In vivo dissection of cis-acting determinants for plastid RNA editing. EMBO Journal, v.15, p.5052-5059, 1996

BOCK, R.; KOSSEL, H. \& MALIGA, P. Introduction of a heterologous editing site into the tobacco plastid genome: The lack of RNA editing leads to já mutant phenotype. Embo Joumal, v.13, p.4623-4628, 1994. 
BOYTON, J.E.; GILLHAM, N.W.; HARRIS, E,H,; HOSLER, J.P.; JOHNSON, A.M.; JONES, A.R.; RANDOLPH-ANDERSON, B.L.; ROBERTSON, D.; KLEIN, T.M.; SHARK, K.B. \& SANFORD, J.C. Chloroplast transformation in Cblamydomonas with high velocity microprojectiles. Science, v.240, p.1534-1538, 1988.

CARRER, H.; HOCKENBERRY, T.N.; SVAB, Z.\& MALIGA, P. Kanamycin resistance as a selectable marker for plastid transformation in tobacco. Mol. Gen. Genet., v.241, p.49-56, 1993.

CARRER H. \& MALIGA, P. Targeted insertion of foreign genes into the tobacco plastid genome without physical linkage to the selectable marker gene. Bio/Technology, v.13, p.791-794, 1995.

CHAUDHURI, S. \& MALIGA, P. Sequences directing $\mathrm{C}$ to $\mathrm{U}$ editing of the plastid $p s b \mathrm{~L}$ mRNA are located within a 22 nucleotide segment spanning the editing site. EMBO Journal, v.15, p.5958-5964, 1996.

CHAUDHURI, S.; CARRER, H. \& MALIGA, P. Site-specific factor involved in the editing of the $p s b \mathrm{~L}$ mRNA in tobacco plastids. EMBO Journal, v.14, p.2951-2957, 1995.

CHRISTOPHER, D.A.; KIM, M. \& MULLET, J.E. A novel light-regulated promoter is conserved in cereal and dicot chloroplasts. Plant Cell, v.4, n.7, p.785-798, Jul, 1992.

DANIELL, H; DATTA, R.; VARMA, S.; GRAY, S. \& LEE, S.-B. Containment of herbicide resistance through genetic engineering of chloroplast genome. Nature Biotechnology, v.16, n.4, p.345-348, 1998.

FISCHER, N.; STAMPACCHIA, O.; REDDING, K. \& ROCHAIX, J.-D. Selectable marker recycling in the chloroplast. Mol. Gen. Genet., v.251, p.373-380, 1996. 
FARIA, R.T. \& ILLG, R.D. Inheritance of in vitro plant regeneration ability in the tomato. Brazilian Joumal of Genetics, v.19, p.113-116, 1996.

FISCHER, N.; STAMPACCHIA, O.; REDDING, K. \& ROCHAIX, J.-D. Selectable marker recycling in the chloroplast. Mol. Gen. Genet., v.251, p.373-380, 1996.

FILLATTI, J.J.; KISER, J.; ROSE, R. \& COMAI, L. Efficient transfer of a glyphosate tolerance gene in tomato using a binary Agrobacterium tumefaciens vector. BioTechnology, v.5, p.726-730, 1987.

GLHAM, N.W.; BOYTON, J.E. \& HARRIS, E.H. Transmission of plastid genes. In: BOGORAD, L. \& VASI, I.K. (Eds.). San Diego, Califomia. The molecular biology of plastids, Chap.3, p.56-92, 1991.

GIL, R.; MALIK, K.A.; SANAGO, M.H.M. \& SAXENA, P.K. Somatic embryogenesis and plant regeneration from seedling cultures of tomato (Lycopersicon esculentum Mill.). Joumal of Plant Physiology, v.2, p.274-276, 1995.

GOLDS, T.; MALIGA, P. \& KOOP, H.U. Stable plastid transformation in PEG-treated protoplasts of Nicotiana tabacum. Bio/Technology, v.11, p.95-97, 1993.

GRAY, M.W. Origin and evolution of plastid genomes and genes. In: BOGORAD, L. \& VASIL, I.K. (Eds). San Diego, California. The molecular biology of plastids, Chap.11, p.303-330, 1991.

HALL, L.N.; TUCKER, G.A.; SMITH, C.J.S.; WATSON, C.F.; SEYMOUR, G.B.; BUNDICK, Y.; BONIWELL, J.M.; FLETCHER, J.D.; RAY, J.A.; SCHUCH, W.; BIRD, C.R. \& GRIERSON, D. Antisense inhibition of pectin esterase gene expression in transgenic tomatoes. The Plant Journal, v.3, n.1, p.121-129, 1993. 
HERRMANN, R.G.; WESTHOFF, P. \& LINK, G. Biogenegis of plastids in higher plants. In: HERRMANN, R.G. (Ed.). Wien, Springer-Verlag. Cell Organelles, p.275-349, 1992.

HIROSE, T.; KUSUMEGI, T.; TSUDZUKI, T. \& SUGIURA, M. RNA Editing sites in tobacco chloroplast transcripts: editing as a possible regulator of chloroplast RNA polymerase activity. Molecular General Genetics, v.262, p. 462-467, 1999.

HOCH, B.; MAIER, R.M.; APPEL, K; IGLOI, G.L. \& KÖSSEL, H. Editing of a chloroplast mRNA by creation of an initiation codon. Nature, v.353, p.178-180, 1991.

HOPKINS, J.W. Introduction in Plant Physiology. New York, 1ed, 1995.

JOHNSTON, S.A.; ANZIANO, P.Q.; SHARK, K; SANFORD, J.C. \& BUTOW, R.A. Science, v.240, p.1538-1541, 1988.

KAVANAGH, T.A.; THANH, N.D., LAO, N.T., McGRATH, N.; PETER, S.O.; HORVÁTH, E.M.; DIX, P.J. \& MEDGYESY, P. Homeologous plastid DNA transformation in tobacco is mediated by multiple recombination events. Genetics, v.152, p.1111-1122, 1999.

KHAN MS, MALIGA P Fluorescent antibiotic resistance marker for tracking plastid transformation in higher plants. Nature Biotechnology, v.17, n.9, p.910-5, Sep, 1999.

KLEIN, T.M.; WOLF, E.D.; WU, R. \& SANFORD, J.C. High-velocity micro-projectiles for delivering nucleic acids into living cells. Nature, v.327, p.70-73, 1987.

KOOP, H.U.; EIGEL, L. \& SPÖRLEIN, B. Protoplasts in organelle research: Transfer and transformation of plastids. Physiol. Plant., v.85, p.339-344, 1992. 
KOOP, H.-H.; STINMULLER, K.; WAGNER, H.; ROBLER, C.; EIBL, C. \& SACHER, L. Integration of foreign sequences into tobacco plastome via polyethilene glycolmediated protoplast transformation. Planta, v.199, p.193-201, 1996.

KOTA, M.; DANIELL, H.; VARMA, S.; GARCZINKI, S.F.; GOULD, F. \& MOAR, W.J. Overexpression of the Bacillus turigiensis (Bt) Cry2Aa2 protein in chloroplasts confers resistance to plants against susceptible and Bt-resistant insects. Proc. Nat. Amer. Soc., v.96, n.5, p.1840-1845, 1999.

LIDHOLM, J.A. The chloroplast genome of Pinus contorta Dougl.: Studies of structure, rearrangementes and gene content. University of Umea, Sweden, 1992.

LIU, C.; TIAN, Y.; SHEN, Q.; JIANG, H.; JU, R.; YAN, T., LIU, C. \& MANG, K Cloning of 1-aminocyclopropane-1-carboxylate (ACC) synthetase cDNA and the inhibition of fruit ripening by its antisense RNA in transgenic tomato plants. Chinese Journal of Biotechnology, v.14, n.2, p.75-84, 1998.

MAIER, RM, NECKERMANN, K. IGLOI, G.L. \& KÖSSEL, H. Complete sequence of the maize chloroplast genome: gene content, hotspots of divergence and fine tuning of genetic information by transcript editing. Journal of Molecular Biology, v.251, p.614628, 1995.

MALIGA, P. Towards plastid transformation in flowering plants. Trends Biotechnology, v.11, p.101-107, 1993.

MALIGA, P.; CARRER H.; KANEVSKI, I.; STAUB, J. \& SVAB, Z. Plastid engineering in land plants: a conservative genome is open to change. Phil. Trans. R. Soc. Lond., v.342, p.203-208, 1993.

MALIGA, P., STAUB, J., CARRER, H., KANEVSKI, I. \& SVAB, Z. Homologous Recombination and Integration of Foreign DNA in Plastids of Higher Plants. In: 
PASZKOWSKI, J. (Ed.) Homologous Recombination and Gene Silence in Plants. Chap. 5, p.83-93, 1994.

McBRIDE, K.E.; SVAB, Z.; SCHAAF, D.J.; HOGAN, P.S.; STALKER, D.M. \& MALIGA,P. Amplification of a chimeric Bacillus gene in chloroplasts leads to an extraordinary level of an insectidal protein in tobacco. Nature Biotechnology, v.13, p.362-365, 1995.

MCCORMICK, S.; NIEDERMEYER, J.; FRY, J.; BARNASON, A.; HORSCH, R. \& FRALEY, R. Leaf disk transformation of cultivated tomato ( $L$ esculentum) using Agrobacterium tumefaciens. Plant Cell Report, v.5, p.81-84, 1986.

MAYFIELD, F. \& BRUICK, C. Light-activated translation of chloroplasts mRNAs. Trends in Plant Science, v. 4, n.5, p.190-195, May, 1999.

MIYAGI, T.; KAPOOR, S.; SUGITA, M. \& SUGIURA, M. Transcript analysis of the tobacco plastid operon $p p s 2 /$ atpl/H/F/A reveal the existence of a non-censensus type II (NCII) promoter upstream of the atpI coding sequence. Molecular and General Genetics, v.257, p.299-307, 1998.

NAKATSUKA, A.; SHIOMI, S.; KUBO, Y \& INABA, A. Expression and internal feedback regulation of ACC synthase and ACC oxidase genes in ripening tomato fruit. Plant Cell Physiology, v.38, n.10, p.1103-10. 1997.

NAKATSUKA, A.; MURACHI, S.; OKUNISHI, H.; SHIOMI, S.; NAKANO, R.; KUBO, $Y \& I N A B A, A$. Differential expression and internal feedback regulation of 1aminocycloprane-1-carboxylate synthase, 1-aminocyclopropane-1-carboxylate oxidase, and ethylene receptor genes in tomato fruit during development and ripening. Plant Physiology, v.118, n.4, p.1295-305, 1998. 
O'NEILL, C.; HORVATH, G.V.; DIX, P.J. \& MEDGYESY, P. Chloroplast Transformation in Plants: Polyethylene glycol (PEG) Treatment of Protoplasts is an alternative to biolistic delivery systems. Plant Journal, v.3, p.729-738, 1993

OSTERYOUNG, K.W., STOKES, K.D., RUTHERFORD, S.M., PERCIVAL, A.L. \& LEE, W.Y. Chloroplast division in higher plants requires members of two functionally divergent gene families with homology to bacterial ftsZ. Plant Cell, v.10, n.12, p.19912004, Dec, 1998.

PALMER, J.D. Comparative organization of chloroplast genomes. Annual Review of Genetics, v.19, p.325-54, 1985.

PHLLIPS, A.L. Restriction map and clone bank of tomato plastid DNA. Curr. Genet., v.10, p.147-152, 1985a.

PHILLIPS, A.L. Localisation of genes for chloroplast componets in tomato plastid DNA. Curr. Genet., v.10, p.153-161, 1985b.

PROMEGA. Protocols and Applications Guide. Promega Corporation: USA, 1996.

RANDOLPH-ANDERSON, B.L.; BOYTON, J.E.; GILLHAM, N.W.; HARRIS, E.H.; JOHNSON, A.M.; DORTHU, M.P.\& MATAGNE, R.F. Mol. Gen. Genet., v.236, p.235-244, 1993.

ROMANO, E. Extração de DNA de Tecidos Vegetais. In: BRASILEIRO, A.C.M. \& CARNEIRO, V.T.C. Manual de Transformação Genética de Plantas. Brasilia: Embrapa-SPI/Embrapa-Cenargen, p.163-175, 1998. 
SANFORD, J.C.; KLEIN, T.M.; WOLF, E.D \& ALLEN, N. Delivery of Substances into Cells and Tssues Using a Particle Bombardment Process. Particle Science Technology, v.5, p.27-37, 1987.

SANFORD, J.C.; DEVIT, M.J.; RUSSEL, J.A.; SMITH, F.D.; HARPENDING, P.R.; ROY, M.K. \& JOHNSTON, S.A. An improved, helium-driven biolistic device. Technique, v.3, p.3-16, 1991.

SERINO G. \& MALIGA P. RNA polymerase subunits encoded by the plastid rpo genes are not shared with the nucleus-encoded plastid enzyme. Plant Physiology, v.117, n.4, p.1165-70, Aug , 1998.

SCHULER, M.A. Plastid Isolation. Methods in plant molecular biology. Academic Press London, 2 ed., 1989.

SHIMADA, H. AND SUGIURA, M. Fine structural features of the chloroplast genome: comparison of the sequenced chloroplast genomes. Nucleic Acids Research, v.19, n.5, p.983-995, 1991.

SHINOZAKI, K., OHME, M., TANAKA, M., WAKASUGI, T., HAYASHIDA, N., MATSUBAYASHI, T., ZAITA, N., CHUNWONGSE, J., OBOKATA, J., YAMAGUCHI-SHINOZAKI, K., OHTO, C., TORAZAWA, K., MENG, B.Y., SUGITA, M., DENO, H., KAMOGASHIRA, T., YAMADA, K., KUSUDA, J., TAKAIWA, F., KATO, A., TOHDOH, N., SHIMADA, H. AND SUGIURA, M. The complete nucleotide sequence of tobacco chloroplast genome: its gene organization and expression. EMBO Journal, v.5, p.2043-2049, 1986.

SIDOROV, V.A.; KASTEN, D.; PANG, S.-Z.; HAJDUKIEWICZ, P.T.J.; STAUB, J.M. \& NEHRA, N.S. Stable chloroplast transformation in potato: use of green fluorescent protein as a plastid marker. The Plant Journal, v.19, n.2, p.209-216, 1999. 
SPÖRLEIN, B.; STREUBEL, M.; DAHLFELD, G.; WESTHOFF, P. \& KOOP, H.U. PEG-mediated plastid transformation: a new system for transient gene expression assays in chloroplasts. Theor. Appl. Genet., v.82, p.717-722, 1991.

STAUB, J. \& MALIGA, P. Long regions of homologous DNA are incorporated into the tobacco plastid genome by transformation. Plant Cell, v.4, p.39-45, 1992.

STAUB, J.M.; GARCIA, B.; GRAVES, J.; HAJDUKIEWICZ, P.T.; NEHRA, N.; PARADKAR, V.; SCHLITTLER, M.; CARROLL, J.A., SPATOLA, L.; WARD, D.; YE, G. \& RUSSELL, D.A. High-yield production of a human therapeutic protein in tobacco chloroplasts. Nature Biotechnology, v.18, n.3, p.333-338, 2000.

STERN, D.B. \& GRUISSEM, W. Control of plastid gene expression: 3 ' inverted repeats act as mRNA processig and stabilizing elements but do not terminate transcription. Cell, v.51, p.1145-1157, 1987.

STRICKBERGER, M.W. Genetics. Macmillan Publishing Company: New York, New York. Third Edition, 842pp, 1985.

SUGIURA, M. The chloroplast genome. Plant Molecular Biology. Kluwer Academic Publishers: Belgium, v.19, p.149-168, 1992.

SVAB, Z.; HAJDUKIEWICZ, P. \& MALIGA, P. Stable transformation of plastids in higher plants. Proc. Nat. Acad. Sci., U.S.A., v.87, p.8526-8530, 1990.

SVAB, Z. \& MALIGA, P. High-frequency plastid transformation in tobacco by selection for a chimeric aadA gene. Proc. Nat. Acad. Sci., U.S.A., v.90, p.913-917, 1993. 
YOSHINAGA, K.; IINUMA, H.; MASUZAWA, T. \& UEDA, K. Extensive RNA editing of $U$ to $C$ in addition to $C$ to $U$ substitution in the rbcL transcripts of homwort chloroplasts and the origin of RNA editing in green plants. Nucleic Acids Research, v.24, p.1008-1014, 1996. 
